Universidad Autónoma de Madrid

Programa de Doctorado en Biociencias Moleculares

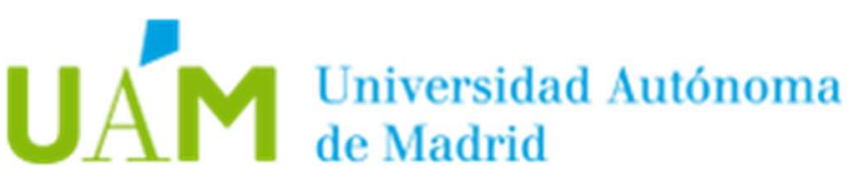

Implicación de Caveolina-1 en procesos de mecanotransducción: modulación de la respuesta a cambios en la rigidez de la matriz extracelular a través del control de la actividad de YAP

Roberto Moreno Vicente 

Departamento de Bioquímica

Facultad de Medicina

Universidad Autónoma de Madrid

\section{UÁM Universidad Autónoma}

\section{Implicación de Caveolina-1 en procesos de mecanotransducción: modulación de la respuesta a cambios en la rigidez de la matriz extracelular a través del control de la actividad de YAP}

Doctorando: Roberto Moreno Vicente (Licenciado en Biología, UAM)

Director de la Tesis: Miguel Ángel del Pozo

Centro Nacional de Investigaciones Cardiovasculares- Carlos III (Madrid, ESP) 


\section{CERTIFICADO DEL DIRECTOR DE TESIS}

El Dr. Miguel Ángel del Pozo Barriuso CERTIFICA que el doctorando Roberto Moreno Vicente ha desarrollado y concluido su trabajo de Tesis Doctoral titulado "Implicación de Caveolina-1 en procesos de mecanodransducción: modulación de la respuesta a cambios en la rigidez de la matriz extracelular a través del control de la actividad de YAP" bajo su supervisión, en el Centro Nacional de Investigaciones Cardiovasculares (CNIC), con la financiación de una beca predoctoral de Formación de Personal Investigador concedida por el Ministerio de Ciencia, Innovación y Universidades.

En Madrid, a 11 de Septiembre de 2018

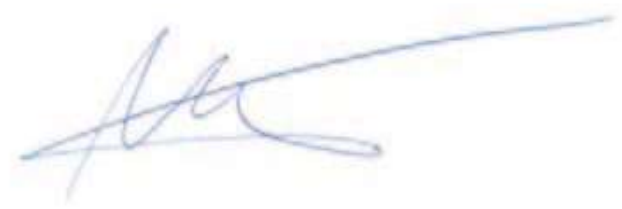

Fdo: Dr. Miguel Ángel del Pozo Barriuso

Full Professor II

Mechanoadaptation \& Caveolae Biology Lab

Coordinator, Cell \& Developmental Biology Area

Centro Nacional de Investigaciones Cardiovasculares Carlos III (CNIC)

Melchor Fernández Almagro, 3

28029 Madrid, Spain 


\section{- Agradecimientos -}

Por lo general solemos dar las gracias a la gente que nos rodea menos de lo que debiéramos, por eso este apartado me hace especial ilusión, porque me brinda la oportunidad de dar las gracias a toda esa gente que me ha rodeado, no sólo en los últimos años durante la realización de esta Tesis, sino desde el principio de mi vida. Todos los que de una manera o de otra han contribuido y siguen contribuyendo a lo que hoy soy y a lo que seré en un futuro como persona. Nuestro futuro no está escrito en ninguna parte, ni existen suficientes evidencias científicas acerca de la existencia de un ser superior que lo condicione, nuestro futuro es fruto del azar y de las decisiones que de forma voluntaria tomamos a lo largo de nuestra vida, y en ese tomar decisiones es dónde influye el entorno, las personas que nos rodean, y yo he tenido la suerte de rodearme de gente maravillosa.

En primer lugar, y como no podría ser de otra manera, porque ellos son lo primero SIEMPRE, por delante de cualquier otra cosa, quiero darle las gracias a mi familia. A mi madre y a mi padre por proporcionarme la mejor educación posible, por protegerme y ponérmelo todo tan fácil, lo habéis hecho muy bien, sólo espero el día de mañana ser tan buen padre cómo vosotros lo habéis sido conmigo. A mi hermanita, Alba, la más inteligente de la familia, por aguantar todas mis tonterías durante tantos años y todo lo que la he hecho de rabiar, y porque detrás de esa coraza que a veces se construye hay una grandísima persona. A mi abuelo y a la Yaya por cuidarme, por estar siempre ahí, por confiar en mí y darme tantísimo cariño, sois un referente en mi vida, gracias por transmitirme vuestros valores. A la Tata, porque es la mejor tía que se puede tener, por ser tan cercana y estar siempre predispuesta a ayudarnos en lo que necesitamos. A mis tíos-abuelos, tío Jesús, tío Isabelo, tía Juli, tío Pascual y tía Mari por quererme tanto y por darme tantísimo durante todos estos años. A mi abuela Margarita; a mis tíos Javi, Paloma, Marga, Diego, Grego, Rosa, Mar y José Manuel y a los primos Susana, Esteban, Cesar, Rodri, Rocío, Jorge y Javi por tantos momentos felices y divertidos, y por tantas cenas y comilonas con sus correspondientes y prolongadas sobremesas. También quiero darles las gracias a los que se han incorporado en los últimos años a mi familia, en especial a los padres de Ana, Ángel y Maribel y a sus hermanos (Javi, Ángel y Sonsoles) por aceptarme como uno más. Mención aparte merecen mis sobrinitos, Lucía, Daniel y la más pequeñaja que está en camino, cuesta comprender cómo unas personitas tan pequeñas te pueden dar tanto.

Incluida por supuesto dentro de la familia, pero con derecho a tener un párrafo para ella sola está Ana, la que hoy es mi mujer. Gran parte de la "culpa" de que yo haya conseguido llegar 
hasta aquí, y que este terminando mi Tesis Doctoral la tiene ella, porque ella no solo me aporta cariño, sino que también me aporta serenidad, comprensión, y sobre todo ese puntito de cordura que a veces me falta. Ha estado a mi lado desde el primer momento, siempre confiando en mí, incluso cuando otros no lo hacían, apoyándome y tirando de mi en los momentos más difíciles. No entiendo ni entendería la vida sin ella a mi lado porque es parte de lo que soy. GRACIAS por darme tanto. TE QUIERO cariño.

Quiero dar las gracias también a mis amigos, a la familia que se elige, porque ellos también han sido muy importantes en mi vida y a lo largo de estos últimos años. A los amigos de la universidad (Carla, Sergio H., Javi, Sergio M., Juanga, Irene, Jorge, Tati, Aza, Adri, Laura y Dani), aunque de la universidad ya sólo somos la mitad, porque hacemos un gran equipo, y por todas esas fiestas, escapadas, casas rurales, barbacoas, etc. Gracias también a los amigos de mi pueblo, Hinojosa de San Vicente, por todos los buenos ratos y todas las cosas que hemos vivido juntos desde pequeños y por permitirme desconectar de Madrid y del trabajo siempre que lo he necesitado.

Por último, quiero dar las gracias a la gente del laboratorio y del CNIC en general por toda la ayuda, tanto laboral como extralaboral, que me han prestado durante todos estos años. La verdad es que ya he perdido hasta la cuenta de los años que llevo aquí, porque cuando entré todavía me quedaba un año para terminar la carrera y me voy con 30 años recién cumplidos. Por ese motivo hay gente que, aunque les incluya en este apartado, podrían perfectamente estar incluidos en el anterior, ya que, además de compañeros de trabajo, son amigos.

En primer lugar, quiero dar las gracias a Olivia, por confiar en mí cuando otros no lo hacían y convencerme de seguir en el laboratorio cuando más dudas tenía. Además, es la persona que me enseño la mayoría de las técnicas que he empleado en este trabajo, así que ella también tiene parte de responsabilidad en que esta Tesis haya salido adelante. En ese sentido tengo que dar las gracias también a Inma, de ella también he aprendido mucho, y no sólo técnicas experimentales, ya que, además de una gran investigadora, es una muy buena persona que sí sabe lo que es trabajar en equipo. Gracias también a Dácil, por toda la ayuda y por su simpatía. A Tere, por todas las risas, los buenos momentos y por aguantarme cuando la he pinchado un poco. Gracias a Sara Sánchez, nuestra manager, también indispensable para el laboratorio, porque es la que sabe dónde están las cosas y la que me compra los bolis. Perdón por haberte dado tanto el coñazo, jeje. Gracias a Inés y a Mauro por su ayuda con los experimentos con los ratoncitos. También mi agradecimiento, reconocimiento y mi admiración a Raff, il professore, gracias por tus consejos, por ser tan crítico y por toda la ayuda que me has 
dado, he aprendido mucho de ti, no sólo a nivel científico. Y gracias a los demás jovenzuelos del grupo: Lucas, Alberto, Mauro, Giulio, Fidel Lolo, María García, María Aboy, Sarah Francoz, Antonio Killer, tbón Ibon, Victor, etc. por las risas y por crear ese ambiente tan bueno y sano en el laboratorio y fuera de él. No quiero olvidarme tampoco de todos los estudiantes que han pasado por el lab, todos ellos muy buena gente.

Una mención aparte merece Miguel Sánchez, no lleva tantos años como otros, pero se ha convertido en una pieza clave e indispensable para el laboratorio. Ha aportado ideas y me ha ayudado a escribir el artículo, hasta el punto de que estoy seguro de que sin su ayuda no estaría publicado todavía. Además, se trata de una persona extraordinaria de una gran nobleza. Y, como no, remarcar la importancia de esos dos titanes que me han flanqueado estos años en el escritorio, Alberto, y sobre todo Lucas, que es el que ha aguantado hasta el final. Nos hemos ayudado y molestado a partes iguales, y lo más importante, nos hemos divertido y lo hemos pasado bien como los que más, eso no nos lo quita nadie.

Me gustaría agradecer también su ayuda en todos los aspectos a "los vecinos", "Ios AGAs", "Ios alicios", y decirles, lo primero, que me alegro de irme ahora del lab porque la planta sin ellos ya no va a ser lo mismo. Gracias en especial a Sergio, con el que llevo coincidiendo desde la universidad (y parece ser que nuestros caminos se seguirán cruzando un tiempo más), que además de ser un experto en temas políticos con mucho criterio es una pequeña, pero a la vez, gran persona. $Y$ también gracias a Cristina, por ser tan simpática y alimentarme con sus chucherías, galletas y frutos secos. Y no me gustaría olvidarme de los que ya no están: Xenia, Mara, Vane, Pili, Chuchi, Álvaro etc. Del mismo modo le quiero dar las gracias a todos los miembros de "los Puros" y "Ios Juanmis" y las diferentes unidades técnicas del CNIC que me han ayudado de una manera o de otra, como por ejemplo Irene y Dani, que además son majísimos.

Gracias también a los que en ocasiones me lo han puesto difícil, que por suerte no han sido muchos, con una mano sobran dedos para contarlos, porque me han hecho potenciar cualidades que sin duda me serán útiles en el futuro, como son la paciencia y el autocontrol.

Y gracias, por supuesto, a Miguel Ángel, el director de esta Tesis Doctoral. Gracias por dejarme formar parte de su laboratorio y proporcionarme la financiación necesaria para llevar a cabo esta Tesis Doctoral. Gracias por la ayuda y por la autonomía que me has dado durante estos años para poder realizar este proyecto de forma totalmente independiente. 
1. Resumen / Summary 


\section{- Resumen -}

Caveolina-1 (CAV1) es una proteína integral de la membrana plasmática que participa en procesos de endocitosis, modula diferentes vías de señalización celular y participa activamente en la mecanotransducción de señales. CAV1 y caveolas son capaces de responder a diferentes estímulos mecánicos, cómo son el estiramiento, las fuerzas de cizallamiento ejercidas por fluidos sobre la superficie de la célula, o la perdida de adhesión celular. En esta Tesis Doctoral se ha caracterizado la modulación por parte de CAV1 de la respuesta a un estímulo mecánico diferente: la rigidez sustrato extracelular. El regulador transcripcional YAP regula importantes funciones celulares, como proliferación, apoptosis y diferenciación, determinando la homeostasis de tejidos, el control del crecimiento de los órganos y la tumorogénesis. Los estímulos mecánicos controlan la actividad de YAP mediante mecanismos que no están completamente caracterizados todavía. Los resultados presentados en este trabajo indican que CAV1 regula positivamente la actividad de YAP en respuesta a cambios en la rigidez de la matriz extracelular (MEC). Esta regulación de YAP por parte de CAV1 es dependiente de la modulación de la dinámica del citoesqueleto de actina, siendo la actividad de Rho necesaria, pero no suficiente para explicar las diferencias observadas. En el control del eje CAV1-YAP, la fosforilación inhibitoria de YAP tiene un papel determinante, observándose una fosforilación mayor en células que no expresan CAV1, y un rescate de la actividad de YAP al sobreexpresar en estas células un mutante de YAP no fosforilable. Sin embargo, la regulación CAV1-dependiente de YAP no opera a través de quinasas canónicas de la vía Hippo. Estudios de espectrometría de masas para la identificación sistemática de los componentes del interactoma de YAP, y su caracterización funcional posterior, sugieren que la regulación de la actividad de YAP dependiente de CAV1 y actina es ejercida a través de la modulación de la interacción de YAP con la proteína con domino 14-3-3 YWHAH. El silenciamiento de Ywhah rescata el defecto en la actividad de YAP en células sin CAV1. La activación constitutiva de YAP en células sin CAV1 rescata fenotipos asociados a la perdida de Cav1, incluyendo el remodelado de la MEC. El control de YAP mediado por CAV1 se ha validado también en un modelo in vivo de metaplasia acinoductal inducido por pancreatitis. En conjunto, los datos presentados en esta Tesis Doctoral apoyan la existencia y relevancia funcional de un nuevo eje de mecanotransducción a través del control de la actividad de YAP por CAV1 con implicaciones potenciales en procesos fisiológicos y patológicos. 


\section{- Summary -}

Caveolin-1 (CAV1) is an integral membrane protein which participates in endocytic processes, modulates different cell signaling pathways and mediates mechanotransduction at the plasma membrane. CAV1 and caveolae can respond to different mechanical stimuli, such as mechanical stretching, fluid shear stress on cell surface, and loss of cell adhesion. In this Doctoral Thesis the ability of CAV1 to modulate the response to an additional mechanical stimulus- substrate rigidity- has been characterized. The transcriptional regulator YAP orchestrates important cell functions, such as proliferation, apoptosis and differentiation, determining tissue homeostasis, organ growth control, and tumorigenesis. Mechanical stimuli are a key input to YAP activity through mechanisms that remain to be characterized. Our results indicate that CAV1 is required for the positive regulation of YAP activity in response to extracellular matrix (ECM) stiffness. This CAV1-YAP regulation is dependent on the modulation of actin cytoskeleton dynamics, for which Rho signaling is necessary, but not sufficient. CAV1dependent YAP regulation is determined by the modulation of the inhibitory phosphorylation of YAP: cells lacking CAV1 exhibit high levels of YAP phosphorylation, and the overexpression of a non-phosphorylatable mutant YAP in CAV1 KO cells rescues YAP activity. This dynamic however, it is independent on the function of canonical Hippo pathway kinases. Data obtained by YAP interactome mass spectrometry studies and subsequent functional characterization of these interactors provide evidence that this Cav1-dependent YAP activity regulation was mediated by the modulation of YAP interaction with the 14-3-3 domain protein YWHAH. Ywhah silencing is enough to rescue the defective YAP activity in cells without Cav1. Constitutive YAP activation rescued phenotypes associated with Cav1 loss, including defective ECM remodeling. Cav1mediated control of YAP activity was validated in vivo in a model of pancreatitis-driven acinarto-ductal metaplasia. Together, data presented in this Doctoral Thesis propose a new mechanotransduction axis through the control of YAP activity by Cav1 with potentially broad physiological and pathological implications. 


\section{- Índice -}

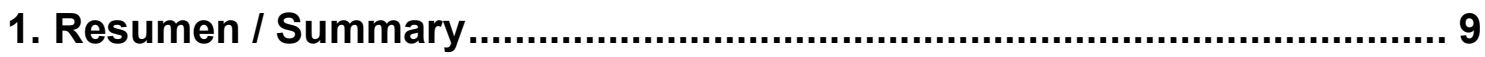

2. Clave de abreviaturas ....................................................................... 19

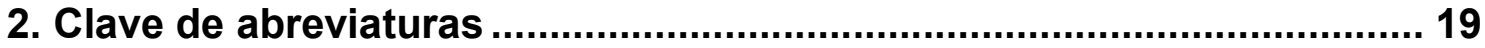

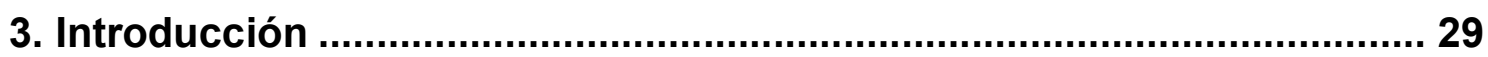

3.1. Mecanotransducción............................................................................

3.2. El citoesqueleto............................................................................

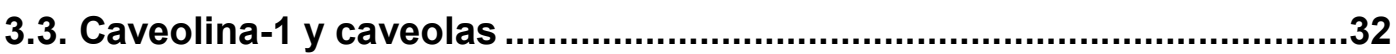

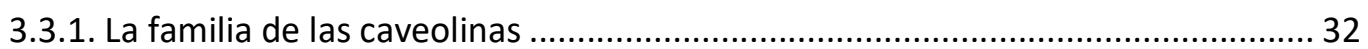

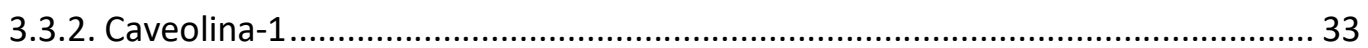

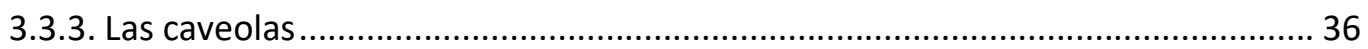

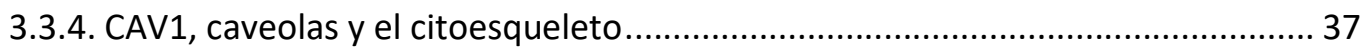

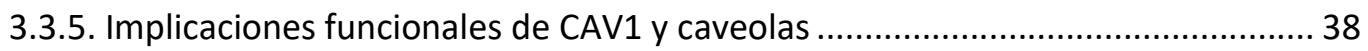

3.3.6. Funciones específicas de las caveolas como unidad estructural ......................... 40

3.3.7. Implicación de CAV1 y caveolas en procesos de mecanotransducción ................ 41

3.4. Ruta de señalización Hippo ................................................................41

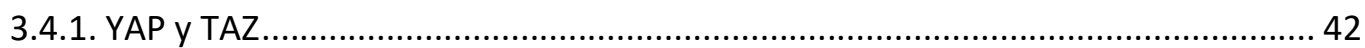

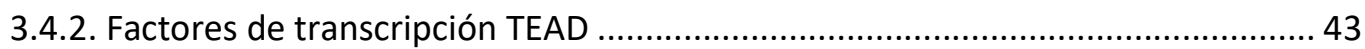

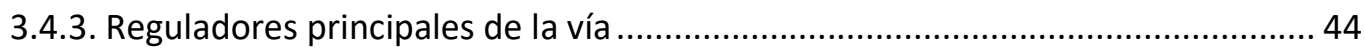

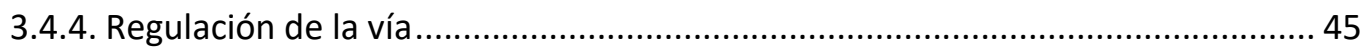

3.4.5. Implicación del citoesqueleto en la regulación de YAP/TAZ ................................46 46

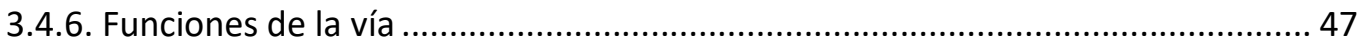

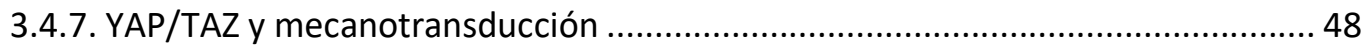

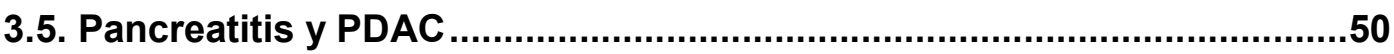

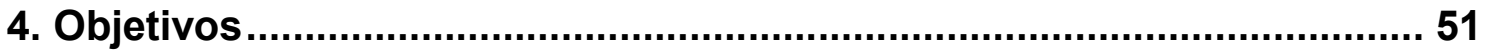

5. Materiales y Métodos ...................................................................... 55

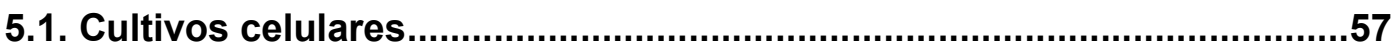

5.2. Transfecciones, transducciones con vectores virales y tratamientos con

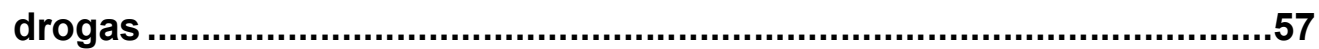

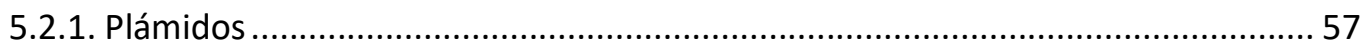

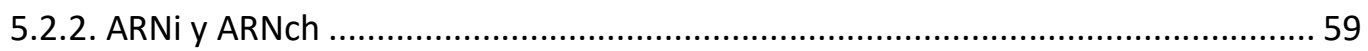

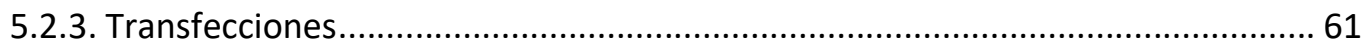

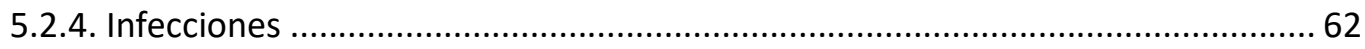

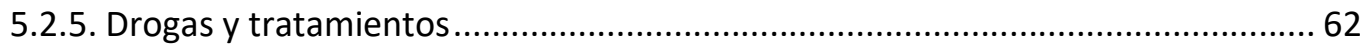


5.3. Ensayos bioquímicos para la inmunodetección de proteínas 62

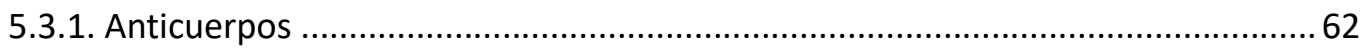

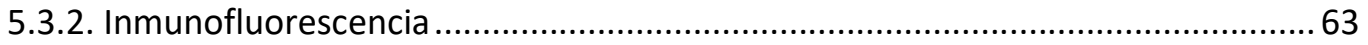

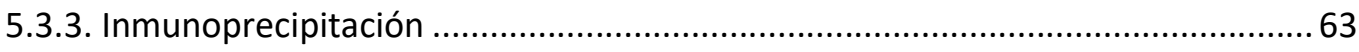

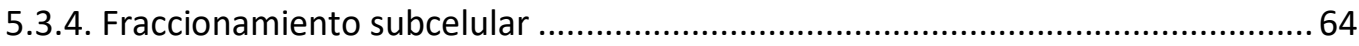

5.3.5. Purificación de dominios de membrana resistentes a detergentes (DRMs).........64 64

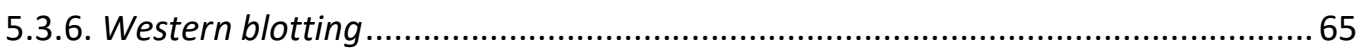

5.4. Estudio de los niveles de ARNm mediante PCR cuantitativa.................65 65

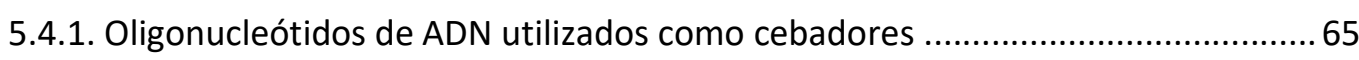

5.4.2. Extracción de ARN, reversotranscripción y PCR cuantitativa ................................66

5.5. Ensayos para el estudio de procesos de mecanotransducción ............67 67

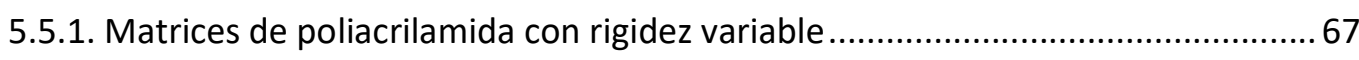

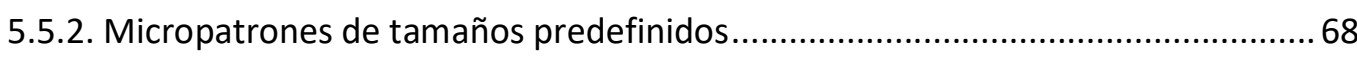

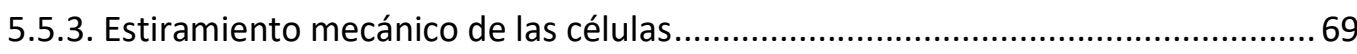

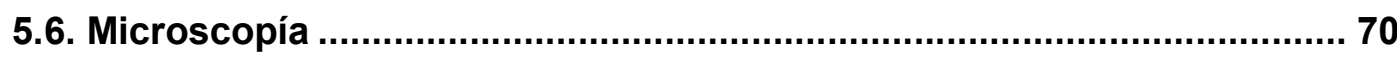

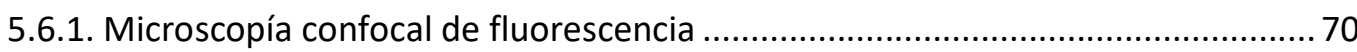

5.6.2. Estudio del ordenamiento de las fibras de colágeno mediante la generación del

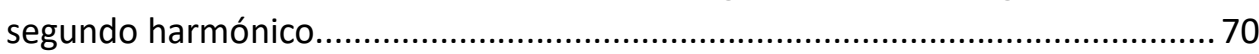

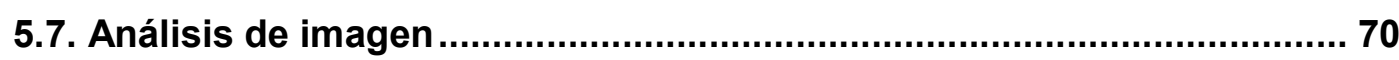

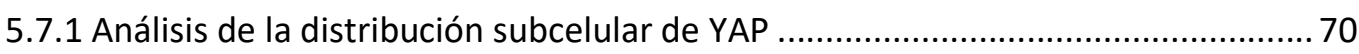

5.7.2. Estudio de la organización de las fibras de actina............................................. 71

5.8. Ensayo de luciferasa para monitorizar la actividad transcripcional de TEAD ............................................................................................ 72

5.9. Ensayo de contracción de colágeno................................................ 73

5.10. Estudio de la expresión global de ARNm mediante ARNsec ............... 73

5.11. Identificación de proteínas por espectrometría de masas ................... 74

5.12. Caracterización de candidatos mediante un ensayo basado en el silenciamiento con ARNi y el análisis de la distribución subcelular de

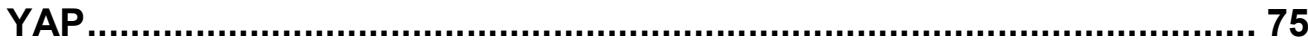

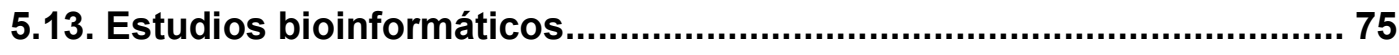

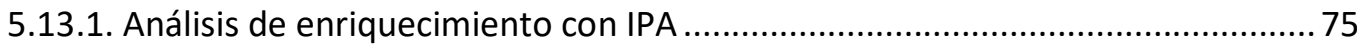

5.13.2. Análisis de co-expresión de genes con SEEK ................................................... 75

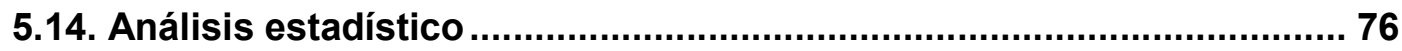

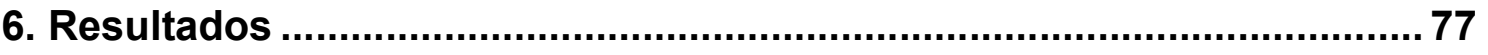

6.1. Dinámica y localización de CAV1 y caveolas en sustratos con diferente

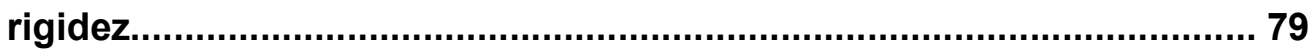

6.1.1. CAV1 se internaliza en condiciones de baja rigidez del sustrato ......................... 79 


\subsection{Estudio de los cambios transcripcionales en MEF WT y Cav1KO} mediados por la rigidez de la MEC.

6.2.1. Análisis comparativo del transcriptoma de MEF WT y Cav1KO en sustratos rígidos y blandos mediante ARNsec.

6.2.2. Análisis computacional de los resultados del ARNsec.

\subsection{Implicación de CAV1 en la modulación de la actividad de YAP en} respuesta a cambios en la rigidez de la MEC.

6.3.1. La actividad transcripcional de YAP esta modulada por CAV1.

6.3.2. La regulación de la actividad transcripcional de YAP por CAV1 es un mecanismo general observado en diferentes células y tejidos

6.3.3. CAV1 regula la translocación núcleo-citosólica de YAP en respuesta a cambios en

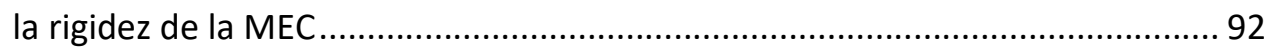

6.3.4. CAV1 regula la actividad de YAP en respuesta al estiramiento celular.

\subsection{Caracterización de los mecanismos moleculares que controlan la} regulación YAP por CAV1.

6.4.1. La regulación de YAP por CAV1 depende de la fosforilación de sus residuos reguladores específicos.

6.4.2. CAV1 regula la dinámica del citoesqueleto de actina

6.4.3. La regulación de YAP por CAV1 es dependiente de la dinámica de actina 100

6.4.4. La regulación de YAP por CAV1 es independiente del control que CAV1 ejerce sobre la actividad de RhoA

6.4.5. La regulación de YAP por la rigidez de la MEC y la dinámica de actina es dependiente de la fosforilación de YAP.

6.4.6. Papel de diferentes quinasas en el aumento de la fosforilación de YAP en ausencia de CAV1.

6.4.7. El control del flujo de $\mathrm{Ca}^{2+}$ determina la regulación CAV1-YAP

\subsection{Estudio y caracterización de los cambios en el interactoma de YAP mediados por presencia/ausencia de CAV1 y la integridad del citoesqueleto de actina}

6.5.1. Estudio del interactoma de YAP mediante espectrometría de masas

6.5.2. Caracterización funcional del interactoma de YAP

6.5.3. La interacción de YAP con YWHAH determina la deficiente actividad de YAP en células Cav1KO

6.6. Implicaciones fisiopatológicas de la regulación de YAP por CAV1 .....121

6.6.1. YAP determina el control del remodelado de la MEC dependiente de CAV1... 121

6.6.2. CAV1 determina la activación de YAP en la metaplasia acino-ductal asociada a pancreatitis 


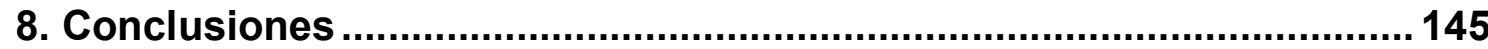

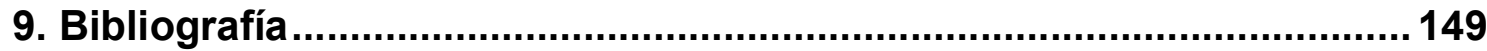

10. Anexo: Publicaciones ............................................................................ 173 


\section{Clave de abreviaturas}




$\begin{array}{ll}\text { ADM } & \text { metaplasia acino-ductal } \\ \text { ADN } & \text { ácido desoxirribonucleico } \\ \text { AHCTF } & \text { at-hook containing transcription factor } 1 \\ \text { AMOT } & \text { angiomotina }\end{array}$

AMOTL1 angiomotin like 1

AMOTL2 angiomotin like 2

AMPK

amp-activated protein kinase, proteína quinasa activada por AMP

ANKRD1

ankyrin repeat domain 1, Ankirina D1

AP1 activator protein-1, proteína activadora 1

ARN ácido ribonucleico

ARNch ARN corto horquillado

ARNi ARN de interferencia

ARNm

ARN mensajero

ARNsec

secuenciación masiva de ARN

ARP2/3 actin-related proteins 2/3, proteínas relacionadas con la actina 2 / 3

ATM ATM serine/threonine kinase, ATM serina/treonina quinasa

ATPasa adenosina trifosfato hidrolasa

BAR

bin/amphiphysin/rvs

BSA

bovine serum albumin, albumina de suero bovina

CAV1

Caveolina-1

CAV3

Caveolina-3

CAV1 $\alpha$

Caveolina-1, isoforma $\alpha$

CAV1及

Caveolina-1, isoforma $\beta$

CAV2

Caveolina-2

CBM

CAV1 binding motif, dominio de unión a CAV1

Cdc42

cell division cycle 42

CEMM colesterol-enriched membrane microdomains, dominios de membrana enriquecidos en colesterol y esfingolípidos 
CK1

CLIC/GEEC

CMM

CMV

colP

CSD

C-terminal

CTGF

CTTN

CYR61

CytD

DIAPH1

DMSO

DRMs

DTT

DYN2

EC

EDTA

EGF

EGFR

EGTA

EHD2

elF2 $\alpha$ casein quinase 1 , caseína quinasa 1

clathrin independent carriers / GPI-AP enriched early endosomal compartment, transportadores independientes de clatrina/ compartimentos endosomales tempranos enriquecidos en GPI-AP

células madre mesenquimales

cuerpo multivesicular

co-inmunoprecipitación

caveolin-scaffolding domain, dominio de anclaje a cav1

extremo carboxilo terminal

connective tissue growth factor, factor de crecimiento del tejido conectivo

cortactin, cortactina

cysteine rich angiogenic inducer 60 , inductor angiogénico rico en cisteina 60

citocalasina D

diafanus-1, mDia1

dimethyl sulfoxide

detergent resistant membranes, dominios de membrana resistentes a detergentes

dithiothreitol

Dinamina-2

estiramiento mecánico cíclico

ácido etilendiaminotetraacético

epithelial growth factor, factor de crecimiento epitelial

epidermal growth factor receptor, receptor del factor de crecimiento epitelial

ethylene glycol tetraacetic acid, ácido etilenglicoltetracético

EH domain containing 2, proteina con dominio EH 2

eukaryotic translation initiation factor $2 a$, factor de iniciación de la traducción $2 \mathrm{a}$ 


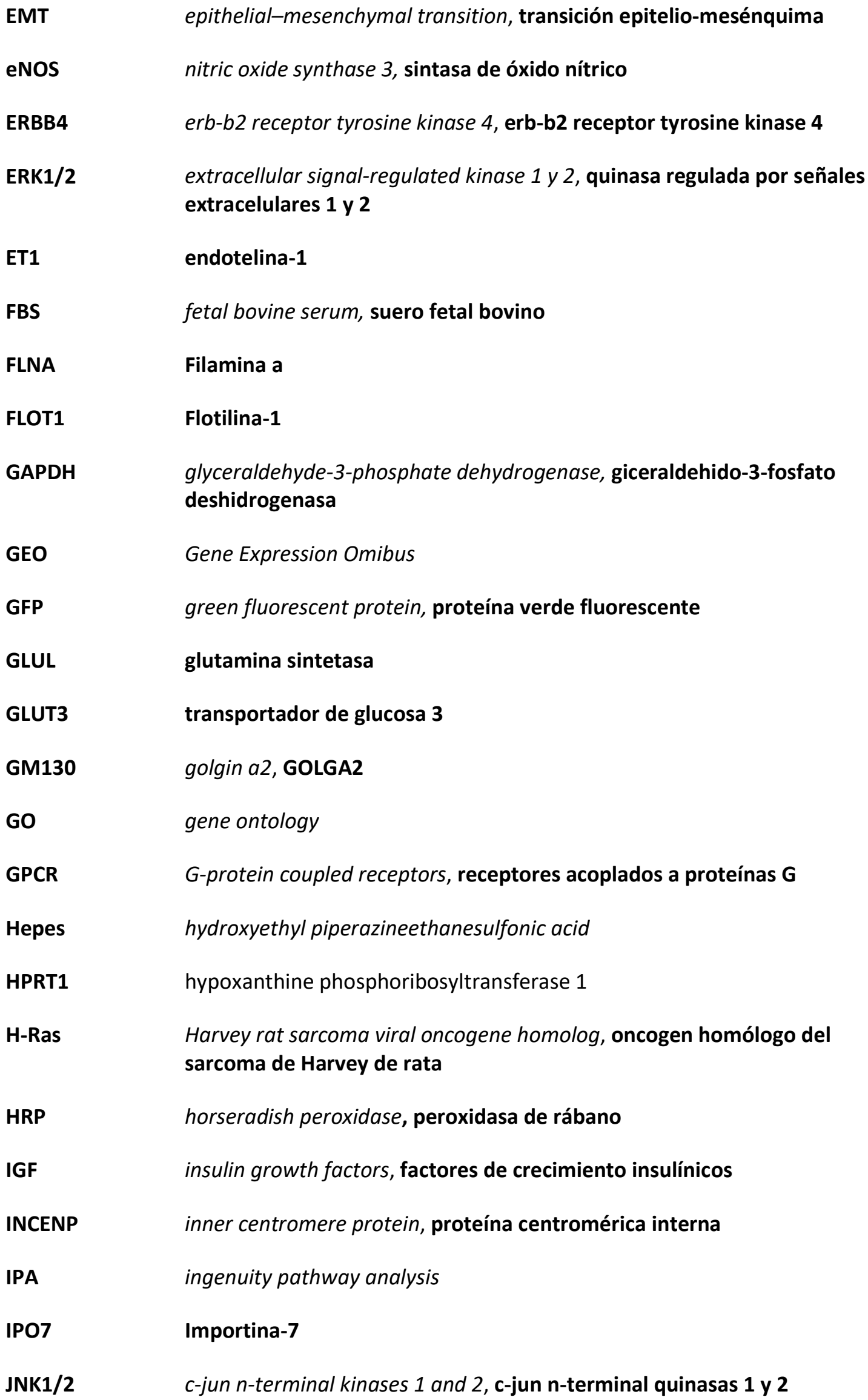

JNK1/2 c-jun n-terminal kinases 1 and 2, c-jun n-terminal quinasas 1 y 2 
KEGG kyoto encyclopedia of genes and genomes

KO knockout

LARII Iuciferase assay reagent ii

LATS1 large tumor suppressor kinase 1, quinasa larga supresora de tumores 1

LATS2 large tumor suppressor kinase 2, quinasa larga supresora de tumores 2

LC-MS/MS liquid chromatography tandem-mass spectrometry, espectrometría de masas de cromatografía líquida en tandem

LPA

ácido lisofosfatídico

MAP4K4

mitogen-activated protein kinase kinase kinase kinase 4, proteína quinasa quinasa quinasa quinasa 4 activada por mitógenos

MAX

myc-associated factor $\mathrm{x}$, factor $\mathbf{x}$ asociado a myc

mDia1

diaphanous related formin 1, DIAPH1

MEC

matriz extracelular

MEF

mouse embrionic fibroblasts, fibroblastos embrionarios murinos

MEF2

myocyte enhancer factor 2 , factor amplificador de miocitos 2

MetLuc

luciferasa metridia

MOI

multiplicidad de infección; número de unidades virales por célula

MP

membrana plasmática

MST1

macrophage stimulating 1, estimuladora de macrófagos 1

MST2

macrophage stimulating 2, estimuladora de macrófagos 2

MTOR

mammalian target of rapamycin, diana de rapamicina de mamíferos

MURC

muscle-restricted coiled-coil protein, proteína colied-coil restringida al músculo, Cavin-4

MY01C Miosina 1c

NDR1/2 dbf2-related kinases, quinasas relacionadas con $\mathbf{d f b} 2$

NF2

Merlin, neurofibromatosis type 2, neurofibromatosis tipo 2

NGS next generation sequencing, secuenciación de última generación

N-terminal extremo amino terminal 


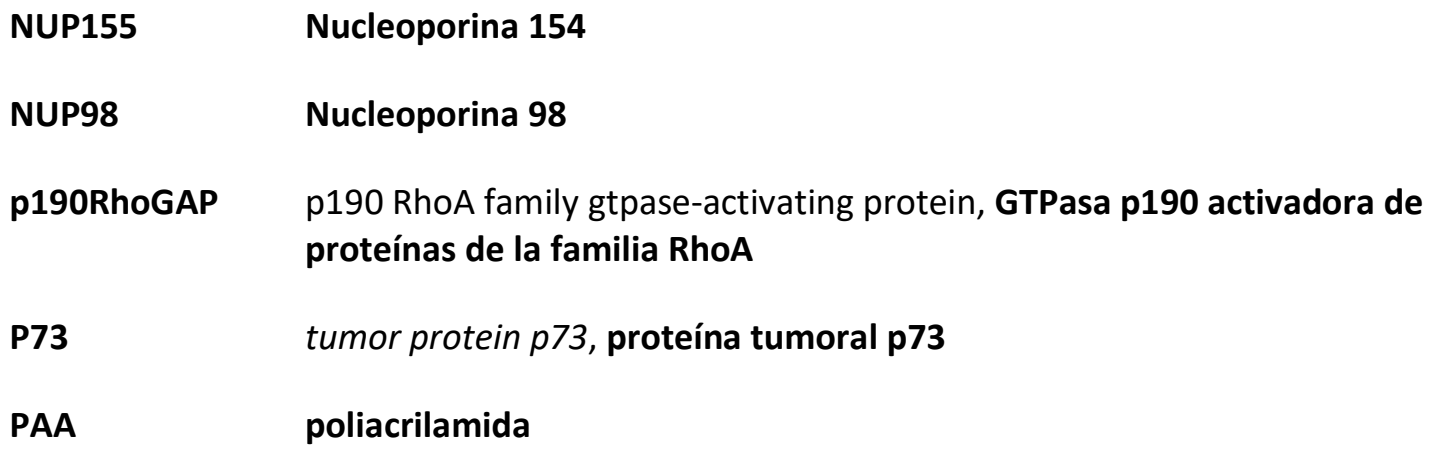

PI3K

PIEZO1

PIEZO2

phosphatidylinositol-4,5-bisphosphate 3-kinase, fosfatidilinositol-4,5bisfosfato 3-quinasa

Piezo type mechanosensitive ion channel component 1, componente 1 del canal de calcio mecanosensitivo Piezo

Piezo type mechanosensitive ion channel component 2, componente 2 del canal de calcio mecanosensitivo Piezo

PK1

fosfofructoquinasa-1, fosfofructoquinasa-1

PKA

protein kinase a, proteína quinasa a

PKC

protein kinase $c$, proteína quinasa c

PMSF

phenylmethylsulfonyl fluoride, fluoruro de fenilmetilsulfonilo

PP1A

protein phosphatase 1 a, proteína fosfatasa 1 a

PP2A

protein phosphatase 1 a, proteína fosfatasa 2 a

PTPN14

proteína tirosina fosfatasa 14

PTRF

polymerase $i$ and transcript release factor, factor de terminación de la transcripción y la polimerasa i.

RE

retículo endoplasmático 
RHOA Ras homolog family member, miembro de la familia de los homologos de Ras

RIN RNA integrity number, valor de integridad del ARN

ROCK1/2 Rho associated coiled-coil containing protein kinase 1, proteína quinasa 1 asociada a Rho conteniendo un dominio coiled-coil

ROI region of interest, región de interés

RT reverse transcription, transcripción reversa

RTKs receptores tirosina quinasa

RT-qPCR reverse transcription quantitative polymerase chain reaction, reacción en cadena de la polimerasa con transcriptasa inversa cuantitativa

RUNX1 RUNT related transcription factor 1 , factor de transcripción relacionado con RUNT 1

RUNX2

RUNT related transcription factor 1 , factor de transcripción relacionado con RUNT 2

RUNX3

S1P

RUNT related transcription factor 1 , factor de transcripción relacionado con RUNT 3

SD

esfingosina-1-fosfato

standard desviation, desviación estándar

SDPR

SDS

serum deprivation response protein, proteína de respuesta a la deprivación de suero

dodecilsulfato sódico

SEEK

search-based exploration of expression compendium

SEM

standard error of the mean, error estándar de la media

SHG

second harmonic generation, generación de la segunda harmónica

SMAD1

SMAD family member 1, miembro de la familia SMAD 1

SMAD2/3

SMAD family members 2 and 3, miembros de la familia SMAD 2 y 3

SRBC

sdr-related gene product that binds to c-kinase, producto del gen relacionado con sdr que se une a c-quinasa, Cavin-3

Src proto-oncogene tyrosine-protein kinase Src, proto-oncogén tirosinaproteína quinasa Src

SREBP sterol regulatory element-binding proteins, proteínas de unión a elementos reguladores de esteroles 
serum response factor, factor de respuesta a suero

signal recognition particle, partícula de reconocimiento de la señal

TAF

fibroblastos asociados a tumores

TAZ

WWTR1, ww domain-containing transcription regulator protein 1, proteína reguladora de la transcripción conteniendo un dominio WW

TBS

tris-buffered saline, solución salina tamponada con tris

TBX5

t-box protein 5, proteína t-box 5

TCEP

tris(2-carboxyethyl)phosphine

TCF4

transcription factor 4, factor de transcripción 4

TEAD

tea domain transcription factors, factores de transcripción con dominio TEA

TEMED

n,n,n',n'-tetramethylethylenediamina

TFA

trifluoroacetic acid, ácido trifluoroacético

TGF- $\beta$

transforming growth factor beta, factor de crecimiento transformante beta

UPR

unfolded protein response, respuesta a proteínas mal plegadas

UV

luz ultravioleta

VEGF

vascular endothelial growth factor, factor de crecimiento endotelial vascular

VGLL

vestigial-like

WB

Western blott

WT

wild type, fenotipo salvaje

WWTR1

TAZ, WW domain-containing transcription regulator protein 1, proteína reguladora de la transcripción conteniendo un dominio WW

YAP

yes-associated protein 1, proteína asociada a yes

YES1

yes proto-oncogene 1 , protooncogen 1 yes

YWHAB

tyrosine 3-monooxygenase/tryptophan 5-monooxygenase activation protein beta, proteína de activación tirosina 3-monoxigenasa/triptófano 5-monoxigenasa beta 
YWHAE tyrosine 3-monooxygenase/tryptophan 5-monooxygenase activation protein epsilon, proteína de activación tirosina 3monoxigenasa/triptófano 5-monoxigenasa epsilon

YWHAG tyrosine 3-monooxygenase/tryptophan 5-monooxygenase activation protein gamma, proteína de activación tirosina 3monoxigenasa/triptófano 5-monoxigenasa gamma

YWHAH tyrosine 3-monooxygenase/tryptophan 5-monooxygenase activation protein eta, proteína de activación tirosina 3-monoxigenasa/triptófano 5-monoxigenasa eta

YWHAQ tyrosine 3-monooxygenase/tryptophan 5-monooxygenase theta

YWHAZ tyrosine 3-monooxygenase/tryptophan 5-monooxygenase activation protein zeta, proteína de activación tirosina 3-monoxigenasa/triptófano 5-monoxigenasa zeta

ZO-2

zonula occludens 2 
3. Introducción 


\subsection{Mecanotransducción}

Las señales que una célula recibe tanto del exterior como del interior celular tienen en muchos casos naturaleza bioquímica. Sin embargo, existen otro tipo de señales, las señales mecánicas, que también determinan la fisiología celular. Estas señales mecánicas son captadas y transducidas a señales bioquímicas por la célula desencadenando respuestas biológicas en la misma, un proceso que se conoce como mecanotransducción. El equilibrio y respuesta adecuadas a las diferentes fuerzas que afectan a las células determina en última instancia el correcto desarrollo de órganos y tejidos (Jaalouk and Lammerding, 2009).

Existen una gran variedad de estímulos mecánicos capaces de afectar a la biología celular, la presión e impedimentos estéricos que ejercen las células vecinas, los propios movimientos del organismo, por ejemplo, en un músculo, la presión y el flujo sanguíneo sobre las células endoteliales y la rigidez del ambiente extracelular en el que se encuentran las células son sólo algunos ejemplos (Orr et al., 2006).

La importancia de la mecanotransducción de señales se pone de manifiesto en multitud de procesos, no sólo fisiológicos, sino también patológicos en los que está implicada. Defectos en mecanotransducción se asocian con arterosclerosis, distrofias musculares, osteoporosis, problemas pulmonares, renales y de desarrollo y con la progresión del cáncer (Jaalouk and Lammerding, 2009). En el caso de la progresión tumoral es especialmente relevante la rigidez del estroma peritumoral, ya que determina tanto el crecimiento del tumor primario como el desarrollo de metástasis (Friedl and Gilmour, 2009; Goetz et al., 2011). En este proceso tienen un papel clave los fibroblastos asociados a tumores (TAF), que están implicados en el remodelado de la MEC (Kalluri, 2016).

\subsection{El citoesqueleto}

Las redes dinámicas de proteínas que constituyen el citoesqueleto forman un andamiaje fundamental que determina la arquitectura de las células, posibilitando la contracción, la movilidad, el transporte de vesículas y orgánulos, la citocinesis, la organización intracelular y la polaridad (Pollard and Goldman, 2018). Una de las proteínas del citoesqueleto más relevantes es la actina, una proteína de 43KDa con tres isoformas diferentes que se puede encontrar en la célula tanto polimerizada formando fibras (F-actina) como en su forma monomérica (G-actina; actina globular). La actina constituye redes y fibras dinámicas gracias a su capacidad de polimerización y despolimerización en un proceso altamente controlado por la célula a través 
de múltiples proteínas reguladoras (Blanchoin et al., 2014; Mishra et al., 2014). El citoesqueleto de actina permite además a las células ejercer fuerzas, gracias a su capacidad contráctil mediada por unas proteínas motoras denominadas miosinas (citoesqueleto de actina-miosina), y transmitir esa fuerza hacia la MEC a través de su conexión directa con las adhesiones focales o hacia otras células por medio de uniones intercelulares (Geiger et al., 2001; Parsons et al., 2010). Precisamente, gracias a esas conexiones con la MEC y las células vecinas, es también esencial para percibir y transmitir las fuerzas provenientes del exterior celular, teniendo una gran relevancia en procesos de mecanotransducción (Elosegui-Artola et al., 2017; Elosegui-Artola et al., 2016; Schwartz, 2010).

\subsection{Caveolina-1 y caveolas}

\subsubsection{La familia de las caveolinas}

La primera evidencia experimental documentada acerca de la existencia de Caveolina-1 (CAV1) data de 1989, identificándose en este momento inicial como el sustrato de fosforilación en residuos de tirosina más prominente en células transformadas con el virus del sarcoma de Rous (Glenney, 1989). Tres años más tarde se publicó su secuencia aminoacídica y se le asignó el nombre de Caveolina, en base a su presencia en unas invaginaciones de la membrana plasmática (MP) a las que previamente se les había otorgado el nombre de caveolas (Glenney and Soppet, 1992; Rothberg et al., 1992; Yamada, 1955). Posteriormente se identificaron dos parálogos similares en su estructura primaria, Caveolina-2 (Scherer et al., 1996) y Caveolina-3 (Tang et al., 1996; Way and Parton, 1995) constituyendo de este modo una familia de proteínas (CAV1, CAV2 y CAV3). Estos tres miembros de la familia se expresan, en mayor o menor medida, en la práctica totalidad de los tejidos y células del organismo. Aunque durante años se consideró que no se expresaban en ciertos tipos celulares tales como las neuronas (Gorodinsky and Harris, 1995), estudios posteriores han demostrado que si se expresan, al menos en estadios de diferenciación específicos (Boulware et al., 2007; Shikanai et al., 2018; Zschocke et al., 2002), por lo que se puede considerar que su expresión es incluso más generalizada de lo que se pensaba inicialmente. CAV1 y CAV2 son especialmente abundantes en adipocitos, células endoteliales y fibroblastos, mientras que CAV3 se expresa de forma específica en células musculares estriadas, sustituyendo a CAV1 (Okamoto et al., 1998), aunque recientemente también se ha visto que se expresa y es funcional también en células no musculares (Niesman et al., 2013). En el caso de CAV2 su distribución es muy similar a la de CAV1 en la MP, dado que CAV1 recluta CAV2 en el Golgi y ambas proteínas se asocian formando hetero-oligómeros (Li et 
al., 1998). Pese a ello, se sabe que CAV1 puede ejercer su función también independientemente de CAV2 (Razani et al., 2002a). Del mismo modo, CAV2 desempeña funciones independientes de CAV1, formando en ocasiones homo-oligómeros independientes de CAV1 y de caveolas en la MP (Kwon et al., 2013).

Los tres genes que componen la familia de las caveolinas presentan un alto grado de conservación en diferentes especies (Tang et al., 1997), siendo esta observación un reflejo de su importancia a nivel funcional. En el caso de CAV1, el gen, que está localizado en el cromosoma 7 en humanos, tiene tres exones que codifican para dos isoformas diferentes; la isoforma $\alpha$, de 178 aminoácidos (CAV1 $\alpha$ ) y la $\beta$ (CAV1 $\beta)$, una variante truncada que carece de los 31 aminoácidos $\mathrm{N}$-terminales debido a que su traducción se inicia en un codón AUG alternativo, situado en la posición 32 (Scherer et al., 1995). CAV2 se encuentra en el mismo cromosoma que CAV1, en una posición consecutiva, y también presenta tres exones y da lugar a dos isoformas diferentes (Scherer et al., 1997). El gen que codifica para CAV3 por su parte presenta sólo dos exones y está localizado en el cromosoma 3 (Minetti et al., 1998). Los tres miembros de la familia comparten tres dominios principales (Figura 1), i) un dominio de unión a otras proteínas (CSD, del inglés Caveolin-Scaffolding Domain), ii) un dominio de unión a la MP y iii) un dominio Cterminal con varias cisteínas susceptibles de ser palmitoiladas y con gran relevancia para la estructura y funcionalidad de las caveolas (Busija et al., 2017).

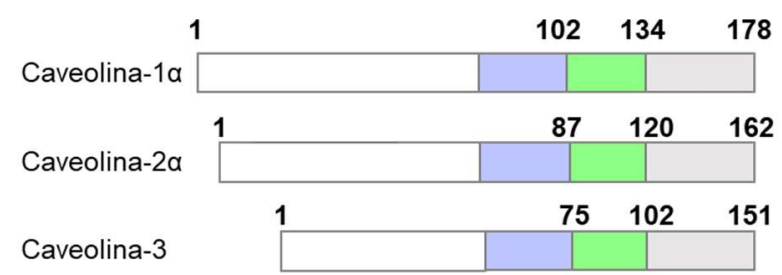

Dominio de unión a otras proteínas (CSD)

Dominio de unión a MP

Dominio C-terminal
Figura 1. Mapa de las proteínas de la familia de las caveolinas. Existe una gran homología entre los tres miembros de la familia, presentando todas ellas tres dominios comunes, el dominio CSD de unión a otras proteínas, el dominio de unión a la MP y el dominio C-terminal susceptible de palmitoilación. Figura adaptada de Sverdlov et al., 2007.

\subsubsection{Caveolina-1}

CAV1 (Figura 2) es una proteína integral de membrana con un peso molecular de aproximadamente 22KDa (Spisni et al., 2005) que se inserta en la MP adquiriendo una topología horquillada sin contacto con el exterior celular, por lo que sus dos extremos, tanto el $\mathrm{N}$ como el C-terminal están orientados hacia la región citosólica (Dupree et al., 1993; Monier et al., 1995). Comparte tres dominios comunes con CAV2 y CAV3; el CSD (residuos 82-101), el dominio integral de MP (residuos 102-134) y la región C-terminal con tres residuos de cisteína 
susceptibles de ser palmitoilados (Razani et al., 2002b). Los tres residuos susceptibles de ser palmitoilados son C133, C143 y C156, y son importantes porque contribuyen a la estabilización de CAV1 en la MP (Monier et al., 1996) y están implicados en el transporte de colesterol (Uittenbogaard and Smart, 2000). El domino CSD, próximo a la inserción a la MP, interacciona con una gran variedad de proteínas de membrana, como es el caso de eNOS, EGFR, PKA y Src quinasas, regulando diferentes procesos de señalización celular (Okamoto et al., 1998). El dominio $\mathrm{N}$-terminal incluye un sitio de fosforilación especifico en la tirosina Y14 (ausente en algunos miembros de la familia, como en el caso de $\operatorname{CAV} 1 \beta)$, que tiene también un papel determinante en diferentes procesos de señalización (Cao et al., 2002; Parton and del Pozo, 2013). En el dominio CSD, el residuo de serina S80, está implicado en la unión de CAV1 a la membrana del retículo endoplasmático (RE) y su entrada en la ruta de secreción (Schlegel et al., 2001).

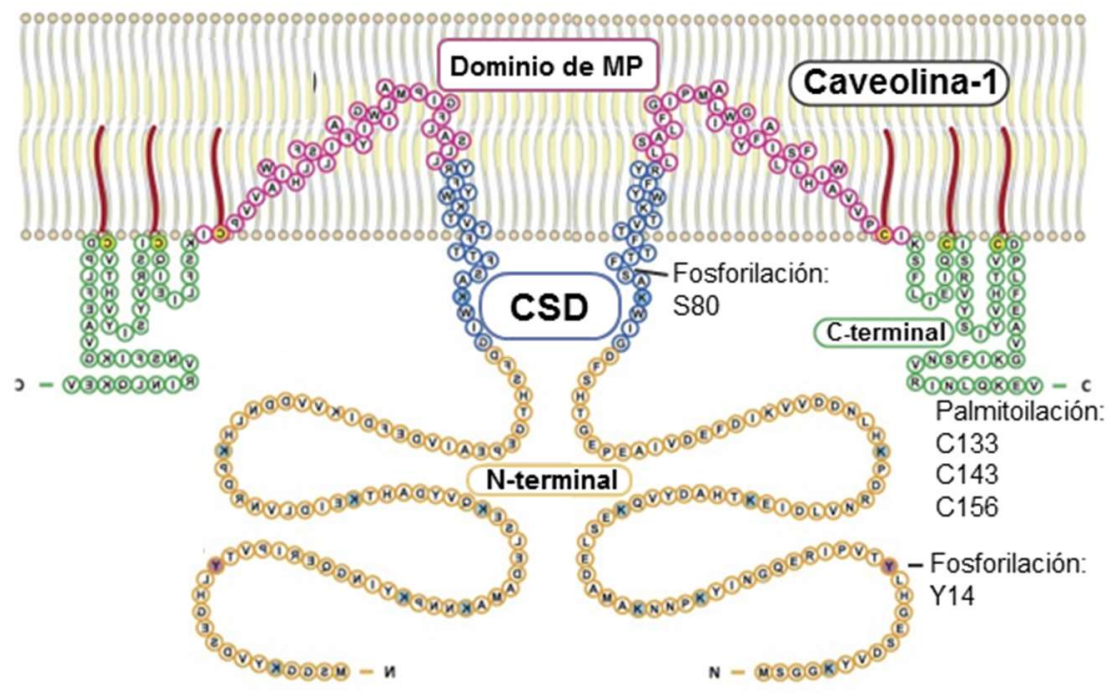

Figura 2. Representación esquemática de dos moléculas de CAV1 insertadas en la MP. Aparecen representados los cuatro dominios principales que la componen, además de los principales sitios de fosforilación y palmitoilación. Figura adaptada de Busija et al., 2017.

CAV1 se inserta en la membrana del RE durante su síntesis, a través de su interacción con el Translocón y la partícula de reconocimiento de la señal (SRP, del inglés signal recognition particle) (Monier et al., 1995). A continuación, oligomeriza dando lugar a homo-oligómeros compuestos por unas 14-16 proteínas, que posteriormente se asocian formando oligómeros de mayor orden en el complejo de Golgi (Li et al., 1996). Tras la asociación con moléculas de colesterol en la membrana (Pol et al., 2005) CAV1 abandona el Golgi en pequeñas vesículas (Tagawa et al., 2005), hasta llegar a la MP donde conforma las caveolas tras la asociación con el resto de componentes de las mismas (Figura 3) (Hayer et al., 2010) 


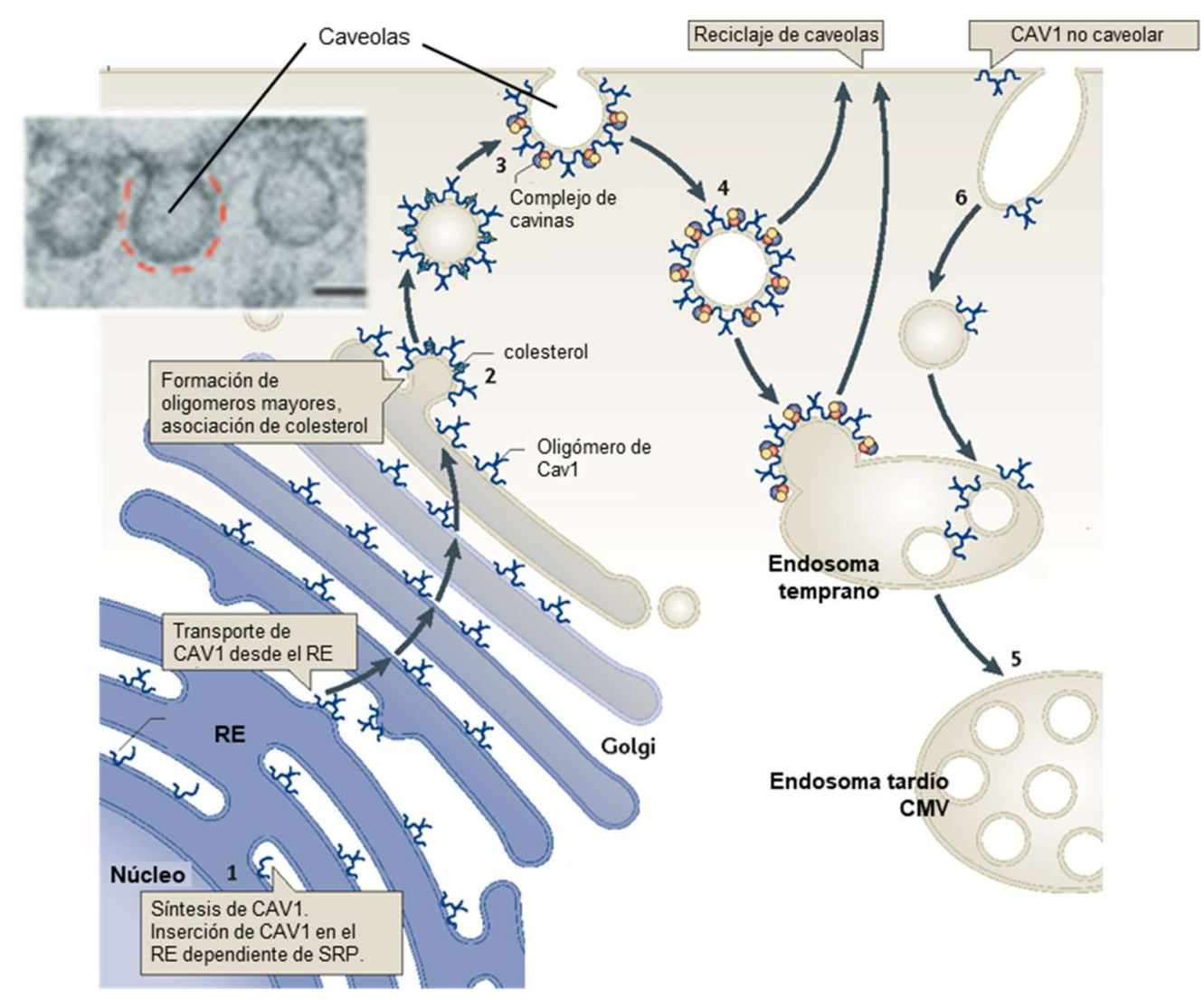

Figura 3. Esquema representando el tráfico de CAV1 a lo largo del sistema de endomembranas celulares. (1) CAV1 se integra en la MP en el RE rugoso durante la traducción gracias a la participación de una SRP. (2) Posteriormente pasa a través del sistema de membranas que compone el aparato de Golgi, donde oligomeriza y se asocia a moléculas de colesterol. (3) Desde el Golgi vesículas con CAV1 oligomerizada viajan hasta la MP, y una vez en la MP reclutan el complejo de las cavinas para conformar las caveolas. (4) Las caveolas se endocitan desde la MP a endosomas tempranos, y también trafican en el sentido contrario, reciclándose de nuevo a la MP para el mantenimiento de la homeostasis de las caveolas. (5) Desde los endosomas tempranos también se puede movilizar hacia el endosoma tardío o cuerpo multivesicular (CMV) para su degradación. (6) En la MP también se puede encontrar CAV1 no caveolar que se puede internalizar por vías de endocitosis independientes de caveolas. En la imagen de microscopia electrónica aparecen tres caveolas asociadas a la MP. Figura adaptada de Parton y del Pozo, 2013.

Además de en caveolas, CAV1 también está presente en otras localizaciones celulares, donde se ha visto que tiene papeles relevantes, como es el caso de las mitocondrias (Bosch et al., 2011a; Bosch et al., 2011b; Li et al., 2001), siendo un componente constitutivo y un regulador esencial de los puntos de contacto entre el RE y la mitocondria (Sala-Vila et al., 2016). También está documentada su presencia en otros orgánulos celulares, como es el caso de los endosomas, lisosomas, peroxisomas y cuerpos lipídicos (Mundy et al., 2012; Ostermeyer et al., 2001; Woudenberg et al., 2010). Además, en la MP se pueden encontrar homo-oligómeros de CAV1 que no están asociados a caveolas (Lajoie et al., 2009a). Todo ello indica que, a pesar de su identificación inicial en caveolas, CAV1 también tiene relevancia funcional fuera de estas. Es importante remarcar esta distinción entre CAV1 caveolar y no caveolar, ya que, al tener 
funciones en señalización diferentes (Echarri and Del Pozo, 2015) el ratio entre la fracción caveolar y la no caveolar podía determinar la aparición determinados fenotipos, y podría ser la explicación de ciertas controversias como en el caso del papel de CAV1 en el cáncer, donde existen trabajos que afirman que CAV1 actúa como un gen supresor de tumores (Bender et al., 2000; Wiechen et al., 2001) y otros que afirman que un aumento en su expresión está asociado a una peor prognosis de la enfermedad (Chatterjee et al., 2015; Nam et al., 2013).

\subsubsection{Las caveolas}

Como ya se ha mencionado, una de las funciones que CAV1 desempeña en la célula, es la formación y estabilización de caveolas. Estos microdominios de la MP fueron identificados por primera vez mediante microscopia electrónica como pequeñas invaginaciones de la MP de unos 60-80 nm de diámetro especialmente abundantes en células endoteliales (Palade, 1953; Yamada, 1955). Las caveolas son dominios de membrana muy estables desde el punto de vista dinámico (Tagawa et al., 2005) y especialmente abundantes en determinados tipos celulares típicamente expuestos a variaciones en la tensión de su MP, como las células de musculo liso, fibroblastos, células endoteliales y adipocitos (Parton and Simons, 2007). Se encuentran situadas en dominios de membrana enriquecidos en colesterol, esfingolípidos y proteínas, comúnmente conocidas como "balsas lipídicas" por su capacidad de moverse como una sola unidad, por difusión en la MP, según el modelo del mosaico fluido (Pike, 2006; Singer and Nicolson, 1972), aunque también han sido definidos por su resistencia a ser digeridos por determinados detergentes (Magee and Parmryd, 2003). Hasta el momento sólo se han identificado caveolas en vertebrados, a pesar de que en algunas especies de invertebrados (Caenorhabditis elegans y Apis melifera) se ha identificado un homólogo funcional de CAV1 (Hansen and Nichols, 2010).

Los principales componentes estructurales de las caveolas son las caveolinas, siendo CAV1 la más relevante, al ser necesaria para la biogénesis de las mismas, excepto en el caso de las células musculares, en las que la proteína principal que conforma estos dominios es CAV3 (Drab et al., 2001; Galbiati et al., 2001). En concreto, se ha estimado que cada caveola contiene unas 140-150 moléculas individuales de CAV1 (Pelkmans and Zerial, 2005).

Una década después de la caracterización de las caveolinas como componentes estructurales de las caveolas se descubrió una nueva familia determinante para el funcionamiento y biogénesis de las mismas, las cavinas (Hansen and Nichols, 2010). La familia de las cavinas está compuesta por cuatro miembros, Cavin-1 (PTRF; Polymerase I and transcript release factor), Cavin-2 (SDPR; serum deprivation response protein), Cavin-3 (SRBC; sdr-related gene product that binds to c-kinase) y Cavin-4 (MURC; muscle-restricted coiled-coil protein) 
(Kovtun et al., 2015). Todas ellas tienen una secuencia y una estructura tridimensional muy similar (Kovtun et al., 2014) y se asocian formando complejos homo- y hetero-oligoméricos que se unen a las caveolas en células que expresan caveolinas contribuyendo a su estabilización en la MP (Bastiani et al., 2009; Gambin et al., 2013). Tanto las caveolinas como las cavinas interaccionan con fosfatidilserina y fosfatidilinositol 4,5 bifosfato (Kovtun et al., 2014; Wanaski et al., 2003), ambos fosfolípidos cargados negativamente que se encuentran enriquecidos en caveolas (Fairn et al., 2011; Fujita et al., 2009; Pike and Casey, 1996). Una de las cavinas más importantes es PTRF, indispensable para la formación de caveolas (Aboulaich et al., 2004; Liu et al., 2008) ya que es responsable del reclutamiento del resto de las cavinas (Bastiani et al., 2009). Junto con las caveolinas, las cavinas forman un complejo homogéneo con un coeficiente de sedimentación de $80 \mathrm{~S}$ que es el encargado de recubrir la cara citosólica de las caveolas, formando lo que se conoce como "complejo de revestimiento de las caveolas" (Ludwig et al., 2013).

Además de las caveolinas y las cavinas existen otras proteínas que se asocian directamente con las caveolas y regulan su dinámica, morfología e internalización. Algunas de ellas se asocian en la zona del "cuello", es decir, la región más próxima a la MP, como es el caso de la Dynamina-2 (DYN2), que media la internalización de las caveolas al posibilitar la escisión de la MP (Henley et al., 1998); la ATPasa EHD2 (Eps-15 homology domain-containing protein 2) (Moren et al., 2012); y la proteína con dominio BAR PACSIN2 (PKC and casein kinase substrate in neurons 2) (Hansen et al., 2011).

\subsubsection{CAV1, caveolas y el citoesqueleto}

La distribución subcelular y la organización de CAV1 y caveolas está ligada a la dinámica del citoesqueleto. Múltiples evidencias, incluyendo su visualización directa mediante microscopía electrónica, apoyan la existencia de una conexión estrecha entre caveolas y los tres componentes principales del citoesqueleto, actina, microtúbulos y filamentos intermedios (Parton and del Pozo, 2013). Los microtúbulos son necesarios para el adecuado reciclaje de caveolas a la membrana (Wickstrom et al., 2010). La red de actina es necesaria para la movilidad lateral de las caveolas en la MP (Muriel et al., 2011) y para la organización de los dominios caveolares, pudiendo fomentar el aplanamiento de las caveolas o la aparición de agrupaciones de caveolas, conocidos como rosetas (Echarri et al., 2012). En la asociación de CAV1 con el citoesqueleto es importante destacar el papel de Filamina A (FLNA) ya que esta proteína conecta directamente CAV1 con las fibras de estrés (Stahlhut and van Deurs, 2000) y media los cambios en la dinámica de las caveolas dependientes de citoesqueleto de actina (Muriel et al., 2011; 
Sverdlov et al., 2009). Otras proteínas importantes en este sentido por su vinculación tanto con caveolas como con el citoesqueleto de actina son EHD2, PTRF y Miosina 1C (MYO1C) (Echarri and Del Pozo, 2015).

La relación de CAV1 con el citoesqueleto es bidireccional, ya que CAV1 también es capaz de afectar a la dinámica del citoesqueleto y las adhesiones focales a través del control de la actividad de quinasas Src y las RhoA GTPasas (Grande-Garcia et al., 2007; Joshi et al., 2008). CAV1 es capaz de modular, por ejemplo, la contracción de actina-miosina a través del control de la actividad de la GTPasa RhoA, mediante la inhibición de p190RhoGAP (Goetz et al., 2011).

\subsubsection{Implicaciones funcionales de CAV1 y caveolas}

A la hora de hablar de las funciones de CAV1 y caveolas es importante hacer una clara distinción entre ambas, ya que, tal y como hemos mencionado anteriormente existen determinadas funciones que CAV1 puede realizar sin formar parte de caveolas (Echarri and Del Pozo, 2015). En ocasiones es difícil discernir entre las funciones propias de las caveolas como estructura y de la CAV1 per se, y las afirmaciones que se hacen al respecto de la implicación de unas y la otra han de ser tomadas con cautela.

Cabe destacar que los ratones deficientes en CAV1, que no presentan caveolas, son viables, fértiles y completan su desarrollo hasta la etapa adulta (Drab et al., 2001; Razani et al., 2001). Por tanto, se considera que CAV1 y caveolas no son estrictamente requeridos para la mayoría de las funciones esenciales de células y organismos. No obstante, la alteración de las funciones de las que toman parte son relevantes y muchos fenotipos son aparentes y visibles en pacientes humanos con mutaciones en CAV1 y otros componentes de las caveolas (Tabla 1), cómo es el caso de la lipodistrofia, la distrofia muscular y el cáncer, poniendo en relieve su importancia fisiopatológica.

Entre las funciones más destacadas de CAV1 se encuentra su participación en la regulación de diferentes rutas bioquímicas de señalización celular. Esta regulación es dependiente en muchas ocasiones de la interacción directa de CAV1 con moléculas reguladoras o de la localización de las mismas en caveolas, como es el caso de las Proteínas G heterotriméricas, Src quinasas, integrinas, ERK1/2, PKC, PI3K ,H-Ras, eNOS y diferentes canales iónicos (Krajewska and Maslowska, 2004; Patel et al., 2008). La interacción de CAV1 con esas moléculas reguladoras tiene lugar frecuentemente a través de su dominio CSD que interacciona con dominios específicos denominados CBM (del inglés CAV1 binding motif) (Couet et al., 1997). Además, CAV1 está implicada en el control del tráfico y transporte de colesterol a nivel 
intracelular (Smart et al., 1996) y regula la composición lipídica de la MP (Ariotti et al., 2014), con el consiguiente efecto que esto tiene también en la señalización. Este control de diferentes rutas de señalización determina en última instancia su implicación en el control del comportamiento celular, afectando a procesos biológicos tales como migración, polarización, supervivencia, apoptosis y proliferación (Boscher and Nabi, 2012)

\begin{tabular}{|c|c|c|c|}
\hline Enfermedad & Fenotipo & $\begin{array}{l}\text { Proteína } \\
\text { mutada }\end{array}$ & Referencias \\
\hline $\begin{array}{l}\text { Lipodistrofia congénita de } \\
\text { Berardinelli-Seip tipo } 3 \\
\text { (CAV1) y } 4 \text { (PTRF) }\end{array}$ & $\begin{array}{l}\text { Perdida de tejido adiposo, } \\
\text { hipertrigliceridemia, resistencia a } \\
\text { insulina, diabetes, cardiomiopatía } \\
\text { hipertrófica, esteatosis hepática. }\end{array}$ & $\begin{array}{l}\text { CAV1, } \\
\text { PTRF }\end{array}$ & $\begin{array}{l}\text { (Cao et al., 2008; } \\
\text { Rajab et al., } \\
\text { 2010) }\end{array}$ \\
\hline $\begin{array}{l}\text { Hipertensión arterial } \\
\text { pulmonar }\end{array}$ & $\begin{array}{l}\text { Proliferación y remodelado de los vasos } \\
\text { pulmonares, elevada presión arterial } \\
\text { pulmonar, fallo del ventrículo derecho. }\end{array}$ & CAV1 & $\begin{array}{c}\text { (Austin et al., } \\
\text { 2012) }\end{array}$ \\
\hline $\begin{array}{l}\text { Distrofia muscular del } \\
\text { anillo óseo }\end{array}$ & $\begin{array}{l}\text { Disminución progresiva de la fuerza y } \\
\text { volumen de los músculos de caderas y } \\
\text { hombros, mioglobinuria, miotonía, } \\
\text { niveles elevados de creatina quinasa en } \\
\text { el suero. }\end{array}$ & CAV3 & $\begin{array}{l}\text { (Minetti et al., } \\
\text { 1998) }\end{array}$ \\
\hline $\begin{array}{l}\text { Enfermedad del músculo } \\
\text { ondulante (rippling) }\end{array}$ & $\begin{array}{l}\text { Contracciones musculares } \\
\text { eléctricamente silentes después del } \\
\text { estímulo mecánico o estiramiento. }\end{array}$ & CAV3 & $\begin{array}{l}\text { (Kubisch et al., } \\
\text { 2003) }\end{array}$ \\
\hline Síndrome de QT largo & $\begin{array}{c}\text { Prolongación del intervalo Q-T en el } \\
\text { electrocardiograma, arritmias, fibrilación } \\
\text { ventricular. }\end{array}$ & $\begin{array}{l}\text { CAV3, } \\
\text { PTRF }\end{array}$ & $\begin{array}{l}\text { (Rajab et al., } \\
\text { 2010) }\end{array}$ \\
\hline $\begin{array}{l}\text { Síndrome de muerte } \\
\text { súbita infantil }\end{array}$ & Muerte repentina. & CAV3 & $\begin{array}{l}\text { (Lariccia et al., } \\
\text { 2014) }\end{array}$ \\
\hline $\begin{array}{l}\text { Cardiomiopatía } \\
\text { hipertrófica o dilatada }\end{array}$ & $\begin{array}{l}\text { Engrosamiento del miocardio, } \\
\text { cardiomiopatía no isquémica, } \\
\text { disminución de la función cardiaca. }\end{array}$ & $\begin{array}{l}\text { CAV3, } \\
\text { PTRF, } \\
\text { MURC }\end{array}$ & $\begin{array}{l}\text { (Lariccia et al., } \\
\text { 2014; Rajab et } \\
\text { al., 2010; } \\
\text { Rodriguez et al., } \\
\text { 2011) }\end{array}$ \\
\hline Cáncer & $\begin{array}{c}\text { Cáncer de mama, próstata, ovárico y de } \\
\text { páncreas. }\end{array}$ & CAV1 & $\begin{array}{l}\text { (Han et al., 2004; } \\
\text { Li et al., 2006) }\end{array}$ \\
\hline
\end{tabular}

Tabla 1. Enfermedades asociadas a mutaciones en caveolinas y/o cavinas en humanos. Tabla adaptada de Busija et al., 2017.

Además del control de la señalización, CAV1 y otros componentes de las caveolas están implicadas en otros procesos, como, por ejemplo, en la regulación de la endocitosis independiente de clatrina por la vía CLIC/GEEC (del inglés clathrin independent carriers / GPI-AP 
enriched early endosomal compartment) (Chaudhary et al., 2014) y en el control de procesos metabólicos (Nwosu et al., 2016). Finalmente, una de las funciones que está adquiriendo una mayor relevancia en la última década es su contribución determinante en procesos de mecanotransducción de señales, tal y cómo se detalla en él apartado siguiente.

\subsubsection{Funciones específicas de las caveolas como unidad estructural}

Inicialmente, debido a su estructura característica como invaginaciones de la membrana abiertas hacia el exterior celular, que recuerda en cierta media a las vesículas de clatrina pero sin el denso revestimiento que caracteriza a estas vesículas (Richter et al., 2008) las caveolas se concibieron como estructuras implicadas en procesos de endocitosis. En este sentido, los primeros estudios encaminados a su caracterización funcional consistieron en demostrar su papel en este proceso, describiéndose su regulación por quinasas y la dependencia del citoesqueleto de actina (Parton, 1994). En un principio se propusieron el virus SV40 y la toxina colérica B como cargos específicos de esta vía de endocitosis, sin embargo, estudios posteriores han puesto en duda la especificidad de estos cargos, demostrando su internalización independiente de caveolas (Damm et al., 2005; Lajoie et al., 2009b). Precisamente esa ausencia de un cargo específico y la ausencia de epítopos externos para el reconocimiento de CAV1 dificultan el estudio del papel de las caveolas en endocitosis. Ese motivo, sumado al hecho de que sólo una pequeña proporción de las caveolas totales se internalizan en condiciones normales (Shvets et al., 2015), existe una gran controversia en el campo respecto a su verdadera relevancia para la fisiología celular. Pese a ello, aunque la internalización de cargos específicos parece no ser la principal función de las caveolas, sí que existe evidencia de que su endocitosis es necesaria para el mantenimiento de su homeostasis en la MP: las caveolas se endocitan hasta endosomas Rab5-positivos y posteriormente vuelven a la MP garantizando la presencia de un número constante de caveolas en la superficie celular (Pelkmans and Zerial, 2005).

En el caso de las células endoteliales, las caveolas participan en el transporte de moléculas desde el lumen de los vasos sanguíneos al espacio sub-endotelial, un proceso conocido como transcitosis (Frank et al., 2009). Además, en los últimos años ha cobrado fuerza la concepción de las caveolas como un sistema de buffer o reservorio de membrana plasmática, al ser capaces de secuestrar o liberar superficie de membrana en función de los requerimientos específicos de la célula, en base, por ejemplo, a cambios en la tensión de la misma (Parton and del Pozo, 2013). 


\subsubsection{Implicación de CAV1 y caveolas en procesos de mecanotransducción}

CAV1 y caveolas contribuyen a la adaptación y la percepción de diferentes señales mecánicas, generalmente relacionadas con cambios en la tensión de la MP, tales como el estiramiento, el estrés por flujo superficial o la perdida de adhesión al sustrato (Cheng and Nichols, 2016). Las caveolas se aplanan en respuesta a estímulos mecánicos, como el estiramiento de la MP, y ese aplanamiento promueve su desensamblaje y la liberación de algunos de sus componentes (Sinha et al., 2011). Este aplanamiento de las caveolas, además de afectar a procesos de señalización, constituye un sistema de adaptación y de protección de la célula frente al estiramiento mecánico, ya que provee material de membrana adicional a la superficie celular actuando a modo de buffer (Echarri et al., 2012; Parton and del Pozo, 2013; Sinha et al., 2011). Otro estímulo mecánico diferente, la pérdida de adhesión al sustrato, determina una disminución en la densidad de caveolas en la MP (del Pozo et al., 2005), lo cual correlaciona con la internalización de CAV1 y su acumulación en endosomas de reciclaje, en un proceso que es dependiente de DYN2 y de la integridad del citoesqueleto (Echarri et al., 2012; Muriel et al., 2011). La internalización de CAV1 puede ser también independiente de caveolas (Hill et al., 2008), por lo que no se puede descartar que la entrada de CAV1 cuando las células pierden la adhesión al sustrato pueda ser un proceso independiente de la internalización de estos dominios de membrana.

\subsection{Ruta de señalización Hippo}

La vía de señalización Hippo se identificó por primera vez en Drosophila melanogaster tras la caracterización de la quinasa de la que recibe su nombre. En cuatro trabajos independientes se describió que tanto la ausencia como mutaciones en el gen hippo, inducían fenotipos hiperproliferativos en diferentes tejidos, derivados de un aumento en la proliferación celular y una disminución de la apoptosis (Harvey et al., 2003; Pantalacci et al., 2003; Udan et al., 2003; Wu et al., 2003). Precisamente el nombre Hippo deriva de esa capacidad de dar lugar a fenotipos hiperproliferativos, dando lugar a "fenotipos similares a hipopótamos" (hippopotamus en inglés). La proteína Hippo ( $\mathrm{Hpo}$ ) codificada por el gen del locus hippo fue identificada inicialmente en los trabajos anteriormente citados como un interactor de otras dos proteínas, Salvador (Sav) y la serina/treonina quinasa Warts (Wts), previamente descritas también como reguladores del tamaño de órganos y tejidos a través del control de la proliferación celular (Kango-Singh et al., 2002; Tapon et al., 2002). Hpo, Sav y Wts forman de ese modo una cascada de quinasas que esta conservada estructural y funcionalmente en humanos, 
siendo los genes MST1/2 (macrophage stimulating 1 y 2), SAV1 (Salvador Family WW Domain Containing Protein 1) y LATS1/2 (large tumor suppressor kinase 1 y 2) los homólogos correspondientes (Zhao et al., 2007). Esta cascada de quinasas actúa de forma coordinada constituyendo una ruta de señalización (Harvey and Tapon, 2007; Udan et al., 2003) que establece en última instancia el balance entre proliferación y apoptosis a la vez que modula la diferenciación celular (Yu and Guan, 2013) adquiriendo un papel determinante en el control del tamaño final de los diferentes órganos y tejidos que constituyen un organismo.

\subsubsection{YAP Y TAZ}

La cascada de quinasas fosforila en última instancia a la proteína Yorkie (Yki), cuyos homólogos humanos (igualmente sustratos últimos de fosforilación de la ruta) son YAP (Yesassociated protein) y TAZ (WWTR1, WW Domain-Containing Transcription Regulator Protein 1) (Huang et al., 2005). El estado de fosforilación de estos factores determina su localización subcelular y por consiguiente su actividad como reguladores transcripcionales. La fosforilación de YAP/TAZ favorece la retención inhibitoria de ambos co-factores en el citoplasma celular, mientras que, en su estado no fosforilado, pueden ser translocadas al núcleo, donde regulan la expresión de una gran variedad de genes que en última instancia determinan sus funciones biológicas (Piccolo et al., 2014).

YAP comparte un 50\% de homología con TAZ en su secuencia y en su estructura terciaria, presentando ambos una regulación y funcionamiento muy similares (Lei et al., 2008). Esa similitud ha propiciado que en muchos trabajos no se hagan distinciones entre ambas proteínas. Sin embargo, las funciones de ambas no son exactamente las mismas, ya que se sabe que en determinados procesos está implicada una y no la otra (Calvo et al., 2013). Ambas proteínas constan de uno o dos dominios WW, un dominio de unión a proteínas 14-3-3 y un dominio Cterminal que contiene un dominio de unión PDZ (Mahoney et al., 2005) (Figura 4).

YAP1

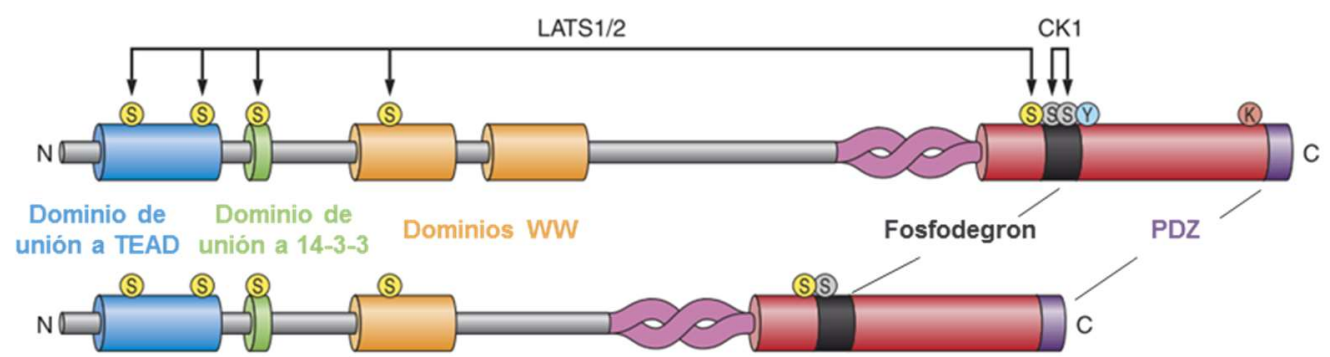

Figura 4. Dibujo esquemático de las proteínas YAP y TAZ. Aparecen representados los dominios comunes en ambas proteínas y los sitios específicos de fosforilación por las quinasas LATS1/2. Figura adaptada de Piccolo et al., 2014. 


\subsubsection{Factores de transcripción TEAD}

Yki no posee una secuencia de unión al ADN, por lo que su actividad reguladora de la transcripción depende de la interacción con el factor de transcripción Scalloped (Sd) (Goulev et al., 2008). En mamíferos los ortólogos de sd que median la actividad reguladora de la transcripción de YAP/TAZ son una familia de genes denominada TEAD, que está compuesta por cuatro miembros: TEAD 1-4 (TEA domain family members 1-4) (Zhao et al., 2008). Los factores de transcripción TEAD se caracterizan por tener un dominio TEA/ATTS de unión al ADN con afinidad por la secuencia GGAATG y un dominio de interacción con co-activadores transcripcionales, a través del cual interacciona con YAP y TAZ (Jacquemin et al., 1996; Lin et al., 2017). Cada uno de los miembros de la familia tiene un patrón tisular de expresión diferente, lo que sugiere que cada uno tiene funciones específicas de tejido (Pobbati and Hong, 2013). TEAD puede además interaccionar con otros co-factores, como, por ejemplo, Fosfofructoquinasa-1 (PK1), VGLL (Vestigial-like), TCF4 (transcription factor 4), AP1 (activator protein-1), PARP (polyADP ribose polymerase), SRF (serum response factor), MEF2 (myocyte enhancer factor 2), MAX (myc-associated factor $X$ ) y receptores esteroideos de la familia p160, de modo que la competencia con estos otros co-factores puede, en algunos casos, ser determinante también para el control de la actividad YAP/TAZ-TEAD (Chen et al., 2004; Enzo et al., 2015; Lin et al., 2017). Pese a ello, se ha visto que las proteínas más importantes en la determinación de la activación transcripcional regulada por TEAD son YAP y TAZ, ya que su silenciamiento inhibe la actividad transcripcional de TEAD casi por completo (Zhao et al., 2008). Otro nivel de regulación de las proteínas de la familia TEAD es a través de modificaciones post-traduccionales (fosforilación y palmitoilación) que pueden afectar a su actividad al regular de su estabilidad y su capacidad para unirse al ADN (Gupta et al., 2000; Jiang et al., 2001; Noland et al., 2016). Además, en determinados contextos, la distribución subcelular de TEAD puede variar, existiendo, cómo en el caso de YAP/TAZ, una translocación núcleo-citosólica (Lin et al., 2017) añadiendo un nivel adicional de complejidad a la regulación de la actividad de YAP/TAZ mediada por TEAD.

YAP/TAZ pueden interaccionar con otros factores de transcripción distintos de TEAD, entre los que se incluyen SMAD1, SMAD2/3, TBX5, RUNX1, RUNX3, RUNX2, ERBB4 y p73. (Alarcon et al., 2009; Basu et al., 2003; He et al., 2016; Komuro et al., 2003; Varelas et al., 2008; Yagi et al., 1999). Estos factores de transcripción alternativos regulan programas transcripcionales diferentes y, curiosamente, tienen en algunos casos funciones antagónicas a las determinadas por el complejo YAP/TAZ-TEAD, como es el caso de la apoptosis en respuesta 
a daño en el ADN mediada por YAP-P73 (Strano et al., 2005) o el bloqueo de la transición epiteliomesénquima (EMT, epithelial to mesenchymal transition) por RUNX1-YAP (Kulkarni et al., 2018).

\subsubsection{Reguladores principales de la vía}

YAP y TAZ son fosforiladas por LATS1/2, que a su vez son fosforiladas por MST1/2, y esa fosforilación conduce a la inhibición de su actividad transcripcional por la interacción con proteínas 14-3-3, que determinan su retención en el citosol (Dong et al., 2007). En paralelo a este núcleo central MST1/2-LATS1/2 aparecen también los reguladores MOB1 y SAV1, ambos fosforilados por MST1/2. MOB1 se une a LATS1/2 cuando esta fosforilado y favorece su actividad quinasa (Chan et al., 2005), mientras que SAV1 funciona como nexo entre MST1/2 y LATS1/2, favoreciendo la fosforilación de LATS1/2 (Callus et al., 2006). Distintas quinasas pueden fosforilar LATS1/2, lo cual permite una regulación independiente de MST1/2 (Zhou et al., 2009). Por encima de las quinasas anteriormente citadas se encuentra una proteína de la familia ezrin/radixin/moesin que aparece íntimamente asociada al citoesqueleto, la proteína Merlin (NF2; Neurofibromatosis type 2) (McClatchey and Giovannini, 2005). NF2 es capaz de activar la vía Hippo a través del reclutamiento de LATS1/2 a la MP favoreciendo su fosforilación por MST1/2 (Yin et al., 2013) (Figura 5).

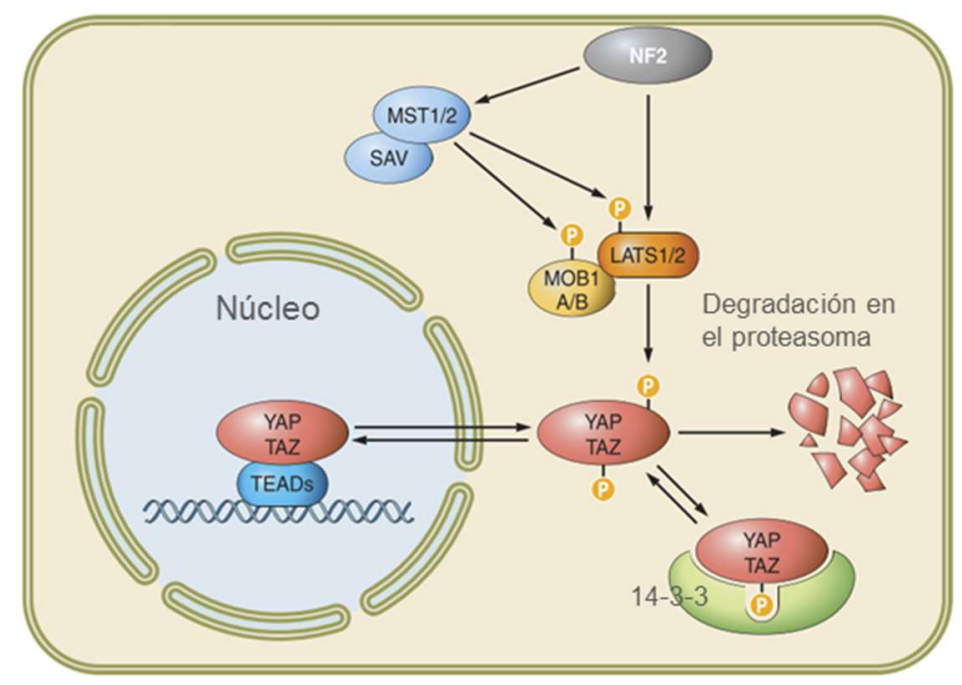

Figura 5. Esquema de los componentes principales de la vía de señalización Hippo. Figura adaptada de Piccolo et al., 2014.

LATS1/2 interaccionan directamente con YAP/TAZ y lo fosforilan. En el caso de YAP la fosforilación es en cinco residuos de serina específicos, de los cuales el más importante, por ser determinante para su retención citosólica, es $S 127$ (Zhao et al., 2007). TAZ posee cuatro residuos de serina aceptores de fosforilación, siendo el más importante a nivel de regulación S89 (Lei et al., 2008). Aparte de la retención citosólica por proteínas 14-3-3 existe otro mecanismo inhibitorio de YAP/TAZ adicional, su degradación en la vía del proteasoma regulada por 
ubiquitinación. En el caso de la degradación proteasomal es clave la fosforilación en el residuo S397 (S311 en TAZ) por LATS1/2, que posibilita la subsiguiente fosforilación por CK1 (Casein quinase 1) formando un phosphodegron que es reconocido por la ubiquitina ligasa E1 (Huang et al., 2012; Liu et al., 2010; Zhao et al., 2010). LATS1/2 no son las únicas quinasas capaces de fosforilar YAP/TAZ; existen otras que también tienen esa capacidad, incluyendo NDR1/2 (Dbf2related kinases), que fosforila YAP en el residuo S127 (Zhang et al., 2015); JNK1/2 (JUN Nterminal kinases 1 y 2) (Tomlinson et al., 2010); c-ABL y YES1 (He et al., 2016).

Pese a tratarse de una cascada de quinasas y su función inhibitoria sobre YAP/TAZ estar mediada por sucesivas fosforilaciones, se sabe que otras modificaciones post-traduccionales también están implicadas en la regulación de los diferentes componentes de la ruta (He et al., 2016). Además, también tienen un papel determinante en la regulación de Hippo las fosfatasas que regulan la defosforilación de YAP y TAZ, como es el caso de PP1A y PP2A (Liu et al., 2011; Schlegelmilch et al., 2011).

El papel de la fosforilación en la regulación de YAP/TAZ es motivo de controversia en el campo, ya que algunos trabajos ponen en duda que sea indispensable para explicar su regulación funcional. En este sentido se ha observado, por ejemplo, que en determinados contextos la fosforilación de YAP no determina necesariamente su exclusión nuclear (Wada et al., 2011) y otros trabajos describen que la regulación de la actividad de YAP puede ser independiente de la fosforilación y de la actividad de las quinasas de la vía Hippo (Dupont et al., 2011; Elosegui-Artola et al., 2017).

\subsubsection{Regulación de la vía}

La densidad celular, la adhesión al sustrato, la polaridad y las uniones célula-célula son factores determinantes en la regulación de la vía de señalización Hippo. En condiciones de alta confluencia celular, YAP/TAZ se encuentran retenidas en el citosol en un proceso que es dependiente de su fosforilación (Zhao et al., 2007). En relación al papel de las adhesiones intercelulares, se ha descrito que la regulación de YAP puede ocurrir a través de su interacción directa con proteínas localizadas en estas uniones, como es el caso de Angiomotina (AMOT), $\alpha$ catenina, Zonula occludens 2 (ZO-2), la proteína tirosina fosfatasa 14 (PTPN14) y Scribble (Cordenonsi et al., 2011; Oka et al., 2010; Remue et al., 2010; Schlegelmilch et al., 2011; Zhao et al., 2011). En el caso de AMOT, se sabe que también recluta y favorece la actividad quinasa de MST1/2 y LATS1/2 (Paramasivam et al., 2011). 
MST1/2 pueden ser fosforiladas por AKT, JNK1 y c-ABL, lo cual permite una comunicación cruzada con las vías de señalización en las que participan esas quinasas (He et al., 2016). Del mismo modo, las quinasas MAP4K4 pueden fosforilar directamente LATS1/2 inhibiendo la actividad de YAP/TAZ (Meng et al., 2015). En el control de la actividad de YAP/TAZ tiene también un papel relevante la señalización mediante receptores asociados a Proteínas $\mathrm{G}$ (GPCR, G-protein coupled receptors), pudiendo activar o bloquear la vía Hippo en función de la proteína $\mathrm{G}$ a la que se asocian. Algunos factores reconocidos por receptores asociados a proteínas G, como es el caso del ácido lisofosfatídico (LPA) y la esfingosina-1-fosfato (S1P) presentes en el suero, inhiben las quinasas LATS1/2 tras la activación de receptores G12/13 o $\mathrm{Gq} / 11$; mientras que la epinefrina y el glucagón activan receptores asociados a Gs activando LATS1/2 e inhibiendo por tanto la actividad de YAP/TAZ (Yu et al., 2012). Existen además otras hormonas y mensajeros bioquímicos cuya capacidad de regular la actividad de YAP/TAZ a través de GPCRs ha sido descrita, tales como la trombina, tromboxano A2, endotelina-1 (ET1) y estrógeno, (Feng et al., 2016; Mo et al., 2012; Wang et al., 2017; Zhou et al., 2015). Factores solubles cuya señalización es mediada por receptores tirosina quinasa (RTKs) también se han caracterizado como posibles reguladores de la vía Hippo, como son los factores de crecimiento insulínicos (IGF) y el factor de crecimiento epitelial (EGF); ambos inhibien la actividad de las quinasas reguladoras de la vía Hippo, y por tanto favorecen la translocación nuclear de YAP/TAZ (Reddy and Irvine, 2013; Strassburger et al., 2012). Existe también una comunicación cruzada entre Hippo y otras vías de señalización, como es el caso de Wnt, la señalización por TGF- $\beta$, Notch y Hedgehog (Attisano and Wrana, 2013; Azzolin et al., 2014; Camargo et al., 2007; Fernandez et al., 2009; Grannas et al., 2015).

\subsubsection{Implicación del citoesqueleto en la regulación de YAP/TAZ}

La morfología celular es uno de los factores más importantes que determinan la distribución subcelular de YAP/TAZ. No es de extrañar por tanto que tanto que su actividad se vea afectada en gran medida por la dinámica del citoesqueleto de actina (Wada et al., 2011). Proteínas implicadas en el control de la dinámica de actina modulan la actividad de YAP/TAZ: reguladores del capping y recorte de fibras de actina (CapZ, Cofilina y Gelsolina) lo modulan negativamente (Aragona et al., 2013) y promotores de la polimerización y estabilización de fibras de actina, como DIAPH1 (Diaphanous-1), actúan como reguladores positivos (Dupont et al., 2011). En efecto, la inducción del colapso del citoesqueleto de actina provoca la retención citosólica de YAP/TAZ (Dupont et al., 2011; Wada et al., 2011; Zhao et al., 2012) mediante mecanismos que no están completamente esclarecidos todavía. Se ha comprobado que la 
fosforilación de YAP aumenta al inducir la despolimerización de la actina con citocalasina D (CytD) y que la inhibición de LATS1/2 mantiene YAP en el núcleo incluso en células tratadas con CytD (Wada et al., 2011). Además, muchos de los componentes de la vía están asociados o regulados por el citoesqueleto de actina. Es el caso por ejemplo de MST1/2, que se asocian con el citoesqueleto de actina y su activación depende de la integridad del mismo, activándose al inducirse la despolimerización (Densham et al., 2009). El reclutamiento de LATS quinasas a la MP por NF2 y AMOT y la regulación de su actividad por GPCRs es dependiente también del citoesqueleto de actina (Paramasivam et al., 2011; Yin et al., 2013; Yu et al., 2012). En el caso de las angiomotinas (AMOT, AMOTL1 y AMOTL2), no sólo son capaces de promover la activación de las quinasas de la ruta Hippo, sino que también son capaces de secuestrar directamente YAP/TAZ en el citosol cuando no interaccionan con F-actina, conectando de esta forma la regulación de YAP/TAZ con la arquitectura del citoesqueleto de actina (Mana-Capelli et al., 2014). El citoesqueleto tiene también un papel clave en la regulación mecánica de la actividad de YAP/TAZ, como veremos más adelante.

\subsubsection{Funciones de la vía}

Entre las funciones principales de YAP/TAZ y la vía Hippo se encuentran el control de la proliferación, la apoptosis celular y la diferenciación. Esas funciones han colocado a esta vía de señalización como un modulador central en la determinación de la homeostasis, crecimiento y desarrollo normal de los diferentes órganos que componen los organismos adultos así como en procesos de regeneración y reparación tisular (Maugeri-Sacca and De Maria, 2018; Varelas, 2014).

YAP/TAZ están implicadas en el desarrollo embrionario pre-implantacional determinando la especificación de los diferentes linajes celulares (Varelas, 2014) y en el mantenimiento de la pluripotencia en células madre embrionarias (Young, 2011). Es conocida también el papel de la vía de señalización Hippo en el control del metabolismo celular. Este control es bidireccional, de forma que el estatus metabólico de la célula controla la actividad de Hippo y a su vez Hippo es capaz de controlar el metabolismo celular (Ardestani et al., 2018). Así, el metabolismo de glucosa, a través de la propia glucosa, metabolitos intermedios del proceso de glicólisis o enzimas implicadas en el proceso, controla la actividad de YAP/TAZ determinando la proliferación celular en función de la disponibilidad energética (Enzo et al., 2015; Peng et al., 2017). Otra vía metabólica importante que controla la actividad de YAP/TAZ a través del control de la localización y actividad de las RhoA GTPasas, es la ruta de síntesis del colesterol SREBP/mevalonato (Sorrentino et al., 2014). Las vías de transducción de señales AMPK y mTOR, 
que actúan cómo sensores del estatus energético y los nutrientes de la célula, controlan de igual manera la actividad de YAP a través de diferentes mecanismos (Santinon et al., 2016). También contribuyen al control metabólico de YAP/TAZ metabolitos tales como aminoácidos, nucleótidos y lípidos, principalmente a través de la señalización por GPCRs (Ardestani et al., 2018). Además, como ya hemos comentado, YAP es capaz de controlar a su vez, a través del control de la expresión y actividad de componentes de estas rutas, procesos metabólicos, como el metabolismo de glúcidos (por ejemplo regulando la expresión de GLUT3; o de HK2 y PFKFB3 a través del IncARN BCAR4) o aminoácidos (por ejemplo regulando la expresión de la glutamina sintetasa GLUL) (Cox et al., 2016; Wang et al., 2015; Zheng et al., 2017). Esta conexión con rutas metabólicas sitúa a YAP/TAZ como un punto de unión esencial entre el control de la proliferación celular y el estatus metabólico de la célula.

Por su contribución al normal desarrollo y funcionamiento de órganos y tejidos, y su estrecha relación con los mecanismos de control del metabolismo celular, la vía de señalización Hippo tiene una importancia capital para el desarrollo de diferentes procesos patológicos, como es el caso del cáncer. De hecho los genes que regulan negativamente la actividad transcripcional de YAP/TAZ, como es el caso de NF2, LATS1/2, SAV1 y MOB, actúan como genes supresores de tumores (Harvey and Tapon, 2007; McClatchey and Giovannini, 2005). En cambio, el propio YAP es considerado un oncogén capaz de inducir EMT en células epiteliales (Overholtzer et al., 2006), bloquear la inhibición del crecimiento celular por contacto (Zhao et al., 2007) y dar lugar a fenotipos hiperproliferativos en órganos y tejidos que desembocan en el desarrollo de tumores (Camargo et al., 2007). De hecho en muchos tipos de cáncer se han reportado niveles elevados de YAP (Zhao et al., 2007). También se han observado elevados niveles de TAZ en tumores de mama, demostrándose su funcionamiento como un oncogén, al inducir la EMT y la proliferación de células epiteliales (Huang et al., 2012). Sin embargo, algunos trabajos ponen en duda la afirmación categórica que relaciona YAP/TAZ con progresión tumoral, indicando que en determinados contextos pueden actuar como genes supresor de tumores (Li and Clevers, 2013; Yuan et al., 2008).

\subsubsection{YAP/TAZ y mecanotransducción}

YAP/TAZ actúan como efectores finales en la transducción de señales mecánicas, estando su translocación al núcleo y su actividad como reguladores transcripcionales afectada por la morfología celular y la rigidez del sustrato en el que se encuentran las células (Dupont et al., 2011). Cuando las células crecen sobre una MEC rígida, o sobre un área de adhesión grande que permite su estiramiento completo, YAP/TAZ ejerce su actividad como co-regulador 
transcripcional en el núcleo, mientras que cuando se encuentra en una MEC blanda o las células se encuentran confinadas en un espacio que no permite su estiramiento ambos co-factores son retenidos en el citosol. En el caso de las células madre mesenquimales (CMM) esta regulación determina su diferenciación a diferentes tipos celulares (Dupont et al., 2011) (Figura 6) Otros estímulos mecánicos diferentes también se han correlacionado con la activación de YAP/TAZ, como es el caso del estrés provocado por el flujo sanguíneo sobre las células endoteliales (Zhong et al., 2013); el estiramiento mecánico de las células (Aragona et al., 2013; Benham-Pyle et al., 2015; Codelia et al., 2014) o la pérdida de adhesión al sustrato, que inactiva YAP a través de la activación de la vía Hippo (Zhao et al., 2012).

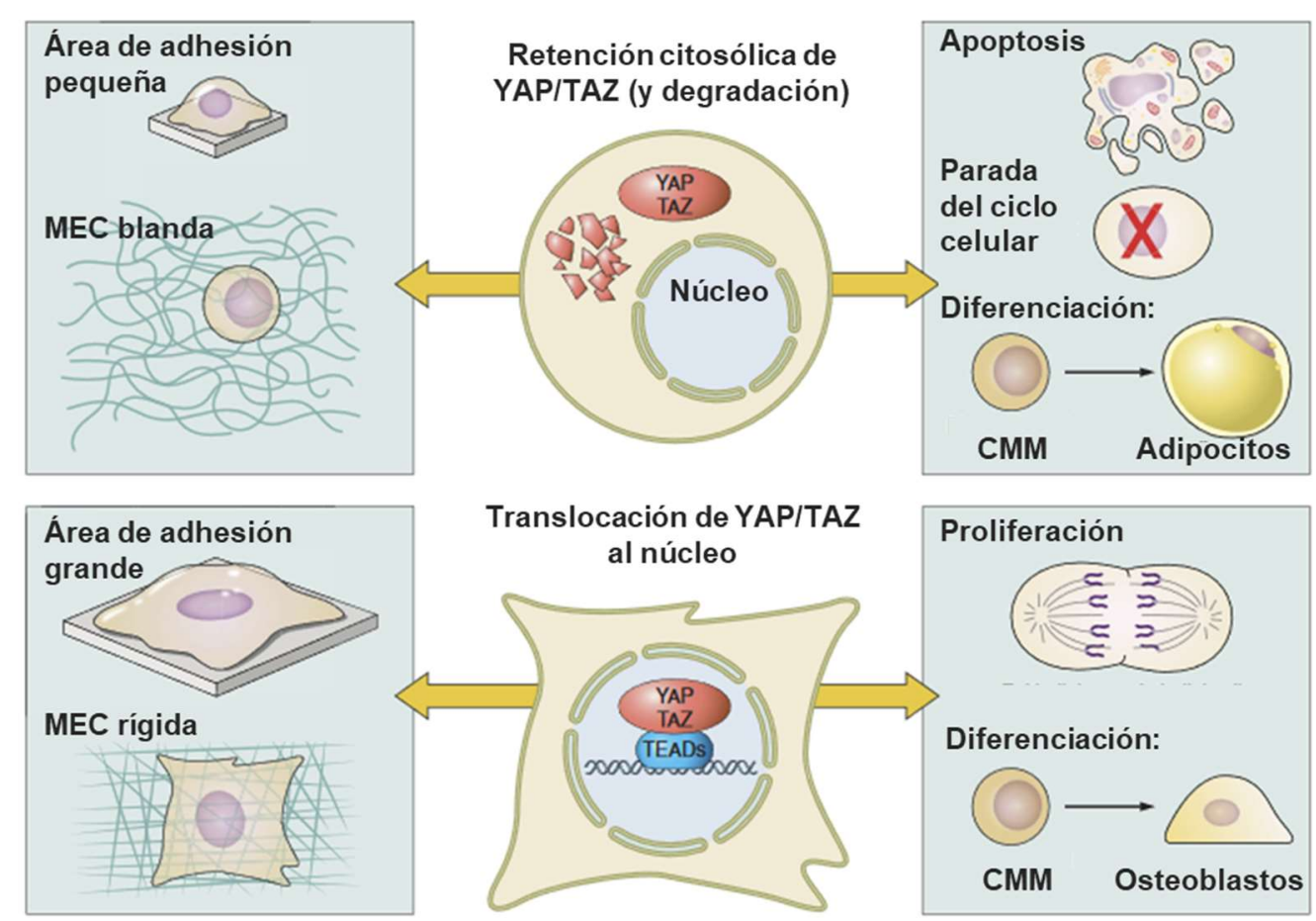

Figura 6. Regulación de YAP/TAZ por la morfología celular y la rigidez de la MEC. Las áreas de adhesión pequeñas y la MEC blanda inactivan YAP/TAZ induciendo apoptosis, parada del ciclo celular y diferenciación de células madre mesenquimales (CMM) a adipocitos. Las áreas de adhesión grandes y las MEC rígidas activan YAP/TAZ induciendo proliferación y diferenciación de CMM a osteoblastos. Figura adaptada de Piccolo et al., 2014.

La regulación mecánica de YAP/TAZ requiere de la integridad y organización del citoesqueleto de actina, la funcionalidad de RhoA y la contracción de actina-miosina (Aragona et al., 2013; Dupont et al., 2011). La dinámica de las integrinas y las adhesiones focales también condiciona la respuesta mecánica de YAP (Chakraborty et al., 2017; Elosegui-Artola et al., 2016; Kaneko et al., 2014) estando las quinasas de las adhesiones focales de la familia Src implicadas en su activación (Calvo et al., 2013). Sin embargo, se sabe que YAP se puede activar también en ausencia de adhesiones focales (Zhao et al., 2012). En esta regulación también participan 
algunos canales de calcio, como los canales Piezo (Pardo-Pastor et al., 2018). La conexión entre el núcleo y el citoesqueleto es también determinante. Los estímulos mecánicos extracelulares se transmiten directamente al núcleo a través de esa conexión, afectando a la apertura de los poros nucleares facilitando o impidiendo de ese modo la entrada de YAP (Driscoll et al., 2015; Elosegui-Artola et al., 2017). El papel de la fosforilación y de las quinasas de la vía Hippo en esta regulación no está del todo claro ya que hay trabajos en los que se afirma que la regulación mecánica de YAP es independiente de su fosforilación y de la actividad de las quinasas de la vía Hippo (Aragona et al., 2013; Dupont et al., 2011)

\subsection{Pancreatitis y PDAC}

La pancreatitis, es un daño en el tejido pancreático asociado a un proceso inflamatorio que induce daño tisular y desmoplasia en el tejido pancreático, siendo un factor de riesgo determinante para el desarrollo del adenocarcinoma ductal de páncreas (PDAC) (Yadav and Lowenfels, 2013). La pancreatitis induce la reprogramación de células acinares a ductales, un proceso conocido como metaplasia acino-ductal (ADM), que se sabe que es dependiente de la activación de YAP/TAZ (Gruber et al., 2016; Morvaridi et al., 2015) y que favorece la iniciación del PDAC (Guerra et al., 2007). Esta dependencia de YAP/TAZ se podría deber a la incidencia de los procesos inflamatorios sobre la rigidez de los tejidos (Hidalgo, 2012), dada la conocida implicación de ambos factores en la respuesta a estímulos mecánicos. Por tanto, la rigidez de la MEC aparece como un factor potencialmente implicado en el desarrollo y progresión de la pancreatitis. 
4. Objetivos 
Una de las principales funciones de CAV1 es su participación en procesos de mecanotransducción de señales, siendo capaz de responder al estiramiento celular, el flujo de fluidos sobre la superficie celular y la perdida de adhesión al sustrato (Boyd et al., 2003; Muriel et al., 2011; Sinha et al., 2011). La respuesta a los cambios en la rigidez de la MEC podría estar modulada también por CAV1, tal y como sugieren trabajos previos (Du et al., 2011; Yeh et al., 2017), pero esta cuestión no ha sido abordada hasta el momento. Por ello, el primer objetivo de esta Tesis es:

1. Estudiar el papel de CAV1 en la respuesta a cambios en la rigidez de la MEC.

a. Estudiar el efecto de la rigidez de la MEC sobre la distribución subcelular de CAV1.

b. Identificar las rutas de señalización celular afectadas por la rigidez del sustrato dependientes de CAV1.

Fruto del abordaje del primero de los objetivos se pudo determinar que CAV1 modula la activación de YAP en respuesta a cambios en la rigidez de la MEC. Esto nos llevó al planteamiento de los objetivos 2 y 3 :

2. Caracterizar los mecanismos moleculares que determinan el control mecánico de la actividad de YAP por CAV1.

3. Estudiar las potenciales implicaciones a nivel fisiológico, y la participación en procesos patológicos, de la regulación de YAP por CAV1. 
5. Materiales y Métodos 


\subsection{Cultivos celulares}

Para la obtención de los resultados presentados en esta tesis doctoral se utilizaron fibroblastos embrionarios murinos (MEF) inmortalizados, fibroblastos primarios asociados a tumores de páncreas (TAF) y hepatocitos neonatales primarios de ratón, además de las líneas celulares humanas establecidas HeLa y MDA-MB-231. Los MEF fueron aislados e inmortalizados a partir de embriones de ratones WT y Cav1KO previamente descritos y caracterizados (Razani et al., 2001) y cedidos por el Dr. Michael P. Lisanti (University of Salford. Biomedical Research Centre (BRC), Manchester, Reino Unido). Los hepatocitos neonatales de ratón fueron aislados, fenotipados (Mayoral et al., 2010) y cedidos por la Dra. Paloma Martín-Sanz (IIBM Alberto Sols, Madrid, España). Las dos líneas celulares humanas, HeLa (células epiteliales de cáncer cervical humano) y MDA-MB-231 (células epiteliales procedentes de un adenocarcinoma de la glándula mamaria) fueron obtenidas de ATCC (Manassas, Virginia, Estados Unidos). Las células HeLa que expresan de forma estable CAV1 fusionada a GFP fueron cedidas por Lukas Pelkmans (ETH, Zürich, Suiza) habiéndose seleccionado posteriormente una población de esta línea celular (expresando niveles bajos de CAV1-GFP) mediante citometría de flujo (Muriel et al., 2011). Los fibroblastos procedentes del estroma de tumores pancreáticos humanos fueron cedidos por el Dr. Manuel Hidalgo (Centro Nacional de Investigaciones Oncológicas, Madrid, Spain).

Los MEF, los hepatocitos y las células HeLa fueron cultivadas en el medio Dulbecco's modified Eagle's medium (DMEM) y las células MDA-MB-231 se crecieron en DMEM/F-12 (Gibco; Thermo Fisher Scientific, Waltham, Massachusetts, Estados Unidos). Para los experimentos para testar el papel del calcio se utilizó un DMEM especifico, comercializado también por Gibco, que carece de este ion. El medio de crecimiento se suplementó con un $10 \%$ de suero fetal bovino (FBS; Gibco), y $100 \mu \mathrm{g} / \mathrm{ml}$ de penicilina y estreptomicina (Gibco). Los TAF pancreáticos se crecieron en Roswell Park Memorial Institute medium (RPMI; Gibco) suplementados con un $20 \%$ de FBS, $100 \mu \mathrm{g} / \mathrm{ml}$ de penicilina y estreptomicina, y un $5 \%$ de glutamina. Todas las células se cultivaron en un incubador con una atmosfera húmeda a $37^{\circ} \mathrm{C} y$ $5 \%$ de $\mathrm{CO}_{2}$.

\subsection{Transfecciones, transducciones con vectores virales y tratamientos con drogas}

\subsubsection{Plásmidos}

- La construcción p2xFlag CMV2-YAP2 (Addgene plasmid \#19045) codifica para la proteína YAP humana fusionada a dos secuencias Flag en su región $\mathrm{N}$-terminal. Esta construcción ha sido 
previamente caracterizada y testada (Oka et al., 2008) y fue cedida por el Dr. Sudol Cambridge, Massachusetts, USA).

- pCMV-flag YAP2 5SA (Addgene \#27371) codifica para la proteína YAP humana en la que las serinas $61,109,127,128,131,163,164$ y 381 se han sustituido por alaninas. En la posición Nterminal la proteína codificada por este plásmido lleva fusionada una secuencia Flag. Este plásmido fue previamente caracterizado (Zhao et al., 2007) y cedido por el Dr. Kunliang Guan (University of California, San Diego, Estados Unidos).

- 8xGTIIC-luciferase (Addgene \#34615) codifica para un reportero de la actividad de TEAD que contiene un gen de luciferasa bajo el control de un promotor que presenta ocho secuencias GTIIC específicas (ACATTCCA) de unión a TEAD (ver Figura 12). Esta construcción fue caracterizada (Dupont et al., 2011) y cedida por el Dr. Stefano Piccolo (University of Padova, Padova, Italia)

- El vector lentiviral pLVX-CMV-CherryFP-P2A-MetLuc fue generado a partir de pLVX_shARN2 (Clontech), pRRL_CMV_CherryFP_P2A (cedido por la Unidad de Vectores Virales del CNIC) y pMetLuc reporter5 (Clontech; también cedido por la Unidad de Vectores Virales del CNIC). CherryFP_P2A fue clonado en el vector pLVX, y a continuación, en el mismo marco de lectura, se clonó la luciferasa secretable Metridia (MetLuc).

- pEGFP-mDia1 (DeltaN3) codifica para una isoforma mutante de la proteína mDia1 humana, que carece del dominio de unión a RhoA en sus regiones FH1 y FH2, y esta fusionada a GFP tal y cómo esta descrito (Ishizaki et al., 2001).

- pEGFP-RhoA(V14) codifica para una isoforma mutante de la proteína RhoA que se encuentra activa de forma constitutiva (del Pozo et al., 1999) clonada en el vector pEGFP-C1 (Clontech).

- El vector lentiviral pRRL-Cav1-GFP codifica para la proteína murina CAV1 y para GFP expresadas a partir del mismo ARNm gracias a la presencia de una secuencia IRES (del inglés Internal Ribosome Entry Site, sitio de entrada independiente para ribosomas,) entre ambos genes. Cav1GFP se clonó en el vector pRRL lentiviral (cedido por la Unidad de Vectores Virales del CNIC) procedente de la construcción pcADN3-Cav1-GFP.

- El vector lentiviral pRRL-IRES-GFP codifica para la proteína para GFP precedida por una secuencia IRES. GFP se clonó en el vector pRRL lentiviral (cedido por la Unidad de Vectores Virales deI CNIC) procedente de la construcción pcDNA3-Cav1-GFP. 


\subsubsection{ARNi y ARNch}

Todos los ARN de interferencia (ARNi) utilizados en esta Tesis Doctoral fueron obtenidos de Dharmacon (Lafayette, Colorado, Estados Unidos). Para todos ellos se utilizó un conjunto de cuatro oligos con sus correspondientes cuatro secuencias diana diferentes (ON-TARGET plus SMARTpool siARNs), excepto en el caso del ARNi contra CAV1, para el que se utilizó una única secuencia diana previamente testada en el laboratorio (GAGCUUCCUGAUUGAGAUU). Las referencias correspondientes a los ARNi de Dharmacon utilizados se detallan en la Tabla 2.

\begin{tabular}{|c|c|}
\hline Número de referencia & Gen diana del ARNi \\
\hline L-046247-01 & Yap \\
\hline L-041057-01 & $T a z$ \\
\hline L-063467-01 & Lats1 \\
\hline L-044602-01 & Lats2 \\
\hline L-061566-00 & $N f 2$ \\
\hline L-043652-01 & Ywhah \\
\hline L-057300-01 & Nes \\
\hline L-062431-01 & Ywhae \\
\hline L-047645-01 & $B a z 1 b$ \\
\hline L-059307-01 & Ywhag \\
\hline L-043147-01 & Col6a1 \\
\hline L-047536-02 & Noc2I \\
\hline L-045131-01 & $W d r 75$ \\
\hline L-064167-01 & Utp18 \\
\hline L-046974-01 & $K I f 2$ \\
\hline L-052204-01 & Nol6 \\
\hline L-041077-00 & Gna13 \\
\hline L-046212-01 & Itih4 \\
\hline L-059668-01 & Slmap \\
\hline L-047702-01 & Magohb \\
\hline L-059426-01 & Nup155 \\
\hline L-043163-01 & $C 1 q c$ \\
\hline L-042297-01 & Ranbp2 \\
\hline L-058593-01 & Bop1 \\
\hline L-051465-02 & Ahctf1 \\
\hline L-042848-01 & Fam160a2 \\
\hline L-060546-00 & Skp1a \\
\hline L-058357-01 & $1 p o 7$ \\
\hline L-051808-01 & Rcc1 \\
\hline L-060137-01 & Nup98 \\
\hline L-051775-01 & $F g g$ \\
\hline L-046642-01 & Actr3 \\
\hline L-048160-01 & Ywhaq \\
\hline L-047321-01 & $A r p c 1 b$ \\
\hline L-053600-01 & Actr2 \\
\hline L-044870-01 & Arpc4 \\
\hline L-043652-01 & Ywhah \\
\hline
\end{tabular}




\begin{tabular}{|c|c|}
\hline Número de referencia & Gen diana del ARNi \\
\hline L-054969-00 & Hmgn1 \\
\hline L-066757-01 & II1rapl1 \\
\hline L-052646-01 & Nup43 \\
\hline L-065649-00 & Trio \\
\hline L-041132-01 & $\mathrm{Cd} 44$ \\
\hline L-065699-01 & Col6a3 \\
\hline L-048982-00 & Runx1 \\
\hline L-057375-00 & Anxa4 \\
\hline L-058941-01 & Srgap3 \\
\hline L-042918-01 & Crlf1 \\
\hline L-043345-01 & Epn2 \\
\hline L-054472-01 & Mmp21 \\
\hline L-047722-02 & Ncoa3 \\
\hline L-059298-01 & Ywhab \\
\hline L-042811-01 & $\operatorname{lnf2}$ \\
\hline L-046026-01 & Mrps5 \\
\hline L-054158-01 & Myl6b \\
\hline L-059002-01 & Disp2 \\
\hline L-041235-01 & Arpc5 \\
\hline L-044721-00 & Cttn \\
\hline L-066145-01 & Hmgb2 \\
\hline L-051327-01 & Smarce1 \\
\hline L-045099-01 & Aimp1 \\
\hline L-043464-01 & Arpc2 \\
\hline L-058621-01 & $B z w 1$ \\
\hline L-047759-01 & Cyc1 \\
\hline L-057957-01 & Med14 \\
\hline L-040695-01 & Gnpat \\
\hline L-043145-00 & Kcnb2 \\
\hline L-043562-01 & Zbtb18 \\
\hline L-065434-01 & Dock7 \\
\hline L-058986-02 & Amot \\
\hline L-040765-01 & Arpc3 \\
\hline L-048355-01 & Myh7 \\
\hline L-043934-01 & Sp100 \\
\hline L-045923-01 & Pkp4 \\
\hline L-042942-01 & Apoa1 \\
\hline L-050911-01 & Nde1 \\
\hline L-041156-00 & Kcnma1 \\
\hline L-062893-00 & Sod2 \\
\hline L-054425-01 & Adam 22 \\
\hline L-053712-01 & Grid2ip \\
\hline L-045013-01 & Myl2 \\
\hline L-048661-01 & Olig3 \\
\hline L-062851-01 & Plekhh3 \\
\hline L-055789-01 & Spink5 \\
\hline L-048413-01 & Antxr1 \\
\hline L-172668-00 & Micalcl \\
\hline L-041728-01 & Serpina9 \\
\hline L-044182-01 & $T b \times 5$ \\
\hline L-053758-01 & Cys1 \\
\hline
\end{tabular}




\begin{tabular}{|c|c|}
\hline Número de referencia & Gen diana del ARNi \\
\hline L-040366-01 & Rap1gap2 \\
\hline L-043598-01 & Usp40 \\
\hline L-061072-01 & Slc45a2 \\
\hline L-042053-01 & Capn5 \\
\hline L-062952-01 & Etv5 \\
\hline L-041090-00 & Map3k1 \\
\hline L-049298-01 & Incenp \\
\hline D-001810-01 & Control \\
\hline D-001810-02 & Control \\
\hline
\end{tabular}

Tabla 2. Listado de pools de cuatro ARNi de Dharmacon utilizados.

Se han utilizado además dos ARN cortos horquillados (ARNch) incluidos dentro de vectores virales para el silenciamiento de p190RhoGAP y de Yap. La secuencia diana de p190RhoGAP en ratón (GTTATGGACGCAACATTAA) se clonó en un vector pSuper.Retro tal y cómo esta descrito (Grande-Garcia et al., 2007). Para el silenciamiento de Yap se utilizó el vector lentiviral PLKO.1_shYAP1 (addgene \#42540) cuya secuencia diana es común tanto para humano como para ratón (GCCACCAAGCTAGATAAAGAA), cedido por William Hahn (Dana-Farber Cancer Institute, Boston, Estados Unidos)

\subsubsection{Transfecciones}

Los ARNi se transfectaron a $20 \mathrm{pmol} / 1000$ células utilizando el reactivo Lipofectamine $^{\circledR}$ ARNiMAX (Invitrogene; Carlsbad, California, Estados Unidos) mediante transfección reversa (las células se sembraron directamente sobre el reactivo de transfección y el ARNi) siguiendo el protocolo optimizado facilitado por el fabricante. Todos los experimentos se llevaron a cabo 48 horas después de la transfección, momento en el cual se obtiene una mayor eficiencia del silenciamiento.

Las transfecciones de ADN en MEF se hicieron mediante electroporación, utilizando $5 \mu \mathrm{g}$ del plásmido a transfectar y $35 \mu \mathrm{g}$ de ADN de esperma de salmón UltraPure ${ }^{T M}$ (Sigma-Aldrich; San Luis, Misuri, Estados Unidos) a 350V y 550ohms durante 10msec. La expresión de los plásmidos es transitoria por lo que los experimentos se realizaron $48 \mathrm{~h}$ después, en el momento en que la expresión es máxima.

En el caso de los experimentos llevados a cabo en células creciendo sobre sustratos con diferente rigidez, $24 \mathrm{~h}$ después de la transfección de ADN o del ARNi las células se sembraron en las matrices de poliacrilamida correspondientes, para la realización de los experimentos $24 \mathrm{~h}$ después. 


\subsubsection{Infecciones}

En todos los casos las infecciones se llevaron a cabo utilizando lentivirus, excepto en el caso del vector conteniendo el ARNch de p190RhoGAP en cuyo caso se utilizaron retrovirus. Las unidades infectivas conteniendo los vectores correspondientes fueron generadas, concentradas y cuantificadas por la Unidad de Vectores Virales del CNIC. Brevemente, se transfectaron células $293 T$ con plásmidos de empaquetamiento de lentivirus de2 ${ }^{a}$ generación y los vectores lentivirales correspondientes en cada caso (pRRL-CAV1-GFP, PLKO.1_shYAP1 y los correspondientes controles vacíos). 48h después se comprobó que la transfección había sido eficiente, se recogieron los sobrenadantes y se ultracentrifugaron para concentrar las partículas lentivirales. Para la infección se usó una MOI (multiplicidad de infección; número de unidades virales por célula) de entre 1 y 5 en células creciendo en medio sin antibióticos y conteniendo el reactivo Polybrene (Sigma-Aldrich) a $8 \mu \mathrm{g} / \mathrm{ml}$.

\subsubsection{Drogas y tratamientos}

Los inhibidores Y27632 (Y0503), tapsigargina (T9033), tunicamicina (T7765) y citocalasina D (C8273) se obtuvieron de Sigma-Aldrich, mientras que jasplakinolide (sc-202191) se obtuvo de Santa Cruz Biotechnology (Dallas, Texas, United States). Las drogas se utilizaron a las concentraciones y tiempos especificados en las leyendas de las figuras de cada experimento concreto. Para los controles se añadió el volumen equivalente de DMSO (Dimethyl sulfoxide; Sigma-Aldrich), el solvente de todas las drogas utilizadas.

\subsection{Ensayos bioquímicos para la inmunodetección de proteínas}

\subsubsection{Anticuerpos}

Anticuerpos monoclonales: anti-YAP (sc-101199) y anti-TEF-1 (sc-376113) fueron obtenidos de Santa Cruz Biotechnology; anti-CAV1 XP (\#3267), anti-YWHAH (14-3-3 n (D23B7); \#5521) y antiYWHAB (14-3-3 $\beta / \alpha$; \#9636) de Cell Signaling (Danvers, Massachusetts, Estados Unidos); antiGM130 (610823) y anti-CAV1 (610406) de BD Trasnduction Laboratories (Franklin Lakes, Nueva Jersey, Estados Unidos); anti-Flotilina1 de Abcam (Cambridge, United Kingdom); anti-Flag M2 (F3167) de Sigma-Aldrich; y anti-glyceraldehyde-3-phosphate dehydrogenase (MAB374), antiFLNa (MAB1680), anti-p190RhoGAP y anti-cortactina (p80/85, clon 4F11) de Millipore (Burlington, Massachusetts, Estados Unidos). 
Anticuerpos policlonales: anti-fosfo-YAP (S127) (\#9411), anti-LATS1 (\#9153) y anti-LATS2 (\#13646) se obtuvieron de Cell Signaling; anti-Histona H3 (ab1791) y anti-PTRF (ab48824) de Abcam; anti-RAB11 (71-5300) de Invitrogen y anti-RhoAGDI (sc-360) de Santa Cruz Biotechnology.

Para la inmunohistoquímica se utilizó el anticuerpo monoclonal anti-YAP (D8H1X) XP de Cell Signaling (\#14074) y el policlonal anti-aSMA de Thermo Fisher Scientific (RB-9010-P0). Para los experimentos de inmunofluorescencia se utilizaron anticuerpos secundarios contra IgGs de ratón o conejo fusionados a los fluorocromos Alexa546 y Alexa488 obtenidos de Molecular Probes (Eugene, Oregón, Estados Unidos). Para la detección de proteínas por WB se usaron los anticuerpos secundarios de cabra anti-lgG de conejo y de ratón fusionados a peroxidasa de rábano (horseradish peroxidase; HRP) obtenidos de Thermo Fisher Scientific.

\subsubsection{Inmunofluorescencia}

Para la detección de proteínas por inmunofluorescencia, las células se fijaron en primer lugar con paraformaldheído al $4 \%$ (peso (p)/volumen (v)) a 37으 durante 10 minutes. La permeabilización y el bloqueo se hizo en un solo paso, en el que se incubaron las células fijadas en buffer fosfato salino (PBS del inglés Phosphate Buffered Saline) conteniendo un $0.2 \%$ Triton X-100 y albumina de suero bovina (BSA) al 1\% (p/v), ambas obtenidas de Sigma-Aldrich, durante 10 min. Posteriormente, las células se incubaron con los anticuerpos primarios específicos durante $24 \mathrm{~h}$, y después con los correspondientes anticuerpos secundarios fusionados a fluorocromos durante 30 minutos. Para las incubaciones con los anticuerpos se usó el buffer de permeabilización diluido a la mitad (1:2) y para los lavados intermedios PBS con un 0,05\% del detergente Tween-20 (Sigma-Aldrich). Para la detección de los núcleos se incluyó en este último paso Hoechst 33342 de Sigma-Aldrich y para marcar la actina.

En el caso de la detección de PTRF y CAV1 en los experimentos de co-localización las células se fijaron y permeabilizaron con metanol a $-20 \circ \mathrm{C}$ durante 5 minutos y posteriormente se bloquearon las preparaciones durante $1 \mathrm{~h}$ utilizando BSA al 2\% en PBS. Para esta tinción se utilizaron el anti-CAV1 monoclonal de ratón de BD y el anti-PTRF de Abcam.

\subsubsection{Inmunoprecipitación}

Para las inmunoprecipitaciones las células se lisaron con un buffer específico $(50 \mathrm{mM}$ Tris- $\mathrm{HCl}$ a pH8, $100 \mathrm{mM} \mathrm{NaCl}, 1 \%$ Triton $\mathrm{X}-100,10 \%$ glycerol, $1 \mathrm{mMMgCl} 2,2 \mathrm{mM}$ PMSF, coctel de inhibidores de proteasas de Roche (Basilea, Suiza)). Los lisados celulares se centrifugaron a 
máxima velocidad durante 10 minutos a $4^{\circ} \mathrm{C}$. Los sobrenadantes resultantes se incubaron con los anticuerpos primarios específicos o con IgG sin epítopos específicos del mismo isotipo como control, durante $2 \mathrm{~h}$ a $4 \stackrel{\circ}{ } \mathrm{C}$. Después se añadieron bolas de agarosa tapizadas con proteína G (GE Healthcare; Chicago, Illinois, Estados Unidos) durante otras dos $2 \mathrm{~h}$ a $4^{\circ} \mathrm{C}$. Las bolas se lavaron con el buffer de lavado (50mM Tris-HCl pH7.5, $150 \mathrm{mM} \mathrm{NaCl}$, 1mM EDTA, $0.25 \%$ gelatina, $0.1 \%$ NP-40 [Sigma-Aldrich]) y se procesaron para la detección de las proteínas adheridas a las bolas mediante western blot (WB) o espectrometría de masas. Para el WB, las proteínas inmunoprecipitadas se eluyeron directamente con el buffer de carga (ver sección 5.3.5).

\subsubsection{Fraccionamiento subcelular}

Para el fraccionamiento subcelular las células se lisaron con un buffer específico (10 mM Hepes, pH 7.6, $10 \mathrm{mM} \mathrm{KCl}, 0.1 \mathrm{mM}$ EDTA, $0.1 \mathrm{mM}$ EGTA, $0.5 \mathrm{mM}$ DTT, $100 \mathrm{mM}$ phenylmethylsulfonyl fluoride, coctel de inhibidores de proteasas de Roche y $0.05 \%$ NP-40). Las fracciones nuclear y citosólica se separaron mediante centrifugación. La fracción citosólica, correspondiente al sobrenadante resultante tras la centrifugación, se precipitó tras la incubación con acetona a $-20 \circ \mathrm{C}$ durante al menos $2 \mathrm{~h}$. La fracción nuclear se lisó con el buffer adecuado (20 mM Hepes, pH 7.6, 0.4 M NaCl, 1 mM EDTA, 1 mM EGTA, 1 mM DTT, 0.75 mM spermidine (Sigma-Aldrich), 0.15mM spermine (Sigma-Aldrich), $100 \mathrm{mM}$ phenylmethylsulfonyl fluoride y el coctel de inhibidores de proteasas de Roche) y se centrifugaron a máxima velocidad para eliminar el ADN, que acaba formando un pellet tras la centrifugación. Las dos fracciones se eluyeron con buffer de carga para el posterior análisis de las proteínas contenidas en cada una de ellas mediante $W B$.

\subsubsection{Purificación de dominios de membrana resistentes a detergentes (DRMs)}

Para la separación de las fracciones resistentes a detergentes se empleó un protocolo previamente descrito (Navarro-Lerida et al., 2002). Las células se despegaron de las placas mediante procedimientos mecánicos con un raspador a $4^{\circ} \mathrm{C}$ utilizando MBS (Mes buffered saline; $25 \mathrm{mM}$ MES, $0.15 \mathrm{M} \mathrm{NaCl}, 1 \mathrm{mM}$ PMSF con $1 \%$ de Triton X-100 a pH 6.5) para la lisis. Posteriormente los lisados se pasaron por una jeringuilla para su homogenización y se centrifugaron en gradientes de sacarosa. Para la generación de los gradientes primero se añadió a la muestra sacarosa al $80 \%$ p/v en MBS hasta conseguir una concentración de sacarosa del $40 \%$. Sobre esa fracción de sacarosa se añadió posteriormente el mismo volumen de sacarosa al $30 \%$ y al $5 \% \mathrm{p} / \mathrm{v}$ formando un gradiente discontinuo. Las diferentes fracciones se separaron por centrifugación a $200,000 \mathrm{~g}$ durante $18 \mathrm{~h}$ a at $4^{\circ} \mathrm{C}$. Tras la centrifugación, se extrajeron y 
separaron las diferentes fracciones en el gradiente continuo de sacarosa formado. Las proteínas de cada fracción se precipitaron con acetona a $-20^{\circ} \mathrm{C}$, tras lo cual se resuspendieron con Buffer Laemmli para su posterior análisis por WB.

\subsubsection{Western blotting}

Las muestras de proteínas se lisaron y desnaturalizaron con el buffer de carga (Buffer Laemmli) a 95C durante 5 minutos. Una vez desnaturalizadas las muestras se corrieron en geles de poliacrilamida (con SDS) para su separación en función de su peso molecular en una electroforesis. Tras la electroforesis se transfirieron a una membrana de nitrocelulosa (Amersham Pharmacia Biotech; Little Chalfont, Reino Unido) que posteriormente se bloqueó con leche desnatada en polvo al $5 \%$ en una solución salina tamponada con Tris (TBS del inglés Tris-buffered saline) conteniendo un $0,1 \%$ de Tween-20. Las membranas se incubaron posteriormente con los anticuerpos primarios durante $24 \mathrm{~h}$ a $4 \stackrel{\circ}{ } \mathrm{C}$ en la solución de bloqueo disuelta 1:5. Los anticuerpos secundarios fusionados a HRP se incubaron en la misma solución durante 1 hora. Por último, las proteínas se visualización por quimioluminiscencia utilizando Amersham ECL (GE Healthcare) como sustrato. Para la cuantificación por densitometría de las diferentes bandas en los geles se utilizó el programa de análisis de imagen ImageJ.

\subsection{Estudio de los niveles de ARNm mediante PCR cuantitativa}

\subsubsection{Oligonucleótidos de ADN utilizados como cebadores}

Los oligonucleótidos utilizados cómo cebadores o sondas para la PCR cuantitativa se seleccionaron con la herramienta web PrimerBank, un repositorio de cebadores para PCR cuantitativa, muchos de ellos testados y validados. $Y$ otros en base a referencias bibliográficas previas. En la Tabla 3 se muestran los diferentes cebadores utilizados en este trabajo.

Cebadores/sondas para ARNm humanos

\begin{tabular}{|c|c|c|}
\hline Gen & & Secuencia $\left(\mathbf{5}^{\prime}\right.$ ' $>$ 3') \\
\hline \multirow{2}{*}{ HPRT1 } & sentido & CCTGGCGTCGTGATTAGTGAT \\
\cline { 2 - 3 } & antisentido & AGACGTTCAGTCCTGTCCATAA \\
\hline \multirow{2}{*}{ BETA-ACTIN } & sentido & CACCTTCCAGCAGATGTCGA \\
\cline { 2 - 3 } & antisentido & AGCATTTGCGGTGGACGATGG \\
\hline \multirow{2}{*}{ CTGF } & sentido & ACCGACTGGAAGACACGTTTG \\
\cline { 2 - 3 } & antisentido & CCAGGTCAGCTTCGCAAGG \\
\hline \multirow{2}{*}{ ANKRD1 } & sentido & AGTAGAGGAACTGGTCACTGG \\
\cline { 2 - 3 } & antisentido & TGTTTCTCGCTTTTCCACTGTT \\
\hline
\end{tabular}


Cebadores/sondas para ARNm de ratón

\begin{tabular}{|c|c|c|}
\hline Gen & & Secuencia (5' -> 3') \\
\hline \multirow{2}{*}{ Hprt1 } & sentido & GCTGGTGAAAAGGACCTCT \\
\hline & antisentido & CACAGGACTAGAACACCTGC \\
\hline \multirow{2}{*}{ Beta-actina } & sentido & AGATGACCCAGATCATGTTTGA \\
\hline & antisentido & CACAGCCTGGATGGCTACGT \\
\hline \multirow{2}{*}{ Ctgf } & sentido & GGACACCTAAAATCGCCAAGC \\
\hline & antisentido & ACTTAGCCCTGTATGTCTTCACA \\
\hline \multirow{2}{*}{ Ankrd1 } & sentido & GCTGGTAACAGGCAAAAAGAAC \\
\hline & antisentido & СCTCTCGCAGTTTCTCGCT \\
\hline \multirow{2}{*}{ Cyr61 } & sentido & CTGCGCTAAACAACTCAACGA \\
\hline & antisentido & GCAGATCCCTTTCAGAGCGG \\
\hline \multirow{2}{*}{ Cav1 } & sentido & CCGCGACCCCAAGCA \\
\hline & antisentido & CTGCAATCACATCTTCAAAGTC \\
\hline \multirow{2}{*}{ Ywhab } & sentido & TGGATAAGAGTGAGCTGGTACA \\
\hline & antisentido & CGTGTCCCTGCTCTGTTACG \\
\hline \multirow{2}{*}{ Ywhah } & sentido & ACGAAGATCGAAATCTCCTCTCT \\
\hline & antisentido & CCGGTAGGCTTTAACTTTCTCCA \\
\hline \multirow{2}{*}{ Yap } & sentido & ACCCTCGTTTTGCCATGAAC \\
\hline & antisentido & TGTGCTGGGATTGATATTCCGTA \\
\hline \multirow{2}{*}{ Taz } & sentido & CATGGCGGAAAAAGATCCTCC \\
\hline & antisentido & GTCGGTCACGTCATAGGACTG \\
\hline \multirow{2}{*}{$N f 2$} & sentido & CAGAAGCTCTTAGAAATCGCCA \\
\hline & antisentido & GTGGTGGTGGAATTGGGTTCA \\
\hline
\end{tabular}

Tabla 3. Cebadores sentido y antisentido utilizados para qPCR.

\subsubsection{Extracción de ARN, reversotranscripción y PCR cuantitativa}

El ARN fue extraído de las muestras celulares utilizando el ARNeasy micro kit (QIAGEN; Hilden, Germany) siguiendo las instrucciones facilitadas por el fabricante. Para cada muestra, $1 \mu \mathrm{g}$ de ARN fue transcrito de forma reversa utilizando para ello el kit Omniscript RT (QIAGEN) con random primers (Promega; Madison, Wisconsin, Estados Unidos) siguiendo las instrucciones facilitadas por el fabricante. La PCR cuantitativa se realizó con el sistema de detección ABI 7900 (Applied Biosystems; Foster City, California, Estados Unidos) utilizando cómo reportero SYBR green (Roche). Se utilizaron los controles positivos y negativos adecuados (incluyendo Hprt1 y actina como genes endógenos para la normalización) y los resultados obtenidos se analizaron con el software qBase plus (Hellemans et al., 2007). 


\subsection{Ensayos para el estudio de procesos de mecanotransducción}

\subsubsection{Matrices de poliacrilamida con rigidez variable}

Las matrices de poliacrilamida se prepararon sobre cubreobjetos de cristal, tal y como se ha descrito previamente (Tse and Engler, 2010). La superficie de los cubreobjetos sobre los que se prepararon las matrices se trataron previamente con 3-aminopropyltrimethoxysilano (Sigma-Aldrich) utilizando un hisopo de algodón. Para conseguir una superficie uniforme sobre la que sembrar las células se utilizó otro cristal tratado con Sigmacote ${ }^{\circledR}$ (Sigma-Aldrich) para evitar la adhesión de la matriz. Ambos cristales se lavaron tras el tratamiento con agua destilada y se dejaron secar. después se prepararon soluciones de acrilamida y bis-acrilamida (Bio-Rad; Hercules, California, Estados Unidos) con las concentraciones apropiadas para obtener las rigideces adecuadas tal y cómo se describe en la Tabla 4.

\begin{tabular}{|c|c|c|}
\hline Acrilamida (\%) & Bis-acrilamida (\%) & $\begin{array}{c}\text { Modulo elástico (rigidez) } \\
\text { (kPa) }\end{array}$ \\
\hline \multirow{5}{*}{5} & 0.05 & 0.43 \\
\hline & 0.075 & 0.6 \\
\hline & 0.1 & 1.431 \\
\hline & 0.15 & 1.64 \\
\hline & 0.2 & 2.02 \\
\hline \multirow{8}{*}{7.5} & 0.01 & 0.233 \\
\hline & 0.03 & 0.689 \\
\hline & 0.05 & 1.535 \\
\hline & 0.075 & 2.286 \\
\hline & 0.1 & 2.833 \\
\hline & 0.15 & 4.069 \\
\hline & 0.2 & 5.356 \\
\hline & 0.3 & 8.64 \\
\hline \multirow{6}{*}{12} & 0.145 & 16.344 \\
\hline & 0.28 & 30.067 \\
\hline & 0.45 & 34.263 \\
\hline & 0.55 & 42.375 \\
\hline & 0.575 & 50.873 \\
\hline & 0.6 & 55.293 \\
\hline
\end{tabular}

Tabla 4. Porcentajes de acrilamida y de bis-acrilamida estimados para obtener matrices con los módulos elásticos que aparecen en la tabla de la derecha. Tabla adaptada de (Fischer et al., 2012). 
Para la polimerización del gel de poliacrilamida se añadieron los iniciadores correspondientes a una concentración final de $0.05 \% \mathrm{p} / \mathrm{v}$ persulfato de amonio y $0.0005 \% \mathrm{v} / \mathrm{v}$ $\mathrm{N}, \mathrm{N}, \mathrm{N}^{\prime}, \mathrm{N}^{\prime}$-tetramethylethylenediamina (TEMED). Una gota de la mezcla se depositó sobre el cristal silanizado y sobre ella se colocó el cristal tratado con Sigmacote; $183 \mu$ l se depositaron sobre cristales redondos ( $40 \mathrm{~mm}$ de diámetro) y $50 \mu \mathrm{l}$ sobre cristales cuadrados ( $24 \times 24 \mathrm{~mm}$ ). Tras la polimerización, se retiró el cristal superior y se fotoactivo la superficie de la matriz de poliacrilamida para posibilitar la adhesión de fibronectina y de las células utilizando para ello sulfo-SANPAH (Sigma-Aldrich) y exponiéndolo a luz ultravioleta. Por último, la superficie de la matriz se recubrió con fibronectina $(5 \mu \mathrm{g} / \mathrm{ml})$ durante $1 \mathrm{~h}$ a $37{ }^{\circ} \mathrm{C}$. Tras retirar la fibronectina se sembraron las células, siempre en condiciones de baja confluencia celular (Figura 7). Todos los experimentos se realizaron $24 \mathrm{~h}$ después de sembrar las células sobre las matrices.

i)

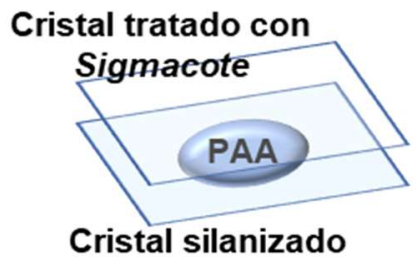

iv)

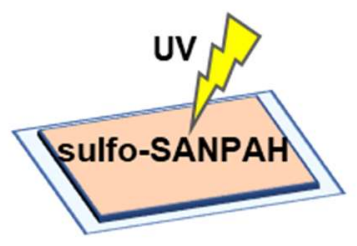

ii)

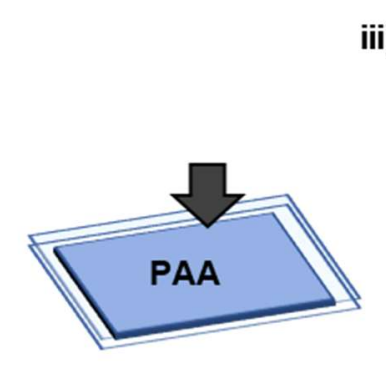

v)

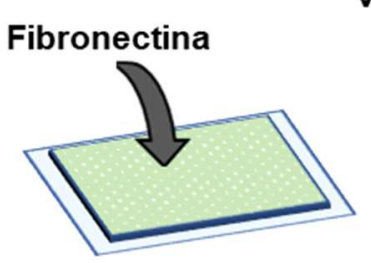

iii)

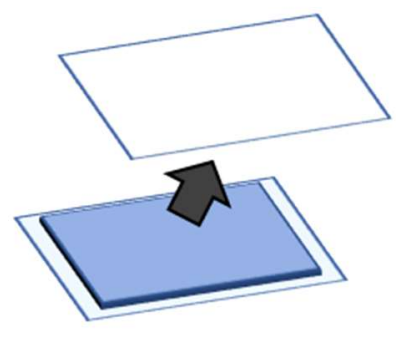

vi)

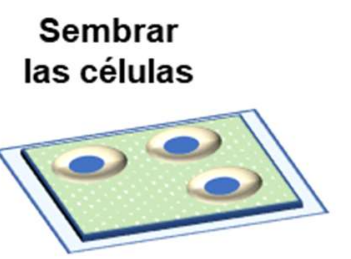

Figura 7. Preparación de matrices de poliacrilamida. i) La gota de poliacrilamida (PAA) se coloca sobre el cristal silanizado. ii) Sobre la gota de poliacrilamida se coloca el cubreobjetos tratado con Sigmacote. iii) Tras la polimerización se retira el cubreobjetos tratado con Sigmacote. iv) La superficie de la matriz de poliacrilamida se fotoactiva con sulfo-SANPHA y luz ultravioleta. v) Para la adhesión de las células a la matriz se añade fibronectina. vi) Por último, se siembran las células.

\subsubsection{Micropatrones de tamaños predefinidos}

Los cubreobjetos (chip) con patrones pre-definidos para el crecimiento de las células fueron obtenidos de Cytoo (Grenoble, France). Los tamaños y el diseño de los patrones fueron descritos y establecidos previamente por el Dr. Stefano Piccolo y sus colaboradores como una herramienta para el estudio de la actividad de YAP (Dupont et al., 2011) (Figura 8). Los patrones se recubrieron con fibronectina siguiendo las instrucciones facilitadas por el proveedor. Las 
células se sembraron y se crecieron durante $24 \mathrm{~h}$, tras lo cual se fijaron para su posterior estudio por inmunofluorescencia.

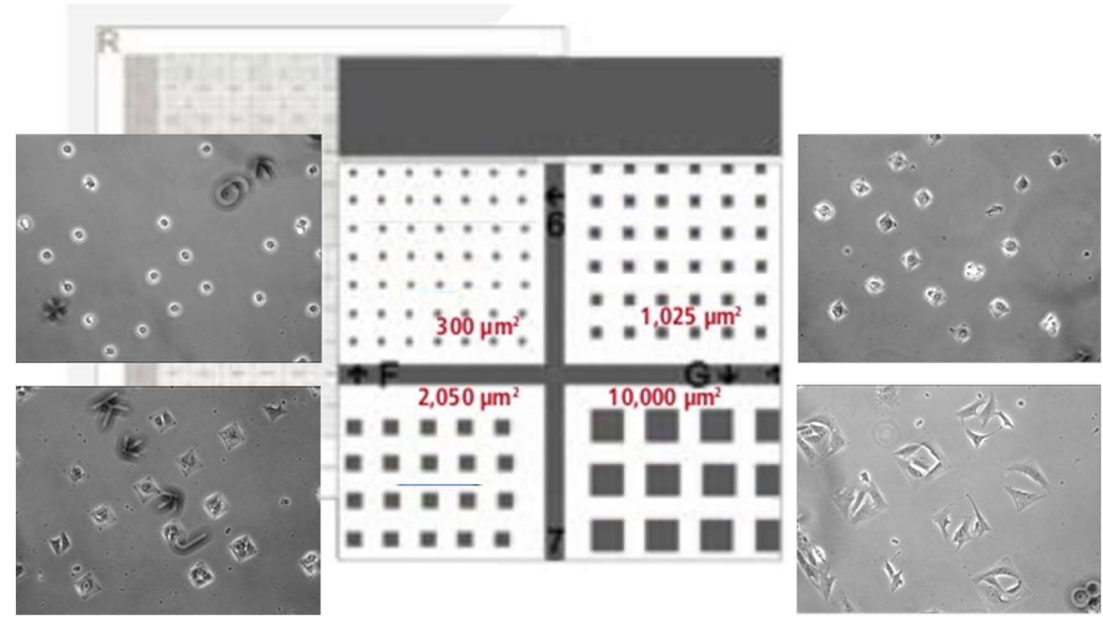

Figura 8. Micropatrones pre-definidos de Cytoo. Las imágenes muestran fotografías de contraste de fase de las células creciendo sobre micropatrones con los cuatro tamaños diferentes contenidos en cada chip.

\subsubsection{Estiramiento mecánico de las células}

Las células fueron sembradas en placas especificas con fondo flexible de silicona para permitir el estiramiento (FlexCell; Burlington, North Carolina, Estados Unidos), 24h después de sembrarlas se sometieron a estiramiento uniaxial de carácter cíclico $(0.7 \mathrm{~Hz}, 8-9 \%$ de amplitud) durante $24 \mathrm{~h}$ utilizando para ello el aparato Flexcell ${ }^{\circledR}$ FX-5000TMTension System (FlexCell) en condiciones de cultivo estándar (Figura 9).
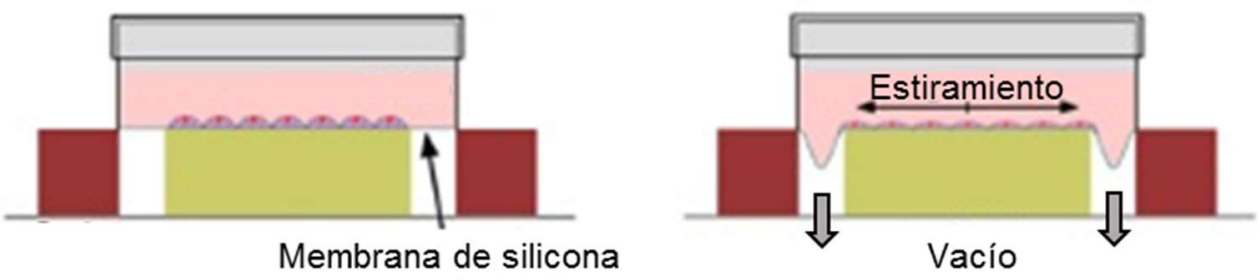

Figura 9. Esquema representativo del mecanismo utilizado para el estiramiento mecánico de las células. Figura adaptada de la presentada en la página web del fabricante. 


\subsection{Microscopía}

\subsubsection{Microscopía confocal de fluorescencia}

Todas las imágenes de microscopía confocal presentadas a lo largo de esta Tesis Doctoral fueron adquiridas con el microscopio Zeiss LSM700 (Carl Zeiss Microscopy; Jena, Alemania) o en el microscopio confocal automático Opera (PerkinElmer; Waltham, Massachusetts, United States).

\subsubsection{Estudio del ordenamiento de las fibras de colágeno mediante la generación del segundo} harmónico

Para la adquisición del colágeno fibrilar se utilizando la técnica del segundo harmónico (SHG, de sus siglas en inglés second harmonic generation) (Chen et al., 2012). Para ello se utilizó el microscopio multifotón Zeiss LSM780 (Carl Zeiss Microscopy) equipado con un láser de pulso corto.

\subsection{Análisis de imagen}

\subsubsection{Análisis de la distribución subcelular de YAP}

La distribución subcelular de YAP se cuantificó utilizando para ello el programa de análisis y almacenamiento de imágenes Columbus ${ }^{\mathrm{TM}}$ (Perkin Elmer) o con ImageJ. Los núcleos se segmentaron utilizando la señal de Hoechst (Figura 10A). Las células mitóticas o con núcleos aberrantes se eliminaron del análisis en base al área y morfología del núcleo y la intensidad de la señal de Hoechst. Las células situadas en los bordes de la imagen también fueron eliminadas. El citosol se segmento creciendo la segmentación de la señal nuclear hacia el exterior (Figura 10B). La región de interés citosólica utilizada para el cálculo de los niveles de YAP en el citosol se estableció creando un anillo de 4 pixeles de grosor en el área citosólica desde el borde de la segmentación nuclear, para minimizar variabilidad en la señal dependiente de efectos como el grosor del área o presencia de estructuras discretas (Figura 10B). Por último, se calculó el ratio entre la señal nuclear y la citosólica. 
A
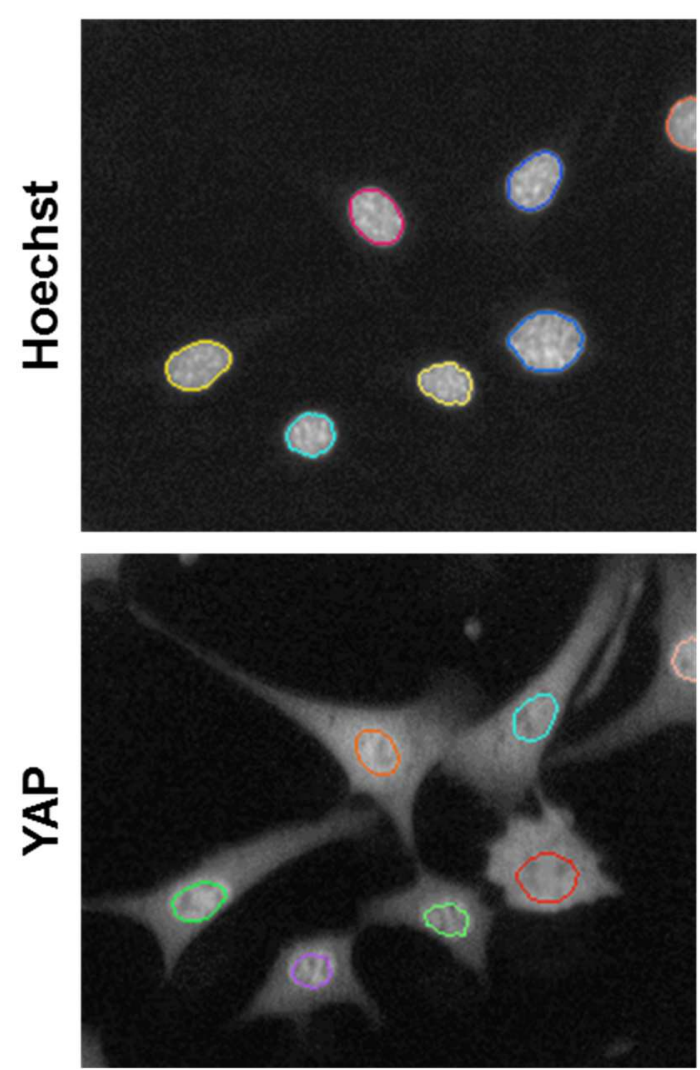

B
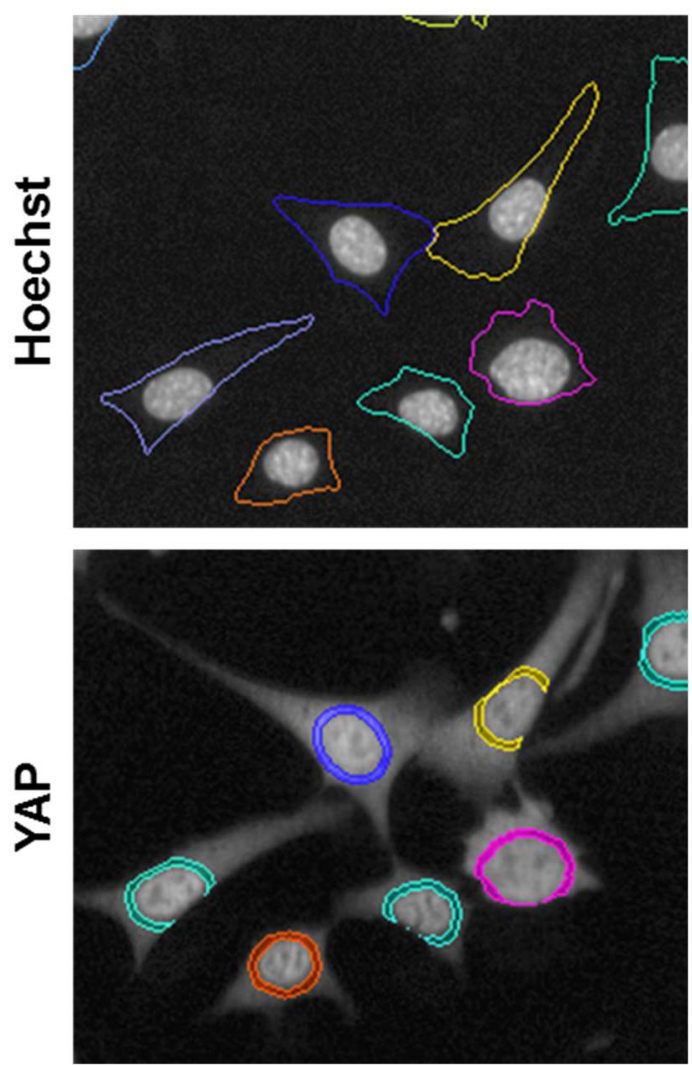

Figura 10. Segmentación de núcleos y citosol. (A) Segmentación de la región nuclear en base a la señal de Hoechst. (B) Segmentación de la región citosólica definida como un área de citosol de 4 pixeles alrededor del núcleo.

\subsubsection{Estudio de la organización de las fibras de actina}

La organización de las fibras de actina se cuantificó utilizando Matlab (R2015a) e ImageJ. El orden, considerando orden el alineamiento de las fibras de forma paralela dentro de las regiones de interés, se midió en base a los niveles de anisotropía cuantificados con en el plug-in FibrilTool de ImageJ (Boudaoud et al., 2014). Con esta herramienta se analizó la organización estructural de la actina obteniéndose valores de anisotropía El valor final de anisotropía se obtuvo calculando la media para cada pixel de la región analizada (Figura 11). En los experimentos de células sembradas sobre micropatrones, se segmentó previamente el citoplasma celular tal y cómo se muestra en la figura. Este análisis se llevó a cabo por la Unidad de Celómica del CNIC. 
Actina
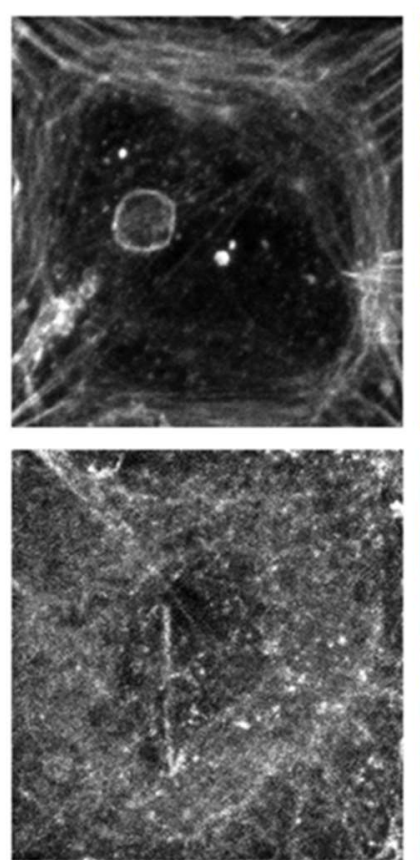

Anisotropía

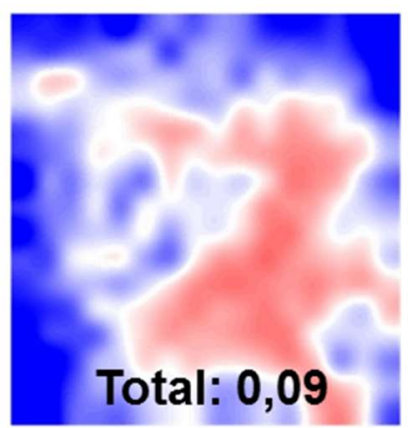

Total: 0,029

Figura 11. Ejemplo del cálculo de la anisotropía de las fibras de actina. En las imágenes superiores se muestra un ejemplo de una célula en el que la actina está organizada y en las inferiores una célula en la que la actina no está organizada.

\subsection{Ensayo de luciferasa para monitorizar la actividad transcripcional de TEAD}

Para el estudio de la actividad transcripcional de TEAD se utilizó el reportero 8xGTIIClux (Figura 12). Las células fueron transfectadas de forma transitoria de manera simultánea con el vector 8xGTIIC-lux y el pLVX-CMV-CherryFP-P2A-MetLuc, cada uno de los cuales da lugar a un tipo de luciferasa diferente. La actividad de la luciferasa se midió utilizando el Dual-Luciferase ${ }^{\circledR}$ Reporter Assay System (Promega; Madison, Wisconsin, Estados Unidos) en el luminómetro de placa ORION II (Titertek Berthold; Bad Wildbad, Alemania). La luciferasa intracelular Firefly, producto del vector 8xGTIIC-lux, se cuantifico a partir del lisado celular utilizando el sustrato Luciferase Assay Reagent II (LARII), y la luciferasa secretable MetLuc, codificada por pLVX-CMVCherryFP-P2A-fue cuantificada en el medio de cultivo celular añadiendo el reactivo Stop \& Glo. La actividad de luciferasa Firefly se normalizó con respecto a la actividad MetLuc para eliminar el efecto de la variabilidad en la eficiencia de las transfecciones. 


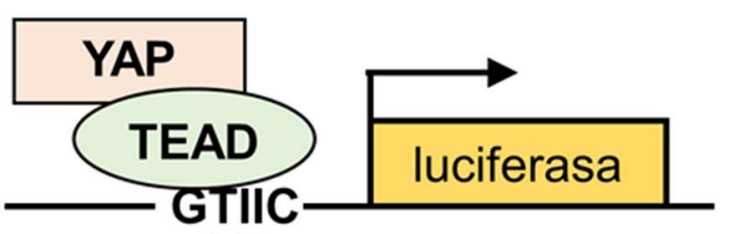

(x8)
Figura 12. Reportero 8xGTIIC-lux. Gen de la luciferasa Firefly controlado por un promotor con 8 dominios GTIIC de unión a TEAD,

\subsection{Ensayo de contracción de colágeno}

Para evaluar la capacidad de los fibroblastos de remodelar la MEC se utilizó un ensayo previamente descrito (Goetz et al., 2011; Orimo et al., 2005) en el que se estudió la capacidad de los fibroblastos de contraer una matriz tridimensional de colágeno. Se incluyeron $5 \times 10^{5}$ MEFs en un gel de $500 \mathrm{ml}$ de colágeno Tipo I (PureCol, Sigma-Aldrich) a 1,5mg/ml en placas de 24 pocillos tratadas para evitar la adhesión de los geles de colágeno y las células al fondo (UItraLow Attachment plates; Corning; Corning, New York, Estados Unidos). Tras la polimerización del gel se añadió medio de cultivo normal y se despegaron los geles de los bordes de la placa con una punta de pipeta. Las matrices tridimensionales obtenidas se cultivaron a $37^{\circ} \mathrm{C}, 5 \% \mathrm{CO} 2$ durante $48 \mathrm{~h}$. Transcurrido ese tiempo se fotografiaron y se cuantifico su contracción con respecto al tamaño inicial utilizando para ello ImageJ.

\subsection{Estudio de la expresión global de ARNm mediante ARNsec}

Los experimentos de secuenciación de nueva generación (NGS, del inglés Next Generation Sequencing) fueron realizados por la Unidad de Genómica del CNIC. La extracción del ARN total se hizo siguiendo el mismo protocolo que para las RT-qPCR. Antes del análisis transcripcional se estudió la integridad de las muestras mediante el estudio de su movilidad electroforética utilizando para ello el Bioanalyzer 2100 (Agilent) (Figura 13). Con este primer análisis se observó que la calidad de las muestras era buena, obteniendo un valor de integridad del ARN (RIN, de sus siglas en inglés) de 10, en una escala en la que el máximo valor es un 10. Para el estudio se utilizaron dos muestras de ARNm por condición mediante secuenciación por lectura simple (SR, del inglés Single Read) en un secuenciador Illumina HiSeq 2500 System (Illumina; San Diego, California, Estados Unidos). Los datos de expresión resultantes se depositaron en el repositorio GEO (ID: GSE120514). El análisis posterior se llevó a cabo en colaboración con la Unidad de Bioinformática del CNIC. 

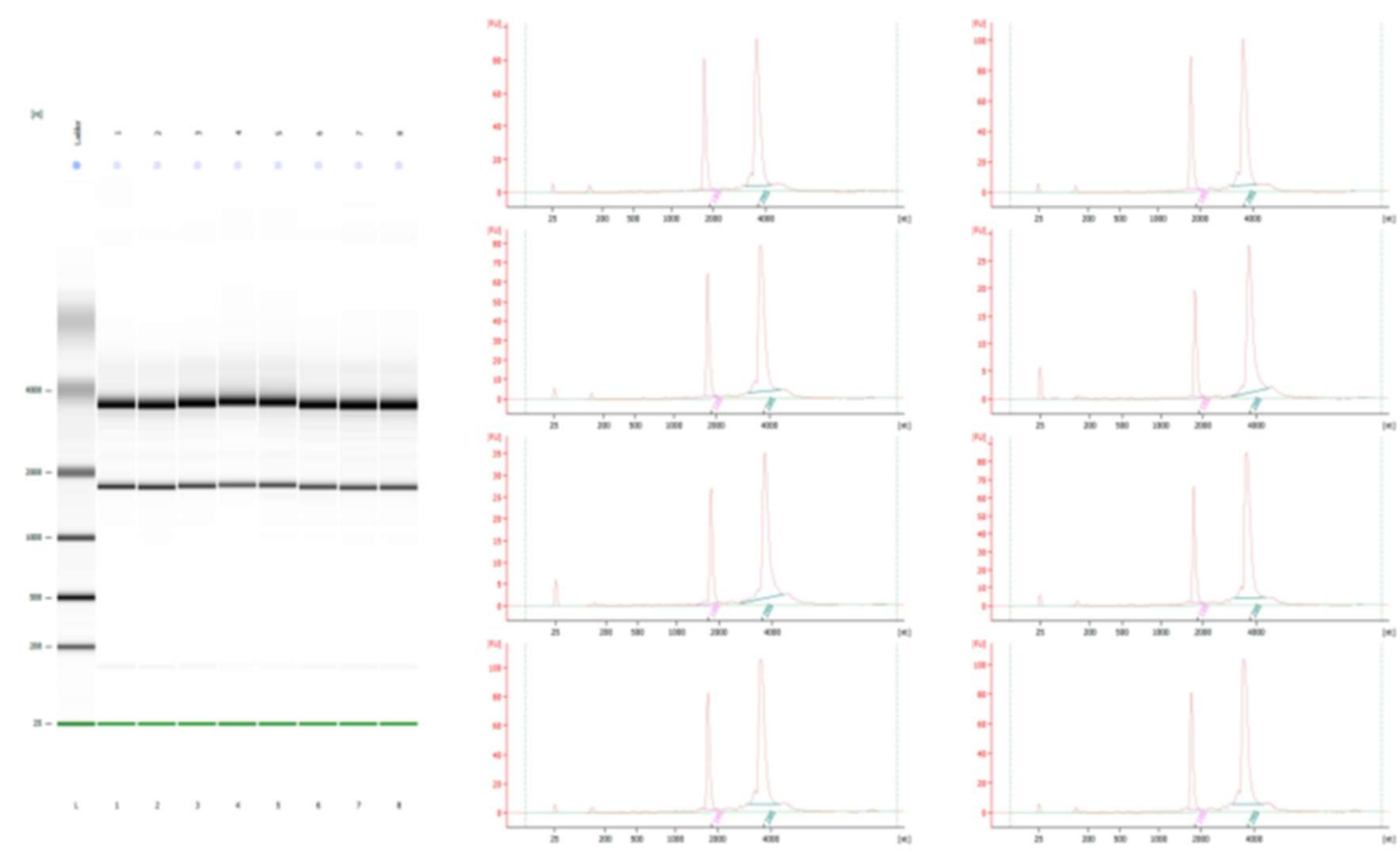

Figura 13. Estudio de la integridad del ARNm previo al análisis ARNsec. Resultados del análisis llevado a cabo con el Agilent Bioanalyzer 2100 para las 8 muestras utilizadas en el ARNsec. Los resultados se muestran en forma de gel, simulando el electroferograma (izquierda), y en forma de gráfico (derecha). Los dos picos y las bandas más con mayor intensidad corresponden a los ARN $18 \mathrm{~S}$ y $28 \mathrm{~S}$.

\subsection{Identificación de proteínas por espectrometría de masas}

Tras la inmunoprecipitación, las bolas de agarosa con Proteína G unidas a las proteínas inmunoprecipitadas se incubaron a temperatura ambiente durante $2 \mathrm{~h}$ en agitación en $60 \mu \mathrm{L}$ de un buffer conteniendo $2 \mathrm{M}$ urea, $50 \mathrm{mM}$ Tris- $\mathrm{HCl}$ pH 8.5, y $10 \mathrm{mM}$ TCEP. Posteriormente se añadió iodoacetamida $(7 \mu \mathrm{L}, 500 \mathrm{mM})$ y se incubó en condiciones de ausencia de luz. Tras la dilución a $0.5 \mathrm{M}$ de urea con bicarbonato de amonio, se añadieron $3 \mu \mathrm{g}$ de tripsina y se incubaron las muestras durante $6-8 \mathrm{~h}$ a $37{ }^{\circ} \mathrm{C}$. Las muestras se acidificaron posteriormente con $1 \%$ TFA, $\mathrm{y}$ los sobrenadantes se desalaron con columnas C18 (The Nest Group; Southborough, MA, Estados Unidos) y se secaron para el análisis posterior. Para el estudio se utilizaron cinco replicas por cada condición. Los péptidos fueron analizados por LC-MS/MS usando nano-columnas de fase reversa C-18 (75 $\mu \mathrm{m}$ I.D. x 50 cm, $2 \mu \mathrm{m}$ tamaño de partícula, Acclaim PepMap RSLC, 100 C18; Thermo Fisher Scientific) en un gradiente continuo de acetonitrilo. Los péptidos resultantes fueron eluidos, ionizados y fragmentados utilizando nanocolumnas y un espectrómetro QExactive HF mass (Thermo Fisher Scientific). Para la identificación de los péptidos, todos los espectros obtenidos se analizaron con Proteome Discoverer (versión 2.1.0.81, Thermo Fisher Scientific) usando SEQUEST-HT (Thermo Fisher Scientific). Para la búsqueda se usó la base de 
datos Uniprot que contiene todas las secuencias de ratón incluyendo algunos contaminantes observados de forma frecuente ( 27 de abril de 2016; 48644 entradas). Los péptidos fueron identificados por el método de probabilidad del ratio. Los experimentos de espectrometría de masas fueron realizados por la Unidad de Genómica del CNIC.

\subsection{Caracterización de candidatos mediante un ensayo basado en el silenciamiento con ARNi y el análisis de la distribución subcelular de YAP}

Los ARNi fueron transfectados mediante transfección reversa en placas de 384 pocillos de fondo óptico (PerkinElmer). 48h después de la transfección se fijaron y se tiñeron las células tal y cómo se describe en el apartado 5.3.2 con anti-YAP y Hoechst. Las imágenes de inmunofluorescencia confocal se adquirieron de forma automática utilizando el microscopio Opera (PerkinElmer). Se realizaron tres réplicas del experimento, incluyendo cuatro pocillos por ARNi en cada una de ellas, incluyendo dos ARNi control diferentes. La eficiencia de la transfección se validó con un ARNi de Incenp, que promueve la aparición de células multinucleadas y con núcleos aberrantes. El ratio de YAP núcleo-citosol fue calculado con Columbus $^{\mathrm{TM}}$ tal y como se describe en el apartado 5.6.3.1, y se calcularon los Z-valores en base $\mathrm{a} Z=(x-$ media del control $) /$ desviación estandar del control $)$.

\subsection{Estudios bioinformáticos}

\subsubsection{Análisis de enriquecimiento con IPA}

Los estudios de enriquecimiento de los datos obtenidos en el ARNsec se llevaron a cabo utilizando el software Ingenuity Pathway Analysis (IPA, QIAGEN).

\subsubsection{Análisis de co-expresión de genes con SEEK}

SEEK (http://seek.princeton.edu) es una herramienta computacional para el estudio de la co-expresión de genes (Zhu et al., 2015). En el buscador de esta herramienta se introdujo una lista de genes regulados transcripcionalmente por YAP y se chequeó la co-expresión de los mismos con el resto de genes del genoma en base a los datos de expresión incluidos en la base de datos de SEEK. De este modo se obtuvo una lista de genes ordenada en base al nivel de coexpresión con los genes regulados por YAP. Utilizando la herramienta web Enrichr (Chen et al., 2013; Kuleshov et al., 2016), se analizó el enriquecimiento en vías de señalización anotadas en 
KEGG y Gene Ontology (GO) entre los 200 genes con un nivel de co-expresión mayor con los genes regulados por YAP.

\subsection{Análisis estadístico}

El análisis de la significancia estadística se evaluó mediante la prueba T de Student utilizando GraphPad Prism. Se representaron en las correspondientes gráficas la media de las diferentes réplicas de cada experimento \pm (error estándar de la media, SEM) o \pm (desviación estándar, SD). Las diferencias fueron consideradas como significativas con $p$-valores inferiores a 0,05. El nivel de significancia se representó mediante asteriscos: ${ }^{*} \mathrm{P}<0.05,{ }^{* *} \mathrm{P}<0.01,{ }^{* * *} \mathrm{P}<0.005, \mathrm{y}$ $* * * * \mathrm{P}<0.0005$. Para analizar la significancia del enriquecimiento en genes regulados por YAP entre los genes regulados por la rigidez de la MEC se recurrió al test de Fisher utilizando para ello una herramienta web (Fisher Exact Test Calculator: https://goo.gl/prQZaA). 
6. Resultados 


\subsection{Dinámica y localización de CAV1 y caveolas en sustratos con diferente rigidez}

\subsubsection{CAV1 se internaliza en condiciones de baja rigidez del sustrato}

Diferentes estudios sugieren que CAV1 podría tener un papel determinante en la respuesta a cambios en la rigidez de la MEC, a través del control de la internalización de integrinas (Du et al., 2011) y/o a través de la regulación de sus niveles de expresión (Yeh et al., 2017). Sin embargo, la implicación de CAV1 en esta regulación no ha sido estudiada en profundidad hasta el momento.

Pese a la existencia de evidencias que sugieren que CAV1 se internaliza en condiciones de baja rigidez de la MEC (Du et al., 2011) los cambios en la dinámica y la distribución de CAV1 y caveolas en respuesta a cambios en la rigidez del sustrato no han sido caracterizados en profundidad. Por ese motivo, decidimos estudiar la distribución de CAV1 exógena fusionada a GFP en células HeLa sembradas sobre matrices de poliacrilamida con diferentes rigideces, una más blanda $(\approx 55 \mathrm{KPa})$ y otra más rígida $(\approx 0,2 \mathrm{KPa})$ (Figura $14 \mathrm{~A})$. En estas células se comprobó que la CAV1 fusionada a GFP (CAV1-GFP) presenta una distribución en forma de pequeñas vesículas distribuidas homogéneamente por toda la célula en sustratos rígidos, mientras que en sustratos blandos se concentraba en una sola vesícula perinuclear de gran tamaño. El mismo fenotipo se observó al analizar la distribución de la CAV1 endógena en células HeLa (Figura 14B).

La distribución de CAV1 observada en las células creciendo sobre matrices blandas es muy similar a la que se observa al eliminar la adhesión de las células al sustrato (del Pozo et al., 2004; del Pozo et al., 2005; Muriel et al., 2011). Cuando se elimina la adhesión al sustrato CAV1 se moviliza desde la membrana plasmática (MP) hasta un compartimento endosomal de reciclaje situado en la región perinuclear, caracterizado por la expresión del marcador RAB11 (Echarri et al., 2012; Muriel et al., 2011). En células creciendo sobre matrices blandas se confirmó que el fenotipo era similar al observado en suspensión, ya que también se pudo constatar una clara colocalización entre CAV1-GFP y RAB11 en la región perinuclear y la ausencia total de colocalización con el marcador de Golgi GM130 (Figura 14C). Estas observaciones apuntaban por tanto a que, tal y como se había sugerido previamente, CAV1 se internaliza cuando el ambiente extracelular sobre el que crecen las células tiene una rigidez baja. 
A
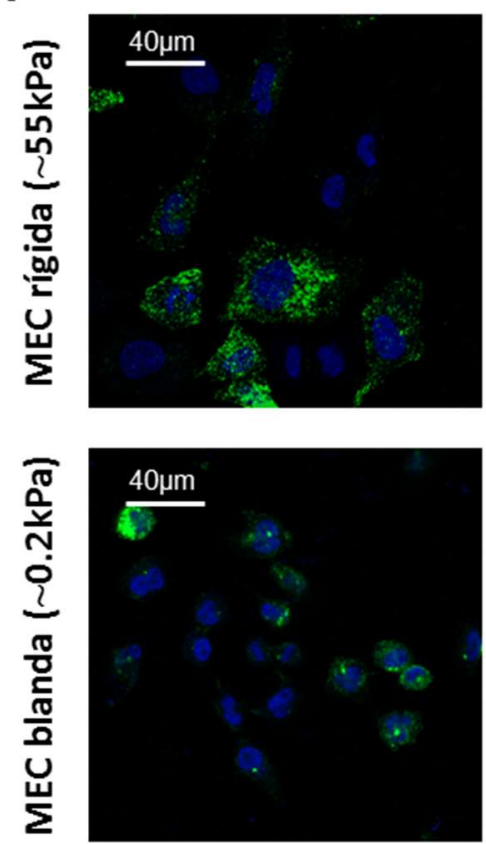

CAV1-GFP

B

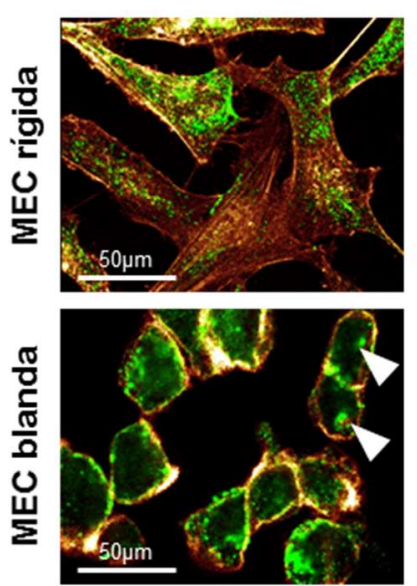

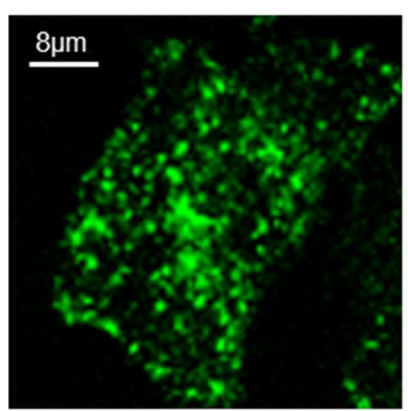

\section{Contraste de fase}
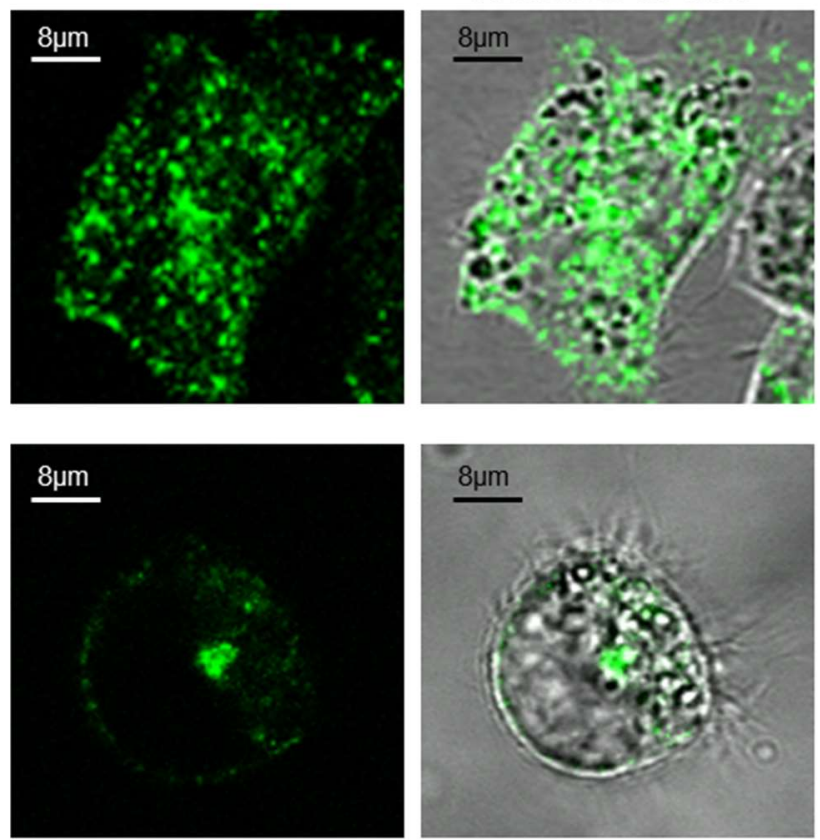

CAV1-GFP

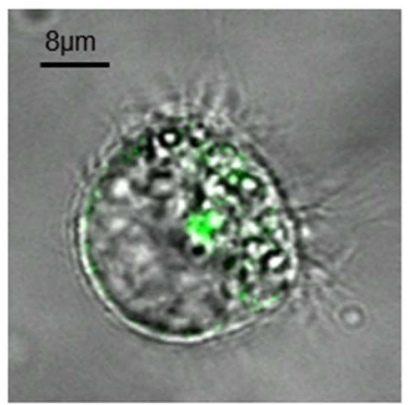

CAV1-GFP

C

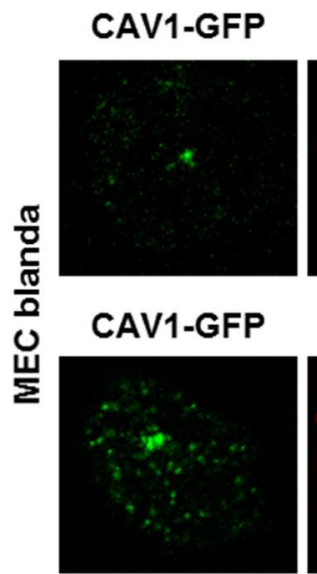

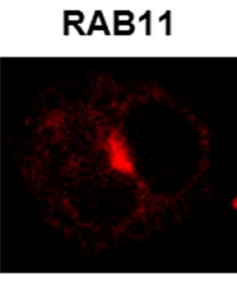

GM130

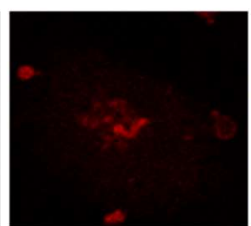

Merge

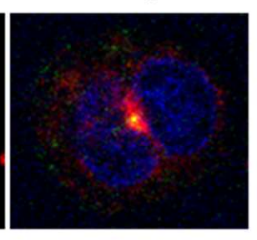

Merge

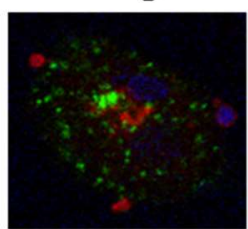

Figura 14. CAV1 se internaliza hasta un endosoma de reciclaje perinuclear en condiciones de baja rigidez de substrato. (A) Imágenes de microscopía confocal de fluorescencia de células HeLa expresando de forma estable CAV1-GFP y sembradas sobre matrices con alta y baja rigidez. En las dos imágenes de la derecha se muestra el contraste de fase correspondiente a las dos imágenes centrales. En las imágenes de la izquierda se tiñó el núcleo con Hoechst (azul). (B) Imágenes de microscopía confocal de células HeLa creciendo sobre sustratos rígidos y blandos en las que se tiñó CAV1 endógena (verde) y la actina utilizando faloidina marcada con un fluoróforo (amarillo). Las puntas de flecha señalizan la acumulación de CAV1 en el endosoma perinuclear en células creciendo sobre sustratos blandos. (C) Imágenes de microscopía confocal de fluorescencia de células HeLa expresando de forma estable CAV1-GFP y sembradas sobre matrices con baja rigidez en las que se tiñó mediante inmunofluorescencia RAB11 (marcador de endosomas de reciclaje), GM130 (marcador del Golgi) y los núcleos utilizando Hoechst (azul).

\subsubsection{La rigidez del sustrato determina la integridad de las caveolas}

Como ya se ha mencionado en la introducción, PTRF es un componente esencial para la biogénesis de caveolas que presenta un alto grado de co-localización con CAV1 en la MP 
(Hill et al., 2008). Tras un estímulo mecánico, como el choque hipoosmótico, las caveolas se desensamblan, provocando una disminución en la co-localización de CAV1 con PTRF (Sinha et al., 2011). Para ver si la rigidez de la MEC afectaba a la estructura y la dinámica de las caveolas se estudió la co-localización de CAV1 y PTRF. De este modo se comprobó que la co-localización entre ambas proteínas caveolares disminuía al reducirse la rigidez de la matriz extracelular (Figura 15A y 15B), nuevamente apoyando nuestra interpretación de que las caveolas se desensamblan en condiciones de baja rigidez.

A
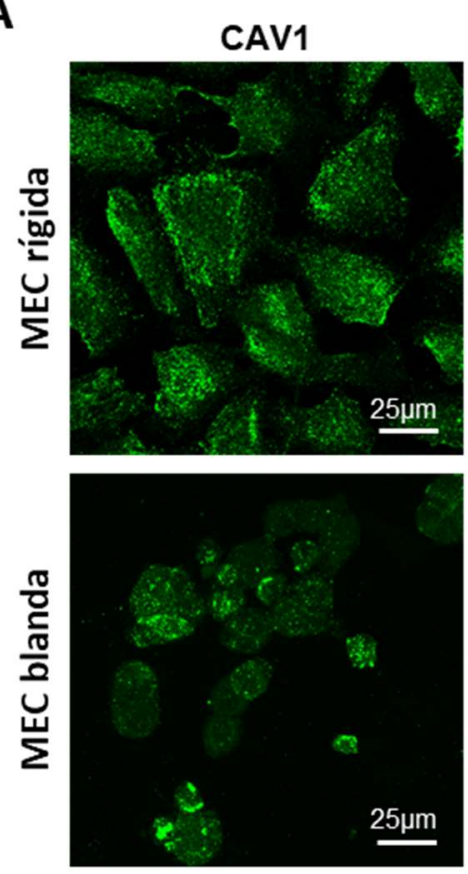

B

\section{Colocalización entre CAV1 y PTRF (IF)}

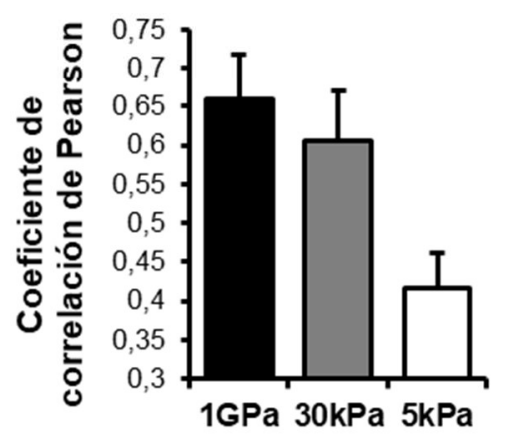

Rigidez del sustrato
PTRF
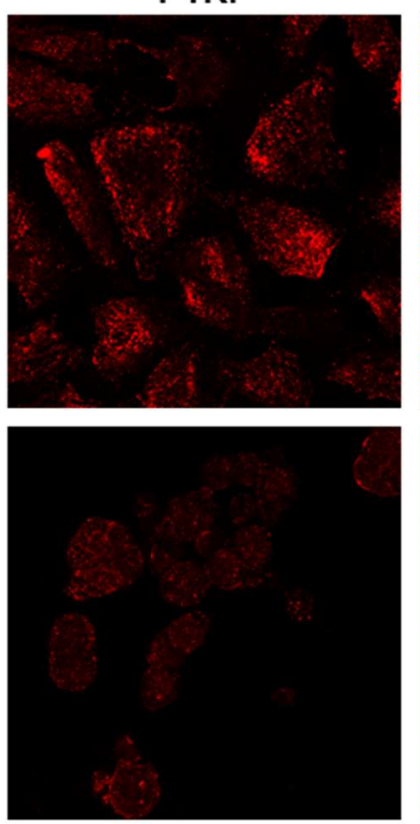

C

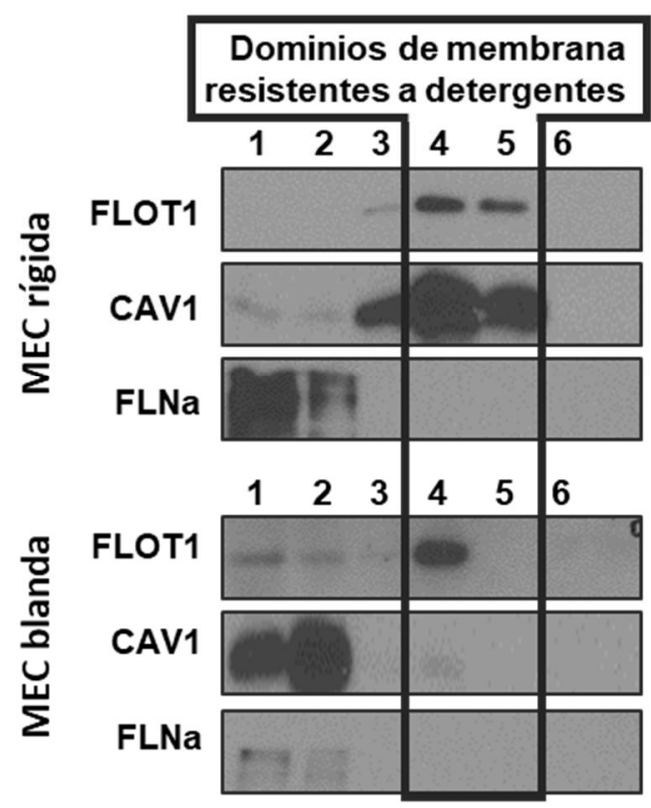

Figura 15. La localización de CAV1 en dominios ordenados de membrana se ve afectada por cambios en la rigidez de la MEC. (A) Imágenes de microscopía confocal de células HeLa creciendo sobre matrices con diferente rigidez en las que se marcó CAV1 y PTRF mediante inmunofluorescencia. Los núcleos se tiñeron 
utilizando Hoechst (azul). (B) Cuantificación con ImageJ de la co-localización entre CAV1 y PTRF en células HeLa creciendo sobre sustratos con diferente rigidez y sobre cristal ( 1GPa). (C) Estudio de la distribución de CAV1 en dominios de membrana resistentes a detergentes (DRMs). Las células (MEF) crecidas sobre sustratos rígidos o blandos se lisaron con detergentes apropiados y después se separaron las fracciones obtenidas tras centrifugar ese lisado en un gradiente de sacarosa. Cada una de las seis fracciones obtenidas se cargaron en un gel para su posterior análisis por WB. Cómo control de proteína localizada en DRMs se utilizó flotilina-1 (FLOT1) y cómo proteína localizada fuera de DRMs se utilizó FLNa.

Las caveolas son dominios de membrana ordenados, enriquecidas en esfingolípidos y colesterol (Richter et al., 2008) y caracterizados por ser resistentes a detergentes no iónicos, en concreto a Triton X-100 (detergent resistant membranes, DRMs) (Hill et al., 2008; Zheng et al., 2011). Por ello, para comprobar si la estabilidad de las caveolas estaba afectada por la rigidez del sustrato se estudió la localización de CAV1 en DRMs mediante fraccionamiento en gradientes de sacarosa tras exponer las células a Triton X-100. De este modo se observó que había un desplazamiento evidente de CAV1 de las fracciones correspondientes a los DRMs hacía regiones no resistentes a detergentes cuando las células se encontraban en matrices blandas (Figura 15C). Los resultados corroboraban, por tanto, la noción de que en condiciones de baja rigidez del sustrato se producía el desensamblaje de caveolas.

\subsection{Estudio de los cambios transcripcionales en MEF WT y Cav1KO mediados por la rigidez de la MEC}

\subsubsection{Análisis comparativo del transcriptoma de MEF WT y Cav1KO en sustratos rígidos y} blandos mediante ARNsec

Nuestras evidencias experimentales confirmaban la existencia de cambios en la distribución de CAV1/caveolas en diferentes condiciones de rigidez de la MEC. Para elucidar si esos cambios correlacionaban con variaciones en la fisiología celular decidimos hacer un análisis de la expresión transcripcional del genoma mediante la secuenciación completa del ARN total (ARNsec). En dicho análisis se utilizaron fibroblastos embrionarios de ratón (MEF) provenientes de ratones deficientes en Cav1 (MEF Cav1KO) y sus correspondientes controles silvestres que sí que expresan Cav1 (MEF WT). Las células de ambos genotipos se sembraron sobre matrices de acrilamida rígidas $(55 \mathrm{KPa})$ y blandas $(0,22 \mathrm{KPa})$. Los resultados de la secuenciación se analizaron a partir de los datos crudos (depositados en el repositorio GEO: GSE120514) obteniéndose valores de expresión de cada uno de los genes del genoma en cada una de las condiciones. En MEF WT se identificaron 2726 genes con una expresión significativamente mayor ( $p$-valor 
ajustado $<0,05$ ) en células sembradas sobre una MEC rígida que en las que crecen sobre una blanda, y en el caso de las Cav1KO se identificaron 3344 genes (Fig.16A). De esos genes, 1914 son compartidos por ambos genotipos, indicando que los cambios en los niveles de expresión de esos genes son dependientes de la rigidez del sustrato, pero independientes de la expresión de CAV1. Del mismo modo se identificaron 3082 genes que presentaban una expresión mayor en MEC blanda que en la rígida en células WT y 3386 en Cav1KO, de los cuales 1997 eran comunes para ambos genotipos. (Figura 16B) Estos resultados apoyaban la hipótesis de la participación de CAV1 en la respuesta a las propiedades mecánicas de la MEC, ya que los patrones de expresión modulados por la rigidez del sustrato son muy diferentes entre células WT y Cav1KO.

A

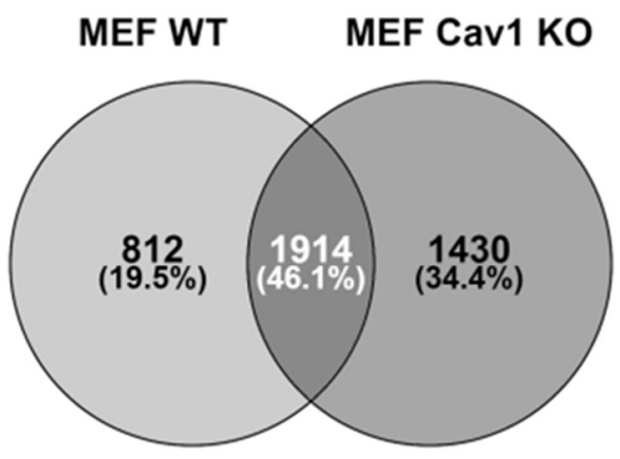

Genes que aumentan su expression en sustratos rígidos
B

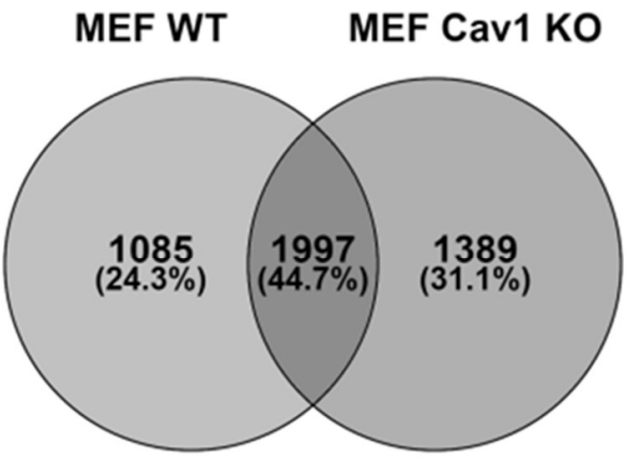

Genes que aumentan su expression en sustratos blandos

Figura 16. La rigidez de la MEC afecta a la expresión génica en células WT y Cav1KO. Diagrama de Venn en el que se representan los genes que aumentan su expresión de forma significativa ( $p$-valor ajustado $<0,5)$ cuando las MEF WT y Cav1KO se encuentran sobre sustratos rígidos (A) o blandos (B) según los datos obtenidos en el ARNsec.

\subsubsection{Análisis computacional de los resultados del ARNsec.}

Los programas funcionales canónicos afectados por la rigidez del sustrato se estudiaron utilizando la herramienta web Ingenuity Pathway Analysis (IPA). Esta herramienta permite la interpretación de los resultados obtenidos como listas de genes para, en base a anotaciones funcionales de los mismos, determinar qué funciones o vías de señalización celulares están activadas o inhibidas. Para el análisis se utilizaron únicamente los genes cuya expresión es modulada por la rigidez del sustrato exclusivamente en células WT, para destacar de ese modo las vías de señalización cuya activación por la rigidez del sustrato dependía de CAV1. Los cambios en la expresión de esos genes indicaban la activación de las siguientes vías de señalización: 
"citoesqueleto de actina", "Paxilina", "Rac", "Cdc42", "receptor de insulina" y "señalización de PAK" (Figura 17). Según estas observaciones los cambios en la motilidad, contractilidad y adhesión de las células determinados por la rigidez de la MEC (Discher et al., 2005; Pelham and Wang, 1997; Peyton and Putnam, 2005; Polte et al., 2004) podrían estar modulados por CAV1

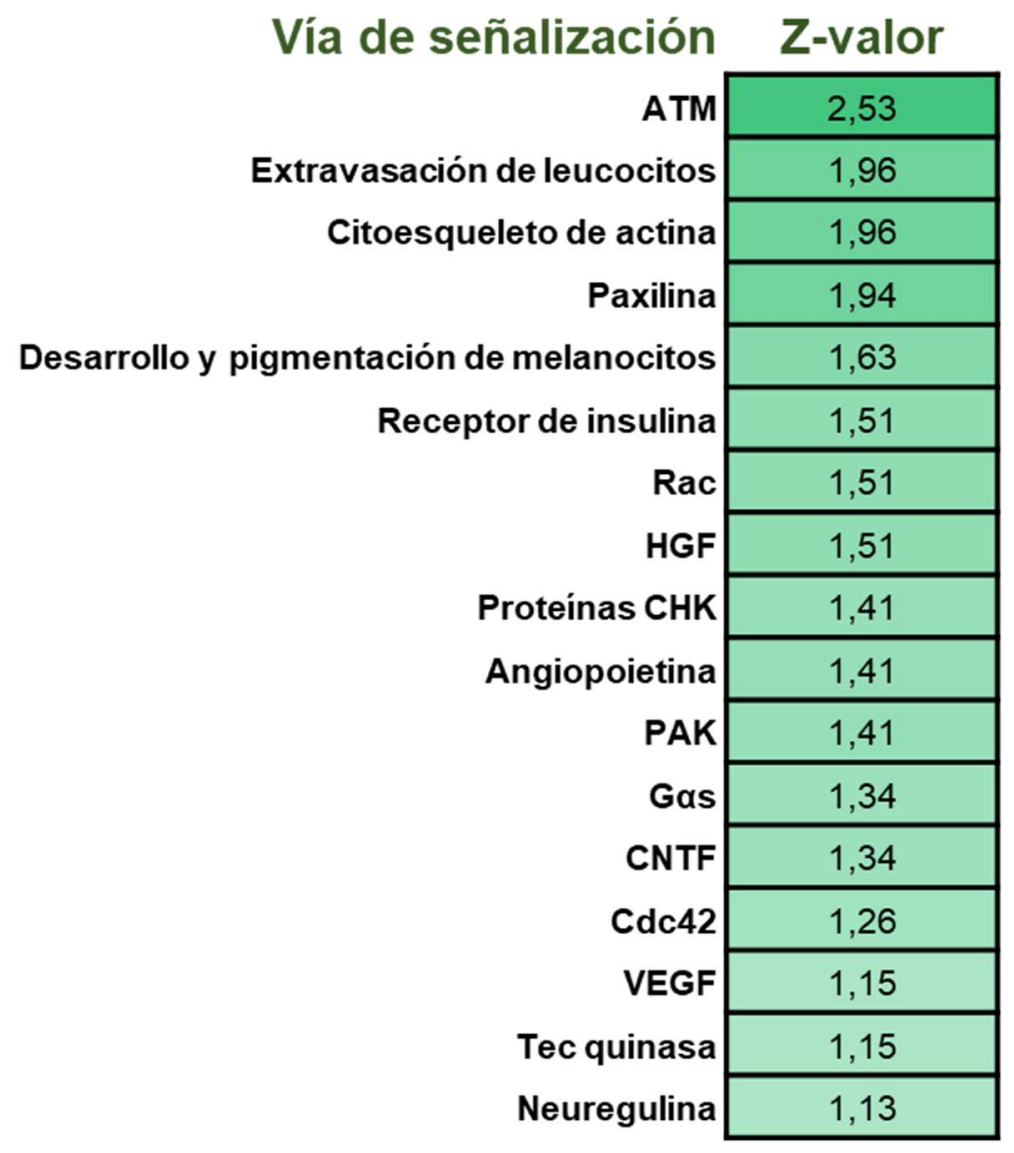

Figura 17. Vías de señalización activadas por la rigidez del sustrato en base a los cambios en los genes afectados por la rigidez del sustrato exclusivamente en células WT. En la tabla se muestran las distintas vías de señalización moduladas por la rigidez del sustrato exclusivamente en células que expresan CAV1 ordenadas de mayor a menor en base a su significancia. La significancia se determinó en base al Z-valor obtenido en el análisis, que aparece representado en la tabla. Únicamente están representadas las vías con un Z-valor superior a 1.

Utilizando la herramienta web Enrichr (Chen et al., 2013; Kuleshov et al., 2016), se estudió el enriquecimiento en los términos anotados en las base de datos KEGG (kyoto encyclopedia of genes and genomes). De esta forma se encontró, entre los genes que presentaban un aumento en su expresión en sustratos rígidos y únicamente en células que expresaban CAV1, un enriquecimiento en los términos relacionados con la dinámica y la estructura citoesqueleto y las adhesiones focales (Figura 18). Estos resultados correlacionan con los resultados obtenidos con IPA. En este análisis también se observó que los genes relacionados con la proliferación celular aumentaban su expresión en sustratos rígidos en ambos genotipos, 
indicando que la modulación de la proliferación por la rigidez de la MEC, ya descrita anteriormente (Klein et al., 2009), no depende de CAV1. Lo mismo sucede con la subida en la expresión de genes que codifican para componentes estructurales de los ribosomas. Otra observación interesante es que la rigidez del sustrato incrementa la expresión de genes implicados en procesos metabólicos, la respiración mitocondrial y componentes del retículo endoplasmático (RE) exclusivamente en células Cav1KO.

\begin{tabular}{|c|c|c|c|}
\hline \multicolumn{4}{|c|}{ Genes que aumentan su expression en sustratos rígidos } \\
\hline Termino KEGG & MEF WT & $\begin{array}{c}\text { MEF WT y } \\
\text { Cav1KO }\end{array}$ & $\begin{array}{c}\text { MEF Cav1 } \\
\text { KO }\end{array}$ \\
\hline Spliceosoma & $1,33 E-05$ & $6,86 \mathrm{E}-17$ & 0,746527037 \\
\hline Regulación del citoesqueleto de actina & 0,001106505 & 1 & 0,999999999 \\
\hline Adhesiones focales & 0,002433696 & 1 & 0,999999999 \\
\hline Uniones adherentes & 0,00719251 & 1 & 0,958817418 \\
\hline Uniónes estrechas & 0,00719251 & 1 & 0,958817418 \\
\hline Transporte de ARN & 0,079845133 & $4,51 \mathrm{E}-17$ & 0,489062944 \\
\hline Biogénesis de ARN & 0,223362547 & $2,52 \mathrm{E}-11$ & 0,885123793 \\
\hline Replicación de ADN & 0,942976109 & $7,90 \mathrm{E}-09$ & 0,633389624 \\
\hline Metabolismo de pirimidinas & 0,81182367 & $3,24 \mathrm{E}-08$ & 0,674332069 \\
\hline Ciclo celular & 0,139766277 & $1,82 \mathrm{E}-07$ & 0,06201733 \\
\hline Proteasome & & $1,23 E-07$ & 0,294135304 \\
\hline Metabolismo de purinas & 0,999998739 & $5,06 \mathrm{E}-05$ & 0,958817418 \\
\hline Ribosomas & & 0,001893987 & $1,10 \mathrm{E}-18$ \\
\hline Sintesis de aminoacyl-ARNt & 0,81182367 & 0,017036445 & 0,758388392 \\
\hline Polimerasa de ARN & 0,079845133 & 0,003387373 & 0,407014367 \\
\hline Metabolismo de metionina y cisteina & 0,999998739 & 0,017036445 & 0,999999999 \\
\hline Rutas metabólicas & 0,999998739 & 0,051996676 & 0,00529584 \\
\hline Fosforilación oxidativa & 0,999998739 & 1 & 0,000102371 \\
\hline Procesado de proteinas en el RE & 0,999998739 & 0,50524548 & 0,001486348 \\
\hline
\end{tabular}

Figura 18. Enriquecimiento en términos KEGG entre los genes aumentados por la rigidez del sustrato. En la tabla se muestran los $p$-valores ajustados del enriquecimiento en los términos KEGG entre los genes aumentados por la rigidez de la MEC exclusivamente en células WT, Cav1KO o de forma común en células de ambos genotipos. 


\subsection{Implicación de CAV1 en la modulación de la actividad de YAP en respuesta a cambios en la rigidez de la MEC}

\subsubsection{La actividad transcripcional de YAP esta modulada por CAV1}

Los resultados del ARNsec indicaban que el aumento de la expresión de determinados genes al aumentar la rigidez del sustrato es dependiente de CAV1. Y en concreto, entre esos genes hay muchos relacionados con el control de la dinámica y la estructura del citoesqueleto de actina y las adhesiones de la célula al sustrato subyacente. Por ese motivo decidimos testar el posible papel de YAP, ya que se sabe que este factor de transcripción controla la expresión de muchos de esos reguladores de la adhesión celular y la organización del citoesqueleto de actina (Stein et al., 2015). Además, hay un número creciente de evidencias apoyando el relevante papel que tiene YAP en la respuesta a señales mecánicas procedentes del ambiente extracelular (Dupont et al., 2011) lo cual lo sitúa cómo un buen candidato en este proceso de regulación.

Para evaluar si la actividad de YAP estaba modulada por la rigidez del sustrato en células con y sin CAV1 en nuestro sistema, analizamos en el ARNsec la expresión de un panel de 61 genes previamente descritos como targets específicos de dicho factor de transcripción (Dupont et al., 2011). De esta forma pudimos observar que la expresión de 26 de esos genes se incrementaba al aumentar la rigidez del sustrato en MEF WT, mientras en las células Cav1KO se observó un incremento significativo únicamente en 15 de ellos (Figura 19A). Para evaluar la significancia estadística de los cambios observados en los genes regulados por YAP en las células WT y Cav1KO decidimos utilizar la prueba exacta de Fisher. Este estadístico es utilizado para evaluar tablas de contingencia, en nuestro caso analizamos la dependencia entre la rigidez del sustrato y la expresión de los genes regulados transcripcionalmente por YAP (Figura 19B). De ese modo pudimos comprobar que la asociación entre el aumento de la rigidez del sustrato y el incremento en la expresión de los targets de YAP era significativa en las células WT, mientras que en las células Cav1KO no lo era.

Para confirmar el papel de CAV1 en el control de la actividad transcripcional de YAP, se analizó mediante RT-qPCR la expresión de Ankrd1 y Ctgf (Figura 19C). La expresión de ambos genes aumentaba al aumentar la rigidez de la MEC únicamente en células WT. La actividad transcripcional de YAP esta mediada por su unión con los factores de la familia TEAD (1-4) que interaccionan con dominios específicos de los promotores génicos induciendo la expresión de los mismos (Yagi et al., 1999; Zhao et al., 2008). Para medir la actividad de TEAD decidimos utilizar una construcción previamente caracterizada consistente en cuatro dominios consecutivos de unión a TEAD insertados en el promotor de un gen reportero de luciferasa. 
Expresando este reportero ( 8 XGTICC lux) en nuestro sistema observamos que la expresión de la luciferasa aumentaba en los sustratos más rígidos únicamente en las células WT (Figura 19D). Estos resultados sugerían que CAV1 controla la regulación transcripcional mediada por YAPTEAD en respuesta a cambios en la rigidez del sustrato.

A

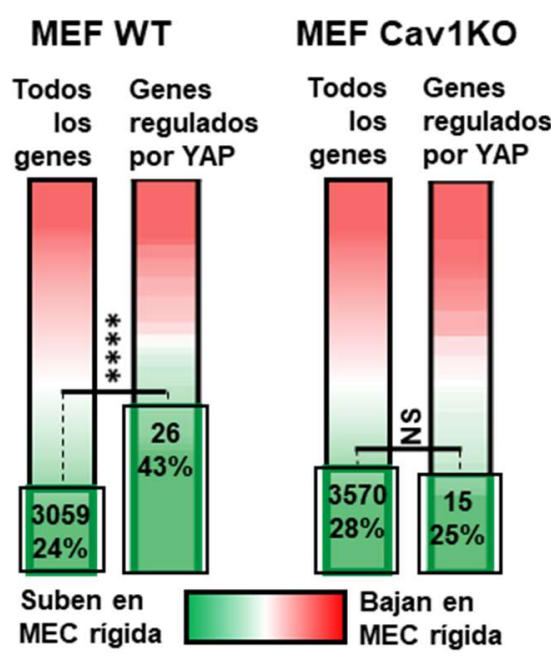

B

\begin{tabular}{|c|c|c|c|}
\cline { 2 - 4 } \multicolumn{1}{c|}{$\begin{array}{c}\text { Test de Fisher } \\
\text { MEF WT }\end{array}$} & $\begin{array}{c}\text { Genes } \\
\text { regulados } \\
\text { por YAP }\end{array}$ & $\begin{array}{c}\text { Genes no } \\
\text { regulados } \\
\text { por YAP }\end{array}$ & TOTAL \\
\hline $\begin{array}{c}\text { Aunmentados por la } \\
\text { rigidez de la MEC }\end{array}$ & 26 & 2726 & 2752 \\
\hline $\begin{array}{c}\text { No aumentados de } \\
\text { la rigidez de la MEC }\end{array}$ & 35 & 9742 & 9777 \\
\hline TOTAL & 61 & 12468 & 12529 \\
\hline \multicolumn{3}{|c|}{$\boldsymbol{p}$-valor $\mathbf{0 . 0 0 0 3}$} \\
\hline
\end{tabular}

\begin{tabular}{|c|c|c|c|}
\cline { 2 - 4 } \multicolumn{1}{c|}{} & $\begin{array}{c}\text { Genes } \\
\text { Mest de Fisher } \\
\text { regulados } \\
\text { por YAP }\end{array}$ & $\begin{array}{c}\text { Genes no } \\
\text { regulados } \\
\text { por YAP }\end{array}$ & TOTAL \\
\hline $\begin{array}{c}\text { Aunmentados por la } \\
\text { rigidez de la MEC }\end{array}$ & 15 & 3344 & 3359 \\
\hline $\begin{array}{c}\text { No aumentados de } \\
\text { la rigidez de la MEC }\end{array}$ & 46 & 9124 & 9170 \\
\hline TOTAL & 61 & 12468 & 12529 \\
\hline
\end{tabular}

D
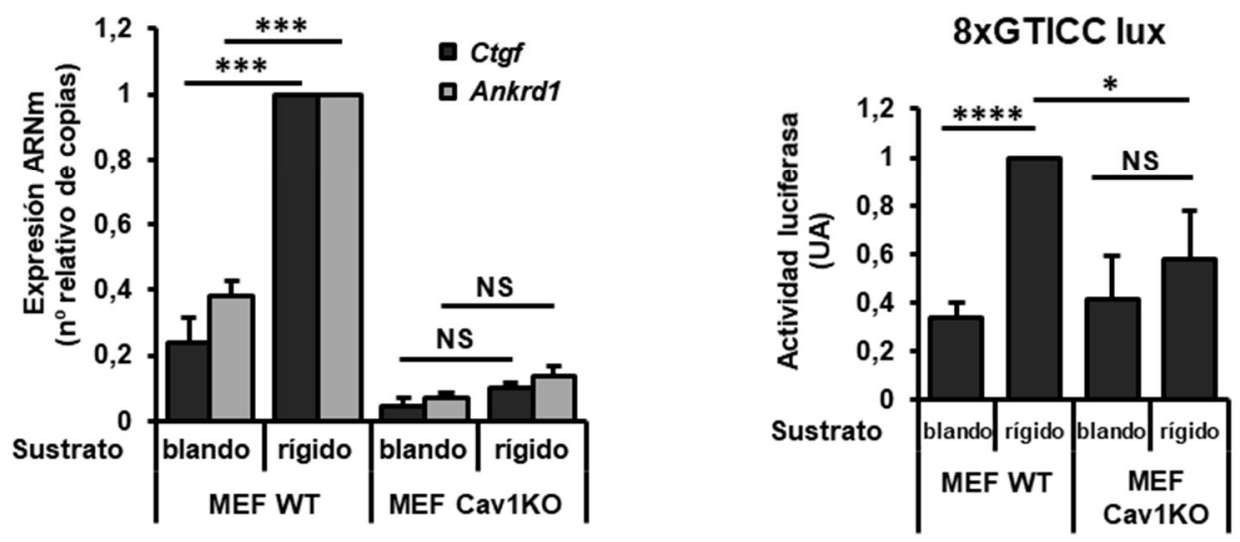

Figura 19. La rigidez de la MEC aumenta la expresión de genes regulados transcripcionalmente por YAP únicamente en células WT. (A) Variaciones en la expresión génica entre células creciendo sobre sustratos rígidos y blandos en el análisis ARNsec. En la gráfica parecen representados todos los genes del genoma (barra de la izquierda) o sólo los genes regulados transcripcionalmente por YAP (barra de la derecha) para el análisis de las células MEF WT y las Cav1KO. Englobado por un cuadro negro con la cuantificación total y el porcentaje sobre el total en el interior aparecen los genes que aumentan de forma significativa ( $p$ valor ajustado $<0,5)$ al aumentar la rigidez de la MEC. La estadística corresponde al cálculo del $p$-valor con el test de Fisher que se muestra en el apartado siguiente. (B) Tablas de contingencia con los valores utilizados para el cálculo del estadístico del test de Fisher en células WT y Cav1KO. (C) Análisis mediante RT-qPCR de la expresión del ARNm de Ctgf y Ankrd1 en células WT y Cav1KO sobre sustratos rígidos o blandos durante 24 horas. Los datos están normalizados con respecto al valor de las células WT creciendo 
sobre sustratos rígidos. $n=3$. (D) Medida de la actividad luciferasa en células que expresan el vector 8xGTIIC-luciferasa para monitorizar la actividad transcripcional de TEAD. Para el ensayo se usaron células WT y Cav1KO creciendo sobre sustratos blandos y rígidos. Todos los datos están normalizados con respecto al valor de las células WT creciendo sobre sustratos rígidos. $n=4$. Los datos están representados cómo la media \pm SEM (error estándar de la media); ${ }^{*} \mathrm{P}<0.05, * * * \mathrm{P}<0.005, \mathrm{y}$ $* * * * \mathrm{P}<0.0005$.

Para confirmar el papel de CAV1 en la regulación de la actividad transcripcional de YAP decidimos expresar una construcción bicistrónica para la expresión simultanea de los genes Cav1 y GFP (CAV1-GFP) en células Cav1KO, mediante transducción lentiviral. En base a los niveles de GFP se separaron por citometría de flujo dos poblaciones de células, una con niveles altos de CAV1 y otra con niveles bajos. En esas poblaciones se analizaron por RT-qPCR los niveles de expresión de Ankrd1 y Ctgf observándose un aumento en la expresión de ambos genes en las células que expresaban niveles más altos de CAV1 (Figura 20A y 20B).

A

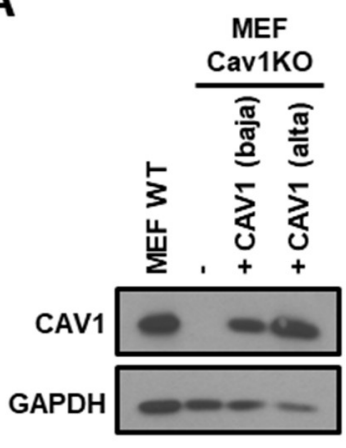

B

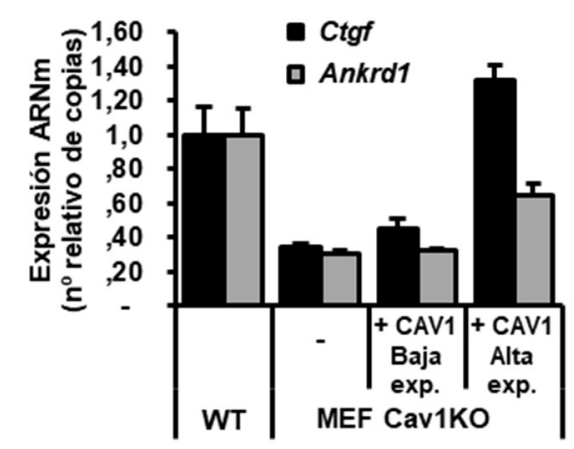

Figura 20. CAV1 modula la actividad de YAP como regulador transcripcional en MEFs. (A) WB en el que se muestra la expresión de CAV1 en células WT, Cav1KO y Cav1KO reconstituidas con niveles bajo o altos de CAV1. GAPDH se utilizó cómo control de carga. (B) Análisis mediante RT-qPCR de la expresión del ARNm de Ctgf y Ankrd1 en células WT, Cav1KO y Cav1KO reconstituidas con niveles bajo o altos de CAV1. Las células se lisaron para la posterior extracción del ARNm 24h después de sembrarlas sobre sustratos con una MEC rígida. Los datos están normalizados con respecto a los valores observados en las células WT.

Posteriormente se decidió estudiar si la regulación de la actividad transcripcional de YAP por CAV1 era extensible a otros tipos celulares diferentes. En primer lugar, se utilizó una línea celular de carcinoma de mama (MDA-MB-231) en la que se silenció CAV1 utilizando un ARN de interferencia (ARNi) especifico. La reducción de los niveles de CAV1 en estas células inducía una bajada en la expresión de Ctgf y Ankrd1 (Figura 21A, 21B y 21C). En paralelo se estudió la actividad de TEAD con el reportero de luciferasa 8xGTIIC-lux y se observó igualmente una bajada significativa en su actividad (Figura 21D). También se estudió la expresión de los targets de YAP 
en hepatocitos inmortalizados procedentes de ratones neonatos. De manera análoga a lo observado en MEFs y MDA-MB-231 la expresión de Ctgf y Ankrd1 en los hepatocitos procedentes de ratones Cav1KO era significativamente más baja que en los procedentes de ratones WT (Figura 21E).

A

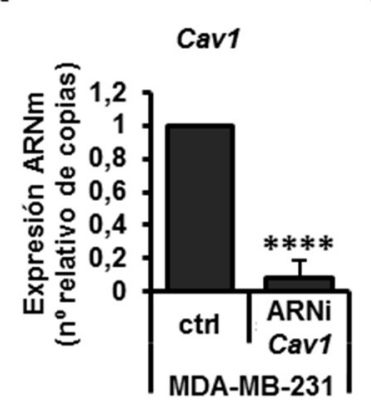

D

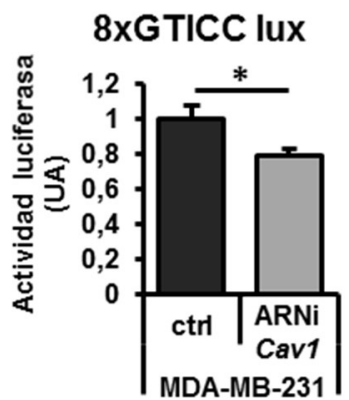

B

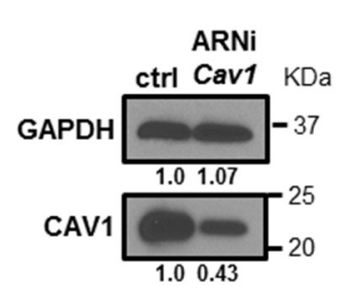

C $\quad$ ctof

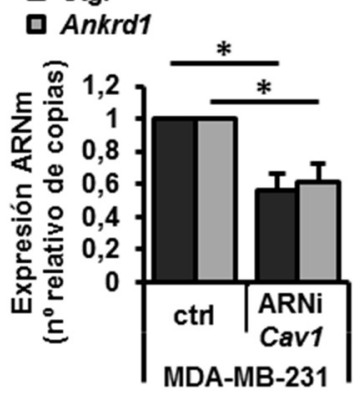

$\mathbf{E}$

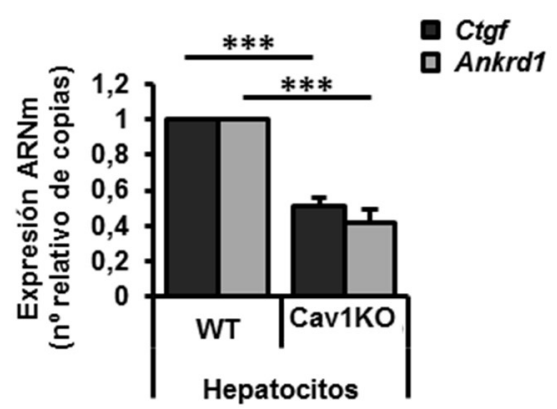

Figura 21. CAV1 modula la actividad de YAP como regulador transcripcional en células MBA-MD-231 y hepatocitos. (A) Expresión de ARNm de CAV1 medida mediante RT-qPCR en células MDA-MB-231 en las que se silenció CAV1 utilizando un ARNi específico o transfectadas con un ARNi control. Las células se lisaron para la posterior extracción del ARNm 24 horas después de sembrarlas sobre sustratos con una MEC rígida. Datos normalizados con respecto a las células transfectadas con el ARNi control. $N=4$. (B) Análisis de la expresión de CAV1 mediante WB en células correspondientes al experimento (B). GAPDH se utilizó como control de carga. (C) Análisis de la expresión de ARNm de Ctgf y Ankrd1 en las células del experimento (B). Los datos están normalizados con respecto a los valores obtenidos en la condición control. $n=4$. (D) Medida de la actividad luciferasa en células MDA-MB-231 expresando el vector 8xGTIIClux. Para el ensayo se usaron células transfectadas con un ARNi contra CAV1 o un ARNi control creciendo sobre sustratos rígidos durante 24 horas. Todos los datos están normalizados con respecto al valor de las células transfectadas con el ARNi control. $n=5$. (E) Análisis mediante RT-qPCR de la expresión de Ctgf y Ankrd1 en hepatocitos neonatales procedentes de ratones WT y Cav1KO. Los datos se normalizaron con respecto a los valores obtenidos en los hepatocitos WT para cada experimento. $n=4$. Los datos están representados cómo la media \pm SEM (error estándar de la media); $* \mathrm{P}<0.05, * * * \mathrm{P}<0.005, \mathrm{y}$ $* * * * \mathrm{P}<0.0005$.

Para confirmar el papel de YAP en los cambios transcripcionales observados, se decidió silenciar la expresión de Yap utilizando ARNi. En este caso, para evitar los mecanismos compensatorios previamente descritos con su proteína homologa TAZ (Finch-Edmondson et al., 2015), se silenció al mismo tiempo la expresión del gen que codifica para dicha proteína (Figura 
22A). Se observó que el silenciamiento de Yap y Taz disminuía la expresión de Ctgf y Ankrd1 en células WT hasta niveles similares a los observados en las células Cav1KO (Figura 22B). Por el contrario, en las células Cav1KO no se observa una bajada significativa en la expresión de ambos genes. Estas observaciones apoyan la especificidad de la dependencia de los cambios transcripcionales observados como dianas de regulación de YAP. Es importante resaltar que la ausencia de CAV1 no afecta a la expresión de YAP, ni el silenciamiento de Yap afecta a la expresión de CAV1, tanto a nivel de ARNm como de proteína (Figura 22A, 22C y 22D), lo cual permite descartar la regulación transcripcional directa entre ambas.

A

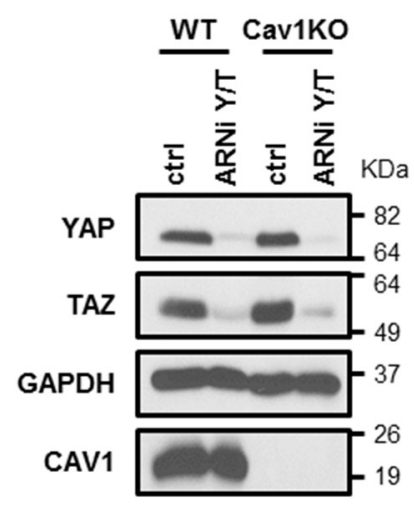

C

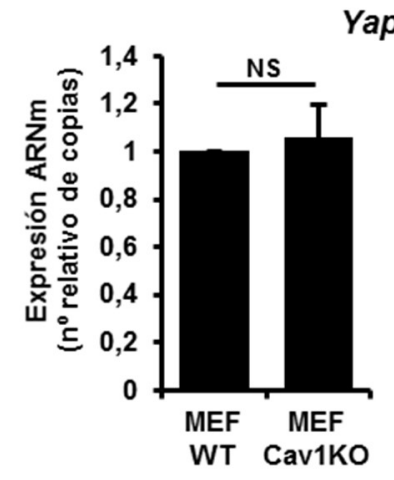

B

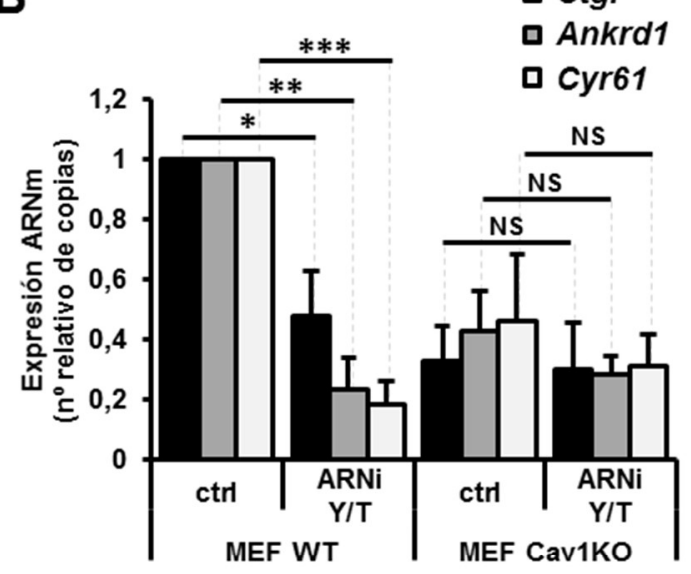

D

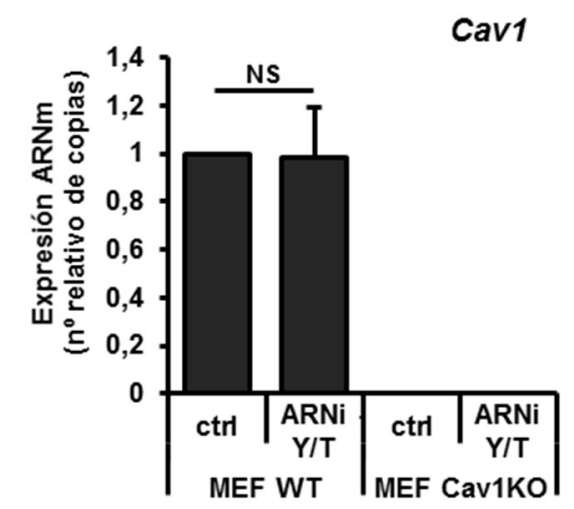

Figura 22. Las diferencias transcripcionales entre células WT y Cav1KO son dependientes de YAP. (A) Análisis de la expresión de YAP y TAZ mediante WB en MEF WT y Cav1KO en las que se silenciaros ambos genes con ARNi. GAPDH se utilizó como control de carga. (B) Estudio por RT-qPCR de la expresión de Ctgf, Ankrd1 y Cyr61 en células WT y Cav1KO en las que se silenció Yap y Taz. Los valores se normalizaron con respecto a los obtenidos en las células $W T$ transfectadas con el ARNi control para cada experimento. $n=$ 3. (C) Expresión del ARNm de YAP en células WT y Cav1KO. Valores normalizados con respecto al WT. $n=$ 3. (D) Expresión de ARNm de CAV1 en las células del experimento (B). Valores normalizados con respecto a las células transfectadas con el ARNi control. $\mathrm{n}=3$. Los datos están representados cómo la media \pm SEM (error estándar de la media); ${ }^{*} \mathrm{P}<0.05,{ }^{*} \mathrm{P}<0.01,{ }^{* * *} \mathrm{P}<0.005$. 


\subsubsection{La regulación de la actividad transcripcional de YAP por CAV1 es un mecanismo general}

\section{observado en diferentes células y tejidos}

Para evaluar la solidez de la relación encontrada entre YAP y CAV1 se llevaron a cabo dos abordajes experimentales computacionales. En primer lugar, se utilizó la herramienta web de acceso libre SEEK que permite estudiar el grado de co-expresión de los genes de interés con el resto de genes del genoma, en base a experimentos de expresión reales en los que se analizaron diferentes órganos, tejidos, tipos celulares y condiciones (Zhu et al., 2015). Utilizando esta herramienta analizamos la co-expresión entre la lista de 61 genes regulados por YAP que ya habíamos utilizado en anteriores análisis con el resto de genes del genoma (Figura 23A y 23B). De este modo pudimos observar que existe una alta correlación entre la expresión de CAV1 y los diferentes targets de YAP, siendo uno de los genes que presentan un Z-valor mayor (0.4994). Lo mismo sucede con PTRF (Z-valor $=0.5232$ ), que como ya he mencionado con anterioridad es un componente indispensable para la formación de las caveolas, y por tanto podría indicar un papel de las mismas en el control de la regulación de YAP por CAV1. También presentan una alta co-expresión con otro miembro de la familia de las caveolinas, CAV2. Para el segundo abordaje se utilizó un estudio publicado previamente en el que se utilizaron 300 líneas celulares diferentes en las que se analizó la correlación entre la expresión de CAV1 y el resto del genoma (Pellinen et al., 2018). Utilizando los datos de ese trabajo se analizó la correlación entre la expresión de CAV1 con los genes regulados por YAP. En ese análisis se pudo comprobar que el 79\% de los genes regulados por YAP correlacionaban de forma positiva con la expresión de CAV1, mientras que sólo un 11\% correlacionaban negativamente con su expresión (Figura 23C). En conjunto, ambos abordajes sugieren que la regulación de la actividad transcripcional de YAP por CAV1 es un mecanismo general que opera en diferentes modelos experimentales.

A

Correlación de la expression con genes regulados por YAP

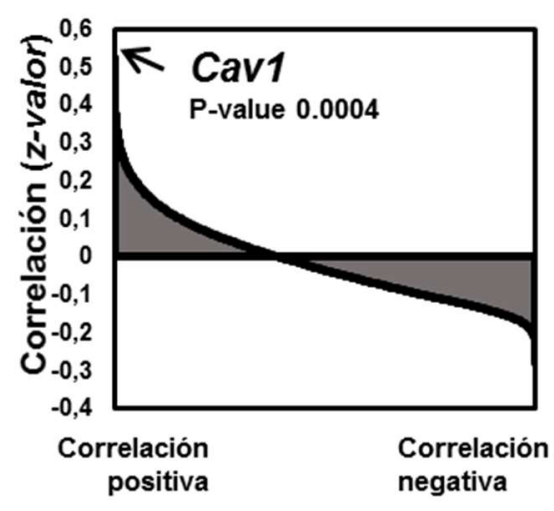

B

\begin{tabular}{|c|c|}
\hline Gen & $\begin{array}{c}\text { Co- } \\
\text { expresión }\end{array}$ \\
\hline Ptrf & 0.5232 \\
\hline Cald1 & 0.511 \\
\hline Cav1 & 0.4994 \\
\hline Sparc & 0.4776 \\
\hline Fbn1 & 0.4665 \\
\hline Heg1 & 0.4532 \\
\hline Frmd6 & 0.4488 \\
\hline Tubb6 & 0.4484 \\
\hline Cav2 & 0.4453 \\
\hline Nexn & 0.4407 \\
\hline
\end{tabular}

C

Correlación entre la expression de Cav1 y los genes regulados por YAP

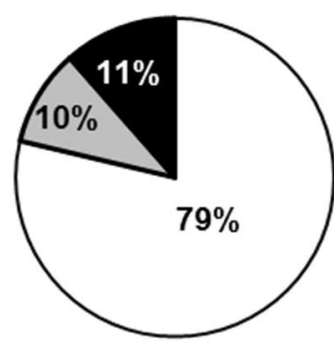

$\square$ Correlación positiva

$\square$ Sin correlación

Correlación negativa 
Figura 23. La expresión de CAV1 correlaciona positivamente con la de los genes regulados por YAP en diferentes células y tejidos. (A) Análisis de la co-expresión de los genes regulados transcripcionalmente por YAP con el resto de genes del genoma utilizando la herramienta bioinformática SEEK. En la gráfica se muestra los Z-valores de la correlación para cada uno de ellos. (B) En la tabla aparecen representados los 10 genes que presentan una correlación mayor con los genes regulados por YAP y su correspondiente Zvalor. (C) Diagrama representando el porcentaje de genes regulados por YAP con una correlación positiva, negativa o sin correlación con la expresión de CAV1 en un análisis de 300 líneas celulares diferentes, considerando correlaciones positivas o negativas aquellas que tiene un $p$-valor $<0,05$.

\subsubsection{CAV1 regula la translocación núcleo-citosólica de YAP en respuesta a cambios en la} $\underline{\text { rigidez de la MEC }}$

Para entender los mecanismos subyacentes a la regulación de la actividad transcripcional de YAP por CAV1 se estudió la distribución subcelular de YAP en células creciendo sobre matrices rígidas o blandas (Fig. 24A) Se analizó de forma cuantitativa categorizando la distribución celular de YAP cómo "citosólica" (C) para aquellas células que presentaban una distribución mayoritariamente citosólica, "nuclear" (N) para las células con una distribución de YAP mayoritariamente nuclear o "distribución homogénea" (N/C) para aquellas células que presentan niveles similares de YAP tanto en el núcleo cómo en el citosol (Fig. 24B). Se observó de esta manera que en las células WT, YAP se acumulaba en el núcleo en células creciendo sobre substratos rígidos, mientras que en substratos blandos estaba retenida en el citosol. Por el contrario, en las células Cav1KO, YAP se encontraba retenido en el citosol en ambas condiciones, tanto en substratos rígidos como en los blandos. Estos resultados se confirmaron en ensayos en los que se separaron mediante fraccionamiento las proteínas citosólicas de las nucleares (Fig. 24C; ver sección de materiales y métodos). Estos resultados sugieren que CAV1 participa en mecanismos de regulación que determinan la retención de YAP en el citosol.

Se sabe, por una parte, que la morfología celular determinada por el grado de estiramiento de las células durante su adhesión al substrato regula la actividad de YAP (Dupont et al., 2011) y, por otro lado, que la expresión de CAV1 determina la morfología celular (GrandeGarcia et al., 2007). Dadas estas dos premisas una hipótesis plausible sobre la regulación observada, sería que la deficiencia en la actividad de YAP en las células Cav1KO es consecuencia de las diferencias que presentan en su morfología con respecto a las células WT. Para testar esta posibilidad decidimos sembrar nuestras células sobre micropatrones de fibronectina de tamaños variables, que permiten controlar la morfología celular adaptándola a patrones de tamaños predefinidos. Se sabe que cuando las células crecen en patrones de tamaños pequeños, que impiden su estiramiento total, YAP se encuentra retenido en el citosol, mientras que en patrones de tamaños mayores YAP se localiza en el núcleo (Dupont et al., 2011). Lo mismo se observó en las células WT, sin embargo, en las células Cav1KO YAP se encontraba retenido en el 
citosol tanto en los patrones grandes cómo en los pequeños (Fig. 25A y 25B). Estos resultados sugieren que la regulación de YAP mediada por CAV1 no es únicamente dependiente de los cambios en la morfología celular, ya que en células WT y Cav1KO con la misma morfología la distribución de YAP es diferente.

A
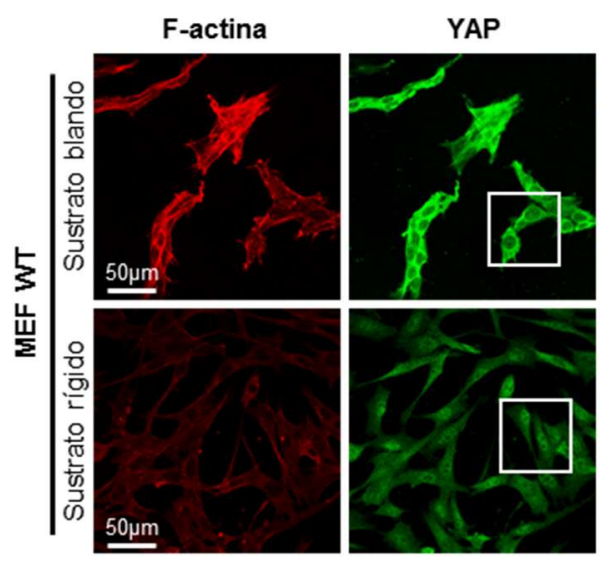

Composición
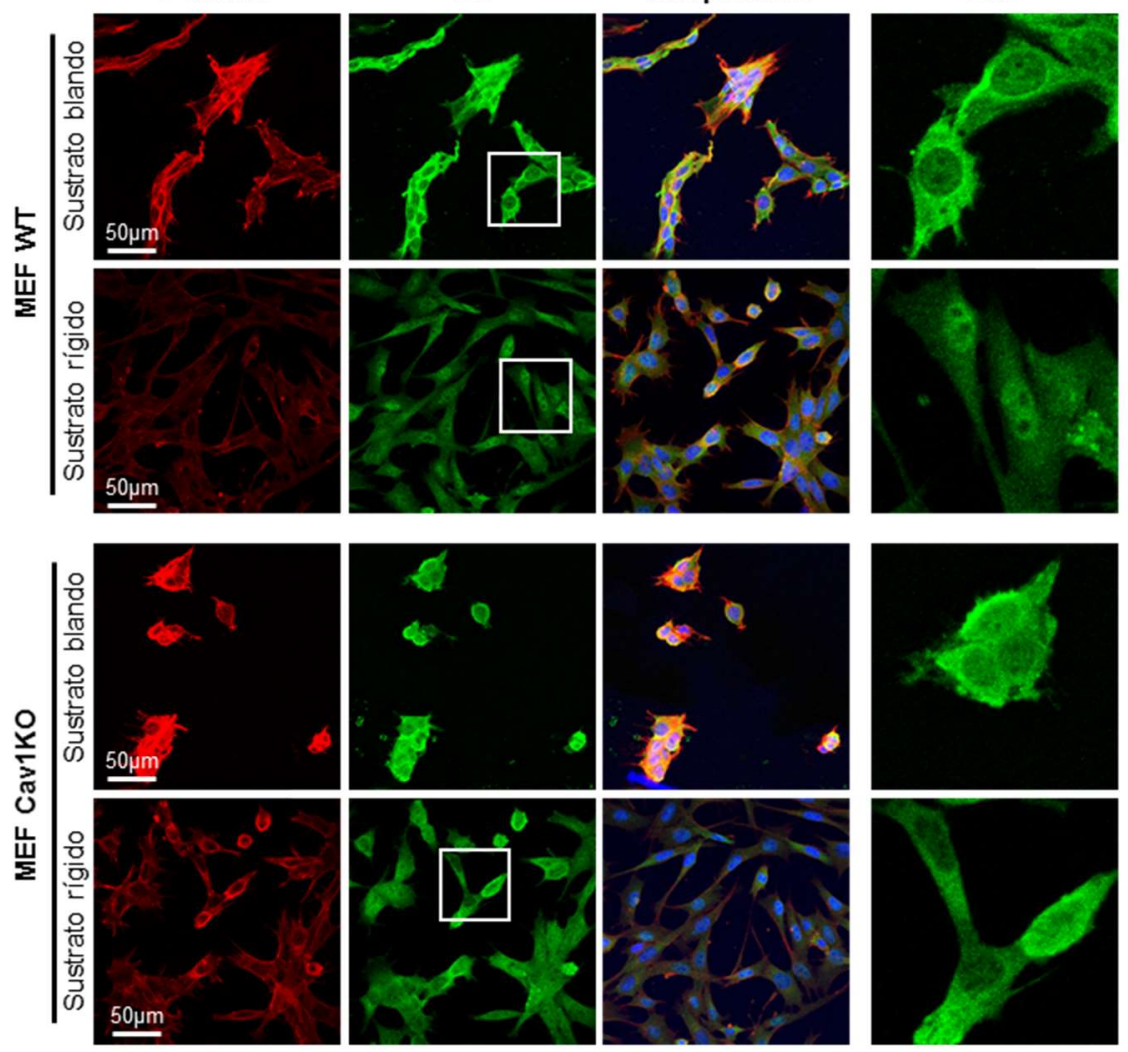

B

C
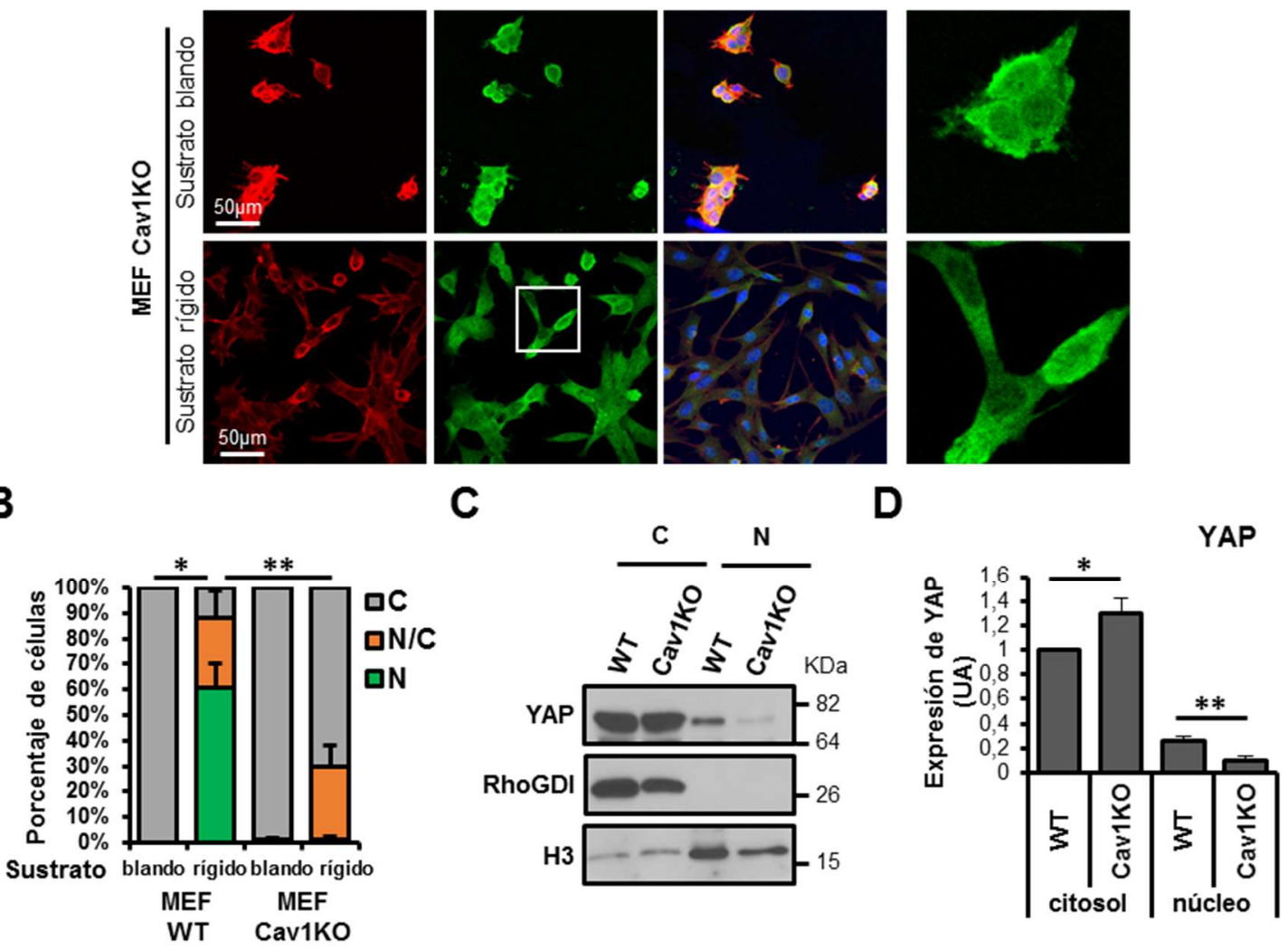

Figura 24. CAV1 modula la translocación de YAP al núcleo en respuesta a cambios en la rigidez de la MEC. (A) Imágenes de microscopía confocal de fluorescencia mostrando la distribución subcelular de YAP (verde) en células WT y Cav1KO creciendo durante $24 \mathrm{~h}$ en sustratos rígidos y blandos. La actina filamentosa (F-actina) se marcó con faloidina marcada con el fluoróforo Alexa647 (rojo) y el núcleo con Hoechst (azul), en las imágenes de la composición con los tres canales utilizados). Las imágenes de la columna de la derecha corresponden a la región de interés (ROI, del inglés region of interest) delimitada por un cuadro blanco en la segunda columna. (B) Porcentaje de células en el experimento (A) con YAP localizado de forma predominante en el núcleo (N), en el citosol (C) o con distribución tanto nuclear cómo citosólica (N/C). La cuantificación se realizó seleccionando aleatoriamente imágenes de tres experimentos diferentes (en total 60-200 células por condición) (C) Distribución subcelular de YAP analizada por WB tras 
el fraccionamiento subcelular. Para el ensayo se utilizaron células WT y Cav1KO creciendo durante 24h en sustratos rígidos. RhoA-GDI y la Histona H3 se utilizaron como marcadores de la fracción citosólica y la nuclear respectivamente. (D) Cuantificación de la distribución de YAP en la fracción nuclear y la citosólica en ensayos similares al representado en el apartado $(C) . n=3$. Los datos están representados cómo la media \pm SD en (B) y \pm SEM en $(D) ;{ }^{*} P<0.05,{ }^{*} P \mathrm{P}<0.01$.

A

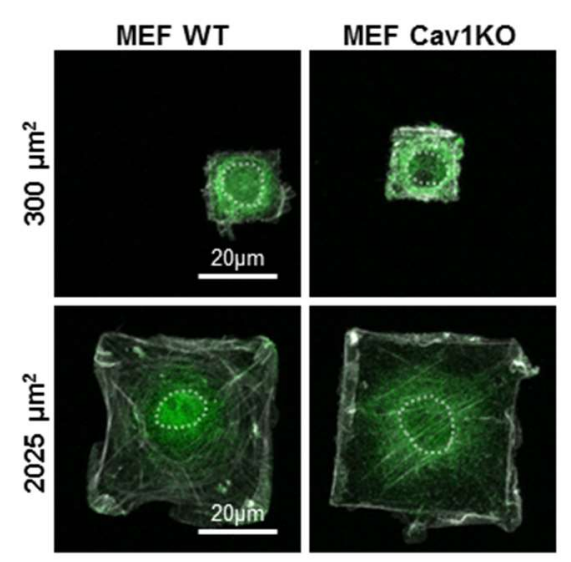

B

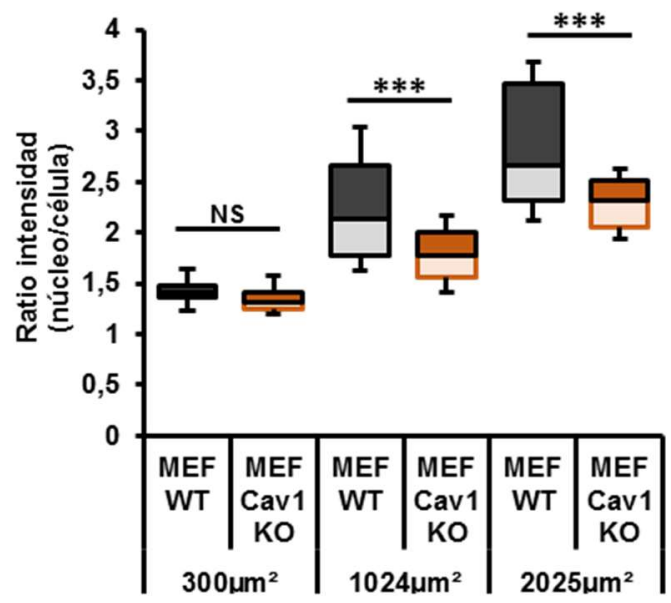

Figura 25. La translocación de YAP al núcleo en respuesta a cambios en la morfología celular es dependiente de CAV1. (A) Imágenes de microscopía confocal de fluorescencia mostrando la distribución subcelular de YAP en células WT y Cav1KO creciendo durante $24 \mathrm{~h}$ en micropatrones prediseñados con dos tamaños diferentes. La F-actina (blanco) se marcó con faloidina marcada con el fluoróforo Alexa647. (B) Diagrama de cajas mostrando la cuantificación con ImageJ de la distribución subcelular de YAP en células WT y Cav1KO creciendo sobre micropatrones con tres tamaños diferentes $\left(300 \mu \mathrm{m}^{2}, 1024 \mu \mathrm{m}^{2}\right.$, y 2025 $\mu \mathrm{m}^{2}$ ). Los datos aparecen representados como la intensidad de señal en el núcleo dividido entre la intensidad celular total. Las cajas se representan la mediana y el primer y tercer cuartil, mientras que los bigotes muestran los percentiles 90 y $10{ }^{* * * P<0.005 . ~}$

\subsubsection{CAV1 regula la actividad de YAP en respuesta al estiramiento celular}

Nuestros resultados evidenciaban la regulación de la actividad de YAP por Cav1 en función de las propiedades mecánicas de la MEC y de la morfología de las células. Para profundizar más en el papel de CAV1 como mecanosensor en el control de la actividad de YAP, decidimos evaluar su papel en la respuesta a un estímulo diferente, el estiramiento mecánico de las células, que se sabe que activa YAP en distintos contextos celulares (Aragona et al., 2013; Codelia et al., 2014). Utilizando para ello un aparato específico capaz de estirar la superficie sobre la cual están sembradas las células (FX 5000 ${ }^{\mathrm{TM}}$, FlexCell Int., USA), aplicamos a células WT y Cav1KO un estiramiento uni-axial con un patrón cíclico. Ese estiramiento inducía un aumento en la expresión de Ctgf y Ankrd1 en células WT, pero no tenía ningún efecto sobre las células Cav1KO (Figura 26A), lo cual indicaba que CAV1 también podría tener un papel en la activación de YAP en respuesta al estiramiento mecánico de las células. En el mismo experimento 
comprobamos que el estiramiento mecánico no afectaba a la expresión de CAV1 (Figura 26B), descartándose por tanto una regulación a nivel transcripcional.

A

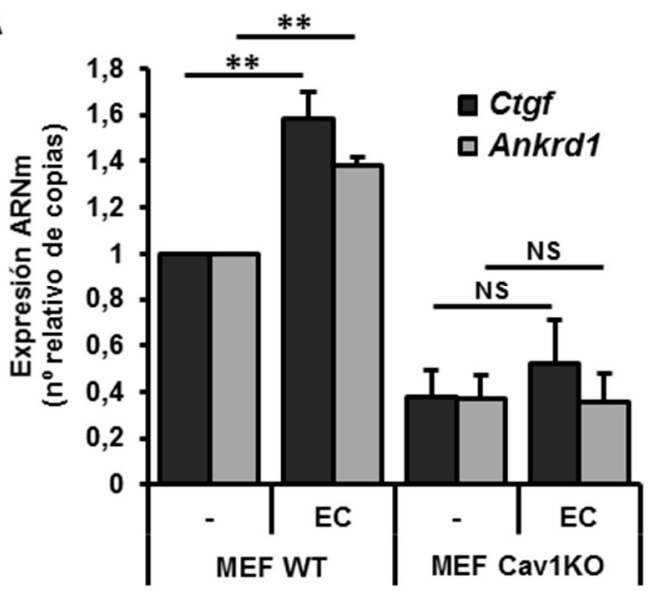

B

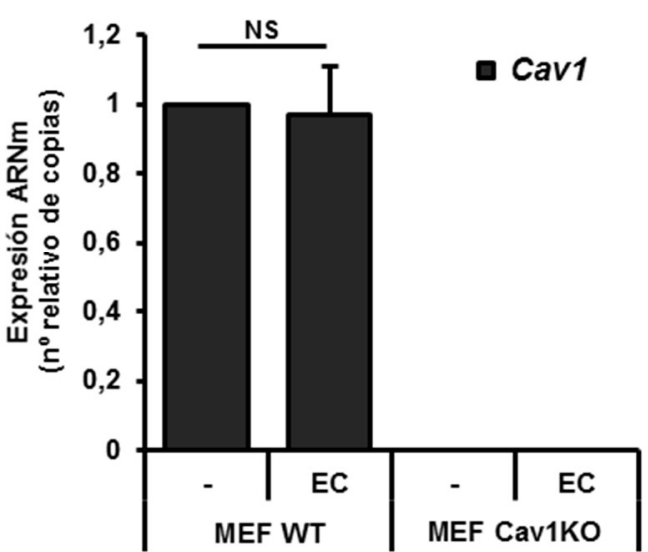

Figura 26. La activación de YAP por el estiramiento mecánico de las células es dependiente de CAV1. (A y B) Análisis por RT-qPCR de la expresión de Ctgf, Ankrd1 (A) y Cav1 (B) en células WT y Cav1KO sometidas a estiramiento mecánico cíclico $(\mathrm{EC})$ durante $24 \mathrm{~h}$ y en los correspondientes controles en condiciones estáticas. Los datos en cada réplica se normalizaron con respecto a los valores obtenidos en células WT en condiciones estáticas. $\mathrm{n}=4$. Los datos están representados cómo la media \pm SEM. ${ }^{* *} \mathrm{P}<0.01$.

\subsection{Caracterización de los mecanismos moleculares que controlan la regulación YAP por CAV1}

\subsubsection{La regulación de YAP por CAV1 depende de la fosforilación de sus residuos reguladores}

\section{específicos}

La fosforilación de YAP en al menos cinco residuos de serina específicos favorece su retención en el citosol al permitir la interacción con proteínas 14-3-3 que lo secuestran (Basu et al., 2003; Zhao et al., 2007). Dada la importante función que esa fosforilación tiene en la regulación de la actividad de YAP decidimos estudiar su papel en nuestro sistema. Estudiamos la fosforilación de YAP en la serina 112 (correspondiente a la S127 en la proteína ortóloga en humanos) y vimos que en las Cav1KO era mayor que en las WT (Figura 27A). Del mismo modo, vimos que la expresión de CAV1 exógena en células Cav1KO inducía una bajada en los niveles de fosforilación de YAP (Figura 27B), lo cual confirmaba el papel de CAV1 en el control de los niveles de fosforilación de YAP en la S112. Algunos autores sugieren que YAP fosforilado no se retiene necesariamente en el citosol y que se puede encontrar también en el núcleo (Wada et al., 2011). Por ese motivo decidimos hacer un fraccionamiento bioquímico para separar las fracciones nucleares de las citosólicas. De este modo comprobamos que la forma fosforilada de YAP sólo 
se localizaba en la fracción citosólica en nuestro sistema (Figura 27C). A la vista de estos resultados, la fosforilación diferencial de YAP podría explicar las diferencias en la actividad de YAP entre células con y sin CAV1.

A

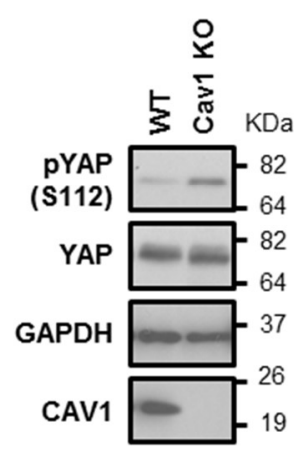

B

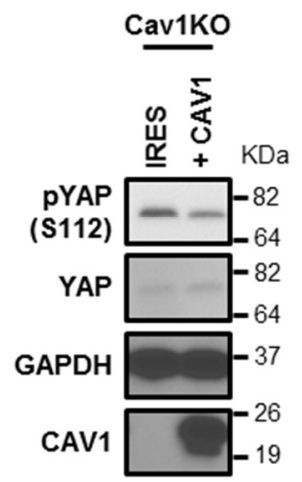

C

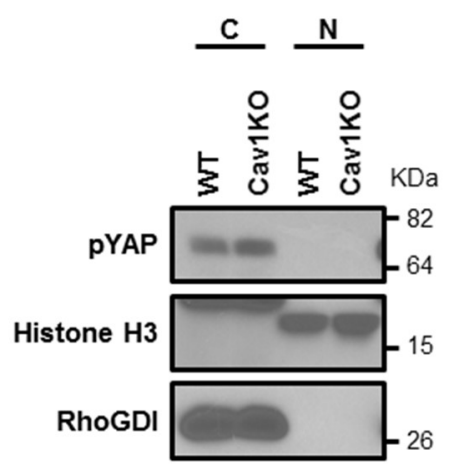

Figura 27. La fosforilación de YAP es mayor en células sin CAV1. (A) WB mostrando los niveles de fosforilación de YAP en S112 en MEF WT y Cav1KO crecidas durante 24h en matrices rígidas. También se muestran como controles los niveles de YAP totales, GAPDH y CAV1. (B) El mismo experimento que en (A) se realizó con células Cav1KO transfectadas con un vector vacío (pRRL-IRES-GFP) y células Cav1KO reconstituidas de manera transitoria con CAV1 exógena. (C) WB mostrando la localización de YAP fosforilado en la S112 en la fracción citosólica y nuclear de células WT y Cav1KO. La separación de ambas fracciones se llevó a cabo mediante métodos bioquímicos y mecánicos, tal y como se detalla en la sección de materiales y métodos. RhoA-GDI y la Histona H3 se utilizaron como marcadores de la fracción citosólica y la nuclear respectivamente.

Para estudiar el papel de la fosforilación en nuestro sistema decidimos utilizar para ello plásmidos que dirigen la expresión ectópica de un mutante de YAP (YAP(5SA)-FLAG-Flag) que tiene varios residuos de serina mutados a alanina, y por tanto no se puede fosforilar en las mismas. Esos residuos mutados en esta construcción son residuos importantes para la regulación de su actividad al ser diana de las quinasas reguladoras de la vía Hippo, como por ejemplo LATS1/2. También se utilizó como control la isoforma silvestre (YAP-Flag). Mediante WB confirmamos que la isoforma silvestre se fosforila y la mutada no (Figura 28A). Al expresar las citadas construcciones en MEF WT y Cav1KO vimos mediante fraccionamiento subcelular que YAP-Flag presentaba la misma distribución que el YAP endógeno, estando localizada mayoritariamente en el núcleo en células WT y retenida en el citosol en las Cav1KO, mientras que la construcción YAP(5SA)-FLAG se localizaba en el núcleo en ambos tipos celulares (Figura 28B y $28 \mathrm{C}$ ). Estos resultados se confirmaron también analizando la distribución subcelular de las construcciones de YAP sobreexpresadas en células WT y Cav1KO mediante microscopia confocal de fluorescencia (Figura 28D y 28E). 
A

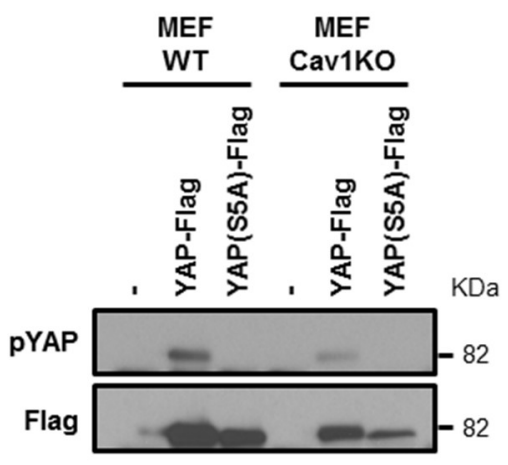

C

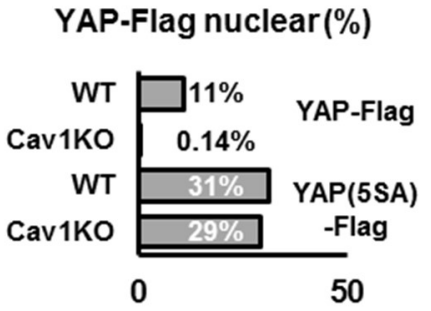

E

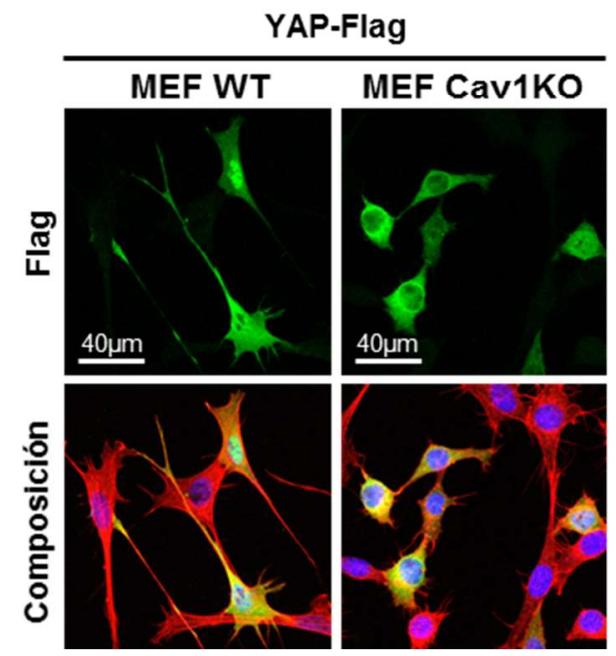

B

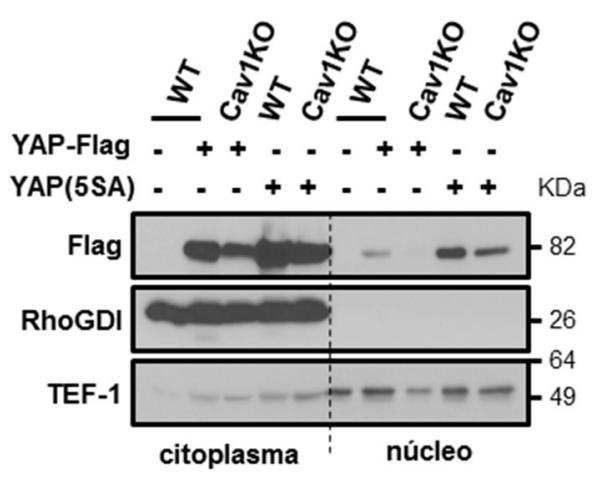

D
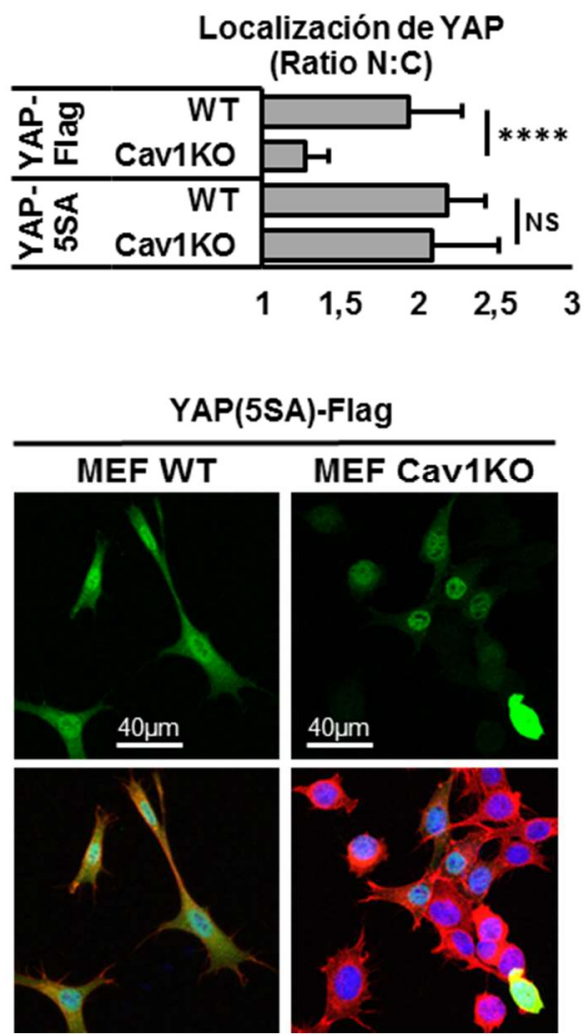

Figura 28. El mutante no fosforilable YAP(5SA)-FLAG se transloca al núcleo en células Cav1KO. (A) WB mostrando los niveles de fosforilación en S127 en YAP-Flag y YAP(5SA)-FLAG-Flag transfectadas en MEF WT y Cav1KO. Para la detección de las construcciones se utilizó un anticuerpo contra el epítopo Flag mostrándose únicamente la fosforilación de YAP a la altura en la que aparecen las construcciones fusionadas a Flag, con un peso molecular mayor que el YAP endógeno. (B) Análisis de la distribución de Flag en las fracciones nuclear y citosólica en MEF WT y Cav1KO transfectados con YAP-Flag y con YAP(5SA)FLAG. RhoA-GDI y la TEF-1 se utilizaron como marcadores de la fracción citosólica y la nuclear respectivamente. (C) Cuantificación del porcentaje de YAP-Flag y de YAP(5SA)-FLAG-Flag localizado en el núcleo en el experimento del apartado (B). (D) Cuantificación con ImageJ de la distribución de Flag en imágenes de inmunofluorescencia de células que fueron transfectadas con las construcciones YAP-Flag Y YAP(5SA)-FLAG-Flag. $n=6-11$ (E) Imágenes representativas de las cuatro condiciones cuantificadas en el apartado. F-actina se marcó con faloidina conjugada con el fluoróforo Alexa647 (rojo), el epítopo Flag con un monoclonal específico (verde) y el núcleo con Hoechst (azul). Los datos están representados cómo la media \pm SEM. $* * * * P<0.0005$. 
Posteriormente analizamos la actividad transcripcional de YAP en células transfectadas con las dos construcciones anteriormente citadas, cuantificando la expresión de Ctgf y Ankrd1 por RT-qPCR (Figura 29A). Se observó de este modo que la expresión de la construcción YAPFlag aumentaba la expresión de Ctgf y Ankrd1 únicamente en células que expresaban CAV1, mientras que la expresión de la isoforma no fosforilable YAP(5SA)-FLAG aumentaba la expresión de ambos transcritos tanto en células WT cómo en Cav1KO. Se analizó también la actividad transcripcional de TEAD usando para ello el reportero 8xGTIIC-lux tras la sobreexpresión de YAPFlag y YAP(5SA)-FLAG. Del mismo modo que en el caso de la expresión de los genes regulados por YAP, la actividad de TEAD aumentaba únicamente en las células WT al expresar YAP-Flag, mientras que al expresar la construcción YAP(5SA)-FLAG la actividad del gen reportero aumentaba tanto en células WT como en las Cav1KO (Figura 29B). Estos resultados permiten concluir que la retención de YAP en el citosol en las células Cav1KO es dependiente de la fosforilación de YAP en sus residuos de serina reguladores.

A

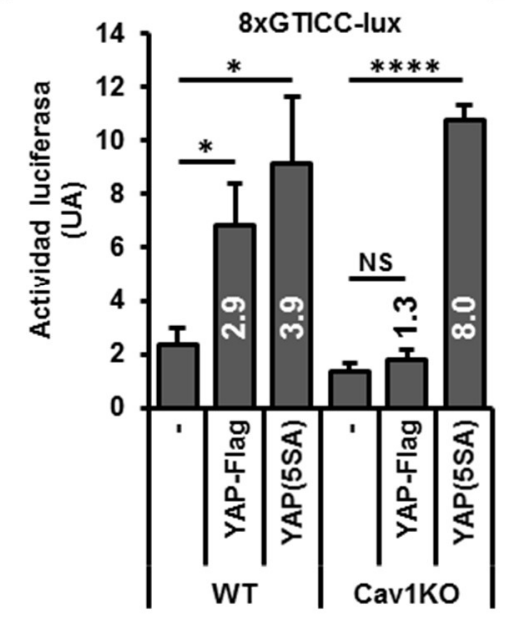

B

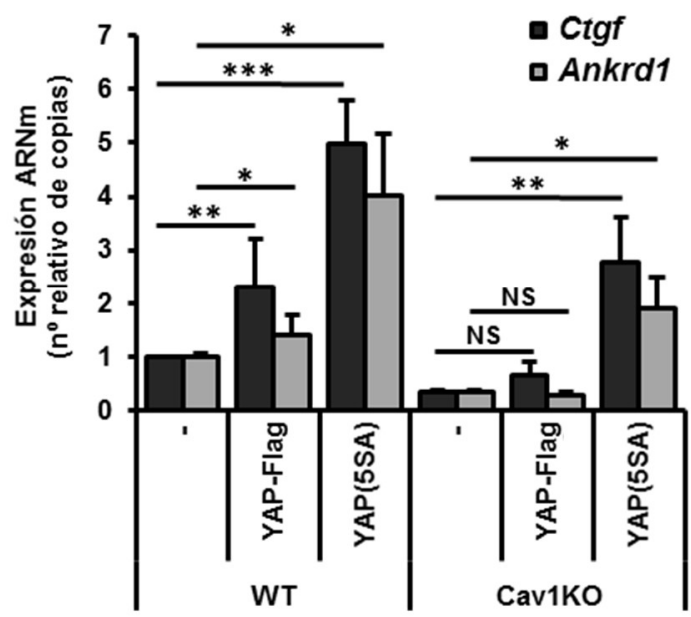

Figura 29. El mutante no fosforilable YAP(5SA)-FLAG rescata la actividad transcripcional de YAP en MEF Cav1KO. (A) Medida de la actividad luciferasa en MEF WT y Cav1KO expresando el co-transfectadas con el vector 8xGTIIC-luciferasa junto con las construcciones YAP-Flag, YAP(5SA)-FLAG-Flag o únicamente con los reporteros y crecidas sobre sustratos rígidos durante $24 \mathrm{~h}$. Los datos están normalizados con respecto a los valores de actividad luciferasa obtenidos para células creciendo en sustratos blandos en cada una de las condiciones estudiadas. El incremento relativo de la actividad luciferasa en las células transfectadas con las construcciones de YAP con respecto a las células transfectadas únicamente con el reportero está indicado sobre las barras del gráfico. n=3. (B) Análisis de la expresión de Ctgf y Ankrd1 mediante RT-qPCR en MEF WT y Cav1KO transfectadas con los vectores YAP-Flag y YAP(5SA)-FLAG-Flag y sin transfectar. Los datos en cada réplica se normalizaron con respecto a los valores obtenidos en células WT sin transfectar. $\mathrm{n}=4$. Los datos están representados cómo la media \pm SEM. ${ }^{*} \mathrm{P}<0.05,{ }^{*} * \mathrm{P}<0.01,{ }^{*} * * \mathrm{P}<0.005, \mathrm{y}$ $* * * * P<0.0005$. 


\subsubsection{CAV1 regula la dinámica del citoesqueleto de actina}

Existen evidencias experimentales acerca del papel que el citoesqueleto de actina desempeña en la regulación de la actividad de YAP (Dupont et al., 2011; Reddy et al., 2013; Wada et al., 2011; Zhao et al., 2012). También ha sido demostrada la regulación en el sentido inverso, ya que se sabe que YAP afecta directamente a la dinámica del citoesqueleto de actina (Matsui and Lai, 2013; Qiao et al., 2017). A la vista de esta asociación estrecha entre la dinámica del citoesqueleto de actina y la regulación de YAP, y considerando la conexión física existente entre las fibras de actina con CAV1 y caveolas (Muriel et al., 2011; Stahlhut and van Deurs, 2000) y el control que CAV1 ejerce sobre la dinámica y distribución de la actina y las adhesiones focales (Grande-Garcia et al., 2007), decidimos estudiar la implicación de ese componente estructural de las células en los fenotipos observados en nuestro sistema. Para ello, primero estudiamos la organización de la actina en MEFs WT y Cav1KO en dos contextos celulares diferentes: sobre una matriz rígida homogénea; o creciendo las células en micropatrones de tamaños predefinidos para estudiar las células de forma individual y eliminando la variable de la morfología celular. La organización de la actina se midió a partir de imágenes obtenidas por microscopia de fluorescencia en las que se marcó utilizando faloidina conjugada con un fluoróforo. En las imágenes obtenidas se calculó la anisotropía, como medida del alineamiento de las fibras (tal y cómo se detalla en la sección de materiales y métodos). De este modo pudimos apreciar que en las células Cav1KO el citoesqueleto de actina estaba más desorganizado que en las células WT (Figura 30A, 30B y 30C), tanto en las células creciendo sobre una MEC rígida como en las células sembradas en los micropatrones. Estas observaciones confirmaban el papel de CAV1 como regulador de la organización del citoesqueleto de actina.

Al analizar la distribución de actina en los patrones predefinidos observamos que, en los patrones más pequeños, en los que YAP se encuentra retenido en el citosol (Figura 25), la actina estaba completamente desorganizada (Figura 30D). Y, lo que es aún más interesante, observamos que la distribución de CAV1 presentaba un alineamiento casi perfecto con la actina en los patrones más grandes, en los que esta está más organizada y YAP presenta una distribución nuclear (Figura 25), mientras que en los patrones más pequeños esa distribución alineada de la CAV1 desaparecía, conjuntamente con la desaparición de las fibras de estrés, y su distribución pasaba a ser similar a la observada en las células creciendo en una MEC blanda, encontrándose acumulada en la región perinuclear. Este resultado sugiere que la conexión CAV1-actina es también dependiente de la morfología celular. 
A
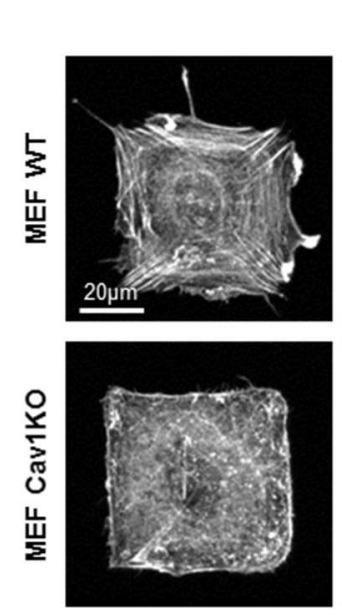

F-actina
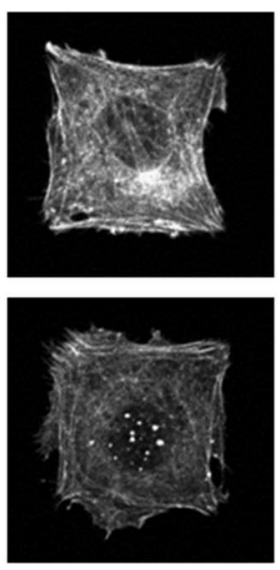

B

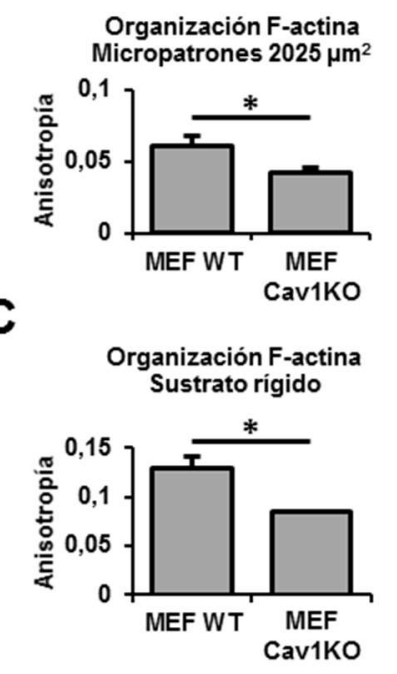

D
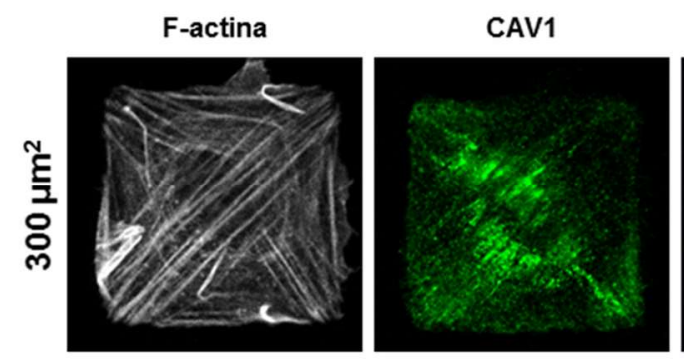

Composición
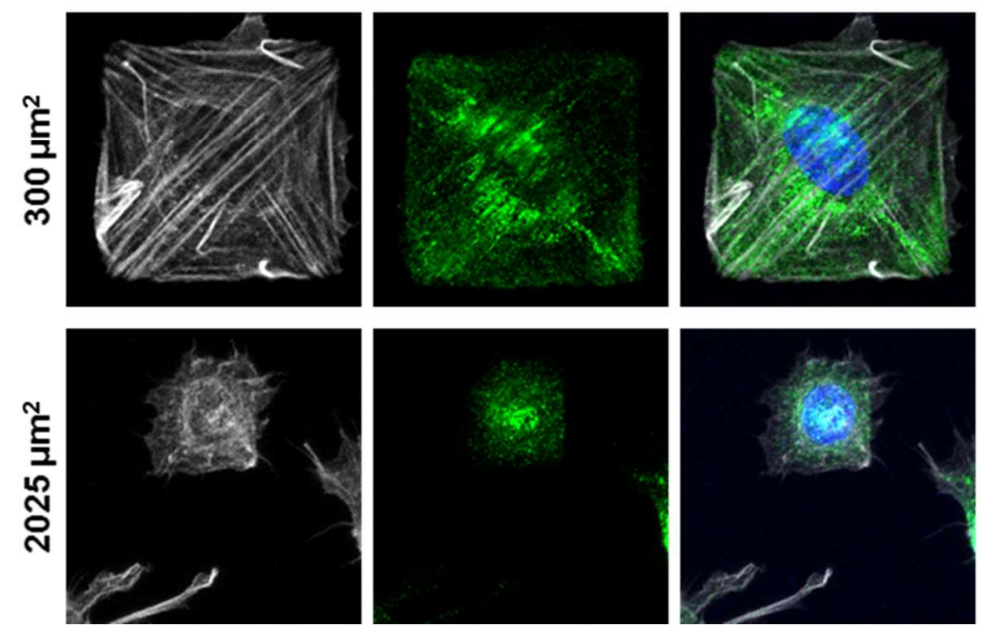

Figura 30. La expresión de CAV1 afecta a la organización de la actina. (A) Imágenes de microscopía confocal de fluorescencia en las que se muestra la distribución de F-actina (marcada con faloidina conjugada con un fluoróforo) en MEFs WT y Cav1KO creciendo sobre micropatrones cuadrados de $2025 \mu \mathrm{m}^{2}$ durante $24 \mathrm{~h}$. (B) Cuantificación de la anisotropía (orden/organización) de las fibras de actina en MEFs WT y Cav1KO creciendo sobre micropatrones de $2025 \mu \mathrm{m}^{2}$. $n=7-10$. (C) Cuantificación de la anisotropía de las fibras de actina en MEFs WT y Cav1KO creciendo sobre una MEC rígida. $n=3$. (D) Estudio mediante microscopía confocal de la distribución de CAV1 (inmunodetectada con un anticuerpo monoclonal de conejo específico; verde) y actina (marcada con faloidina conjugada; rojo) en células WT creciendo sobre micropatrones cuadrados con dos tamaños diferentes. El núcleo se marcó con Hoechst (azul). Los datos están representados como la media \pm SEM. ${ }^{*} \mathrm{P}<0.05$.

\subsubsection{La regulación de YAP por CAV1 es dependiente de la dinámica de actina}

La organización del citoesqueleto de actina aumenta en paralelo a la rigidez de la MEC (Engler et al., 2006) y tiene un papel clave en la mecanotransducción de señales provenientes de la MEC. Esas observaciones junto con la regulación de la dinámica del citoesqueleto de actina por CAV1, descrita en el apartado anterior, sugerían una posible implicación de este 
componente estructural en los fenotipos observados. Para estudiar esta hipótesis utilizamos dos drogas: una droga que estabiliza e induce la polimerización de los filamentos de actina (Figura 31A y 31B) denominada jasplakinolide (Casella et al., 1981; Holzinger, 2009) y otra que actúa como inhibidor de la polimerización de los filamentos de actina (Figura 32A) llamada citocalasina D (CytD). La despolimerización de los filamentos de actina con CytD inducía la retención de YAP en el citosol en MEF WT, mientras que la inducción de la polimerización de actina con jasplakinolide aumentaba la translocación de YAP al núcleo tanto en células WT como Cav1KO (Figura 32A, 32B y 32C). Estas observaciones se confirmaron también mediante el análisis por WB de las fracciones citosólica y nuclear de células WT y Cav1KO tras el tratamiento con ambas drogas (Figura 32D). En el caso de las células Cav1KO la acumulación de YAP en el núcleo llega a alcanzar los niveles observados en las células WT, indicando que la defectiva polimerización de la actina podría ser responsable de la retención citosólica de YAP en estas células.

A

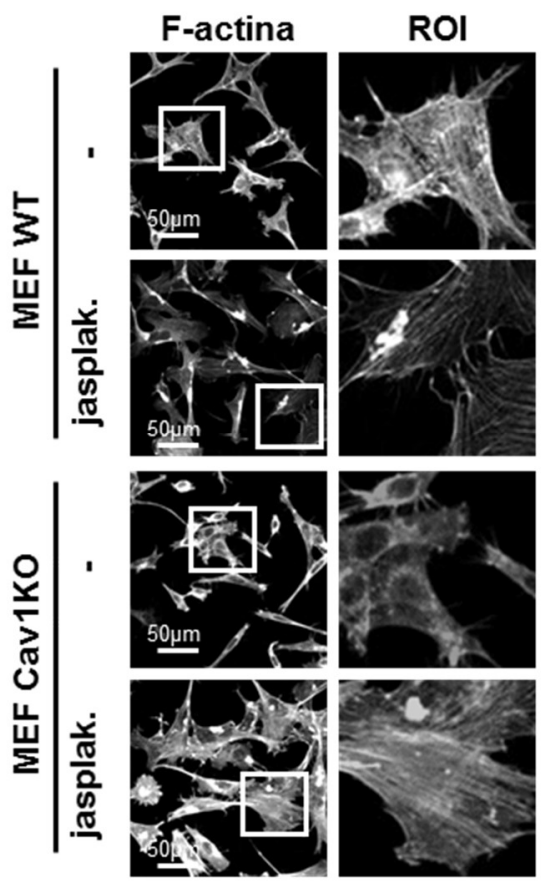

B
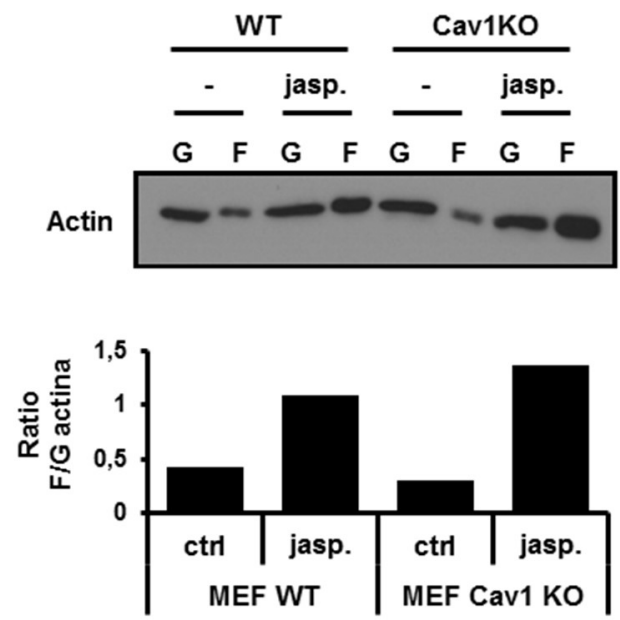

Figura 31. El tratamiento con jasplakinolide aumenta la polimerización de actina en células Cav1KO. (A) Imágenes de microscopia confocal de fluorescencia de F-actina (marcada con faloidina conjugada con un fluoróforo) en MEF WT y Cav1KO tratadas durante 24h con jasplakinolide (0,05 $\mu \mathrm{M})$ o DMSO. (B) Análisis de los niveles de actina filamentosa (F) y globular (G) mediante WB en MEFs WT y Cav1KO tratadas durante $24 \mathrm{~h}$ con jasplakinolide $(0,05 \mu \mathrm{M})$ o DMSO. La F y G-actina se separaron in vitro usando un kit específico para tal propósito. El gráfico situado en la parte inferior de la figura corresponde a la cuantificación del WB por densitometría. 
A

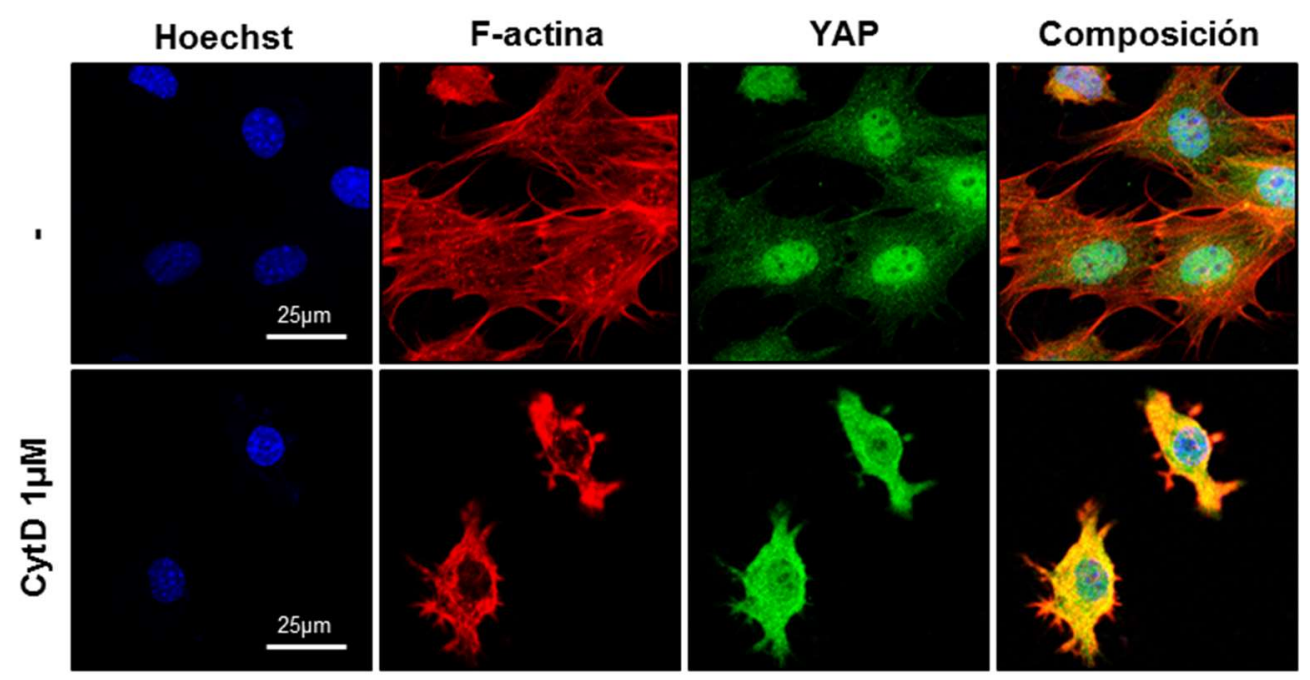

B
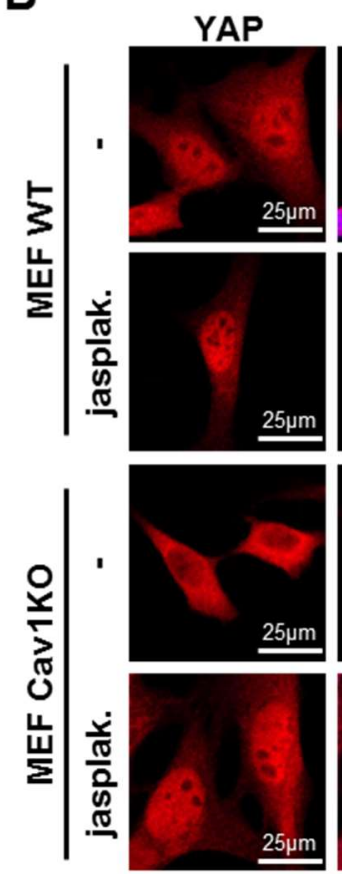

C
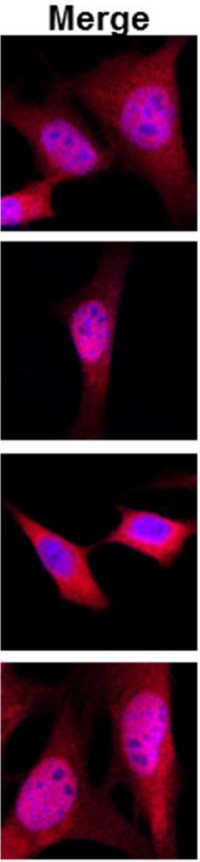

D
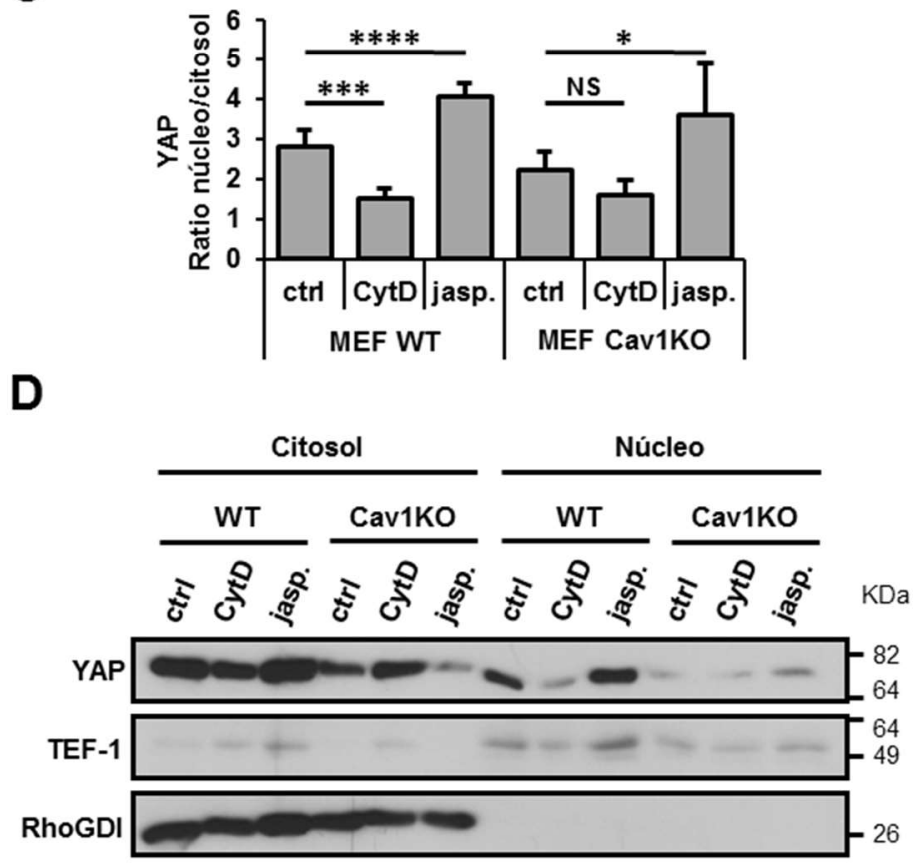

Figura 32. La polimerización de actina determina la deficiente translocación de YAP al núcleo en Cav1KO. (A) Imágenes de microscopía confocal de fluorescencia en las que se muestra YAP (marcado con un anticuerpo monoclonal; verde) y F-actina (marcada con faloidina conjugada; rojo) en MEF WT tratadas durante $24 \mathrm{~h}$ con CytD (1 $\mu \mathrm{M})$ o DMSO. El núcleo se marcó con Hoechst (azul). (B) Imágenes de microscopía confocal de fluorescencia en las que se muestra YAP en MEF WT y Cav1KO tratadas durante 24h con jasplakinolide $(0,05 \mu \mathrm{M})$ o DMSO. El núcleo se marcó con Hoechst. (C) Cuantificación con ImageJ de la distribución subcelular de YAP en MEF WT y Cav1KO tratadas con CytD y jasplakinolide como en (A) y (B). Los datos fueron obtenidos de 3-8 experimentos independientes y representados como la media \pm SD; $* \mathrm{P}<0.05, * * * \mathrm{P}<0.005, \mathrm{y} * * * * \mathrm{P}<0.0005$. (D) Análisis de la distribución subcelular de YAP en MEF WT y Cav1KO tratadas durante $24 \mathrm{~h}$ con $1 \mu \mathrm{M}$ CytD o $0.05 \mu \mathrm{M}$ jasplakinolide (jasp.). Las fracciones nuclear y citosólica se separaron mediante un proceso de fraccionamiento bioquímico. RhoA-GDI y TEF-1 se usaron como marcadores de la fracción citosólica y nuclear respectivamente. 
Para comprobar que los cambios en la distribución de YAP correlacionaban con cambios en su actividad, analizamos los niveles de expresión de los genes que regula transcripcionalmente tras el tratamiento con CytD y jasplakinolide (Figura 33A). La inducción de la despolimerización de los filamentos de actina con CytD provocaba una bajada significativa en la expresión de Ctgf, Ankrd1 y Cyr61 en células WT, mientras que, en las Cav1KO, en las que el citoesqueleto de actina está más desorganizado, no se detectó una bajada relativa tan evidente. En el caso de la inducción de la polimerización de actina con jasplakinolide, pudimos observar un aumento en la expresión de los tres genes estudiados, siendo especialmente significativa en las células Cav1KO. Además, la expresión de un mutante constitutivamente activo de mDia1 (mDia1 $\Delta N 3$ ) que aumenta el ratio de polimerización de actina (Watanabe et al., 1999) también rescataba el defecto en la expresión de los genes regulados por YAP en las MEF Cav1KO (Figura 33B). Todos estos datos respaldaban nuestra hipótesis, sugiriendo que el defecto en la organización de actina es responsable directo de la bajada en la actividad de YAP en las células Cav1KO.

A

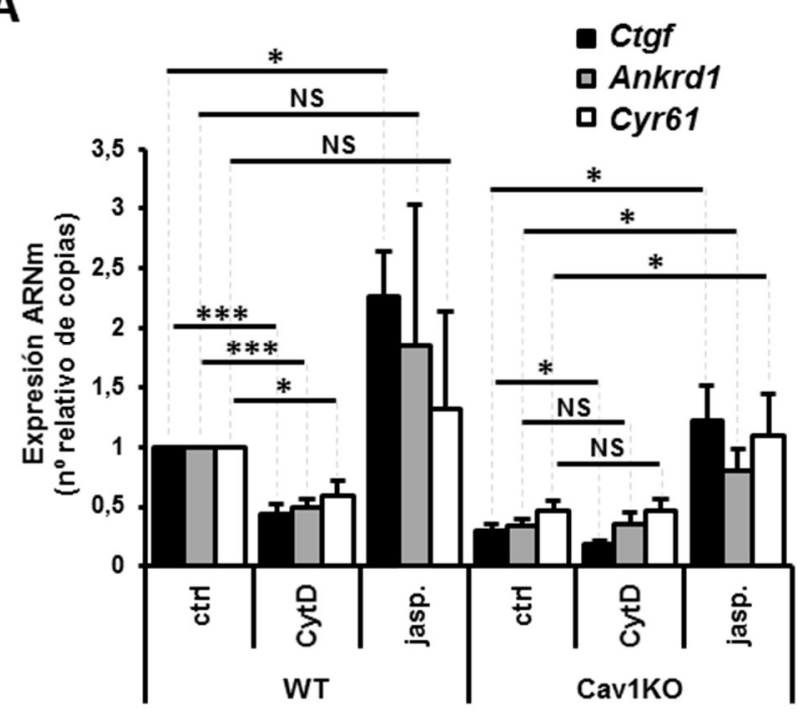

B

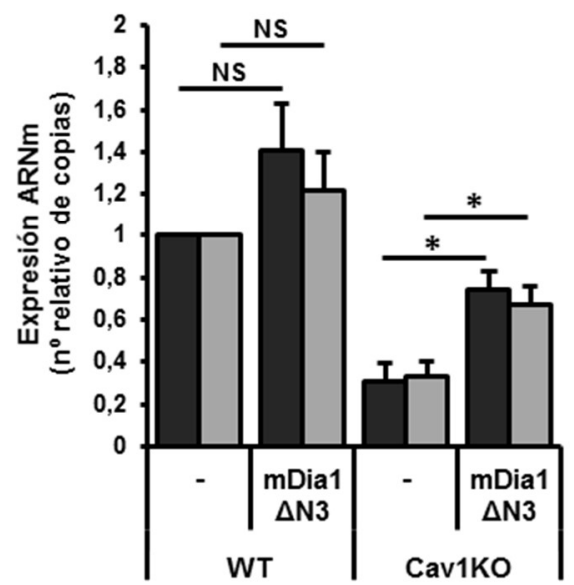

Figura 33. El tratamiento con jasplakinolide aumenta la polimerización de actina en células Cav1KO. (A) Análisis mediante RT-qPCR de la expresión de genes regulados por YAP en MEFs WT y Cav1KO tratadas durante $24 \mathrm{~h}$ con $1 \mu \mathrm{M}$ CytD, $0.05 \mu \mathrm{M}$ jasplakinolide, o DMSO (control). Los datos del tratamiento con jasplakinolide $(n=5)$ y CytD $(n=3)$ se normalizaron con respecto a los valores obtenidos en MEF WT tratadas con DMSO. (B) Análisis mediante RT-qPCR de la expresión de Ctgf y Ankrd1en MEF WT y Cav1KO transfectadas de manera transitoria con la isoforma constitutivamente de mDia1 (mDia $\Delta N 3)$ o transfectadas sin vector como control. Los datos se normalizaron con respecto a los valores obtenidos para las células WT transfectadas sin vector. $n=5$. Los datos están representados cómo la media \pm SEM ${ }^{*} \mathrm{P}<0.05, * * * \mathrm{P}<0.005$. 


\subsubsection{La regulación de YAP por CAV1 es independiente del control que CAV1 ejerce sobre la}

\section{actividad de RhoA}

CAV1 controla la contracción de actina-miosina a través de la regulación de la actividad de RhoA GTPasas (Goetz et al., 2011). Por otro lado, la regulación mecánica de YAP es también dependiente de esa contracción del citoesqueleto de actina-miosina (Dupont et al., 2011), lo cual sitúa el control de la función de RhoA cómo un posible mecanismo implicado en la regulación de la actividad de YAP por CAV1. Para evaluar el papel de RhoA en nuestro sistema decidimos utilizar Y27632, una droga que inhibe la actividad de las quinasas ROCK1/2, y por tanto bloquea la actividad de RhoA. La exposición de las células a esta droga inducía una bajada significativa en la expresión de Ctgf y Ankrd1 en células WT (Figura 34A), recapitulando lo observado en las células tratadas con CytD (Figura 33A), mientras que, como era de esperar, y tal y como ocurría también con el tratamiento con CytD, Y27632 tenía un efecto mucho menos notable en las células que no expresan CAV1, dado que en estas células YAP está menos activo.

Los resultados obtenidos con el inhibidor Y27632 confirmaban que la actividad de RhoA es necesaria para la activación de YAP en nuestro sistema, y, por tanto, la deficiente activación de RhoA en células Cav1KO podría explicar los fenotipos observados en estas células en cuanto a la actividad de YAP. Para evaluar esta posibilidad decidimos rescatar la actividad de RhoA en células Cav1KO para comprobar si ese rescate aumentaba la actividad de YAP. Así, decidimos silenciar el regulador negativo de Rho p190RhoGAP, una aproximación que anteriormente fue publicada como capaz de rescatar la actividad de RhoA en células sin CAV1, en las que p190RhoGAP se encuentra activo (Goetz et al., 2011; Grande-Garcia et al., 2007). Para silenciar p190RhoGAP decidimos expresar de manera estable, mediante transducción vírica, un ARN de interferencia corto horquillado (ARNch) (Figura 34B). Mediante esta aproximación se pudo comprobar que el rescate en la actividad de RhoA no aumentaba la expresión de los genes regulados por YAP en células Cav1KO (Figura 34C) ni afectaba a la translocación de YAP al núcleo (Figura 34D). Los resultados obtenidos indicaban por tanto que el rescate de la actividad de RhoA en las células Cav1KO no es suficiente para rescatar la actividad de YAP. Para confirmar este resultado se decidió aumentar la actividad de RhoA en las células Cav1KO mediante un abordaje diferente: expresar de forma transitoria una isoforma de RhoA constitutivamente activa (RhoA(V14)). La expresión de RhoA(V14) aumentaba la expresión de Ctgf y Ankrd1 en células WT, pero no aumentaba de forma significativa la expresión de los genes regulados por YAP en las células Cav1KO (Figura 34A). En conjunto, estos resultados sugieren que la modulación de la actividad de YAP por CAV1 es independiente de la regulación de RhoA. 
A

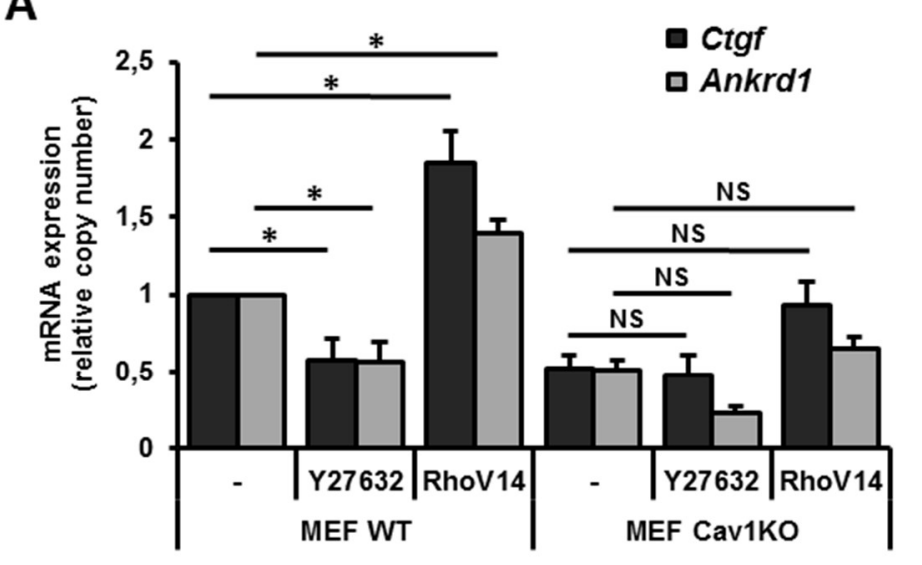

B

C

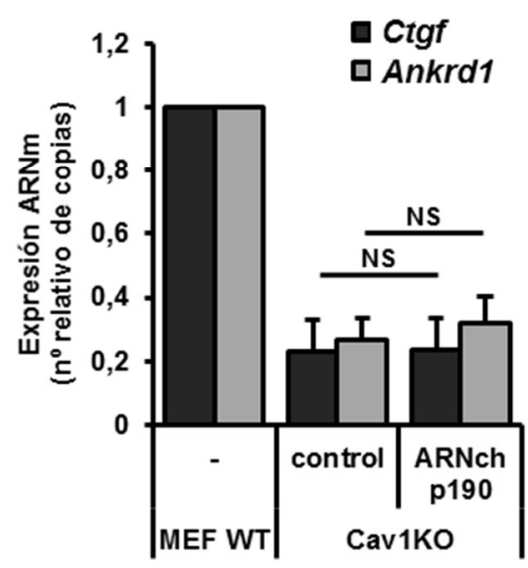

D

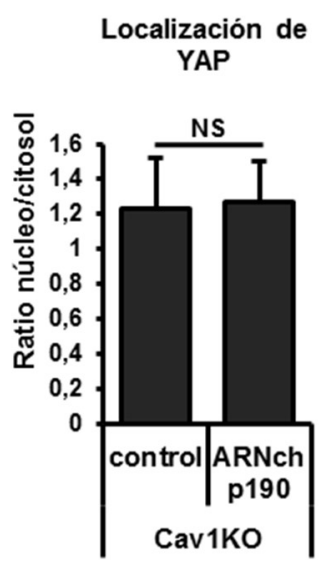

Figura 34. Las diferencias en la actividad de RhoA no son suficientes para explicar el defecto en la actividad de YAP en MEF Cav1KO. (A) Análisis mediante RT-qPCR de la expresión de Ctgf y Ankrd1 en MEFs WT y Cav1KO transfectadas con el mutante de RhoA constitutivamente activo RhoA(V14) o tratadas durante $24 \mathrm{~h}$ con el inhibidor Y27632 (25 $\mathrm{MM})$. Los datos fueron normalizados con respecto a los valores obtenidos en células WT sin transfectar y tratadas con DMSO. $n=4$. (B) Análisis mediante WB de la expresión de p190RhoGAP en MEF Cav1KO en las que se silenció de forma estable p190RhoGAP con un ARNch mediante la infección con retrovirus. GAPDH se utilizó como control de carga. (C) RT-qPCR de la expresión de Ctgf y Ankrd1 en MEFs Cav1KO en las que se silenció de forma estable p190RhoGAP con un ARNch mediante la infección con retrovirus, o infectadas con el correspondiente vector vacío como control. Los datos obtenidos se normalizaron con respecto a los valores obtenidos para células WT sin infectar. $n=4$. (D) Cuantificación con ImageJ de la localización subcelular de YAP en imágenes de microscopia confocal en las que se tiñó YAP y Hoechst. Se realizó la cuantificación en imágenes de MEFs Cav1KO en las que se expresó de forma estable un ARNch contra p190RhoGAP o el correspondiente vector vacío (control). En total se cuantificaron 30-40 células de diferentes imágenes y experimentos. Los datos están representados cómo la media $\pm S E M * P<0.05$.

\subsubsection{La regulación de YAP por la rigidez de la MEC y la dinámica de actina es dependiente de}

\section{la fosforilación de YAP}

Existe una gran controversia acerca del papel de la fosforilación de YAP en la regulación de su actividad en respuesta a estímulos mecánicos y a cambios en la dinámica del citoesqueleto de actina. Algunos autores sugieren que esta regulación es independiente de la fosforilación de YAP (Aragona et al., 2013; Dupont et al., 2011; Elosegui-Artola et al., 2017) y otros apuntan a 
que la fosforilación tiene un papel relevante (Chakraborty et al., 2017; Das et al., 2016). Para evaluar la implicación de la fosforilación en el control de la regulación mecánica de la actividad de YAP en nuestro sistema celular decidimos utilizar las YAP-Flag y YAP(5SA)-FLAG. La expresión de YAP(5SA)-FLAG en células creciendo sobre una MEC blanda o tratadas con CytD aumentaba la actividad transcripcional de YAP en estos contextos celulares (Figura 35A). Ese aumento observado con el mutante no fosforilable YAP(5SA)-FLAG sugiere que la fosforilación tiene un papel relevante en la inhibición de la actividad de YAP en condiciones de baja rigidez de la MEC o en condiciones en las que el citoesqueleto de actina esta despolimerizado. Para una mejor caracterización del papel de la fosforilación en la regulación de YAP dependiente de actina, se estudiaron también los niveles de fosforilación de YAP al tratar las células con CytD. Se trataron células WT y Cav1KO con CytD y, para analizar la reversibilidad de los efectos observados, se incluyó también una condición en la que el medio de las células previamente tratadas con CytD era reemplazado por medio $\sin C y t D$, induciendo de este modo la re-polimerización de la actina. De esta manera pudimos comprobar que la despolimerización de la actina en células WT inducía un aumento en la fosforilación de YAP en la serina situada en la posición 112 (Figura 35B), y que ese aumento era reversible, ya que al inducir la re-polimerización la fosforilación volvía a los niveles iniciales. En el caso de las células Cav1KO, en las que la actina está más desorganizada, la fosforilación de YAP no aumenta al tratar las células con CytD, tal y como era de esperar. Estos datos ponen de manifiesto la relevancia que tiene la fosforilación en la regulación de la actividad de YAP por cambios en la dinámica del citoesqueleto de actina. La rigidez de la MEC determina la dinámica y estructura del citoesqueleto de actina, y este a su vez controla la actividad de YAP en un proceso que depende de su fosforilación.

A

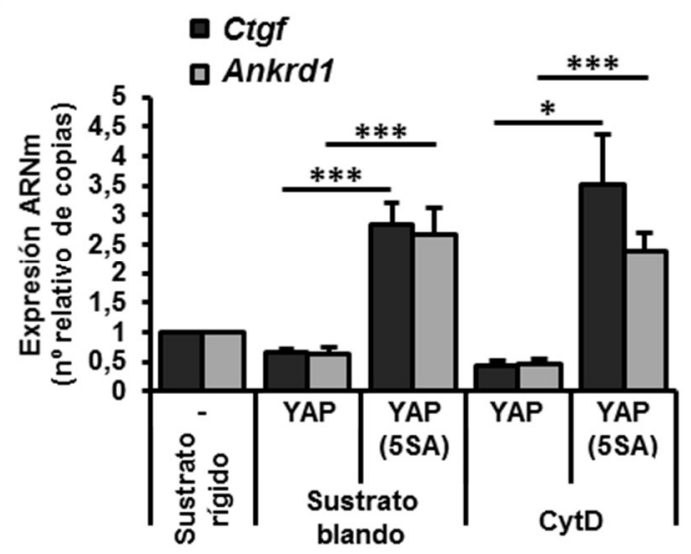

B

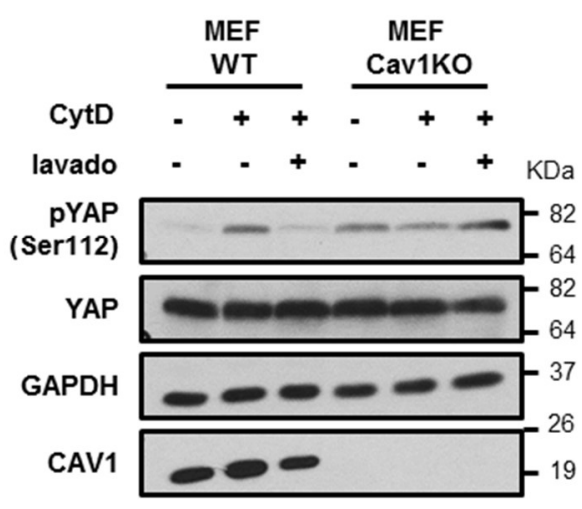

Figura 35. Las diferencias en la actividad de RhoA no son suficientes para explicar el defecto en la actividad de YAP en MEF Cav1KO. (A) Análisis por RT-qPCR de la expresión de Ctgf y Ankrd1 en MEF WT transfectados con los vectores YAP(S5A)-Flag, YAP-Flag o sin vectores, creciendo sobre sustratos blandos o tratadas con CytD $(1 \mu \mathrm{M})$ durante $24 \mathrm{~h}$. Los datos obtenidos se normalizaron con respecto a los valores obtenidos en la condición control, células WT transfectadas sin vector (-) creciendo sobre un sustrato 
rígido. $\mathrm{n}=6$. (B) Inmunodetección por WB de los niveles de fosforilación de YAP en Se112 en MEF WT y Cav1KO tratadas durante $24 \mathrm{~h}$ con CytD $(1 \mu \mathrm{M})$ o DMSO, o tratadas con CytD y luego lavadas con medio fresco. YAP total, GAPDH y CAV1 se utilizaron como controles internos. Los datos están representados cómo la media $\pm S E M * P<0.05,{ }^{* * *} \mathrm{P}<0.005 \mathrm{y} * * * * \mathrm{P}<0.0005$.

\subsubsection{Papel de diferentes quinasas en el aumento de la fosforilación de YAP en ausencia de}

\section{CAV1}

La fosforilación de YAP puede estar mediada por diferentes quinasas, de entre las cuales las que tienen un papel más relevante y están mejor caracterizadas son las LATS1 y LATS2 quinasas (Zhao et al., 2007). Para estudiar la posible implicación de estas quinasas en la regulación CAV1-YAP se decidió silenciar la expresión de ambos genes mediante la transfección de ARNi (Figura 36A, 36B y 36C). El silenciamiento de Lats1 y Lats2 sólo inducía una leve bajada en la fosforilación de YAP, similar en células WT y Cav1KO (Figura 36A). Se vio además que esa bajada en la fosforilación coincidía con un ligero aumento en la expresión de Ctgfy Ankrd1 tanto en células WT cómo en Cav1KO (Figura 36B). Se analizó también la actividad de TEAD utilizando el reportero de luciferasa específico, observándose también un aumento en la actividad de TEAD tanto en células WT como en Cav1KO (Figura 36D). Estos resultados sugieren que, aunque LATS1 y LATS2 contribuyen a la regulación de la actividad de YAP en nuestro sistema, no son los efectores claves que determinan las diferencias entre las células WT y Cav1KO.

LATS1 y LATS2 son los componentes últimos de la cascada de quinasas que conforma la vía de señalización Hippo. Por encima de esta cascada, controlando su actividad quinasa, se han identificado otras proteínas, cómo es el caso de la proteína NF2 (Zhang et al., 2010). NF2, al igual que CAV1, está localizada en dominios de membrana enriquecidos en colesterol y esfingolípidos (CEMM; del inglés colesterol-enriched membrane microdomains) determinando esa localización su actividad quinasa (Stickney et al., 2004). La ausencia de CAV1 afecta a la distribución y organización de estos dominios ordenados en la membrana plasmática (Gaus et al., 2006; Roy et al., 1999), potencialmente afectando así a la actividad de NF2. Este regulador aparecía, por tanto, como un candidato potencial en el establecimiento de las diferencias observadas en la fosforilación de YAP entre células WT y Cav1KO. Para investigarlo se utilizó un ARNi específico contra Nf2 que reducía de manera significativa la expresión de Nf2 (Figura 36E). El silenciamiento de $N f 2$ provocaba un incremento significativo en la expresión de los genes regulados por YAP en MEF WT, mientras que en MEF Cav1KO no tenía ningún efecto (Figura 36F). Esta observación permitió descartar el papel de NF2 en la inhibición de YAP en células que no expresan CAV1. Además el hecho de que el silenciamiento de CAV1 disminuyese la actividad 
de YAP en células MDA-MB-231, que no expresan NF2 (Dupont et al., 2011), también apunta en la misma dirección.

A

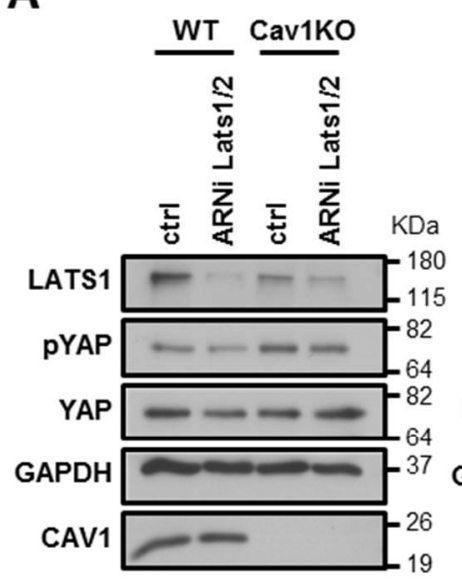

C

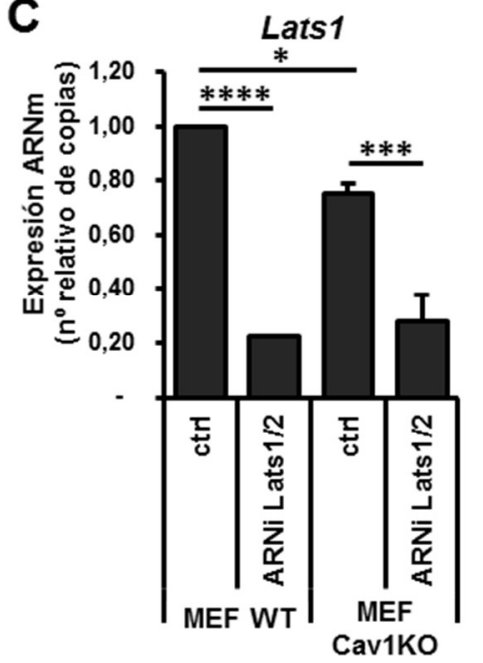

B

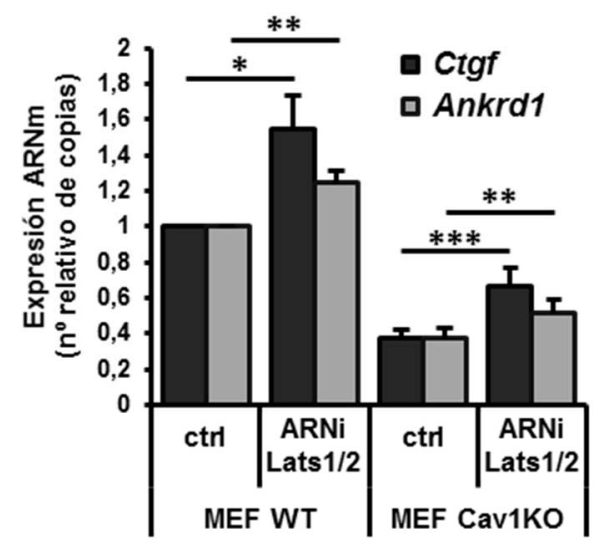

D

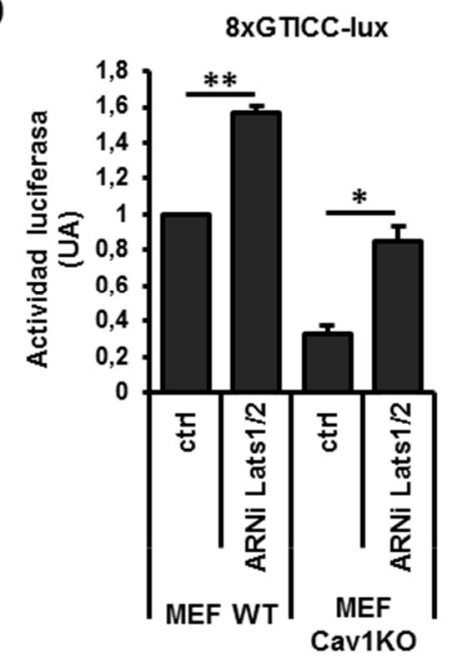

$\mathbf{E}$

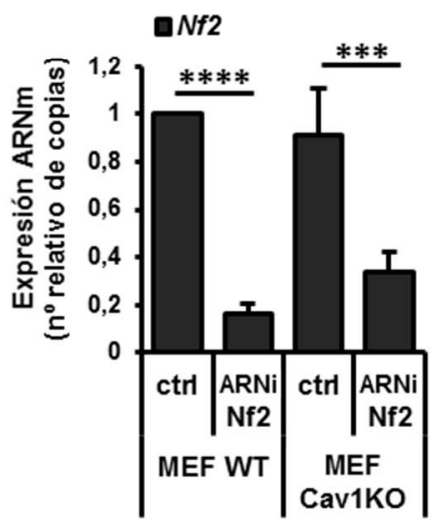

Lats2

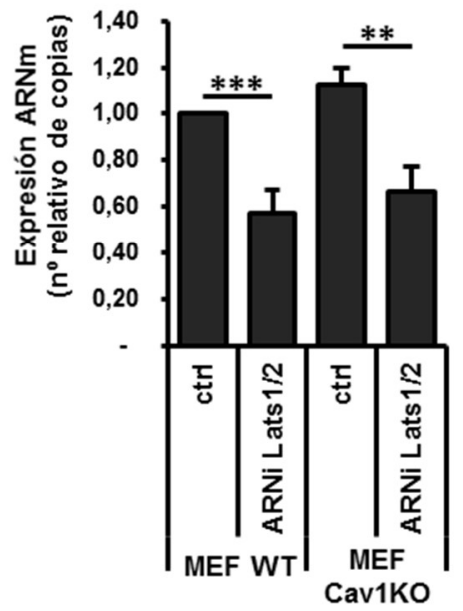

Ctgf 口. Ankrd1

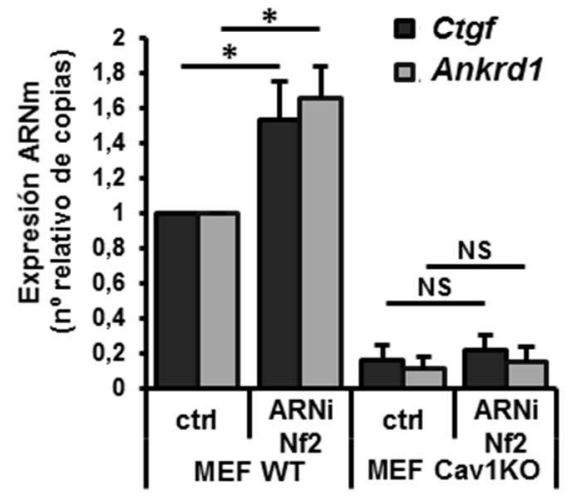

Figura 36. Las quinasas LATS1/2 no determinan las diferencias entre MEF WT y Cav1KO. (A) WB para la detección de LATS1 y LATS2, CAV1, YAP fosforilado en S112 y YAP total en células transfectadas con ARNi contra LATS1 y LATS2 o un ARNi control. GAPH se utilizó como control de carga. (B) Análisis mediante RTqPCR de la expresión de Ctgf y Ankrd1 en MEF WT y Cav1KO en las que se Silenció Lats1 y Lats2 igual que 
en (A). Los datos se normalizaron con respecto al valor de las células WT transfectadas con el ARNi control. $n=10$. (C) Expresión de LATS1 y LATS2 en el experimento (B). Los datos se normalizaron con respecto al valor de las células WT transfectadas con el ARNi control. $n=6$. (D) Medida de la actividad transcripcional de TEAD utilizando el reportero 8xGTICC-lux en MEF WT y Cav1KO transfectadas con ARNi contra LATS1 y LATS2 o un ARNi control. Los valores obtenidos se normalizaron con respecto al valor obtenido con las células WT transfectadas con el ARNi control en cada experimento. n=3. (E y F) Expresión de Nf2 (E) Ctgf y Ankrd1 (F) en MEF WT y Cav1KO transfectadas con ARNi contra Nf2 o un ARNi control. Los datos se normalizaron con respecto al valor de las células WT transfectadas con el ARNi control. $\mathrm{n}=4$. Los datos están representados cómo la media \pm SEM); ${ }^{*} \mathrm{P}<0.05, * * \mathrm{P}<0.01, * * * \mathrm{P}<0.005$ y $* * * * P<0.0005$.

\subsubsection{El control del flujo de $\mathrm{Ca}^{2+}$ determina la regulación CAV1-YAP}

Se ha descrito que el flujo de $\mathrm{Ca}^{2+}$ es dependiente de la rigidez del sustrato y que es determinante para el control de la actividad de YAP (Pathak et al., 2014). Por otro lado, se sabe también que existe una estrecha relación de CAV1 y caveolas con el funcionamiento de diferentes canales de calcio, Hasta el punto de que muchos de esos canales han sido identificados en caveolas (Brazer et al., 2003; Pani and Singh, 2009). Teniendo en cuenta estas observaciones previas, aparecía como una hipótesis plausible la regulación mecánica de la actividad de YAP a través del control del flujo de $\mathrm{Ca}^{2+}$ por CAV1/caveolas.

Para confirmar el papel del $\mathrm{Ca}^{2+}$ en la regulación de la actividad de YAP en MEFs se analizó la expresión de Ctgf y Ankrd1 por RT-qPCR en ausencia y presencia de este ion. Como era de esperar la ausencia de $\mathrm{Ca}^{2+}$ provocaba una bajada en los niveles de expresión de ambos genes en células WT, mientras que, en las Cav1KO, en las que YAP no está activo, no tenía ningún efecto (Figura 37A). Se estudió también el efecto del $\mathrm{Ca}^{2+}$ en la fosforilación de YAP (Figura 37B). La ausencia de suero provocaba un aumento de la fosforilación de YAP en células WT, tal y como está descrito en numerosas publicaciones (Adler et al., 2013; Miller et al., 2012). Para ver el papel del $\mathrm{Ca}^{2+}$ se utilizó medio de cultivo con o $\sin \mathrm{Ca} 2+$ suplementado con un $0,5 \%$ de suero (ya que como hemos visto el suero es necesario para la activación de YAP). De esta forma se comprobó que la ausencia de $\mathrm{Ca}^{2+}$ aumentaba la fosforilación de YAP en células WT (Figura 37B). Cabe destacar también que en este experimento no se apreciaron cambios en la fosforilación de YAP en MEF Cav1KO, dado que la fosforilación de YAP en estas células ya es elevada en condiciones basales. Estos resultados confirman el requerimiento de la señalización por $\mathrm{Ca}^{2+}$ para la actividad de YAP en nuestras células. 
A

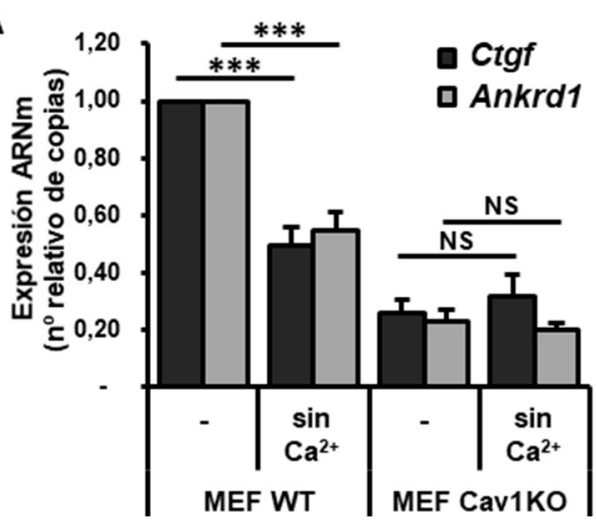

B

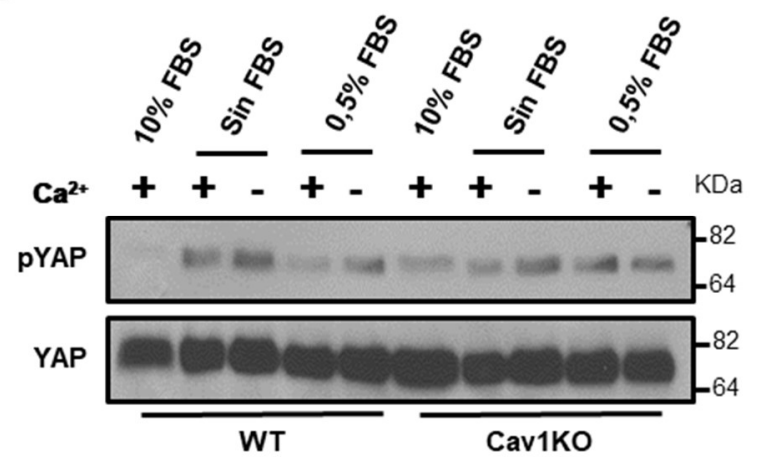

Figura 37. EL $\mathrm{Ca}^{2+}$ es necesario para la activación de YAP en MEF WT. (A) Análisis mediante RT-qPCR de la expresión de Ctgf y Ankrd1 en MEF WT y Cav1KO cultivadas en presencia o ausencia de calcio con un $0,5 \%$ de suero (FBS) durante $24 \mathrm{~h}$. Los datos se normalizaron con respecto al valor de las células WT crecidas en medio con suero. $n=4$. (B) Análisis por WB de los niveles de YAP fosforilado en S112 y YAP total en células cultivadas en presencia o ausencia de calcio igual que en (A) o sin FBS. Los datos están representados cómo la media \pm SEM); ${ }^{* * *} \mathrm{P}<0.005$.

Dado que el $\mathrm{Ca}^{2+}$ aparecía como un factor de señalización importante, se decidió investigar si determinaba la deficiente actividad de YAP en células Cav1KO. Para ello se utilizó una droga llamada tapsigargina, que es capaz de aumentar los niveles de calcio en el citosol al bloquear la bomba Ca+-ATPasa del RE (Razani-Boroujerdi et al., 1994; Thastrup et al., 1990). Usando este inhibidor farmacológico se observó un aumento en la actividad transcripcional de YAP en células Cav1KO (Figura 38A). Curiosamente en células creciendo sobre sustratos blandos también se vio un incremento de la actividad de YAP, incluso mayor, llegando a superar incluso los niveles de actividad observados en células creciendo sobre sustratos rígidos. El rescate en la actividad de YAP en células Cav1KO correlacionaba con un aumento de la translocación de esta proteína al núcleo (Figura 38B) y con una bajada en sus niveles de fosforilación (Figura 38C).

El tratamiento con tapsigargina, además de aumentar los niveles de $\mathrm{Ca}^{2+}$ en el citosol, induce estrés del RE y activa la respuesta a proteínas mal plegadas (UPR, de sus siglas en ingle Unfolded Protein Response). Para descartar la posible influencia del estrés del retículo y la UPR en los cambios observados en la actividad de YAP se decidió usar otra droga, tunicamicina, que al igual que tapsigargina inducía la UPR cómo se puede observar por el aumento en la fosforilación del factor de iniciación traduccionalelF2 $\alpha$ (Figura 38D) (Ron and Walter, 2007), pero sin afectar a la bomba Ca ${ }^{2+}$-ATPasa (Guha et al., 2017). De este modo se observó que el tratamiento con tunicamicina no aumentaba la actividad de YAP ni en células WT ni en Cav1KO, apreciándose incluso una pequeña bajada en células WT (Figura 38E). Estos datos permitieron descartar el papel del estrés del RE y de la UPR en el aumento de la actividad de YAP en MEF 
Cav1KO tratadas con tapsigargina, apoyando la implicación de los niveles intracelulares de $\mathrm{Ca}^{2+}$ en esa regulación.

A

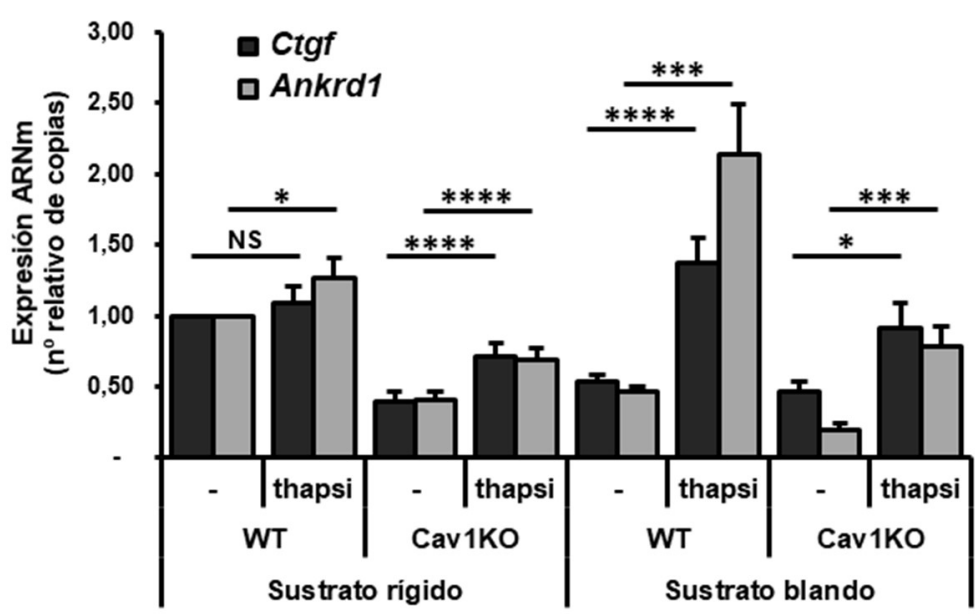

B

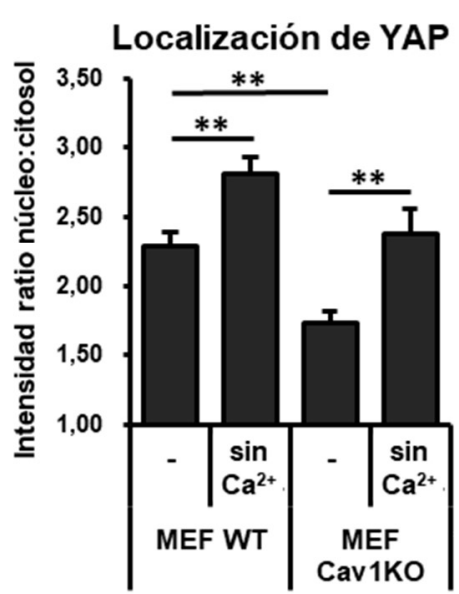

C

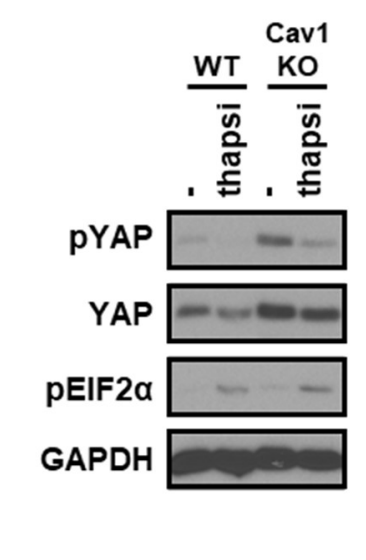

D

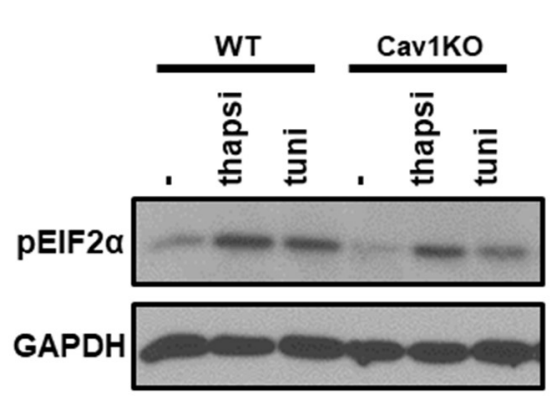

E

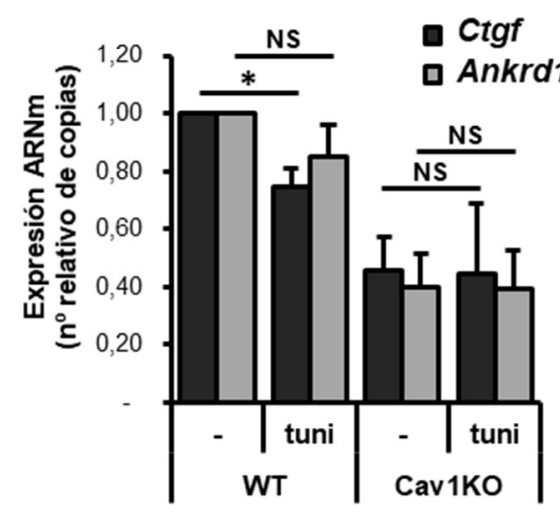

Figura 38. El aumento de los niveles de $\mathrm{Ca}^{2+}$ intracelular rescata la actividad de YAP en MEF Cav1KO. (A) Análisis de la expresión de Ctgf y Ankrd1 mediante RT-qPCR en células WT y Cav1KO creciendo sobre sustratos rígidos o blandos y tratados con tapsigargina (tapsi; 300nM) o DMSO (-). Todos los valores se normalizaron con respecto a los obtenidos en células WT sobre sustratos rígidos y tratadas con DMSO en cada uno de los replicados del experimento. $n=10$. (B) Cuantificación de la distribución subcelular de YAP en células WT y Cav1KO tratadas durante $24 \mathrm{~h}$ con tapsigargina (tapsi; 300nM) o DMSO (-). Se analizaron diferentes imágenes de cuatro experimentos independientes, $n=4$. (C) Estudio mediante WB de los niveles de expresión de YAP fosforilado en S112 y YAP total en células WT y Cav1KO tratadas durante 24h con 
tapsigargina (tapsi; 300nM) o DMSO. Se estudiaron también los niveles de pEIF2 para evaluar el estrés provocado por la droga y GAPDH se utilizó como control de carga. (D) Análisis por WB de los niveles de pEIF2 en células tratadas con tapsigargina y tunicamicina igual que en los apartados anteriores. GAPDH se utilizó como control de carga. (E) Estudio de la expresión de Ctgf y Ankrd1 mediante RT-qPCR en células WT y Cav1KO tratadas durante $24 \mathrm{~h}$ con tunicamicina (tuni) o DMSO (-). Todos los valores se normalizaron con respecto a los obtenidos en células WT tratadas con DMSO. $\mathrm{n}=6$. Los datos están representados cómo la media \pm SEM); ${ }^{*} \mathrm{P}<0.05,{ }^{*} \mathrm{P}<0.01, * * * \mathrm{P}<0.005 \mathrm{y} * * * * \mathrm{P}<0.0005$.

En conjunto, los resultados sugieren que las diferencias en la señalización por calcio podrían ser determinantes para explicar la deficiente actividad de YAP observadas en células sin CAV1, y también en condiciones de baja rigidez del sustrato.

\subsection{Estudio y caracterización de los cambios en el interactoma de YAP mediados por presencia/ausencia de CAV1 y la integridad del citoesqueleto de actina}

\subsubsection{Estudio del interactoma de YAP mediante espectrometría de masas}

Para identificar los mecanismos responsables del efecto de la dinámica de actina y de CAV1 en la actividad de YAP, se investigó el interactoma de YAP en MEF WT y Cav1KO, y en células WT tratadas con CytD. Para ello se inmunoprecipitaron YAP y las proteínas que interaccionan en cada condición con YAP, utilizando como cebo un anticuerpo monoclonal específico contra YAP; y las proteínas purificadas por afinidad mediante este método se identificaron por espectrometría de masas (Figura 39 y 40). Es importante resaltar que aunque el interactoma de YAP ya había sido analizado en trabajos anteriores (Couzens et al., 2013; Kohli et al., 2014; Wang et al., 2014), ésta es la primera vez en que se estudió en condiciones en que la polimerización de actina estaba afectada (en células Cav1KO y tras el tratamiento con CytD). Como control de la robustez del ensayo se identificó YAP, el cebo de la inmunoprecipitación, en todas las condiciones excepto en los controles negativos. Además, se identificaron otras proteínas previamente caracterizadas como interactores de YAP, como es el caso de AMOTL2 (Zhao et al., 2011), POLR2A (Gavva et al., 1997), RUNX1 (Levy et al., 2008), y varias proteínas de la familia 14-3-3, las proteínas YWHA (Couzens et al., 2013) y algunos interactores de componentes de la vía Hippo de señalización previamente caracterizados, como son RBM15, CORO1C, DBN1, DOCK7, LIMA1, MTCL1, PKP4, RAD21, Y SLMAP (Couzens et al., 2013). 
MEF WT

MEF Cav1KO

MEF WT +CytD

MEF Cav1KO +CytD
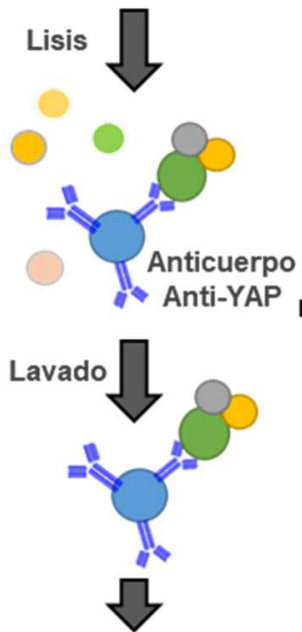

Espectrometria de masas

号, 曷

らミミ옹 YAP1 $\square$ HIST1H1E $\square \square$ WWTR1 $\square \square \square$ \begin{tabular}{l|l|l|l|} 
HPCAL1 & & & \\
\hline
\end{tabular} \begin{tabular}{l|l|l|l} 
RSL1D1 & & & \\
\hline
\end{tabular}

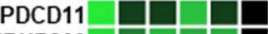
SNRNP200

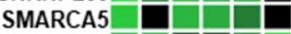

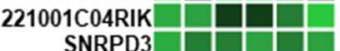
\begin{tabular}{l|l|l|l} 
SNRPD3 & & & \\
\hline
\end{tabular} WDR43

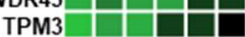

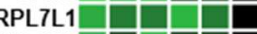

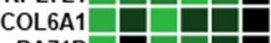
BAZ1B 1

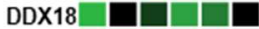

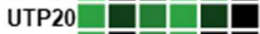

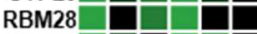

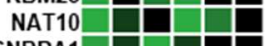
SNRPA1 $\square$ -

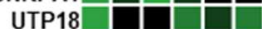

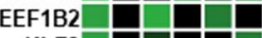
KLF2 $\square$ 口

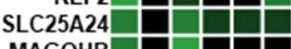
MAGOHB $\square$ -

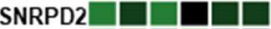

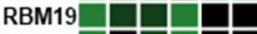

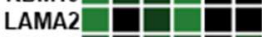

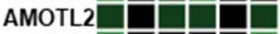
TPM2 $\square \square \square \square \square$

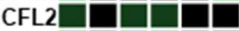
NUP153

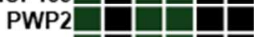

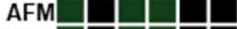
LRFN4

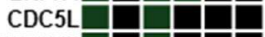

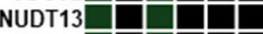

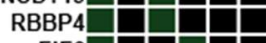

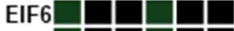

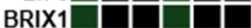

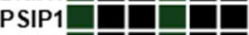

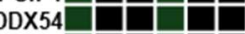

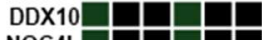

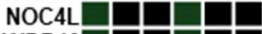

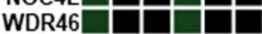
CLSTN3 10 :
TMEM263 $\square \square \square$

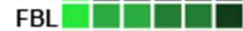

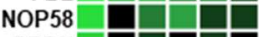

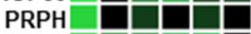

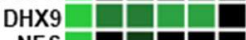

NES $\square \square \square \square$

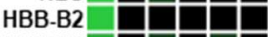

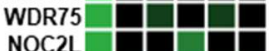

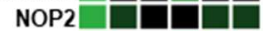

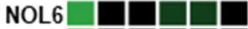

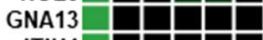
ITIH $4 \square \square \square \square \square$

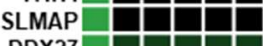

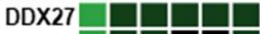

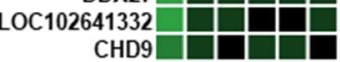
\begin{tabular}{r|rl|l|l} 
CHD9 & & & & \\
NOLC1 & & & & \\
\hline
\end{tabular}

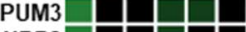

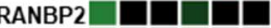
BOP1 $\square$ 口

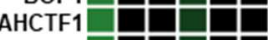
FAM160A2 $\square$ SKP1A $-{ }^{-1}$

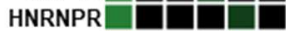

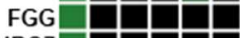

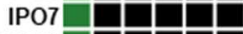
\begin{tabular}{l|l|l|l|l} 
KRT76 & & & & \\
\hline
\end{tabular}

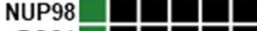
RCC1 10

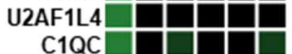

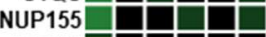
ACTN1 $\square$ -

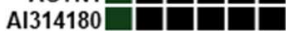
RUNX1

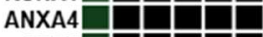

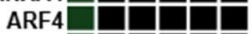
BMS1 $\square \square \square \square$

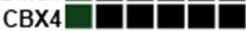

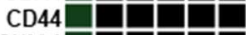

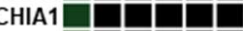

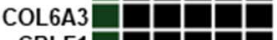
CRLF1 $\square\left[\begin{array}{lll}\hline & \end{array}\right.$ DDX49 $\square$ 口

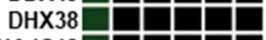

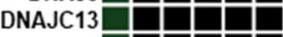

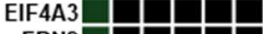

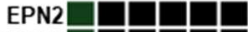

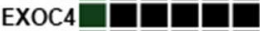

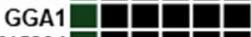

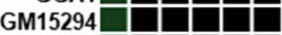

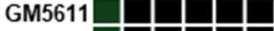
HRG $\square$ 口

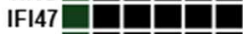

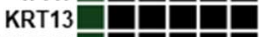

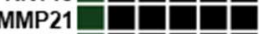

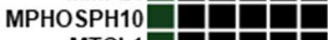

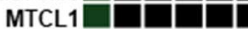

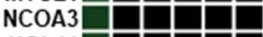

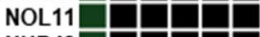

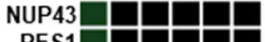

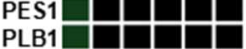

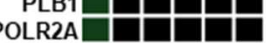
\begin{tabular}{lllllll} 
PPIG & & & & & \\
\hline
\end{tabular}

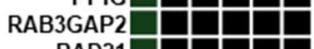

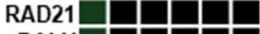
RALY $\square \square \square \square$

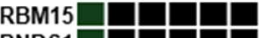

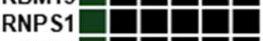

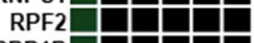

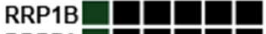
RRPTA $\square$ D

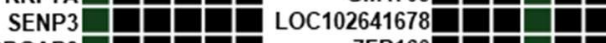

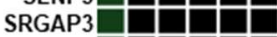

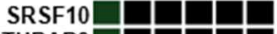

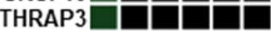

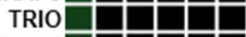

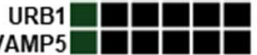

$$
\begin{aligned}
& 0 \\
& N^{0} \text { péptidos (media) }
\end{aligned}
$$

EPRS $-\square \square \square$ YWHAE

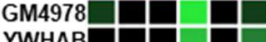
YWHAH RPS5 $\square \square \square \square \square$ HP1BP3 $\square \square \square \square \square$ KARS $\square \square \square-\square \square$ DDX47 $\square \square \square$ EEF1D $\square \square \square \square \square$

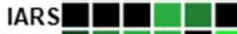
\begin{tabular}{l|l|l|l} 
YWHAQ & & & \\
MRPS5 & & & \\
\hline
\end{tabular} HMGN1 $\square \square \square \square$ DPY30 $\square \square \square$

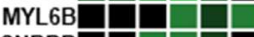

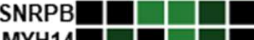

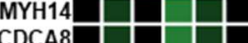
BYSL $\square \square \square \square$ TAF15 $\square \square \square \square \square \square$ EIF4A1 $\square \square \square \square \square \square$

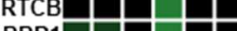
RASL2-9

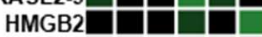
SMARCE1 $\square \square \square \square \square$ AIMP1 $\square \square \square \square \square$ H1F0 $\square \square \square \square$ CYC1 $\square \square \square \square$ OLFR1046 ILF2 $\square \square \square$ SPTBN1 $\square \square \square \square \square$ EIF5A $\square \square \square \square$ MCM7 $\square \square \square \square \square$

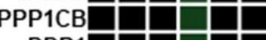

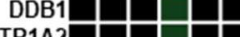

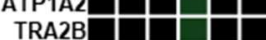

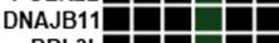

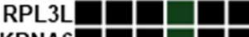
KPNA6 $\square \square \square$ YLPM1 $\square \square \square \square \square \square$ DDX24 $\square \square \square \square \square \square$ \begin{tabular}{l|l|l|l|l} 
PELP1 & & & & \\
\hline
\end{tabular} NSF $\square \square \square \square$

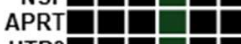
\begin{tabular}{ll|l|l|l} 
UTP3 & & & & \\
\hline
\end{tabular} \begin{tabular}{lllll}
\hline & &
\end{tabular} GOLGB1

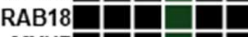

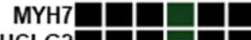

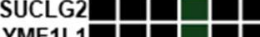
NDE1 $\square \square \square \square \square$

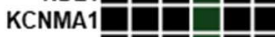

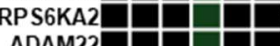

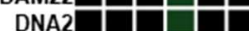
DSTYK $\square \square \square \square \square \square$

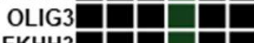

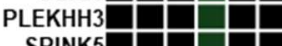
ANTXR1

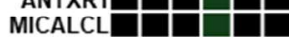

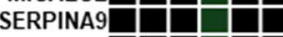
TBX5 $\square \square \square \square \square \square$ ADGRF4 $\square$ 口

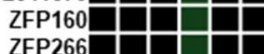
$\square \square \square$

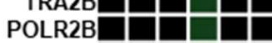

ACTR3 YWHAG HIST1H1D $\square \square \square$ ARPC1B ARPC4 $\square \square$ PRPF19 PRDX1 $\square \square \square \square$ ACTR2 $\square \square \square \square$ INF2 $\square \square \square \square \square$ SERPINB8 $\square \square \square \square$ ITM2B $\square$ DISP2 $\square \square \square \square \square$ H2AFJ $\square \square \square \square$ FBLL1 $\square \square \square \square$ COR01C $\square \square \square \square$ ARPC5 $\square \square \square \square$

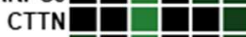
IL1RAPL1 $\square \square \square \square$

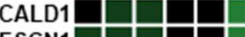

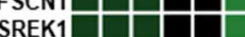

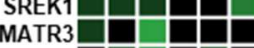
SF3A3 $\square \square \square \square$ ARPC2 $\square \square \square \square$

BZW1 $\square \square \square \square$ GNPAT $\square \square \square \square$

UBB $\square \square \square \square \square$ TAP1 $\square \square \square \square \square$

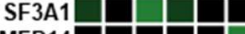
MED14 $\square \square \square \square \square$ KCNB2 $\square \square \square \square \square$ CYS1 $\square \square \square \square$

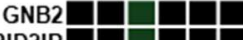
GRID2IP HSPA1L $\square$ KMT2C $\square \square \square \square \square$ KRT83 $\square \square \square \square \square$ PKP4 $\square \square \square \square \square$ PLCG2 $\square \square \square \square \square$ RAB33B $\square$ 口

RAP1GAP2 $\square \square \square \square \square$ SPRR2B $\square \square \square \square \square$

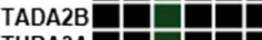
TUBA3A $\square \square \square \square$ USP40 $\square \square \square \square$ ATP2A3 $\square \square \square \square$ BEND4 $\square \square \square \square \square$ DOCK7 $\square \square \square \square$

EZR $\square \square \square \square$

FHL1 1

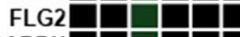
GAPDH $\square \square \square \square$ HIST1H2BA $\square$ QRICH2 $\square \square \square \square$ RPRD2 $1 \square \square \square \square$

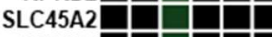
STMN4 $\square \square \square \square$ USP39 $\square \square \square \square$ ZFP518A $\square \square \square \square$ FABP5 $\square \square \square \square \square$

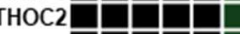

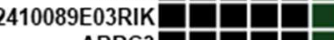

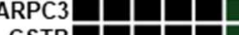

CSTB $\square \square \square \square$ DNAH7A $\square \square \square \square \square$ DYNC1LI2 $\square \square \square \square$ PPP1R9B $\square \square \square \square$ PSMB6口 $\square \square \square$ SMC3 $\square \square \square \square \square$

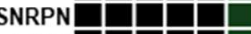
SOD2 $\square \square \square \square \square$ SQRDL $\square \square \square \square$

TPPP $\square \square \square \square$ TRRAP $\square \square$ APOA1 $\square \square \square \square \square \square$ BCAS3 $\square \square \square \square$ CAPN5 $\square \square \square \square$ ETV5 $\square \square \square \square$ MAP3K1 $\square \square \square \square$

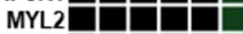
NCAPH $\square \square \square \square \square$ PHF5A $\square \square \square \square$ PRSS1 $\square \square \square \square$

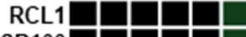
SP100 $\square \square \square \square$ XLR4C 
Figura 39. Interactores de YAP identificados en el estudio de espectrometría de masas. En la figura se muestra un dibujo esquemático (arriba a la izquierda) de los diferentes pasos del ensayo. En las Tablas aparecen representados los diferentes interactores identificados para cada una de las seis condiciones: células WT y Cav1KO tratadas y sin tratar con CytD $(1 \mu \mathrm{M})$ durante $24 \mathrm{~h}$. Como controles negativos se hizo el mismo ensayo en células WT y Cav1KO, pero sin incluir el anticuerpo secundario específico contra YAP ("WT -" y "Cav1KO -“). Los controles negativos aparecen representados en la segunda y la quinta columna. No se muestran en la figura aquellas proteínas que aparecen sobrerrepresentadas en los controles negativos.

A

\section{Interactoma de YAP}

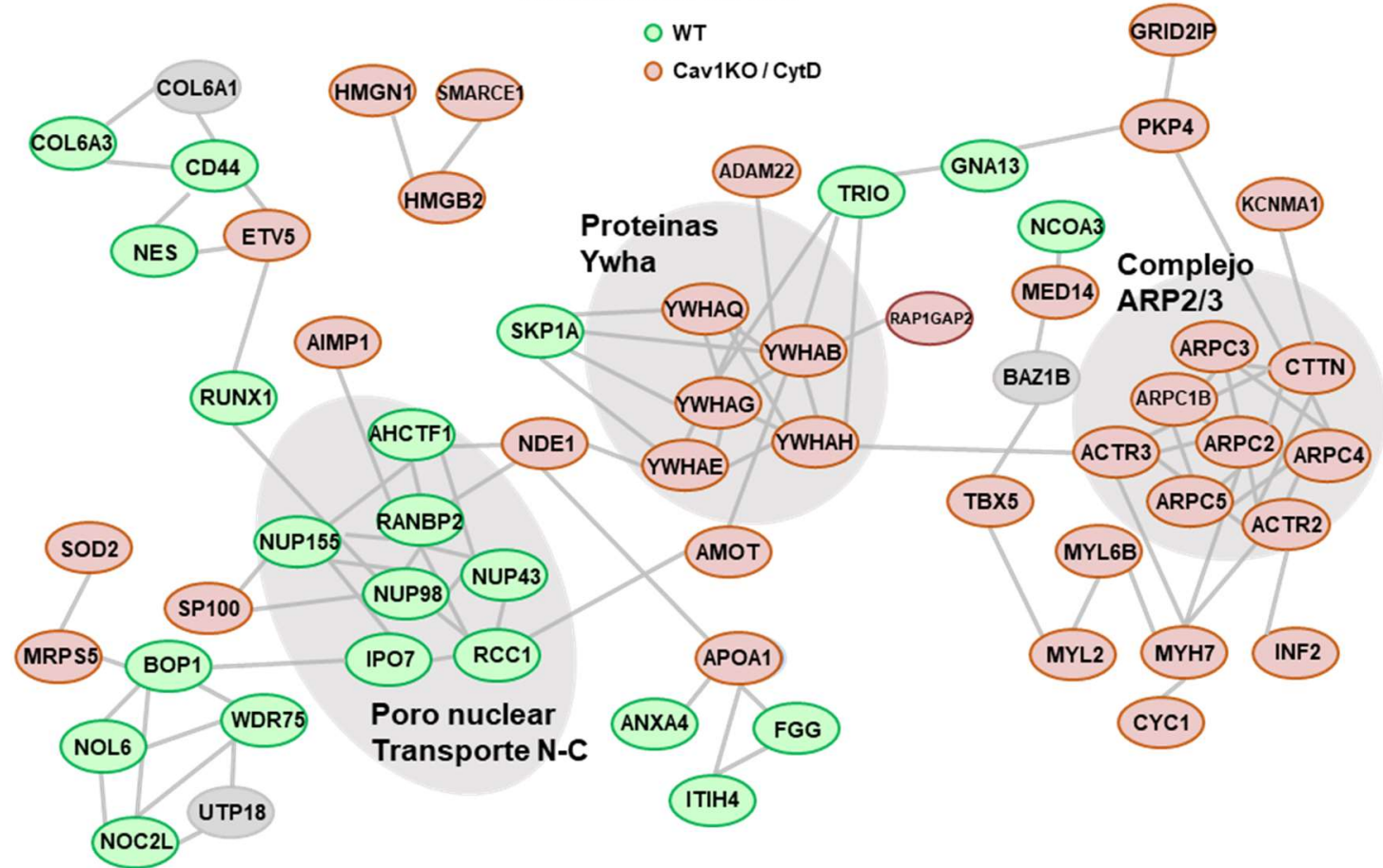

B

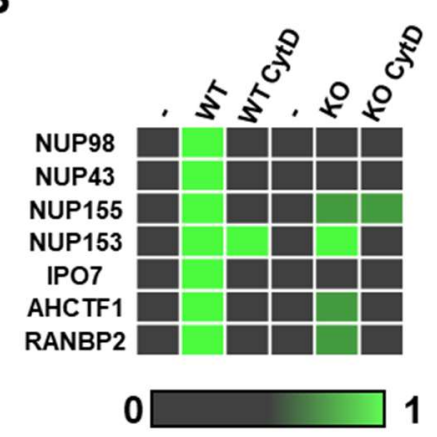

C

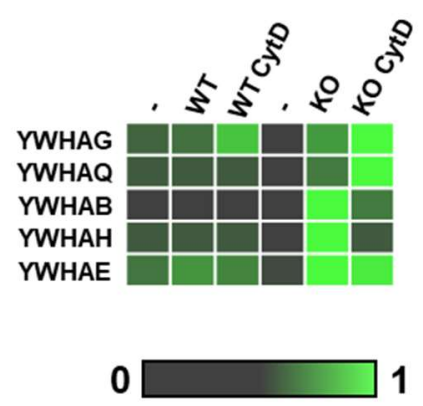

D

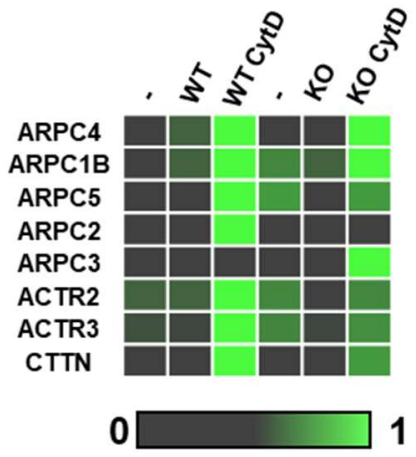

Figura 40. Caracterización funcional de los interactores de YAP identificados. (A) Red de asociaciones funcionales entre los interactores de YAP identificados por espectrometría de masas, elaborada a partir de múltiples fuentes de interacción entre ellos anotadas en STRING (Szklarczyk et al., 2017). En verde se representan las proteínas que interaccionan con YAP preferencialmente en células WT y en rojo las que interaccionan con YAP preferencialmente en MEF Cav1KO, o en células tratadas con CytD. (B, C y D) Resultados del análisis por espectrometría de masas de la interacción de YAP en cada una de las seis condiciones testadas, por parte de (B) las proteínas que forman parte del poro nuclear o están implicadas en el transporte núcleo-citosólico (C), las proteínas de la familia YWHA y (D) los componentes del complejo Cttn-Arp2/3. La escala de color representa el numero relativo (unidades arbitrarias) de péptidos identificados para cada proteína y condición. Los controles negativos (-) están representados en la primera y la cuarta columna. $n=5$. 
En células WT sin tratar, en las que YAP se encuentra activo realizando su papel cómo cofactor transcripcional en el núcleo, es detectable la interacción de YAP con componentes del poro nuclear y otras proteínas implicadas en el transporte entre el núcleo y el citosol (Figura 40A y 40B), que aparecen por tanto como candidatos a la regulación positiva de la actividad de YAP.

Tanto en células Cav1KO como en células tratadas con CytD, YAP interaccionaba con diferentes proteínas de la familia 14-3-3 (en concreto, se identificaron cinco isoformas diferentes de la familia YWHA) (Figura 40A y 40C). Como ya se ha mencionado previamente, estas proteínas interaccionan con proteínas fosforiladas en residuos de serina (Muslin et al., 1996; Yaffe et al., 1997), y en el caso de YAP lo retienen en el citosol cuando este se encuentra fosforilado (Basu et al., 2003). Por tanto, estos resultados confirman el papel de la fosforilación de YAP en la inhibición de su actividad, a través de su interacción con proteínas 14-3-3 al verse afectada la dinámica de actina. En células Cav1KO, que presentan un citoesqueleto de actina más desorganizado, la interacción de YAP con esas proteínas 14-3-3 podría determinar también su retención en el citosol y consecuentemente la bajada en su actividad transcripcional.

Del mismo modo se vio que, en las células tratadas con CytD, YAP interaccionaba con componentes del complejo Arp2/3 (del inglés Actin-Related Proteins 2 y 3, proteínas relacionadas con la actina) y con Cortactina (CTTN) (Figura $40 \mathrm{~A}$ y 40C). A la vista de estos resultados el complejo Arp2/3-CTTN podría estar reteniendo a YAP en el citosol en condiciones en las que la dinámica de actina se ve alterada, como ocurre en las MEF Cav1KO. Sin embargo, en las células que no expresan CAV1, YAP no interacciona ni con CTTN ni con el complejo Arp2/3, indicando que la interacción con Arp2/3-CTTN no media la retención de YAP en el citosol en las células sin CAV1. El hecho de que, en las Cav1KO, que también tienen una dinámica de actina alterada no se observe esta interacción, podría indicar que dicha interacción podría ser un efecto secundario del tratamiento con CytD. La co-inmunoprecipitación (colP) de CTTN con YAP se confirmó por WB (Figura 41A). Para ver si esa interacción era dependiente de la fosforilación de YAP se expresaron de forma transitoria las construcciones de YAP previamente citadas: YAP-Flag y YAP(5SA)-FLAG. Se analizó mediante colP, usando como cebo el epítopo Flag presente en ambas, la interacción de estas construcciones con CTTN tras el tratamiento con CytD. Este experimento reveló que la interacción de YAP con CTTN es dependiente del estado de fosforilación de YAP, ya que fuimos capaces de capturar la interacción con CTTN únicamente en células tratadas con CytD que expresaban YAP-Flag, pero no en aquellas que expresaban YAP(5SA)-Flag (Figura 41B). Esto sugiere que la interacción de YAP con CTTN podría no ser un 
mero efecto secundario del tratamiento con CytD, y que por el contrario podría tener relevancia funcional en la regulación de YAP en contextos fisiológicos específicos.

A

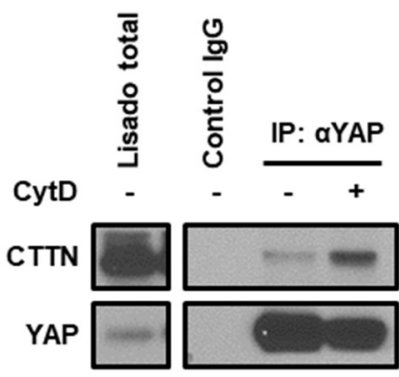

B

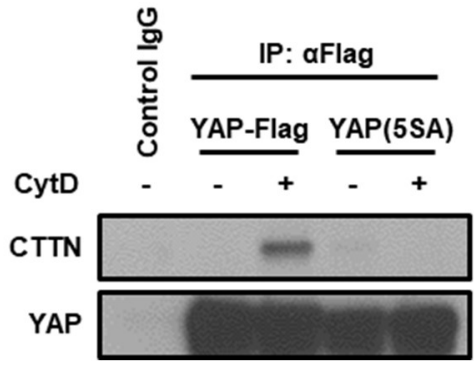

Figura 41. La interacción de YAP con CTTN en células tratadas con CytD es dependiente de la fosforilación de YAP. (A) Estudio de la interacción de YAP y CTTN en lisados de MEF WT tratadas con CytD $(1 \mu \mathrm{M})$ o DMSO durante $24 \mathrm{~h}$. Los lisados se inmunoprecipitaron con un anticuerpo anti-YAP o con un anticuerpo IgG cómo control. (B) Análisis de la inmunoprecipitación de YAP-Flag y YAP(5SA)-Flag y CTTN en lisados de células transfectadas con vectores para la sobreexpresión de ambas construcciones y tratadas con CytD o DMSO igual que en (A). Los lisados se inmunoprecipitaron con un anticuerpo anti-Flag o con un anticuerpo IgG cómo control.

\subsubsection{Caracterización funcional del interactoma de YAP}

Tras la identificación de los potenciales interactores de YAP se decidió testar el posible papel de estos en la regulación de la actividad de YAP. Para ello se testó la relevancia de los interactores de YAP en la regulación de su distribución subcelular. Se estableció un ensayo consistente en el silenciamiento sistemático por ARNi de los interactores identificados por espectrometría de masas en células WT y Cav1KO, y el posterior análisis de la distribución de YAP por inmunofluorescencia, mediante la adquisición y análisis de imagen automatizados

(Figura 42A; ver detalles en la sección de materiales y métodos).

Para evaluar la eficiencia de la transfección se usaron dos ARNi que permitían estimar la penetrancia del ARNi en nuestro sistema, en base a un fenotipo asociado medible directa y fácilmente mediante inmunofluorescencia. Se incluyeron (1) un ARNi contra el propio transcrito de Yap (que a su vez permitiría obtener información sobre la especificidad de la tinción); y (2) un ARNi para silenciar la expresión de la proteína centromérica INCENP, que resulta en la aparición de núcleos aberrantes de un mayor tamaño y células multinucleadas (Figura 42B), ya que bloquea la citocinesis (Mackay et al., 1998). Ambos controles confirmaron que el sistema funcionó adecuadamente en cada una de las tres replicas que se llevaron a cabo, en ambos fondos genéticos WT y Cav1KO. También se midieron variaciones en el número de células con los diferentes $\mathrm{ARNi}$, como una medida indirecta de viabilidad. De este modo se comprobó que 
ninguno de los ARNi tenía un efecto drástico en este sentido, no afectando ninguno de ellos de forma significativa a la viabilidad celular (Figura 42C).

A

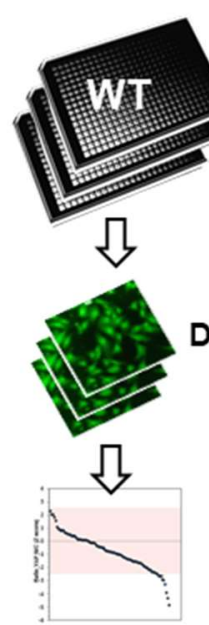

Librería de ARNi (89 interactores de YAP identificados)

Transfección reversa

Distribución subcelular de (inmunofluorescencia)

Análisis de imágen (calculo del Z-valor)

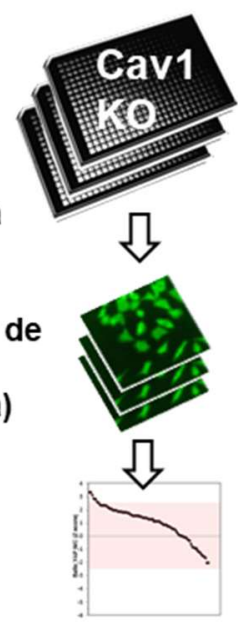

B
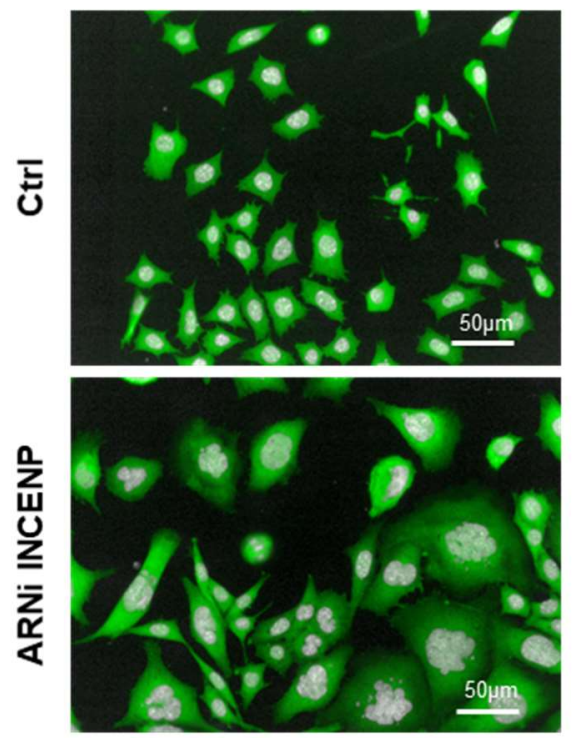

C

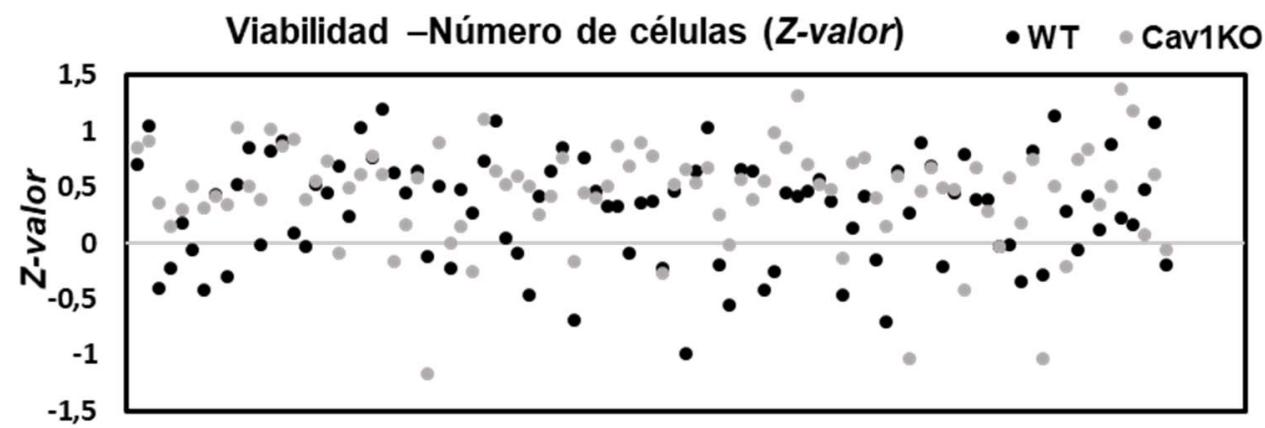

Figura 42. Ensayo para la caracterización de los interactores de YAP. (A) Esquema representativo del ensayo utilizado para caracterizar el efecto de los interactores de YAP en su distribución subcelular. (B) Imágenes representativas obtenidas en el ensayo descrito en (A) del efecto del silenciamiento de Incenp en células WT. En verde está representado YAP y en blanco los núcleos marcados con Hoechst. (C) Estudio de la viabilidad celular en el ensayo, cuantificada como el Z-valor del número de células. En la gráfica se representa la media de los Z-valores de los tres experimentos que se llevaron a cabo.

Para el estudio del efecto de cada uno de los ARNi en la distribución subcelular de YAP se calculó el ratio entre los niveles de YAP en el núcleo celular con respecto a los observados en el citosol tras el silenciamiento. Para la evaluación de los resultados se calculó el Z-valor, un parámetro estadístico ampliamente utilizado en el análisis de este tipo de estudios y que representa el número de desviaciones estándar que un valor se desplaza con respecto a la media (Birmingham et al., 2009). La media de los Z-valores en las tres réplicas del ensayo para cada uno de los genes estudiados aparece representa en la Figura 43A. De todos ellos, enfocamos nuestra atención en aquellos cuyo Z-valor medio estaba por encima o por debajo de 2,5 o respectivamente (Figura 43B). Curiosamente, entre los genes cuyo silenciamiento provocaba 
una disminución en el ratio núcleo-citosol de YAP en células WT, con un Z-valor menor de -2,5, aparecían los componentes del poro nuclear AHCTF, NUP155 y NUP98, proteínas que, como hemos visto en los resultados de proteómica, interaccionan preferencialmente con YAP en células WT. Por tanto, este hecho podría indicar la posible implicación de estas proteínas en el transporte de YAP del citosol al núcleo a través de una interacción directa con YAP. Se observó que el silenciamiento de algunos genes derivaba en un aumento de la translocación de YAP al núcleo $(Z>2,5)$ específicamente en células Cav1KO (Figura 43B, panel derecho). Entre esos genes se encuentras dos isoformas de la familia YWHA, YWHAH e YWHAB, que como hemos visto anteriormente interaccionan con YAP preferencialmente en células Cav1KO.

A

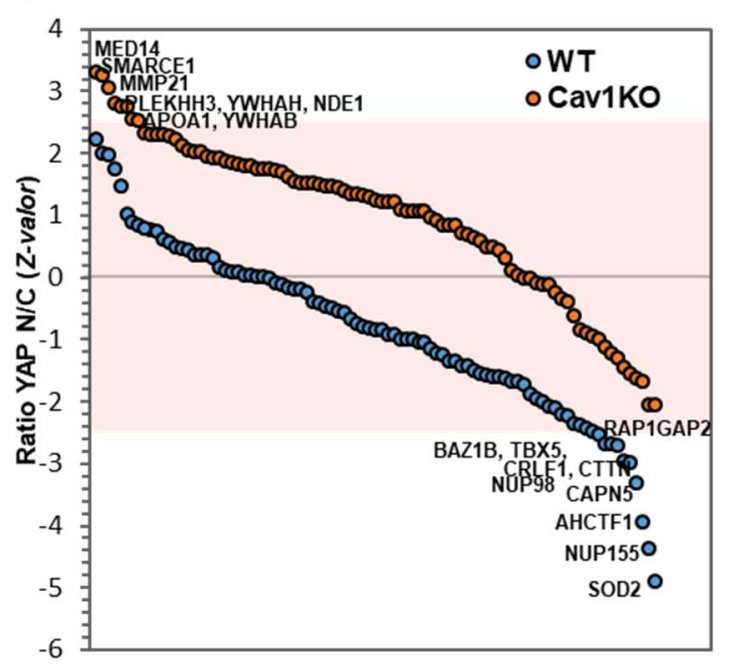

B

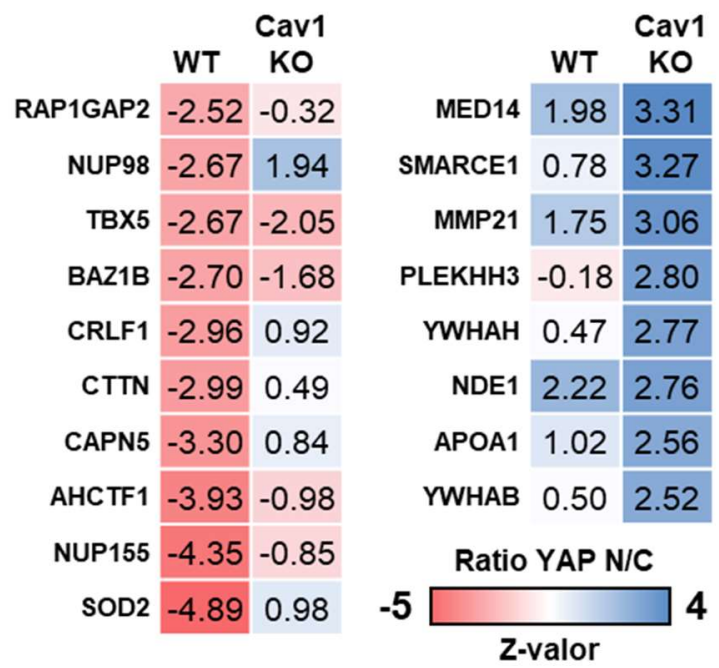

Figura 43. Resultados del ensayo de caracterización de los interactores de YAP. (A) En el gráfico aparecen representados los Z-valores medios del ratio núcleo/citosol de YAP para cada uno de los genes silenciados con ARNi en células WT y Cav1KO. (B) Genes para los que su silenciamiento da lugar a un Z-valor medio que esta por encima de 2,5 o por debajo de $-2,5$ en células WT y Cav1KO.

\subsubsection{La interacción de YAP con YWHAH determina la deficiente actividad de YAP en células}

\section{Cav1KO}

Tal y como hemos mencionado en el apartado anterior, en el ensayo de caracterización se vio que el silenciamiento de Ywhah provocaba un aumento en la translocación de YAP al núcleo en MEF Cav1KO (Figura 44A) indicando que la retención citosólica de YAP en estas células podría estar mediada por la interacción YAP-YWHAH. Para estudiar esta hipótesis, en primer lugar, se llevó a cabo una colP de YAP para confirmar los resultados obtenidos por espectrometría de masas. De este modo se confirmó que YWHAH interaccionaba preferencialmente con YAP en células Cav1KO y en células WT tratadas con CytD (Figura 44B). 
A
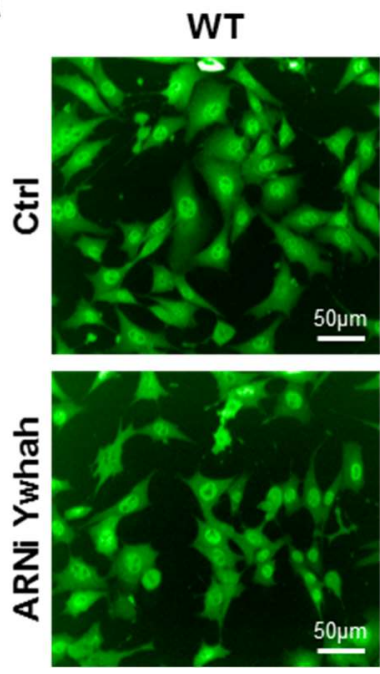

Cav1Ko
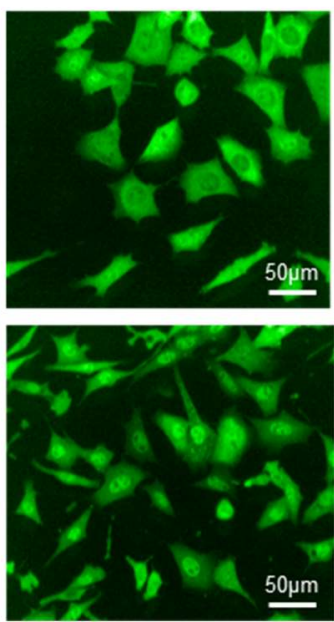

B

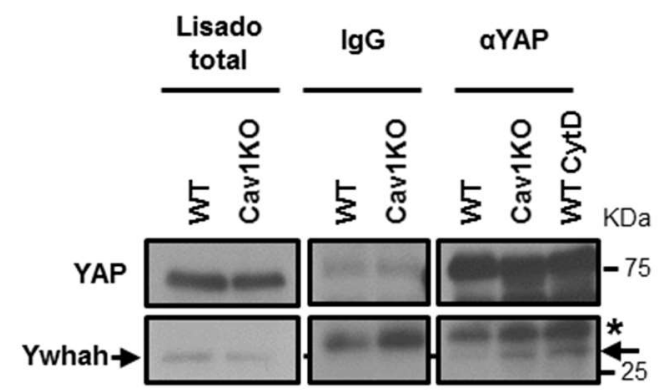

Figura 44. La retención citosólica de YAP en MEF Cav1KO está determinada por su interacción con YWHAH. (A) Imágenes de microscopía confocal de fluorescencia extraídas del ensayo de caracterización de los interactores de YAP. En las imágenes se muestra la localización de YAP en MEF WT y Cav1KO transfectadas con ARNi contra Ywhah o un ARNi control. (B) Estudio de la interacción de YAP e YWHAH en lisados de MEF WT y Cav1KO. Los lisados se inmunoprecipitaron con un anticuerpo anti-YAP o con un anticuerpo IgG cómo control. El asterisco marca una banda inespecífica y la flecha indica la banda correspondiente a YWHAH.

Para evaluar la posibilidad de que la interacción YAP-YWHAH determinase la retención citosólica de YAP en células Cav1KO se silenció Ywhah con ARNi y se analizó la expresión de Ctgf y Ankrd1 por RT-qPCR (Figura 45A, 45B y 45C). El silenciamiento de Ywhah provocaba un aumento significativo en la actividad transcripcional de YAP en las Cav1KO, sugiriendo que nuestra hipótesis era acertada, es decir, la interacción de YAP con YWHAH estaría determinando la retención de YAP en el citosol en estas células. Para ver el papel que la interacción YAPYWHAH tenía en la inhibición de la actividad de YAP mediada por defectos en el citoesqueleto de actina y por la presencia de una MEC con una baja rigidez se analizó también el efecto de su silenciamiento en células sembradas en matrices blandas o tratadas con CytD (Figura 45B). En el caso de las células tratadas con CytD sí que se pudo observar un rescate en la actividad transcripcional de YAP tras el silenciamiento, pero no sucedía lo mismo en las células creciendo sobre matrices blandas, sugiriendo que otros mecanismos, independientes probablemente de la fosforilación como ya se ha sugerido en trabajos previos (Aragona et al., 2013; Dupont et al., 2011; Elosegui-Artola et al., 2017), podrían tener un papel en la inhibición de la actividad de YAP en ese contexto. En conjunto, los datos sugieren que CAV1 controla la actividad de YAP a través del control de la dinámica de actina, que determina en última instancia una disminución en la interacción de YAP con YWHAH, y por tanto favorece su translocación al núcleo. 
El silenciamiento de Ywhah derivaba en una disminución de la fosforilación de YAP, asociada a una drástica reducción de sus niveles de proteína totales (Figura 45A). La regulación de la actividad de YAP en muchas situaciones está determinada por el control de sus niveles de expresión, bien a través de su degradación por la vía del proteasoma o mediante el control de su expresión a nivel transcripcional (Moroishi et al., 2015; Zhao et al., 2010). Mediante RT-qPCR se determinó que la bajada en los niveles de proteína se debía, al menos en parte, a la bajada a en la expresión de YAP a nivel transcripcional (Figura 45D). Esta regulación añade un nuevo nivel de complejidad al control de la actividad de YAP por YWHAH, ya que la bajada de los niveles de YWHAH promueve un aumento de la translocación de YAP al núcleo, pero, al mismo tiempo regula negativamente la actividad de YAP al inducir una bajada de sus niveles de expresión.

A

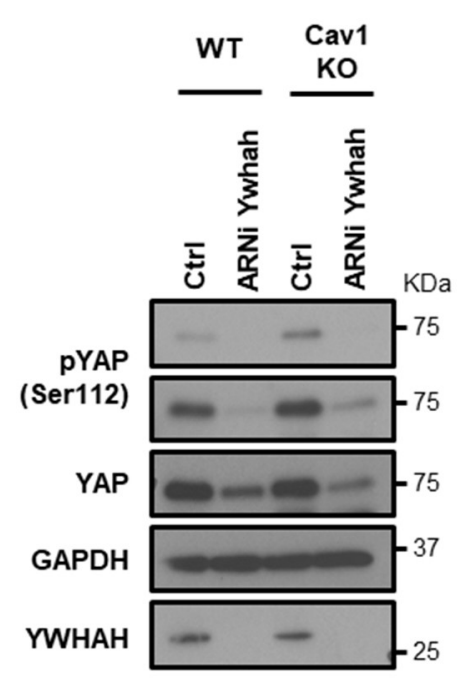

C

Ywhah
B

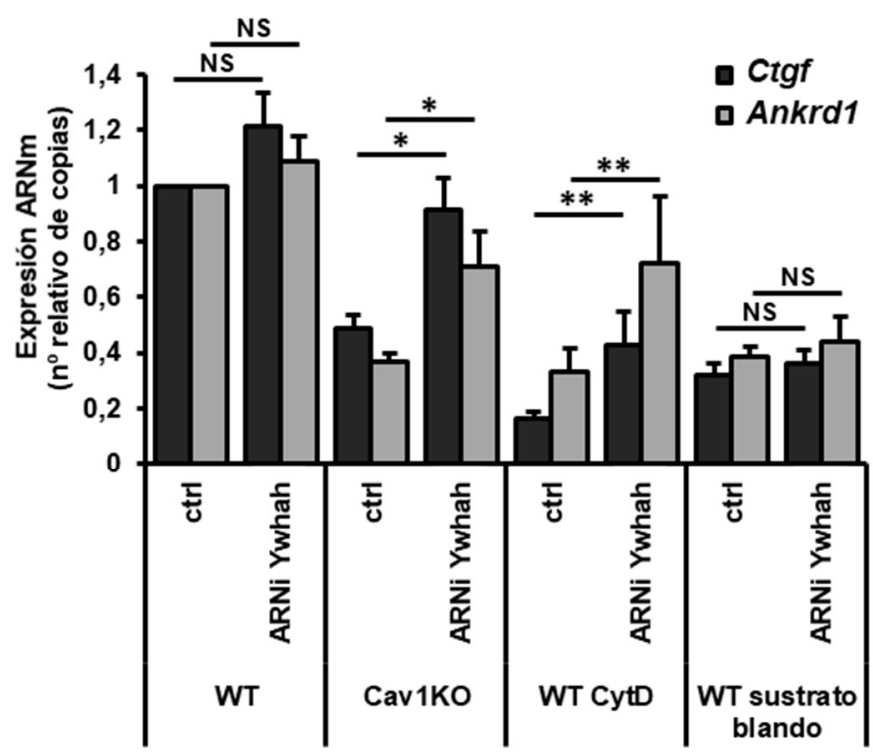

D

YAP
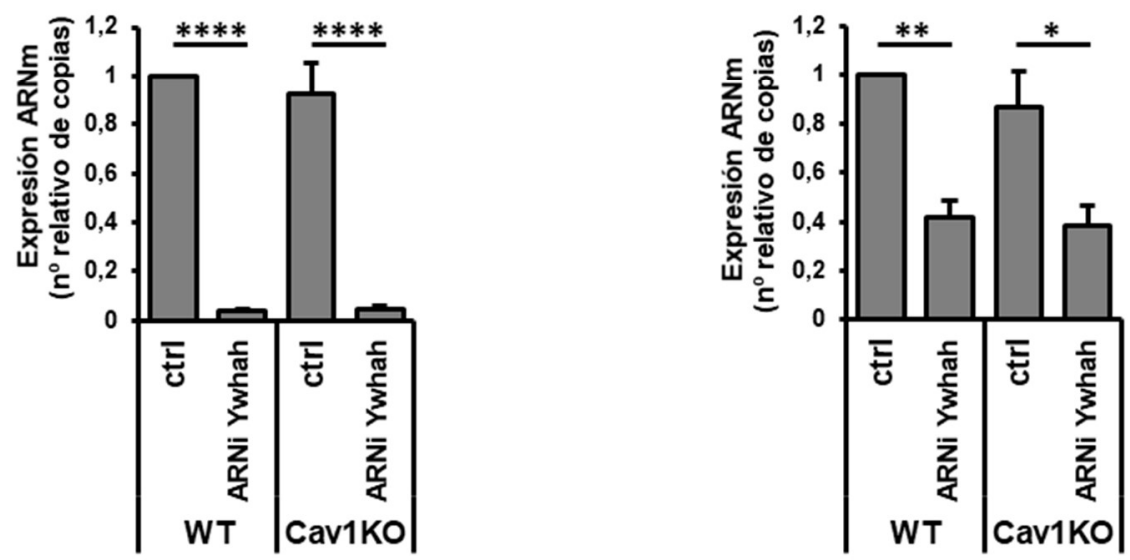

Figura 45. La interacción de YAP con Ywhah determina la inhibición de la actividad de YAP en MEF Cav1KO. (A) WB para la detección de YWHAH, YAP fosforilado en S112 y YAP total en MEF WT y Cav1KO 
transfectadas con ARNi contra Ywhah o un ARNi control. GAPDH se utilizó como control de carga. (B) Análisis mediante RT-qPCR de la expresión del de Ctgf y Ankrd1 en células transfectadas con ARNi contra Ywhah o un ARNi control: en MEF WT y Cav1KO sembradas sobre sustratos rígidos, MEF WT creciendo sobre sustratos blandos y MEF WT tratadas con CytD $(1 \mu \mathrm{M})$ durante $24 \mathrm{~h}$. Los datos están normalizados con respecto al valor de las células WT sin CytD, creciendo sobre sustratos rígidos y transfectadas con ARNi control. $n=5$. (C y D) Análisis de la expresión de Ywhah (C) y Yap (D) en MEF WT y Cav1KO transfectadas con ARNi contra Ywhah o un ARNi control. Los datos están normalizados con respecto al valor de las células WT transfectadas con ARNi control. $n=5$. Los datos están representados cómo la media \pm SEM; $* \mathrm{P}<0.05, * * \mathrm{P}<0.01 \mathrm{y} * * * * \mathrm{P}<0.0005$.

\subsection{Implicaciones fisiopatológicas de la regulación de YAP por CAV1}

\subsubsection{YAP determina el control del remodelado de la MEC dependiente de CAV1}

Tanto YAP como CAV1 están implicadas en el remodelado de la MEC, un proceso biológico de especial relevancia en un gran número de procesos fisiopatológicos, como en el caso de la progresión tumoral (Calvo et al., 2013; Goetz et al., 2011). Dado que ambas proteínas están implicadas en el proceso, se decidió estudiar la posibilidad de que la regulación de YAP por CAV1 pudiera tener un papel relevante. Para estudiar esa posibilidad se cuantificó la capacidad de las células para remodelar la matriz extracelular utilizando para ello un ensayo in vitro consistente en cultivar los fibroblastos embebidos en una matriz de colágeno en 3D y cuantificar la contracción de esa matriz después de varios días en cultivo (ver sección de materiales y métodos). Para confirmar los datos previamente publicados (Calvo et al., 2013; Goetz et al., 2011) se estudió el remodelado de colágeno por MEF WT, Cav1KO y silenciando Yap con un ARNch (Figura 46A y 46B). De este modo se determinó que tanto las células que no expresan CAV1 como aquellas en las que se silenció Yap tienen una capacidad para remodelar la MEC de colágeno relativamente mermada en comparación con células WT. Para evaluar si la disminución en la capacidad de remodelar la MEC en las Cav1KO se debía específicamente a una bajada en la actividad de YAP, se hizo el ensayo de contracción de colágeno en células en las que se expresaron de forma transitoria las construcciones YAP-Flag o YAP(5SA)-Flag. Se observó que la expresión de YAP(5SA)-FLAG, insensible a la regulación negativa observada en células Cav1KO y capaz de rescatar la actividad transcripcional de YAP en dicho fondo genético (Figura 13D y 13E), también aumentaba la capacidad de estas células para remodelar la MEC. Por el contrario, la expresión de YAP-Flag en células Cav1KO no revertía la merma en la actividad remodeladora de matriz (Figura 46C y 46D). El aumento en la capacidad de remodelado al rescatar la actividad de YAP en células Cav1KO se confirmó analizando el ordenamiento de las fibras de colágeno utilizando un microscopio multifotón para la generación del segundo armónico (SHG, de sus 
siglas en inglés Second Harmonic Generation). Mediante esta técnica se pudo comprobar que la expresión de YAP(5SA)-FLAG en Cav1KO aumentaba el ordenamiento de las fibras de colágeno (Figura 46C), confirmando por tanto un aumento en la capacidad de remodelado de la MEC. Del mismo modo el silenciamiento de Lats1 y Lats2, qué también aumentaba la actividad de YAP en células Cav1KO (Figura 36B), aumentaba ligeramente la capacidad de las células Cav1KO de remodelar la MEC, aunque en este caso el aumento no era significativo estadísticamente (Figura 46E).

A

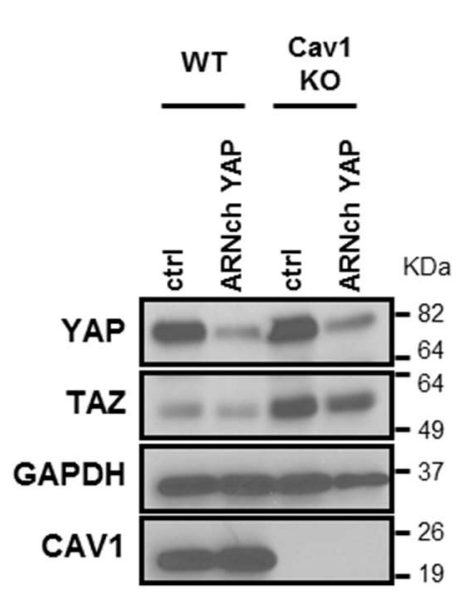

C
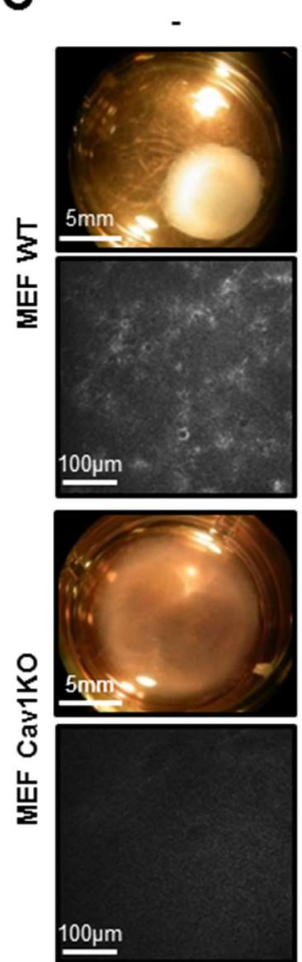

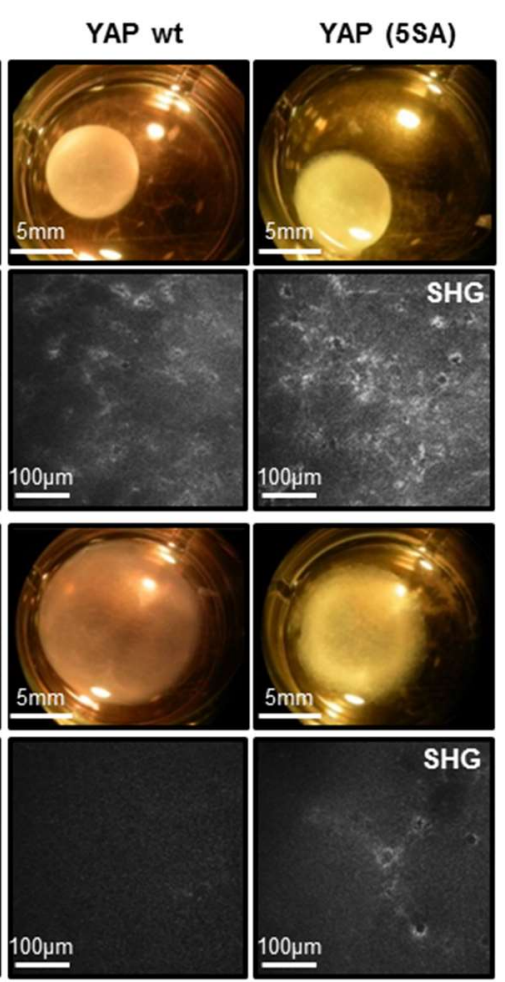

B

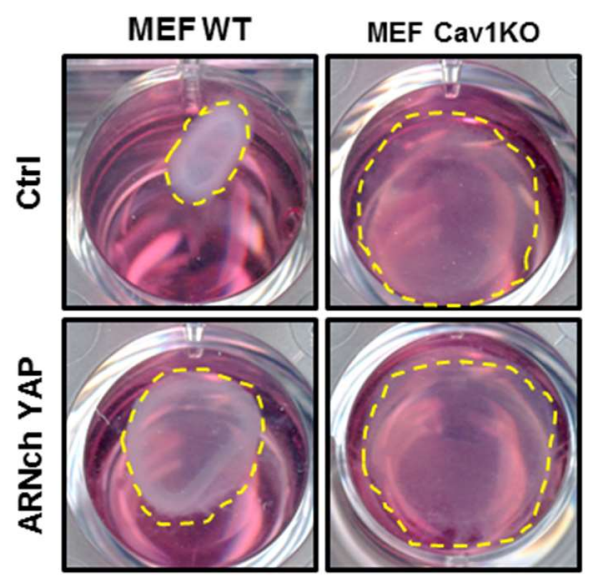

D

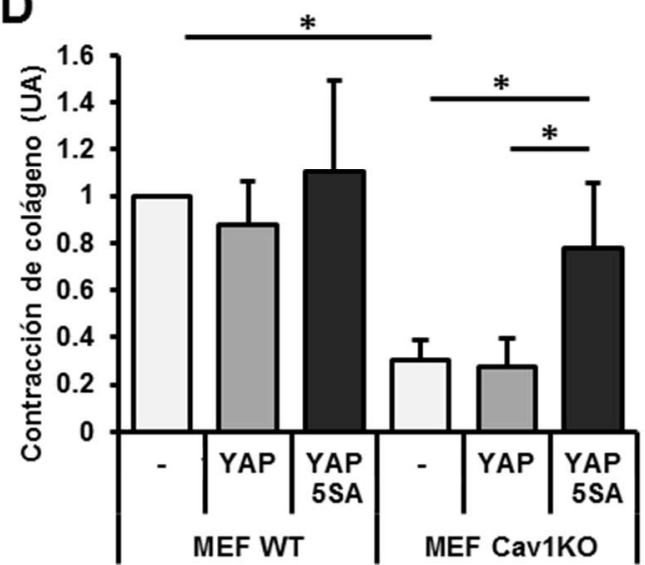

$\mathbf{E}$

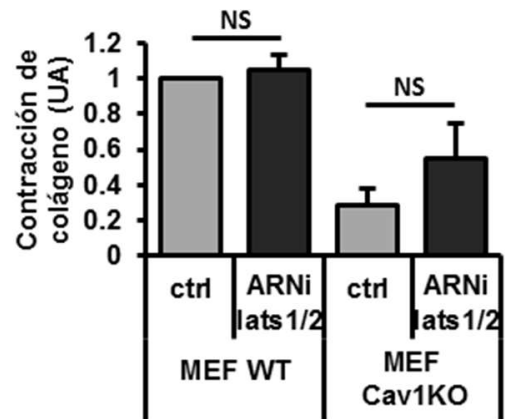

Figura 46. YAP determina el control de CAV1 sobre el remodelado de la MEC. (A) WB para la detección de YAP, TAZ y CAV1 en MEF WT y Cav1KO infectadas con un vector para la expresión de un ARNch contra Yap o un vector vacío. GAPDH se utilizó como control de carga. (B) Contracción de matrices 
tridimensionales de colágeno inducida por MEF WT y Cav1KO infectadas con un vector para la expresión de un ARNch contra Yap o un vector vacío tras $72 \mathrm{~h}$ embebidas en la misma. (C) Contracción de matrices tridimensionales de colágeno inducida por MEF WT y Cav1KO transfectadas con YAP-Flag, YAP(5SA)-FLAG o sin vector tras $72 \mathrm{~h}$ embebidas en la misma. La organización del colágeno se visualizó mediante SHG con un microscopio multifotón (imágenes en blanco y negro). (D) Cuantificación con ImageJ de la contracción de las matrices tridimensionales de colágeno con MEF WT y Cav1KO transfectadas con YAP-Flag, YAP(5SA)-FLAG o sin vector tras $72 \mathrm{~h}$ embebidas en la misma, medidas como el cambio relativo normalizado con respecto a la contracción observada en matrices conteniendo células WT transfectadas sin ningún vector. $n=3$. (E) Cuantificación con ImageJ de la contracción de las matrices tridimensionales de colágeno con MEF WT y Cav1KO transfectadas con ARNi contra Lats1 y Lats2 o un ARNi control tras $72 \mathrm{~h}$ embebidas en la misma, medidas como el cambio relativo normalizado con respecto a la contracción observada en matrices conteniendo células WT transfectadas con un ARNi control. $n=3$. Los datos están representados cómo la media $\pm \mathrm{SD} ;{ }^{*} \mathrm{P}<0.05$.

El remodelado de la matriz tiene un papel clave en la progresión de determinadas enfermedades, como es el caso de determinados tipos de cáncer, en los que la rigidez y ordenamiento de la matriz que rodea a los tumores determina la progresión tumoral, controlando tanto el crecimiento de los tumores, como la capacidad de células malignizadas de colonizar otros órganos y tejidos de manera independiente del tumor primario generando metástasis tumorales (Kalluri and Zeisberg, 2006). Los encargados de ese remodelado de la MEC peritumoral son los fibroblastos asociados a tumores, TAF (tumour-associated fibroblasts), en su estado activo. Por ello, una vez confirmado el papel de la regulación de YAP por CAV1 en el remodelado de la matriz extracelular en MEF, se decidió estudiar la relevancia de la misma en TAF. En concreto se utilizaron TAF extraídos de la región peritumoral de tumores de páncreas humanos. Se analizó por inmunofluorescencia en esos TAF la expresión simultánea de CAV1 y YAP, y se apreció que existía una correlación inversa entre la expresión de CAV1 y la localización nuclear de YAP, es decir: en células con bajos niveles de CAV1 la localización de YAP era predominantemente citosólica, mientras que en las células con altos niveles de CAV1 se localizaba en el núcleo (Figura 47A). Esta observación se confirmó mediante adquisición y análisis automatizado de imagen en colecciones extensas de células, comprobándose que existía una correlación positiva entre los niveles de expresión de CAV1 y el grado de localización nuclear de YAP (Figura 47B). Además, se silenció CAV1 con un ARNi en estas células y se observó que la bajada en los niveles de CAV1 inducía una disminución en los niveles de YAP en el núcleo (Figura 47C y 47D). Estos resultados sugieren que el eje de regulación CAV1-YAP podría tener una relevancia importante en el remodelado del estroma peritumoral, y por tanto tener un papel clave la progresión tumoral y el desarrollo de metástasis. 
A

Fibroblastos asociados a tumores

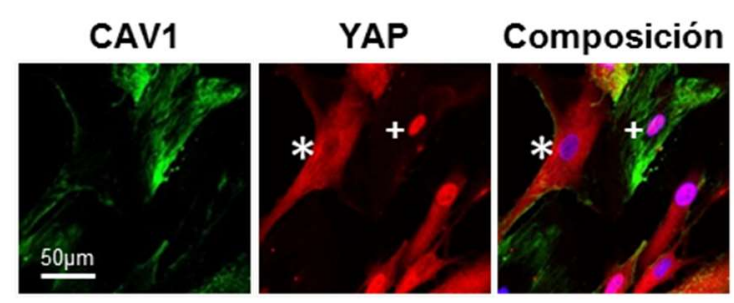

B

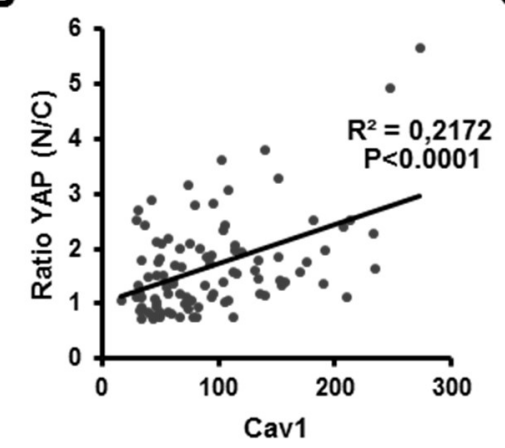

C

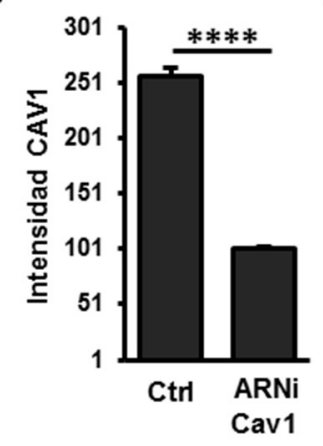

D

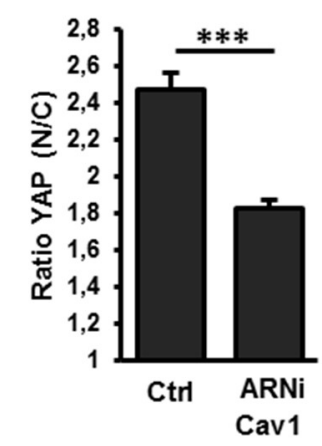

Figura 47. CAV1 modula la translocación nuclear de YAP en TAF. (A) Imágenes de microscopía confocal de CAV1 y YAP en TAF extraídos del estroma de tumores pancreáticos humanos y crecidos in vitro. Los núcleos se marcaron con Hoechst (azul). Los símbolos marcan células con niveles de CAV1 bajos $\left({ }^{*}\right)$ o altos (+). (B) Estudio de la correlación de la expresión de CAV1 y la localización subcelular de YAP en TAF, representada como el ratio entre el YAP nuclear y el localizado en el citosol. Cada punto del gráfico corresponde a una célula individual analizada utilizando Columbus. $n=97$. (C y D) Análisis de la expresión de CAV1 (C) y la localización subcelular de YAP igual que en (B), cuantificada usando Columbus en imágenes de inmunofluorescencia de TAF en los que se silenció CAV1 o transfectados con un ARNi control. Se cuantificaron aproximadamente 500 células por experimento y condición en cuatro experimentos independientes. Los datos están representados cómo la media $\pm \mathrm{SEM} ;{ }^{* * *} \mathrm{P}<0.005 \mathrm{y} * * * * \mathrm{P}<0.0005$.

\subsubsection{CAV1 determina la activación de YAP en la metaplasia acino-ductal asociada a}

\section{pancreatitis}

El adenocarcinoma ductal de páncreas (PDAC) está caracterizado por una serie de cambios tanto a nivel genético cómo a nivel estructural, viéndose afectado el estroma pancreático. Se ha caracterizado, en modelos animales generados mediante ingeniería genética que recapitulan la ontogenia del PDAC en humanos, que, aparte las alteraciones genéticas en los oncogenes KRas, otros eventos no genéticos como el daño en el tejido son determinantes en la iniciación del PDAC (Guerra et al., 2007). De hecho, el daño en el tejido pancreático asociado a la pancreatitis, es un factor de riesgo clave en el inicio del PDAC (Yadav and Lowenfels, 2013). La pancreatitis causa un daño en el tejido pancreático que está asociada a una reacción inflamatoria y tras la cual algunas áreas del tejido pancreático presentan o bien un proceso de regeneración o una desmoplasia. En algunas regiones del tejido ocurre un fenómeno de 
reprogramación celular por el cual las células acinares se transforman en ductos, conocido como metaplasia acino-ductal (ADM) (Guerra et al., 2007). Se sabe además que la activación de YAP es necesaria para la progresión y desarrollo de la ADM asociada a la pancreatitis (Gruber et al., 2016; Morvaridi et al., 2015), lo que sugiere también una posible contribución de los cambios en las condiciones mecánicas, por ejemplo la rigidez de la MEC, que podrían estar teniendo lugar durante la pancreatitis. A la vista de esta hipótesis, se decidió analizar el papel de la conexión de CAV1 con la activación de YAP en respuesta a estímulos mecánicos en la reprogramación ADM asociada a pancreatitis.

Para inducir pancreatitis aguda se administró a los ratones ceruleína, un agonista del receptor de colecistoquinina, por vía intraperitoneal. Tras la administración de la ceruleína a ratones WT y Cav1KO se analizó el daño en el tejido pancreático a diferentes tiempos. En las imágenes de hematoxilina-eosina obtenidas se pudo observar que existía una respuesta inflamatoria notable dos horas después de la administración de la ceruleína tanto en ratones WT como en los Cav1KO, observándose una elevada infiltración entre los acinos del tejido pancreático (Figura 48). Cuatro y siete días después del tratamiento se aprecia la recuperación progresiva del tejido, observándose en algunas zonas áreas que manifiestan una cronificación de la pancreatitis. En esas zonas donde se cronifica el daño se puede observar una extensiva ADM, caracterizada por la dediferenciación de los acinos, que adquieren un fenotipo propio de células ductales (Figura 49A) y fibrosis, observándose un aumento de la expresión de SMA en las células estrelladas pancreáticas (Figura 49B). Estas regiones con pancreatitis crónica se cuantificaron, midiendo el porcentaje del área total del páncreas ocupado por las mismas cuatro días después de la administración de la droga, determinándose que ese porcentaje era mayor en los páncreas de los ratones WT que en el de los Cav1KO (Figura 49C). Estas diferencias en la respuesta al tratamiento con ceruleína se comprobó que eran coincidentes con una mayor translocación de YAP al núcleo en los ratones WT a ese mismo tiempo tras la administración de la droga. (Figura 49D y 49E). Se pudo determinar además que la activación de YAP era prácticamente inmediata, observándose el aumento dos horas después del tratamiento. La activación de YAP es necesaria para el proceso de ADM (Gruber et al., 2016) y una mayor activación de YAP en ratones WT correlaciona con un incremento mayor en la ADM que en el caso de los Cav1KO. Esto nos llevó a plantear la posibilidad de la existencia de una relación causaefecto entre ambos factores. Por tanto, los resultados obtenidos sugieren la participación de CAV1 en la respuesta al proceso inflamatorio inducido por ceruleína, a través de la modulación de la actividad de YAP, que controla en última instancia el proceso de ADM. 


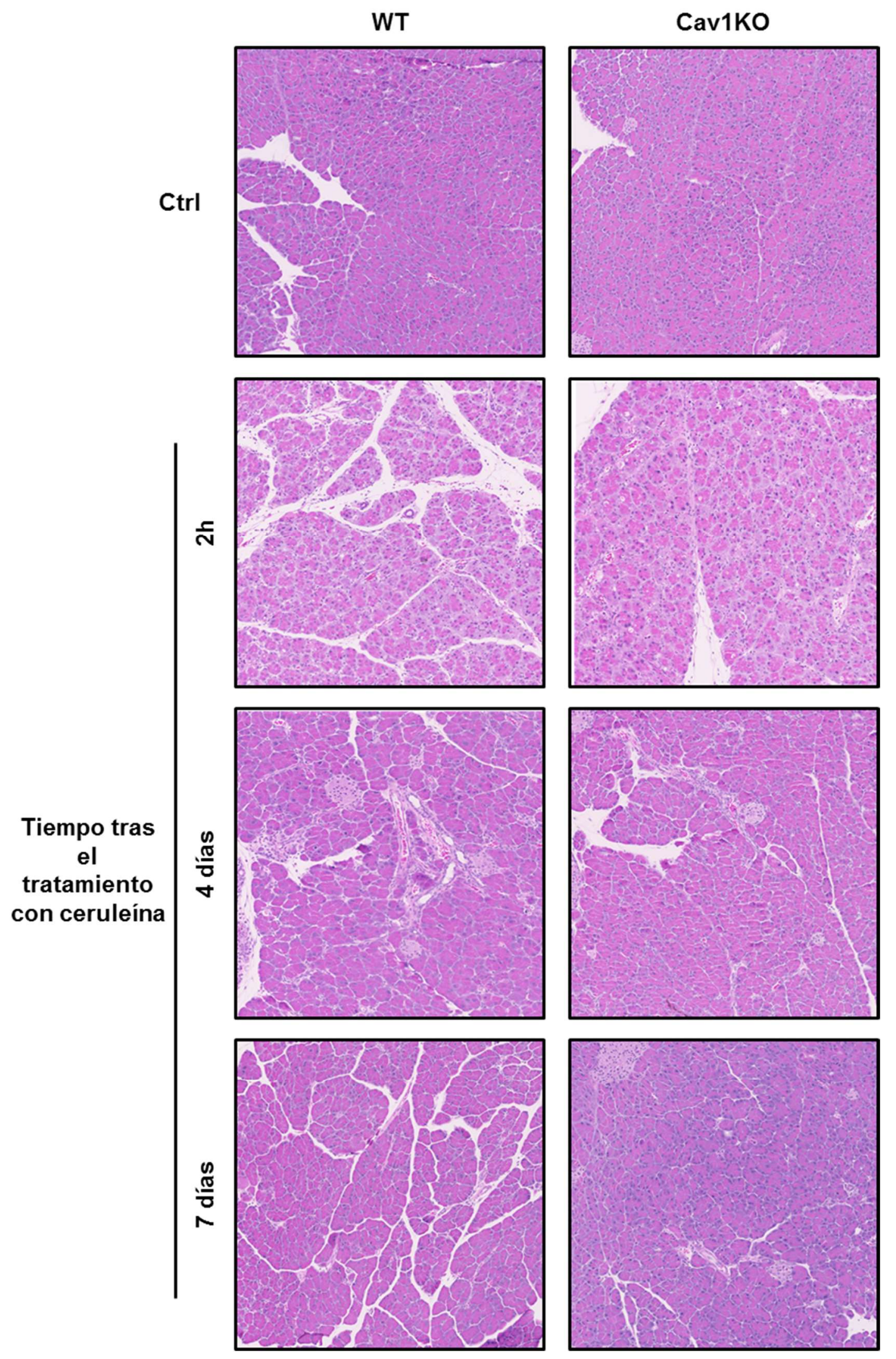

Figura 48. El tratamiento con ceruleína induce un proceso inflamatorio reversible en el tejido pancreático. Imágenes de cortes de tejido pancreático procedentes de ratones WT y Cav1KO sin tratar y $2 \mathrm{~h}, 4$ días y 7 días después del tratamiento con ceruleína. Los cortes se tiñeron con Hematoxilina-eosina para visualizar la infiltración inter-acinar en el proceso inflamatorio. 
A

WT (4 dias después del tratamiento con ceruleina)

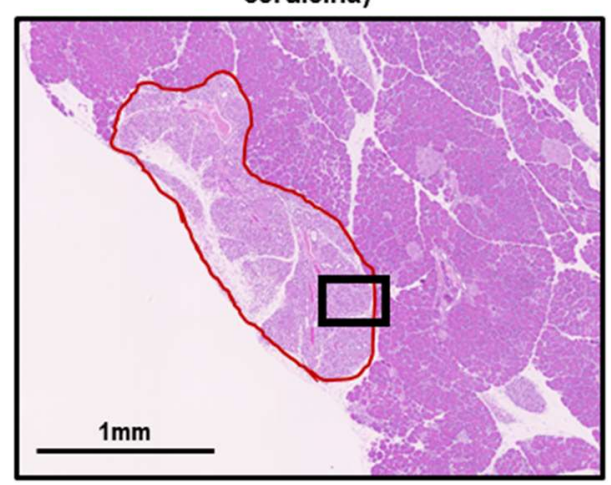

ROI

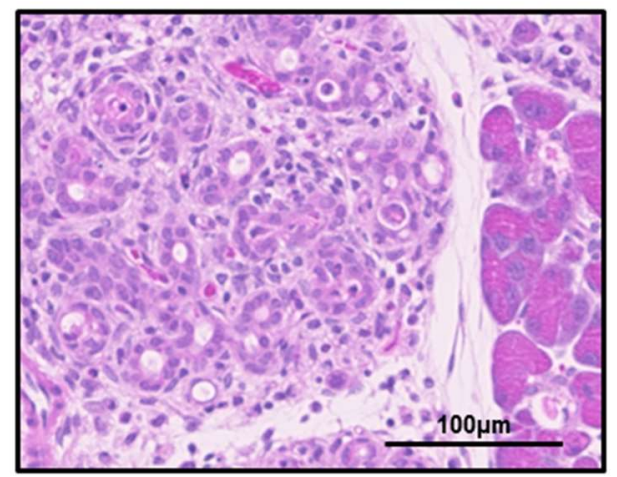

B

WT
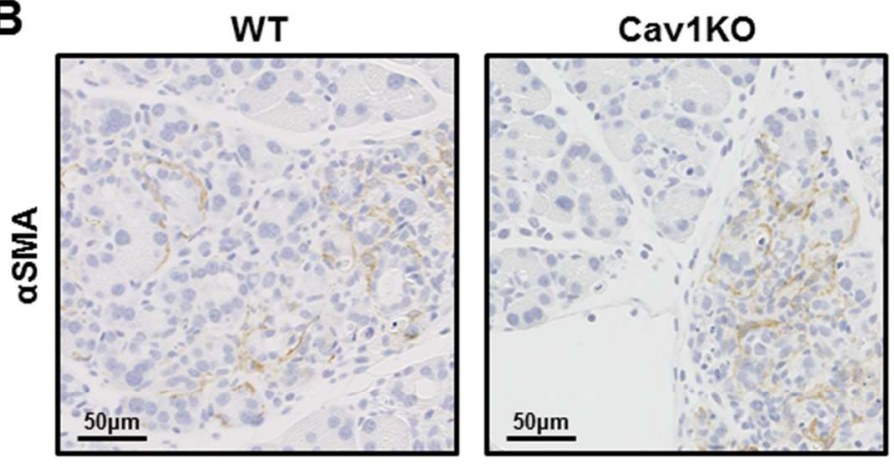

C

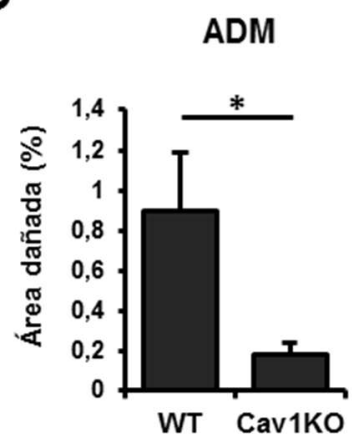

D
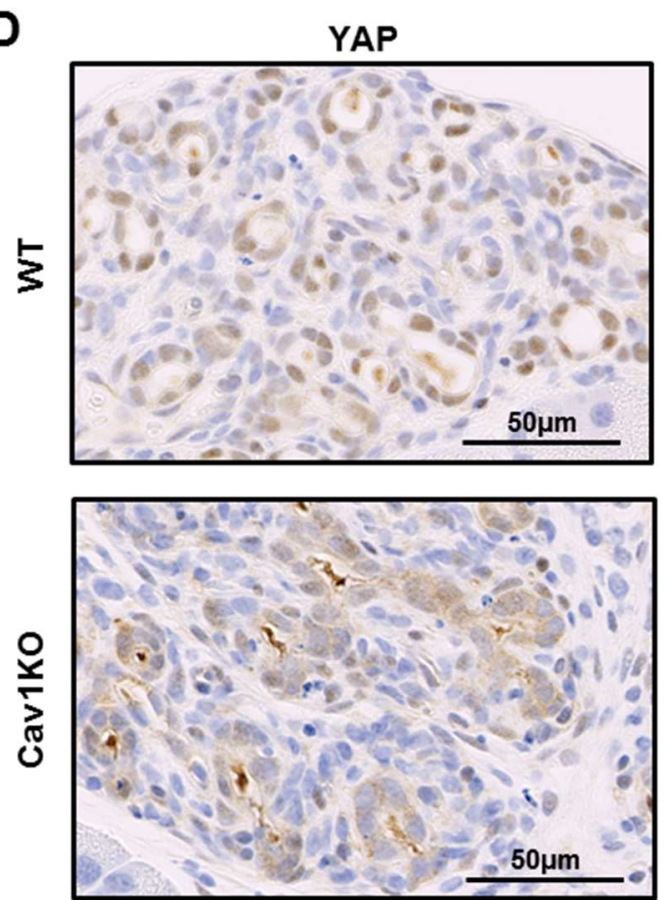

E

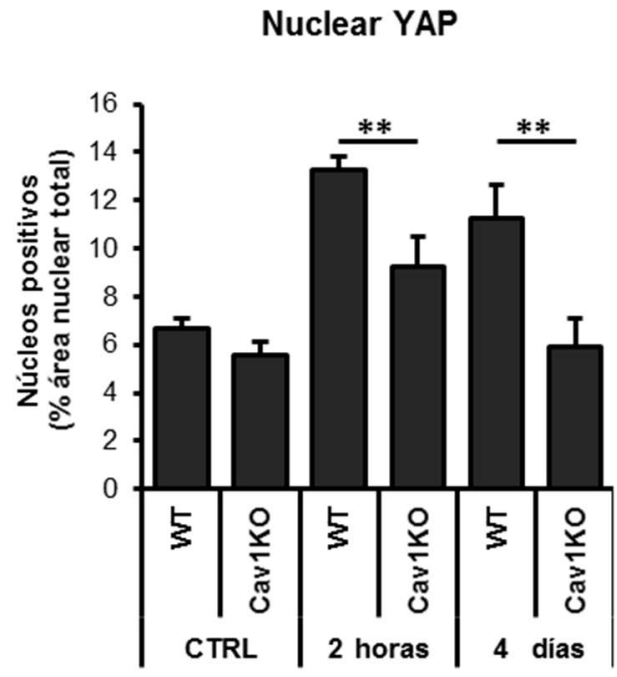

Figura 49. CAV1 determina la activación de YAP y la ADM en la pancreatitis inducida por ceruleína. (A) Área de tejido pancrático procedente del páncreas de un ratón WT cuatro días después del tratamiento con ceruleína teñido con Hematoxilina-eosina. La línea roja engloba una región con un fenotipo generalizado de ADM. En el panel de la derecha se representa la región de interés (ROI) encuadrada con un cuadro negro en la imagen de la izquierda ampliada. (B) Análisis mediante inmunohistoquímica de la expresión de aSMA en tejido pancreático procedente de ratones WT y Cav1KO cuatro días tras el tratamiento con ceruleína. (C) Cuantificación del porcentaje de tejido pancreático afectado por una ADM generalizada cuatro días después del tratamiento con ceruleína en ratones WT ( $n=4)$ y Cav1KO ( $n=3)$. (D) Análisis de la expresión de YAP mediante inmunohistoquímica en tejido pancreático procedente de 
ratones WT y Cav1KO cuatro días después del tratamiento con ceruleína. (E) Cuantificación del porcentaje de área nuclear total cubierta por tinción de YAP en imágenes de inmunohistoquímica de tejido pancreático procedente de ratones WT y Cav1KO $2 \mathrm{~h}$ y cuatro días después del tratamiento con ceruleína y sin tratar (control). $n=8$. Los datos están representados cómo la media $\pm S E M ; * P<0.05$ y * $P<0.01$. 
7. Discusión 
CAV1 y caveolas están implicadas en diferentes procesos de mecanotransducción de señales, siendo capaces de responder a diferentes señales mecánicas provenientes del ambiente extracelular, tales como las fuerzas de cizallamiento ejercidas por el flujo sanguíneo sobre las células endoteliales (Boyd et al., 2003), la pérdida de adhesión al sustrato (del Pozo et al., 2004) y el aumento de la tensión en la MP por estiramiento de la célula o por variaciones en el volumen a raíz de cambios en la osmolaridad extracelular (Sinha et al., 2011). En esta Tesis Doctoral se ha estudiado el papel de CAV1 en la respuesta a cambios en la rigidez de la MEC. Se ha analizado en primer lugar, utilizando para ello matrices con diferente rigidez, como la rigidez del ambiente extracelular que rodea a las células afecta a la dinámica y la distribución de CAV1. Posteriormente, mediante un estudio detallado de los cambios transcripcionales globales en células con y sin CAV1, se identificaron los programas transcripcionales específicos que estaban regulados por CAV1 en respuesta a cambios en la rigidez de la MEC. Así, se pudo determinar la existencia de la regulación por parte de CAV1 de la actividad de YAP, un co-factor transcripcional con un papel relevante como efector final en procesos de mecanotransducción (Dupont et al., 2011). Los experimentos presentados en esta Tesis apoyan la existencia de un módulo de regulación de la adaptación mecánica operado por CAV1-YAP de relevancia sustancial en procesos fisiopatológicos, y describen mecanismos clave que determinan su funcionamiento. En particular se ha estudiado su implicación en el control del remodelado de la MEC (in vitro) y en un modelo in vivo de pancreatitis inducida por la administración de ceruleína en ratones.

Trabajos previos han sugerido que CAV1 podría determinar la respuesta a la rigidez de la MEC. En particular, se ha visto que la internalización y activación de integrinas en células creciendo sobre sustratos blandos es dependiente de CAV1, y que ese mecanismo determina la diferenciación de las células madre de la médula ósea (Du et al., 2011). También, en un trabajo más reciente, se ha estudiado la implicación de CAV1 en la regulación de las adhesiones focales en respuesta a cambios en la rigidez de la MEC a través del control de los niveles de integrina $\beta 1$ (Yeh et al., 2017). El primero de los estudios sugiere que CAV1 se internaliza en sustratos blandos y el segundo que sus niveles varían en función de la rigidez, siendo menores en sustratos blandos. Los resultados presentados en esta Tesis apoyan una regulación de CAV1 mediada por su internalización en sustratos blandos. Además, hemos podido comprobar que la internalización de CAV1 promueve su movilización a un compartimento perinuclear que expresa la GTPasa Rab11, es decir, un endosoma de reciclaje (Sonnichsen et al., 2000). De esa observación se deduce que el destino final de CAV1 tras la internalización en condiciones de baja rigidez de la MEC no es la degradación, sino un endosoma que permite el retorno de CAV1 a la MP. Se trata, como ya hemos mencionado, de la misma vía de internalización que sigue CAV1 al 
eliminar la adhesión de las células al sustrato (Muriel et al., 2011). CAV1 colocaliza con PTRF en la MP formando parte de las caveolas y dando lugar a un patrón de distribución específico (Hill et al., 2008). Los resultados obtenidos indican que la colocalización entre ambas proteínas disminuye en sustratos blandos. Esa disminución en la colocalización correlaciona con la movilización de CAV1 desde la fracción resistente a detergentes a la fracción soluble sugiriendo la salida de esta de los dominios ordenados enriquecidos en colesterol y esfingolípidos, lo que podría indicar también que existe una disminución en el número de caveolas. Estos cambios de distribución de CAV1 tienen una relevancia potencial notable porque permitirían la integración o coordinación de esta regulación dinámica con la modulación de múltiples rutas de señalización cuyos nodos de control (por ejemplo, receptores de membrana) se localizan específicamente en caveolas. Esa modulación de la señalización celular en respuesta a cambios en la rigidez de la MEC situaría a CAV1 como un mecanosensor específico de este estímulo mecánico concreto.

La rigidez de la MEC afecta de forma significativa a los patrones transcripcionales de las células tanto en 2D como en 3D (Loring et al., 2001) determinando la morfología celular, la adhesión al sustrato, la migración, la proliferación, el destino celular de las células madre, las interacciones celulares y procesos como la regeneración tisular (Evans et al., 2009; Huebsch et al., 2015; Lo et al., 2000; Schrader et al., 2011; Yeung et al., 2005). En el análisis del transcriptoma mediante ARNsec, pudimos comprobar que existían diferencias notables entre los cambios observados en células que expresan CAV1 y las que no la expresaban, incluyendo redes de genes que responden específicamente a la rigidez del sustrato. Estos resultados confirman nuestra hipótesis en base a la cual CAV1 es un regulador clave de la mecanotransducción de información mecánica derivada de la rigidez del sustrato. El análisis del ARNsec nos proporcionó, además, gran cantidad de datos preliminares interesantes, no sólo acerca de los procesos y funciones potencialmente controlados por CAV1, sino también otros que son regulados por la rigidez de la MEC independientemente de CAV1 que merecería la pena evaluar más en detalle. Sin embargo, dado que el interés de nuestro estudio era ver el papel de CAV1 en la respuesta a cambios en la rigidez de la MEC, decidimos centrarnos únicamente en la caracterización de los patrones transcripcionales modulados por esta proteína.

Entre los genes regulados positivamente por la rigidez de la MEC exclusivamente en células con CAV1 se encontraban muchos componentes de las adhesiones focales y del citoesqueleto, que se sabe que tienen un papel determinante en el control de los cambios asociados a las variaciones en la rigidez del ambiente extracelular (Chan and Odde, 2008; Gupta et al., 2015; Pelham and Wang, 1997). La regulación a nivel transcripcional de sus componentes y reguladores se ha descrito como un mecanismo de respuesta y adaptación al estímulo 
mecánico (Nardone et al., 2017) y este control transcripcional de esos componentes estructurales de la célula está mediado en gran medida por YAP (Nardone et al., 2017). Nuestras observaciones apoyan que CAV1 regula la actividad transcripcional de YAP en diferentes modelos celulares apareciendo como un mecanismo general que opera en diferentes tipos celulares incluyendo fibroblastos murinos, células tumorales humanas o hepatocitos primarios. Estudios de correlación de la expresión génica en colecciones extensas de transcriptomas (300 líneas celulares establecidas) corroboran la interdependencia de la expresión de CAV1 y los programas transcripcionales regulados por YAP. Dado que el control de la expresión de la proteína CAV1 está regulado a también nivel transcripcional (Sonntag et al., 2014) y este control transcripcional es relevante a nivel funcional (Pellinen et al., 2018) estas observaciones apoyaban la existencia de un sistema mecanotransductor responsivo a cambios en la rigidez de sustrato, regulado por CAV1 y operado a nivel transcripcional por YAP.

Tal y como se ha mencionado en la sección de introducción los efectores finales de la vía de señalización Hippo son YAP y TAZ. En muchos trabajos se hace referencia a ambos como si se tratase de una misma proteína, dado que su regulación es muy similar, pero existe cierto grado de especificidad en sus funciones. Una evidencia clara en este sentido es el hecho de que la ablación genética de Yap es letal a nivel embrionario (Morin-Kensicki et al., 2006), mientras que los embriones Taz KO sí que llegan a término (Hossain et al., 2007; Makita et al., 2008). Existen otros ejemplos de funciones exclusivas de YAP o de TAZ, cómo el papel de YAP en el remodelado de la MEC (Calvo et al., 2013) y la existencia de algunos mecanismos de regulación diferentes entre ambas proteínas (Chao Tang, 2018). Así, en los resultados presentados en este trabajo hacemos referencia únicamente a YAP, ya que la mayoría de los experimentos están enfocados a caracterizar el papel y los mecanismos que controlan esta proteína, como es el caso de los experimentos con las construcciones YAP-Flag y YAP(S5A)-Flag, los datos de interatómica y el estudio de los niveles de fosforilación. Sin embargo, dado que muchos de los genes regulados por el complejo YAP-TEAD son regulados también por TAZ-TEAD (Pobbati and Hong, 2013), y a la vista de los cambios transcripcionales y de actividad de TEAD observados, es posible que muchas de las conclusiones obtenidas sean también extensibles a la función de TAZ. Pese a ello, serían necesarios experimentos adicionales para confirmar tal extremo.

Tratándose de una vía de regulación tan importante a nivel funcional para células y organismos no es de extrañar que existan en esta vía mecanismos de control diversos para su regulación precisa. Uno de estos mecanismos de control es la regulación de la expresión de componentes de la vía Hippo, como por ejemplo NF2 y LATS2 por parte de YAP/TAZ. La expresión de esos componentes inhibe a su vez la actividad de YAP/TAZ, constituyendo de esta manera 
una retroalimentación negativa que determina la activación transitoria de la vía (Chen et al., 2015; Dai et al., 2015; Moroishi et al., 2015). Otro mecanismo interno de regulación implica la regulación cruzada de la expresión de YAP y TAZ, de tal forma que la bajada en los niveles o la actividad de YAP provocan un aumento en los niveles de TAZ y el aumento en los niveles o la actividad de TAZ una bajada en los niveles de YAP, mediante un mecanismo post-transcripcional dependiente de la degradación en el proteasoma (Moroishi et al., 2015). En nuestro caso no observamos cambios en la expresión ni de NF2 ni de LATS2 entre células WT y Cav1KO, lo cual indica que en nuestro sistema esta regulación no es determinante de las diferencias fenotípicas observadas entre ambos genotipos. Sin embargo, sí que pudimos observar un aumento en los niveles de TAZ tanto a nivel de ARNm como de proteína en las células Cav1KO, sugiriendo que podría existir un nivel diferente de regulación a nivel transcripcional, que junto con la regulación postranscripcional previamente descrita estaría contribuyendo a la formación del bucle de retroalimentación negativa. Estos mecanismos de regulación han sido además descritos como específicamente asociados a la dinámica de formación y desensamblaje de adhesiones focales, sugiriendo un papel relevante en la mecanotransducción de información derivada de la comunicación entre célula y sustrato (Sero and Bakal, 2017). Para confirmarlo sería necesario silenciar Yap en MEF WT y comprobar si eso provocaba un aumento de Taz a nivel transcripcional. Sin embargo, es importante destacar que ese aumento en los niveles de TAZ en Cav1KO no es suficiente para rescatar la deficiente actividad de YAP/TAZ en estas células, al menos en nuestro sistema.

La translocación de YAP del citoplasma al núcleo se ha descrito como un indicador del aumento en su actividad (Yagi et al., 1999). En este sentido los cambios observados en la actividad transcripcional de YAP correlacionan con cambios en su localización subcelular, de tal forma que en las células Cav1KO YAP se localizaba retenido en el citosol, mientras que en las WT se observó una mayor acumulación de este cofactor en el núcleo. Uno de los factores determinantes en la regulación de la actividad de YAP es el área celular, de modo que en las células que no presentan un estiramiento completo, por ejemplo por encontrarse localizadas en un espacio de crecimiento restringido o sobre una matriz blanda, YAP se encuentra retenido en el citosol (Dupont et al., 2011). Esta regulación se sabe además que es independiente de la superficie de adhesión, ya que no se observan diferencias en la distribución de YAP en células con un mismo área pero con una superficie de adhesión diferente (Nardone et al., 2017). Además del área celular, también regulan su actividad la densidad celular, el contacto con otras células y el número de protrusiones celulares y su extensión (Nardone et al., 2017; Zhao et al., 2007). El uso de micropatrones de área y geometría definidos nos permitió minimizar la 
influencia de variables como área celular, confluencia relativa y contactos célula-célula en la activación de YAP. Los resultados obtenidos con estos micropatrones, en los que se observó que existían diferencias en la localización subcelular de YAP entre células WT y Cav1KO con la misma morfología y área celular, sugieren, por tanto, que las diferencias observadas entre ambos genotipos no son secundarios, derivados del impacto de los niveles de Cav1 sobre los parámetros anteriores. De hecho, cabe inferir que, en base a los resultados obtenidos, CAV1 es necesario para la respuesta de YAP a cambios en el área celular.

Además de en la modulación de la respuesta de YAP a cambios en la rigidez de la MEC y de la morfología celular, CAV1 está implicada en la modulación de la respuesta a un estímulo diferente, el estiramiento mecánico. Se ha descrito que esta activación mecánica de YAP puede depender de la activación de la quinasa c-Jun N-terminal (JNK), que inhibe la actividad de las quinasas LATS1/2 (Codelia et al., 2014) o bien ser independiente de la actividad de las quinasas de la vía Hippo (Aragona et al., 2013). De igual forma, se sabe que CAV1 puede activar JNK en determinados contextos (Wang et al., 2018). Por todo ello sería interesante de cara al futuro estudiar el papel de JNK en la activación de YAP dependiente de CAV1 en respuesta al estiramiento mecánico y comprobar si la regulación es dependiente o independiente de LATS1/2. Además, sería interesante comprobar si los mecanismos moleculares que están mediando esta respuesta son los mismos que determinan la respuesta a cambios en la rigidez de la MEC.

El citoesqueleto de actina integra muchas de las señales que modulan la actividad final de YAP, como por ejemplo la señalización por GPCRs, a través del control de las quinasas de la vía Hippo (Yu et al., 2015). Su integridad es también esencial para la transducción de señales mecánicas desde el exterior celular y el control mecánico de la actividad de YAP. El citoesqueleto constituye un andamiaje funcional que implica la conexión directa de la MEC con el nucleoesqueleto, transmitiendo fuerzas entre el exterior y el interior celular. En este sentido, se ha descrito (Nardone et al., 2017) que esa conexión directa a través de un complejo multiproteico que une el citoesqueleto y el nucleoesqueleto es necesaria para la translocación de YAP al núcleo en respuesta a estímulos mecánicos (Driscoll et al., 2015). Esa conexión posibilita la transmisión directa de la fuerza desde el exterior celular afectando a la estructura y morfología nuclear y determinando la apertura de los poros nucleares, posibilitando de esa manera la entrada de YAP, en un proceso que sería independiente de la actividad de las quinasas de la vía Hippo (Elosegui-Artola et al., 2017). En este contexto, el control de la dinámica y la estructura del citoesqueleto de actina por CAV1 aparece como determinante en el control de la actividad de YAP en nuestro sistema, ya que (i) en células sin CAV1 el citoesqueleto de actina se 
encuentra más desorganizado, y (ii) la inducción de la polimerización de actina en células sin CAV1 aumenta la translocación de YAP al núcleo y su actividad transcripcional hasta niveles similares a los observados en células WT.

Inicialmente, el hecho de que CAV1 controlase la actividad de RhoA y el citoesqueleto de actina-miosina (Goetz et al., 2011; Grande-Garcia et al., 2007) y de que RhoA y la contracción de actina-miosina controlase la actividad de YAP (Dupont et al., 2011; Ohgushi et al., 2015) nos llevó a plantearnos la hipótesis de la existencia de una regulación a través de un eje CAV1-RhoAYAP que explicaría los fenotipos observados. Sin embargo, los resultados obtenidos no confirmaban esta hipótesis inicial, sugiriendo que otros mecanismos adicionales estarían participando en la regulación de YAP por CAV1. Así, aunque la actividad de RhoA, tal y como se deduce de los experimentos con el inhibidor de ROCK, es necesaria para la activación de YAP en nuestro sistema, el rescate de la actividad de RhoA en células Cav1KO no es suficiente para rescatar la actividad normal de YAP.

El control del flujo y la distribución del calcio intracelular por parte de determinados canales iónicos tiene un papel determinante en el control de muchos procesos de mecanotransducción de señales, siendo algunos de esos canales capaces de responder a cambios en la rigidez de la MEC, como es el caso de los canales catiónicos activados por estiramiento mecánico (Leclerc et al., 2012; Pathak et al., 2014; Tonelli et al., 2012). Los datos presentados en esta Tesis Doctoral sugieren que la entrada de calcio es necesaria para la regulación CAV1-YAP, determinando la actividad de YAP como regulador transcripcional a través del control de su fosforilación y su consiguiente retención en el citosol. En ausencia de CAV1, la actividad de YAP aumenta al aumentar los niveles de calcio en el citosol con el tratamiento con tapsigargina, lo cual es indicativo de la relevancia del calcio en esta ruta de señalización. Los datos indican, por tanto, que los niveles de calcio en el citosol podrían ser más bajos en las células Cav1KO que en las WT y esa diferencia explicaría las diferencias observadas en la actividad de YAP, pero para confirmar esa hipótesis serían necesarios experimentos adicionales. Una posibilidad es que las diferencias proviniesen de diferencias en la entrada de calcio a través de la membrana plasmática, es decir que CAV1 estuviera regulando de alguna manera la funcionalidad de los canales de calcio, una posibilidad apoyada por evidencias experimentales que confirman el papel de CAV1 en la regulación de algunos de esos canales y en la consiguiente modulación de la señalización por calcio (Pani and Singh, 2009). En particular, sería interesante estudiar el papel de dos canales concretos, PIEZO1 y PIEZO2, ya que se ha descrito que ambos canales son capaces de regular los niveles de calcio intracelular en respuesta a cambios mecánicos (Coste et al., 2010; Li et al., 2015), determinan en última instancia la actividad de 
RhoA y la dinámica del citoesqueleto de actina (Pardo-Pastor et al., 2018) y están implicados en el control de la actividad de YAP en respuesta a cambios la rigidez de la MEC, (Pathak et al., 2014).

Hay trabajos que sugieren que la regulación mecánica de YAP por el citoesqueleto de actina es independiente de la fosforilación y de las quinasas de la vía Hippo, ya que (i) el silenciamiento de la expresión de las quinasas LATS1/2 no afecta a la respuesta mecánica de YAP (Aragona et al., 2013; Dupont et al., 2011), (ii) los mutantes de YAP no fosforilables no son capaces de rescatar los defectos en la actividad de YAP cuando las células se encuentran sobre sustratos blandos (Aragona et al., 2013; Elosegui-Artola et al., 2017) y (iii) la rigidez del sustrato no afecta a la fosforilación de YAP (Elosegui-Artola et al., 2017). Otros estudios apuntan en la dirección contraria, y describen que la fosforilación de YAP aumenta en las células que crecen sobre sustratos blandos (Chakraborty et al., 2017; Das et al., 2016). Además otros trabajos afirman que la integridad del citoesqueleto de actina determina la actividad de las quinasas Hippo, controlando la fosforilación y la distribución subcelular de YAP (Densham et al., 2009; Wada et al., 2011) y en algunos casos esa regulación dependiente de la fosforilación juega un papel importante en la respuesta a algunos estímulos mecánicos, como la perdida de adhesión al sustrato (Zhao et al., 2012). Todo ello indica que no existe un sólo mecanismo de regulación actina-YAP, sino que podrían coexistir una regulación dependiente de la fosforilación y una regulación independiente y ambos mecanismos podrían ser importantes en la modulación de la respuesta a estímulos mecánicos. Los datos obtenidos en este trabajo apuntan en esa dirección. Hemos observado que la regulación CAV1-YAP en respuesta a estímulos mecánicos depende de la integridad del citoesqueleto de actina y que esta regulación de YAP por actina parece ser dependiente de la fosforilación ya que (i) la fosforilación de YAP aumenta con el tratamiento con CytD exclusivamente en células WT y (ii) la sobreexpresión del mutante de YAP no fosforilable rescata la actividad de YAP en células tratadas con CytD. También hemos visto que esa regulación es independiente de la actividad de las quinasas de la vía Hippo, lo cual sugiere que no se trata de la vía de regulación actina-YAP a través del control de las quinasas LATS1/2 que se había caracterizado previamente (Wada et al., 2011; Zhao et al., 2012), sino que se trata de una ruta diferente dependiente de fosforilación e independiente de LATS1/2 quinasas. Nuevamente, la ausencia de un rescate en la actividad de YAP al silenciar Ywhah en sustratos blandos también apoya la participación de un mecanismo de regulación mecánica de la actividad de YAP que es independiente de la fosforilación en nuestro sistema celular. Por tanto, según los datos obtenidos en esta Tesis, y teniendo en cuenta los datos publicados previamente, podría 
considerarse que existen tres mecanismos diferentes de regulación de la actividad de YAP por actina (Figura 50).

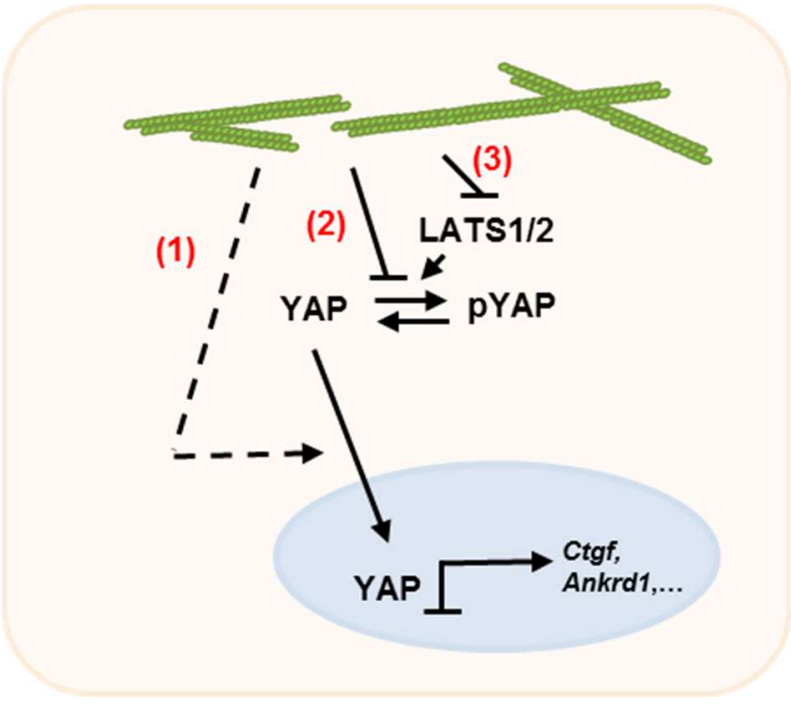

Figura 50. Mecanismos de regulación de la actividad de YAP por el citoesqueleto de actina. (1) Regulación independiente de la fosforilación, a través del control del núcleo y la apertura de los poros nucleares. (2) Nueva regulación identificada, dependiente de la fosforilación e independiente de las quinasas de la vía Hippo. (3) Regulación dependiente del control de la actividad de las quinasas LATS1/2 por actina.

Se conocen y están bien caracterizadas muchas proteínas que interaccionan con YAP contribuyendo a la regulación de su actividad, como es el caso de las diferentes quinasas capaces de fosforilarlo, las proteínas 14-3-3 o los factores nucleares que posibilitan su actividad transcripcional. En trabajos previos se ha estudiado el interactoma de diferentes componentes de la vía mediante estudios de proteómica como el presentado en esta Tesis Doctoral. Estos estudios se han realizado utilizando células en condiciones en las que YAP está activo en una sola condición experimental (Couzens et al., 2013; Hauri et al., 2013; Kohli et al., 2014). En el estudio presentado aquí, hemos utilizado tres condiciones experimentales diferentes, una utilizando células WT, en la que YAP se encuentra activo; otra con células Cav1KO, en las que YAP está inactivo, y una tercera con células tratadas con CytD, en las que YAP también está inactivo. Además hemos usado como cebo de la inmunoprecipitación la proteína YAP endógena, a diferencia de trabajos previamente publicados en los que se han utilizado construcciones expresadas de forma exógena (Couzens et al., 2013; Hauri et al., 2013; Kohli et al., 2014). Tal y como hemos comentado en la sección de resultados algunos de los interactores identificados ya se conocían, y otros se habían descrito como interactores de otros componentes de la vía.

La translocación de YAP al núcleo depende en gran medida de la estructura y conformación de los poros nucleares, siendo esta translocación un proceso activo mediado por Ran GTPasas (Elosegui-Artola et al., 2017). YAP carece de señales de localización y de exportación nucleares, por lo que precisa de transportadores accesorios para su salida y entrada 
del núcleo (Liu et al., 2012). Sin embargo, esos transportadores y sus mecanismos de regulación no se conocen bien. En este sentido nuestro estudio de proteómica puede contribuir a clarificar este punto ya que hemos identificado diferentes componentes del poro nuclear, así como proteínas implicadas en el transporte núcleo-citosol, que podrían por tanto ser partícipes de estos procesos. Es el caso, por ejemplo, de la Importina-7 (IPO7) que está implicada en el transporte de proteínas al núcleo de forma autónoma a través del reconocimiento de señales de localización nuclear, mediante mecanismos dependientes de la GTPasa Ran, o bien en asociación con la subunidad de la importina beta (KPNB1) (Golomb et al., 2012; Jakel et al., 2002). El papel de estas importinas podría ser determinante en la translocación de YAP al núcleo, ya que otra importina, la Importina $\alpha 1$, se ha identificado como un mediador en el transporte al núcleo de Yki en Drosophila (Wang et al., 2016). Además de las importinas, se identificaron también otras proteínas implicadas en el transporte de proteínas al núcleo, cómo es el caso de una isoforma de la proteína de unión a GTP Ran (RASL2-9), la proteína de unión a Ran 2 (RANBP2) y otros componentes estructurales y organizadores del poro nuclear. Nuestro análisis funcional sistemático posterior usando microscopia y análisis de imagen automatizados demostraron que distintos interactores de estas categorías funcionales (NUP155, NUP98 y AHCTF) eran de hecho necesarios para determinar la entrada al núcleo de YAP. Los diferentes componentes del poro nuclear determinan el reconocimiento selectivo y la modificación de los cargos y transportadores específicos con los que interaccionan de forma directa para permitir su paso a través de los mismos, regulando de esta manera el tráfico núcleo-citosólico (Wente and Rout, 2010). Por tanto, NUP155, AHCTF1 y NUP98 podrían estar implicadas en ese reconocimiento específico de YAP, o de las importinas/exportinas o Ran GTPasas y otros reguladores que determinan su translocación al núcleo, posibilitando su entrada en ese compartimento subcelular.

El hecho de que YAP interaccione con proteínas 14-3-3 tanto en células tratadas con CytD como en Cav1KO sugiere que la retención en el citosol por estas proteínas podría ser determinante en nuestro sistema, en el que CAV1 regula la actividad de YAP a través del control del citoesqueleto de actina. En concreto hemos identificado la interacción de YAP con varias proteínas de la familia YWHA, una familia muy conservada de proteínas reguladoras con dominio 14-3-3 de unión a fosfo-serina/treonina formada por 7 miembros (YWHAB, YWHAE, YWHAG, YWHAH, YWHAQ, SFN e YWHAZ). En el análisis funcional posterior analizamos el papel de YWHAB, YWHAQ, YWHAG, YWHAE e YWHAH en la retención de YAP en el citosol en células Cav1KO, y observamos que el silenciamiento de Ywhab e Ywhah aumentaba la translocación de YAP al núcleo, por lo que ambas parecían estar implicadas en su retención en el citosol. En el 
caso concreto de Ywhah su silenciamiento rescataba además la actividad transcripcional de YAP en células Cav1KO y en células tratadas con CytD. La interacción de YAP con proteínas 14-3-3 aumenta en las células que crecen sobre sustratos blandos (Chakraborty et al., 2017; Das et al., 2016), por lo que se podría pensar que esa interacción podría tener una implicación también en la inactivación de YAP en ese contexto mecánico. Sin embargo, hemos podido comprobar que el silenciamiento de Ywhah no aumenta la actividad transcripcional de YAP en células creciendo sobre sustratos blandos, lo cual indica que existe un mecanismo de regulación mecánica de YAP independiente y dominante sobre el eje CAV1-actina-Ywhah. Podría tratarse de un mecanismo de regulación directa de los poros nucleares por fuerzas mecánicas independiente de fosforilación, previamente descrito (Elosegui-Artola et al., 2017). Según esta hipótesis, en células creciendo sobre sustratos blandos la eliminación de YWHAH no sería capaz de aumentar la translocación al núcleo, pese a disminuir su retención citosólica, porque la conformación de los poros nucleares lo estaría impidiendo.

Es importante remarcar que en este trabajo nos hemos enfocado en el papel de CAV1 en la modulación de la actividad mecánica de YAP, pero no hemos estudiado el papel concreto de las caveolas. Sería interesante de cara al futuro distinguir si los fenotipos observados son dependientes de caveolas o dependen de la CAV1 no-caveolar. Para ello se podrían hacer experimentos silenciando los diferentes componentes de las caveolas, o utilizando líneas celulares que expresan CAV1, pero no presentan caveolas al carecer de PTRF, como es el caso de la línea celular de cáncer de próstata PC-3 (Hill et al., 2008).

Nuestros experimentos confirman por un lado que los cambios en la rigidez de la MEC controlan la distribución subcelular de CAV1 y por otro lado que CAV1 modula la activación de YAP en respuesta a esos cambios en la rigidez de la matriz extracelular. Sin embargo, no se aportan suficientes evidencias experimentales para confirmar una relación entre ambas observaciones, no se puede asegurar con los datos presentados que CAV1 actúe como un mecanosensor de la rigidez de la matriz extracelular determinando la activación de YAP en función de esta. Pero, pese a ello, las evidencias mostradas permiten especular acerca de esa posibilidad. Una hipótesis posible es que en condiciones de baja rigidez de la MEC la distribución diferente de CAV1 impida su efecto directo sobre el citoesqueleto de actina manteniendo YAP inactivo en el citosol, mientras que, en condiciones de alta rigidez de la MEC, en las que CAV1 se localiza en la MP estaría controlando la organización del citoesqueleto de actina y permitiendo por tanto la translocación de YAP al núcleo celular. En el futuro, nuevos experimentos permitirán evaluar estas hipótesis, para confirmar o descartar el papel de CAV1 cómo mecanosensor en esta vía y los detalles mecanísticos subyacentes a esta regulación. 
CAV1 y YAP comparten su implicación en la progresión y el desarrollo de algunas patologías (Tabla 5). Por tanto, en todos estos procesos fisiopatológicos, la regulación CAV1-YAP descrita en esta Tesis Doctoral podría ser relevante.

\begin{tabular}{|c|c|c|}
\hline Proceso patológico & Implicación de YAP & Implicación de caveolina \\
\hline $\begin{array}{l}\text { Regeneración } \\
\text { hepática }\end{array}$ & $\begin{array}{l}\text { YAP se activa tras la hepatectomía } \\
\text { parcial y contribuye a la regeneración } \\
\text { del hígado (Grijalva et al., 2014). }\end{array}$ & $\begin{array}{l}\text { Los ratones Cav1KO no son capaces } \\
\text { de regenerar el hígado tras una } \\
\text { hepatectomía parcial (Fernandez et } \\
\text { al., 2006). }\end{array}$ \\
\hline Distrofia muscular & $\begin{array}{l}\text { Los miofibroblastos procedentes de } \\
\text { pacientes de distrofia muscular con } \\
\text { mutaciones en LMNA presentan una } \\
\text { menor activación de YAP por estímulos } \\
\text { mecánicos y cambios en la rigidez de la } \\
\text { MEC (Bertrand et al., 2014). }\end{array}$ & $\begin{array}{l}\text { Los pacientes con distrofia muscular } \\
\text { de Limb-girdle presentan una } \\
\text { reducción en los niveles de } \\
\text { expresión de CAV3 (Minetti et al., } \\
\text { 1998). } \\
\text { La deficiencia en Cav3 en ratones } \\
\text { provoca degeneración muscular } \\
\text { (Hagiwara et al., 2000). }\end{array}$ \\
\hline $\begin{array}{l}\text { Remodelado de la } \\
\text { MEC por TAF }\end{array}$ & $\begin{array}{l}\text { YAP es necesario para el remodelado } \\
\text { de la MEC por los TAF, favoreciendo la } \\
\text { capacidad de los tumores de invadir y la } \\
\text { angiogénesis (Calvo et al., 2013). }\end{array}$ & $\begin{array}{c}\text { La expresión de CAV1 en el estroma } \\
\text { peritumoral favorece la invasión y la } \\
\text { metástasis (Goetz et al., 2011). }\end{array}$ \\
\hline $\begin{array}{l}\text { Desarrollo y } \\
\text { progresión tumoral }\end{array}$ & $\begin{array}{l}\text { YAP y TAZ están implicados en el } \\
\text { desarrollo y el crecimiento de una gran } \\
\text { variedad de tipos de tumores. Su } \\
\text { activación determina la } \\
\text { reprogramación, proliferación y } \\
\text { supervivencia de las células tumorales, } \\
\text { y favorece la quimioresistencia y la } \\
\text { metástasis (Zanconato et al., 2016). }\end{array}$ & $\begin{array}{c}\text { En algunos tipos de cáncer CAV1 } \\
\text { actúa como un oncogén } \\
\text { favoreciendo la transformación y el } \\
\text { crecimiento de las células tumorales } \\
\text { y favoreciendo la metástasis (Goetz } \\
\text { et al., 2008). }\end{array}$ \\
\hline
\end{tabular}

Tabla 5. Procesos fisiopatológicos afectados por la actividad de YAP y de proteínas de la familia de las caveolinas.

La rigidez de la MEC regula el correcto desarrollo y la homeostasis de órganos y tejidos (Mammoto and Ingber, 2010) existiendo por tanto una relación directa entre las alteraciones de la rigidez de la MEC y la progresión y desarrollo de algunas patologías. Es el caso de la progresión tumoral, contexto en el que determina tanto el crecimiento de los tumores como la invasión y la metástasis (Friedl and Gilmour, 2009; Levental et al., 2009; Paszek et al., 2005; Zhang et al., 2017). Las células responsables de controlar la rigidez de la MEC a través de la regulación de su composición y su organización tridimensional son los fibroblastos (Bonnans et al., 2014). En el caso de tumores, esos fibroblastos reciben el nombre de fibroblastos asociados a tumores (TAF). El estroma asociado a tumores presenta una rigidez superior que el tejido conectivo sano en su misma localización, debido a un aumento en la concentración de componentes y el remodelado 
de la MEC (Maller et al., 2013). Esa rigidez del estroma peritumoral induce la proliferación, supervivencia, migración y EMT de las células tumorales determinado la malignidad del tumor (DuFort et al., 2011; Levental et al., 2009). No es de extrañar por tanto que la activación de los TAF, a través de su implicación en el remodelado de la MEC, contribuya a la malignidad de los tumores y a su progresión (Calvo et al., 2013; Goetz et al., 2011). La activación de YAP por el aumento de la rigidez de la MEC en el ambiente peritumoral determina la activación de los TAF, contribuyendo al remodelado del estroma y al aumento de la rigidez de la MEC y formando un bucle de retroalimentación positivo que favorece la progresión tumoral (Calvo et al., 2013). Del mismo modo, la expresión de CAV1 contribuye positivamente al remodelado de la MEC por los TAF, favoreciendo en última instancia la progresión del tumor y la metástasis (Goetz et al., 2011). Nuestras observaciones sugieren una estrecha relación entre ambas asociaciones, ya que la expresión de YAP(5SA)-Flag, que rescata los programas de expresión génica dependientes de YAP en MEF Cav1KO, rescata también la actividad remodeladora de la MEC. Los resultados presentados en este trabajo sugieren por tanto que la regulación de YAP por CAV1 determina la activación de los TAF y el remodelado de la MEC lo que sitúa el eje de regulación CAV1-YAP como un factor clave en la comunicación estroma-tumor determinando la malignidad del cáncer.

La participación de YAP en el desarrollo y progresión tumoral se pone de manifiesto también en su contribución al desarrollo del PDAC. En este contexto patológico YAP contribuye a la dediferenciación acinar en el proceso de ADM (Gruber et al., 2016; Murakami et al., 2017). Los resultados presentados en este trabajo sugieren que la regulación CAV1-YAP tiene un papel en la progresión y desarrollo de la ADM, ya que observamos una menor incidencia/extensión de este fenotipo en los páncreas de ratones Cav1KO tratados con ceruleína que en los de ratones WT. La pancreatitis está caracterizada por la infiltración de células inmunes, y la generación de un edema interlobular e interacinar y el desarrollo de fibrosis (Murakami et al., 2017). Se sabe, además, que los procesos inflamatorios aumentan la rigidez de los tejidos (Hidalgo, 2012), lo cual permite hipotetizar que la activación de YAP mediada por CAV1 en este proceso patológico se podría deber al aumento en la rigidez del estroma pancreático, inducido por la inflamación derivada del tratamiento con cerulina. Las evidencias experimentales presentadas suponen una confirmación de la existencia de la regulación CAV1-YAP in vivo, e indican la potencial implicación de esta regulación en la iniciación y progresión del PDAC.

En conjunto, los datos presentados a lo largo de esta Tesis Doctoral, presentan un nuevo mecanismo por el cual CAV1 modula la respuesta de las células a la rigidez de la MEC y otros estímulos mecánicos, a través del control de la actividad de YAP (Figura 51). Los resultados obtenidos permiten confirmar que CAV1 afecta positivamente a la actividad de YAP en 
condiciones de alta rigidez de la MEC y en diferentes tipos celulares. Hemos observado además que la rigidez de la MEC afecta a la distribución subcelular de CAV1, por tanto, aunque no se puede confirmar con los datos expuestos, CAV1 podría estar actuando en este contexto cómo un mecanosensor capaz de responder a cambios en la rigidez de la MEC a través del control de la actividad de YAP. Esta regulación de YAP por CAV1 en respuesta a estímulos mecánicos es dependiente de la fosforilación de YAP, estando mediada por la participación de YWHAH, que determina su retención citosólica cuando YAP esta fosforilada. En esta regulación hemos visto que tiene un papel fundamental el citoesqueleto de actina, siendo el control de la actina por CAV1 determinante para el control de la actividad de YAP. Por último, hemos caracterizado la implicación de este nuevo eje de regulación CAV1-YAP en el control de procesos fisiopatológicos, como el remodelado de la matriz extracelular y la respuesta a la pancreatitis. Dado que ambas proteínas están relacionadas con la progresión de otras patologías comunes (Tabla 5), no sería de extrañar la implicación en otros procesos fisiológicos y patológicos. En conjunto, estas observaciones sugieren que el módulo descrito de regulación CAV1-YAP podría determinar el desarrollo y la progresión de diferentes patologías, como por ejemplo el cáncer, y podría por tanto constituir una potencial diana terapéutica y un potencial marcador diagnóstico.
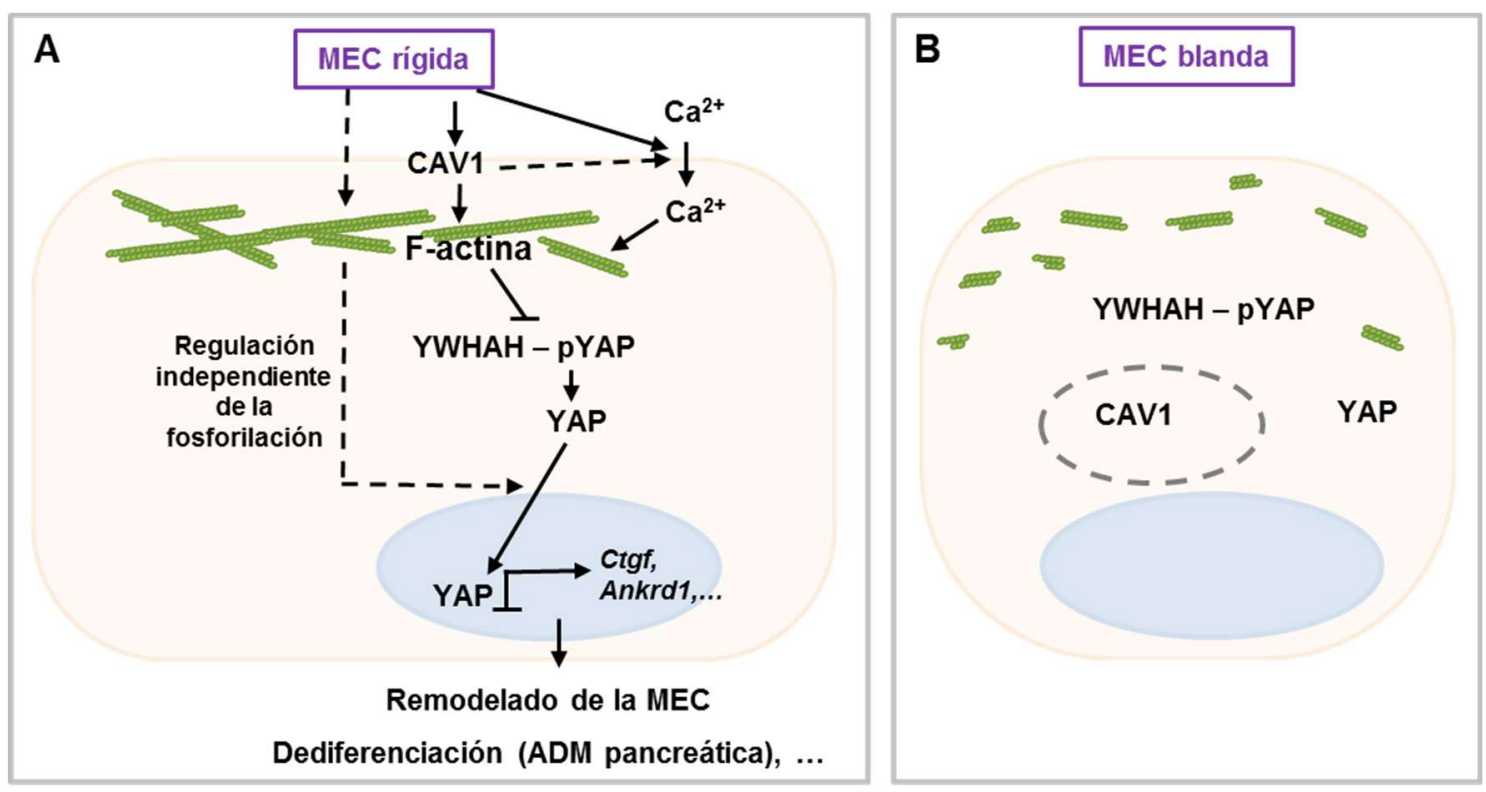

Figura 51. Esquema representativo de la regulación de la actividad de YAP por CAV1 en respuesta a cambios en la rigidez de la MEC. (A) En células creciendo sobre sustratos blandos CAV1 se encuentra localizada preferentemente en la MP. En esta condición CAV1 regula negativamente la interacción de YAP (fosforilado) con YWHAH inhibiendo su retención citosólica y favoreciendo su translocación al núcleo, en un proceso que es dependiente del citoesqueleto de actina. La actina se polimeriza formando fibras en un proceso que depende de CAV1 facilitando la transmisión del estímulo mecánico desde el exterior al interior celular, favoreciendo la translocación de YAP al núcleo mediante mecanismos tanto dependientes como independientes de la fosforilación. El control del citoesqueleto de actina podría depender de la mayor entrada de $\mathrm{Ca}^{2+}$ en condiciones de alta rigidez de la MEC, tal y como se ha descrito (Pathak et al., 2014), y esa entrada diferencial de $\mathrm{Ca}^{2+}$ podría ser dependiente a su vez de CAV1, según nuestros 
resultados. Esa regulación de YAP por CAV1 determinaría procesos fisiopatológicos cómo son el remodelado de la MEC y la ADM en el páncreas. (B) Cuando las células crecen sobre matrices blandas CAV1 se internaliza, la actina no polimeriza formando fibras y en consecuencia YAP permanece retenida en el citosol. 


\section{Conclusiones}


I. La distribución subcelular de CAV1 se ve afectada por la rigidez de la matriz extracelular, internalizándose en condiciones de baja rigidez y acumulándose en un endosoma de reciclaje.

II. CAV1 determina la activación de YAP en respuesta a diferentes estímulos mecánicos, entre ellos la rigidez de la matriz extracelular.

III. La regulación de YAP por CAV1 depende del control que CAV1 ejerce sobre la dinámica y organización del citoesqueleto de actina.

IV. La actividad de RhoA es necesaria para la regulación CAV1-YAP, pero las diferencias en la actividad de RhoA entre células con y sin CAV1 no son suficientes para explicar los cambios fenotípicos observados, indicando que otros mecanismos independientes de RhoA tienen un papel determinante.

V. La regulación CAV1-YAP depende de la fosforilación de YAP, detectándose un aumento en la fosforilación de YAP en células sin CAV1, pero no es estrictamente dependiente de la actividad de las quinasas de la vía Hippo.

VI. El transporte regulado de Ca2+ es un factor determinante en el control de la actividad de YAP por CAV1.

VII. La interacción de YAP con la proteína con dominio 14-3-3 YWHAH, determina la retención de YAP en el citosol en células sin CAV1 y en las que presentan un citoesqueleto de actina desorganizado, indicando que CAV1 regula negativamente la interacción YAP-YWHAH a través del control del citoesqueleto de actina.

VIII. El control de la actividad de YAP por CAV1 determina el papel de ambas proteínas en el remodelado de la MEC por parte de los fibroblastos.

IX. El eje de regulación CAV1-YAP controla el proceso de dediferenciación de células acinares (ADM) en respuesta al proceso inflamatorio inducido por el tratamiento con ceruleína. 
9. Bibliografía 
Aboulaich, N., Vainonen, J.P., Stralfors, P., and Vener, A.V. (2004). Vectorial proteomics reveal targeting, phosphorylation and specific fragmentation of polymerase $I$ and transcript release factor (PTRF) at the surface of caveolae in human adipocytes. Biochem J 383, 237-248.

Adler, J.J., Johnson, D.E., Heller, B.L., Bringman, L.R., Ranahan, W.P., Conwell, M.D., Sun, Y., Hudmon, A., and Wells, C.D. (2013). Serum deprivation inhibits the transcriptional co-activator YAP and cell growth via phosphorylation of the 130-kDa isoform of Angiomotin by the LATS1/2 protein kinases. Proc Natl Acad Sci U S A 110, 17368-17373.

Alarcon, C., Zaromytidou, A.I., Xi, Q., Gao, S., Yu, J., Fujisawa, S., Barlas, A., Miller, A.N., ManovaTodorova, K., Macias, M.J., et al. (2009). Nuclear CDKs drive Smad transcriptional activation and turnover in BMP and TGF-beta pathways. Cell 139, 757-769.

Aragona, M., Panciera, T., Manfrin, A., Giulitti, S., Michielin, F., Elvassore, N., Dupont, S., and Piccolo, S. (2013). A mechanical checkpoint controls multicellular growth through YAP/TAZ regulation by actin-processing factors. Cell 154, 1047-1059.

Ardestani, A., Lupse, B., and Maedler, K. (2018). Hippo Signaling: Key Emerging Pathway in Cellular and Whole-Body Metabolism. Trends in endocrinology and metabolism: TEM 29, 492509.

Ariotti, N., Fernandez-Rojo, M.A., Zhou, Y., Hill, M.M., Rodkey, T.L., Inder, K.L., Tanner, L.B., Wenk, M.R., Hancock, J.F., and Parton, R.G. (2014). Caveolae regulate the nanoscale organization of the plasma membrane to remotely control Ras signaling. J Cell Biol 204, 777-792.

Attisano, L., and Wrana, J.L. (2013). Signal integration in TGF-beta, WNT, and Hippo pathways. F1000prime reports 5, 17.

Austin, E.D., Ma, L., LeDuc, C., Berman Rosenzweig, E., Borczuk, A., Phillips, J.A., 3rd, Palomero, T., Sumazin, P., Kim, H.R., Talati, M.H., et al. (2012). Whole exome sequencing to identify a novel gene (caveolin-1) associated with human pulmonary arterial hypertension. Circulation Cardiovascular genetics 5, 336-343.

Azzolin, L., Panciera, T., Soligo, S., Enzo, E., Bicciato, S., Dupont, S., Bresolin, S., Frasson, C., Basso, G., Guzzardo, V., et al. (2014). YAP/TAZ incorporation in the beta-catenin destruction complex orchestrates the Wnt response. Cell 158, 157-170.

Bastiani, M., Liu, L., Hill, M.M., Jedrychowski, M.P., Nixon, S.J., Lo, H.P., Abankwa, D., Luetterforst, R., Fernandez-Rojo, M., Breen, M.R., et al. (2009). MURC/Cavin-4 and cavin family members form tissue-specific caveolar complexes. J Cell Biol 185, 1259-1273.

Basu, S., Totty, N.F., Irwin, M.S., Sudol, M., and Downward, J. (2003). Akt phosphorylates the Yes-associated protein, YAP, to induce interaction with 14-3-3 and attenuation of p73-mediated apoptosis. Mol Cell 11, 11-23.

Bender, F.C., Reymond, M.A., Bron, C., and Quest, A.F. (2000). Caveolin-1 levels are downregulated in human colon tumors, and ectopic expression of caveolin-1 in colon carcinoma cell lines reduces cell tumorigenicity. Cancer Res 60, 5870-5878.

Benham-Pyle, B.W., Pruitt, B.L., and Nelson, W.J. (2015). Cell adhesion. Mechanical strain induces $\mathrm{E}$-cadherin-dependent Yap1 and beta-catenin activation to drive cell cycle entry. Science 348, 1024-1027.

Bertrand, A.T., Ziaei, S., Ehret, C., Duchemin, H., Mamchaoui, K., Bigot, A., Mayer, M., QuijanoRoy, S., Desguerre, I., Laine, J., et al. (2014). Cellular microenvironments reveal defective mechanosensing responses and elevated YAP signaling in LMNA-mutated muscle precursors. Journal of cell science 127, 2873-2884. 
Birmingham, A., Selfors, L.M., Forster, T., Wrobel, D., Kennedy, C.J., Shanks, E., Santoyo-Lopez, J., Dunican, D.J., Long, A., Kelleher, D., et al. (2009). Statistical methods for analysis of highthroughput RNA interference screens. Nat Methods 6, 569-575.

Blanchoin, L., Boujemaa-Paterski, R., Sykes, C., and Plastino, J. (2014). Actin dynamics, architecture, and mechanics in cell motility. Physiol Rev 94, 235-263.

Bonnans, C., Chou, J., and Werb, Z. (2014). Remodelling the extracellular matrix in development and disease. Nat Rev Mol Cell Biol 15, 786-801.

Bosch, M., Mari, M., Gross, S.P., Fernandez-Checa, J.C., and Pol, A. (2011a). Mitochondrial cholesterol: a connection between caveolin, metabolism, and disease. Traffic 12, 1483-1489.

Bosch, M., Mari, M., Herms, A., Fernandez, A., Fajardo, A., Kassan, A., Giralt, A., Colell, A., Balgoma, D., Barbero, E., et al. (2011b). Caveolin-1 deficiency causes cholesterol-dependent mitochondrial dysfunction and apoptotic susceptibility. Curr Biol 21, 681-686.

Boscher, C., and Nabi, I.R. (2012). Caveolin-1: role in cell signaling. Adv Exp Med Biol 729, 29-50.

Boudaoud, A., Burian, A., Borowska-Wykret, D., Uyttewaal, M., Wrzalik, R., Kwiatkowska, D., and Hamant, O. (2014). FibrilTool, an ImageJ plug-in to quantify fibrillar structures in raw microscopy images. Nat Protoc 9, 457-463.

Boulware, M.I., Kordasiewicz, H., and Mermelstein, P.G. (2007). Caveolin proteins are essential for distinct effects of membrane estrogen receptors in neurons. The Journal of neuroscience : the official journal of the Society for Neuroscience 27, 9941-9950.

Boyd, N.L., Park, H., Yi, H., Boo, Y.C., Sorescu, G.P., Sykes, M., and Jo, H. (2003). Chronic shear induces caveolae formation and alters ERK and Akt responses in endothelial cells. Am J Physiol Heart Circ Physiol 285, H1113-1122.

Brazer, S.C., Singh, B.B., Liu, X., Swaim, W., and Ambudkar, I.S. (2003). Caveolin-1 contributes to assembly of store-operated $\mathrm{Ca} 2+$ influx channels by regulating plasma membrane localization of TRPC1. J Biol Chem 278, 27208-27215.

Busija, A.R., Patel, H.H., and Insel, P.A. (2017). Caveolins and cavins in the trafficking, maturation, and degradation of caveolae: implications for cell physiology. Am J Physiol Cell Physiol 312, C459-C477.

Calvo, F., Ege, N., Grande-Garcia, A., Hooper, S., Jenkins, R.P., Chaudhry, S.I., Harrington, K., Williamson, P., Moeendarbary, E., Charras, G., et al. (2013). Mechanotransduction and YAPdependent matrix remodelling is required for the generation and maintenance of cancerassociated fibroblasts. Nat Cell Biol 15, 637-646.

Callus, B.A., Verhagen, A.M., and Vaux, D.L. (2006). Association of mammalian sterile twenty kinases, Mst1 and Mst2, with hSalvador via C-terminal coiled-coil domains, leads to its stabilization and phosphorylation. Febs J 273, 4264-4276.

Camargo, F.D., Gokhale, S., Johnnidis, J.B., Fu, D., Bell, G.W., Jaenisch, R., and Brummelkamp, T.R. (2007). YAP1 increases organ size and expands undifferentiated progenitor cells. Curr Biol 17, 2054-2060.

Cao, H., Alston, L., Ruschman, J., and Hegele, R.A. (2008). Heterozygous CAV1 frameshift mutations (MIM 601047) in patients with atypical partial lipodystrophy and hypertriglyceridemia. Lipids in health and disease 7, 3. 
Cao, H., Courchesne, W.E., and Mastick, C.C. (2002). A phosphotyrosine-dependent protein interaction screen reveals a role for phosphorylation of caveolin-1 on tyrosine 14: recruitment of C-terminal Src kinase. J Biol Chem 277, 8771-8774.

Casella, J.F., Flanagan, M.D., and Lin, S. (1981). Cytochalasin D inhibits actin polymerization and induces depolymerization of actin filaments formed during platelet shape change. Nature 293, 302-305.

Codelia, V.A., Sun, G., and Irvine, K.D. (2014). Regulation of YAP by mechanical strain through Jnk and Hippo signaling. Curr Biol 24, 2012-2017.

Cordenonsi, M., Zanconato, F., Azzolin, L., Forcato, M., Rosato, A., Frasson, C., Inui, M., Montagner, M., Parenti, A.R., Poletti, A., et al. (2011). The Hippo transducer TAZ confers cancer stem cell-related traits on breast cancer cells. Cell 147, 759-772.

Coste, B., Mathur, J., Schmidt, M., Earley, T.J., Ranade, S., Petrus, M.J., Dubin, A.E., and Patapoutian, A. (2010). Piezo1 and Piezo2 are essential components of distinct mechanically activated cation channels. Science 330, 55-60.

Couet, J., Li, S., Okamoto, T., Ikezu, T., and Lisanti, M.P. (1997). Identification of peptide and protein ligands for the caveolin-scaffolding domain. Implications for the interaction of caveolin with caveolae-associated proteins. J Biol Chem 272, 6525-6533.

Couzens, A.L., Knight, J.D., Kean, M.J., Teo, G., Weiss, A., Dunham, W.H., Lin, Z.Y., Bagshaw, R.D., Sicheri, F., Pawson, T., et al. (2013). Protein interaction network of the mammalian Hippo pathway reveals mechanisms of kinase-phosphatase interactions. Sci Signal 6, rs15.

Cox, A.G., Hwang, K.L., Brown, K.K., Evason, K., Beltz, S., Tsomides, A., O'Connor, K., Galli, G.G., Yimlamai, D., Chhangawala, S., et al. (2016). Yap reprograms glutamine metabolism to increase nucleotide biosynthesis and enable liver growth. Nat Cell Biol 18, 886-896.

Chakraborty, S., Njah, K., Pobbati, A.V., Lim, Y.B., Raju, A., Lakshmanan, M., Tergaonkar, V., Lim, C.T., and Hong, W. (2017). Agrin as a Mechanotransduction Signal Regulating YAP through the Hippo Pathway. Cell Rep 18, 2464-2479.

Chan, C.E., and Odde, D.J. (2008). Traction dynamics of filopodia on compliant substrates. Science 322, 1687-1691.

Chan, E.H., Nousiainen, M., Chalamalasetty, R.B., Schafer, A., Nigg, E.A., and Sillje, H.H. (2005). The Ste20-like kinase Mst2 activates the human large tumor suppressor kinase Lats1. Oncogene 24, 2076-2086.

Chao Tang, A.T.-K., Ippei Kikuchi, Chi Ben, Masanori Hatakeyama (2018). Transcriptional Coactivator Functions of YAP and TAZ Are Inversely Regulated by Tyrosine Phosphorylation Status of Parafibromin. iScience 2, 103.

Chatterjee, M., Ben-Josef, E., Thomas, D.G., Morgan, M.A., Zalupski, M.M., Khan, G., Andrew Robinson, C., Griffith, K.A., Chen, C.S., Ludwig, T., et al. (2015). Caveolin-1 is Associated with Tumor Progression and Confers a Multi-Modality Resistance Phenotype in Pancreatic Cancer. Sci Rep 5, 10867.

Chaudhary, N., Gomez, G.A., Howes, M.T., Lo, H.P., McMahon, K.A., Rae, J.A., Schieber, N.L., Hill, M.M., Gaus, K., Yap, A.S., et al. (2014). Endocytic crosstalk: cavins, caveolins, and caveolae regulate clathrin-independent endocytosis. PLoS Biol 12, e1001832. 
Chen, E.Y., Tan, C.M., Kou, Y., Duan, Q., Wang, Z., Meirelles, G.V., Clark, N.R., and Ma'ayan, A. (2013). Enrichr: interactive and collaborative HTML5 gene list enrichment analysis tool. BMC Bioinformatics 14, 128.

Chen, H.H., Maeda, T., Mullett, S.J., and Stewart, A.F. (2004). Transcription cofactor Vgl-2 is required for skeletal muscle differentiation. Genesis 39, 273-279.

Chen, Q., Zhang, N., Xie, R., Wang, W., Cai, J., Choi, K.S., David, K.K., Huang, B., Yabuta, N., Nojima, H., et al. (2015). Homeostatic control of Hippo signaling activity revealed by an endogenous activating mutation in YAP. Genes Dev 29, 1285-1297.

Chen, X., Nadiarynkh, O., Plotnikov, S., and Campagnola, P.J. (2012). Second harmonic generation microscopy for quantitative analysis of collagen fibrillar structure. Nat Protoc 7, 654669.

Cheng, J.P.X., and Nichols, B.J. (2016). Caveolae: One Function or Many? Trends Cell Biol 26, 177189.

Dai, X., Liu, H., Shen, S., Guo, X., Yan, H., Ji, X., Li, L., Huang, J., Feng, X.H., and Zhao, B. (2015). YAP activates the Hippo pathway in a negative feedback loop. Cell Res 25, 1175-1178.

Damm, E.M., Pelkmans, L., Kartenbeck, J., Mezzacasa, A., Kurzchalia, T., and Helenius, A. (2005). Clathrin- and caveolin-1-independent endocytosis: entry of simian virus 40 into cells devoid of caveolae. J Cell Biol 168, 477-488.

Das, A., Fischer, R.S., Pan, D., and Waterman, C.M. (2016). YAP Nuclear Localization in the Absence of Cell-Cell Contact Is Mediated by a Filamentous Actin-dependent, Myosin II- and Phospho-YAP-independent Pathway during Extracellular Matrix Mechanosensing. J Biol Chem 291, 6096-6110.

del Pozo, M.A., Alderson, N.B., Kiosses, W.B., Chiang, H.H., Anderson, R.G., and Schwartz, M.A. (2004). Integrins regulate Rac targeting by internalization of membrane domains. Science 303, 839-842.

del Pozo, M.A., Balasubramanian, N., Alderson, N.B., Kiosses, W.B., Grande-Garcia, A., Anderson, R.G., and Schwartz, M.A. (2005). Phospho-caveolin-1 mediates integrin-regulated membrane domain internalization. Nat Cell Biol 7, 901-908.

del Pozo, M.A., Vicente-Manzanares, M., Tejedor, R., Serrador, J.M., and Sanchez-Madrid, F. (1999). Rho GTPases control migration and polarization of adhesion molecules and cytoskeletal ERM components in T lymphocytes. Eur J Immunol 29, 3609-3620.

Densham, R.M., O'Neill, E., Munro, J., Konig, I., Anderson, K., Kolch, W., and Olson, M.F. (2009). MST kinases monitor actin cytoskeletal integrity and signal via c-Jun N-terminal kinase stressactivated kinase to regulate p21Waf1/Cip1 stability. Mol Cell Biol 29, 6380-6390.

Discher, D.E., Janmey, P., and Wang, Y.L. (2005). Tissue cells feel and respond to the stiffness of their substrate. Science 310, 1139-1143.

Dong, J., Feldmann, G., Huang, J., Wu, S., Zhang, N., Comerford, S.A., Gayyed, M.F., Anders, R.A., Maitra, A., and Pan, D. (2007). Elucidation of a universal size-control mechanism in Drosophila and mammals. Cell 130, 1120-1133.

Drab, M., Verkade, P., Elger, M., Kasper, M., Lohn, M., Lauterbach, B., Menne, J., Lindschau, C., Mende, F., Luft, F.C., et al. (2001). Loss of caveolae, vascular dysfunction, and pulmonary defects in caveolin-1 gene-disrupted mice. Science 293, 2449-2452. 
Driscoll, T.P., Cosgrove, B.D., Heo, S.J., Shurden, Z.E., and Mauck, R.L. (2015). Cytoskeletal to Nuclear Strain Transfer Regulates YAP Signaling in Mesenchymal Stem Cells. Biophys J 108, 27832793.

Du, J., Chen, X., Liang, X., Zhang, G., Xu, J., He, L., Zhan, Q., Feng, X.Q., Chien, S., and Yang, C. (2011). Integrin activation and internalization on soft ECM as a mechanism of induction of stem cell differentiation by ECM elasticity. Proceedings of the National Academy of Sciences of the United States of America 108, 9466-9471.

DuFort, C.C., Paszek, M.J., and Weaver, V.M. (2011). Balancing forces: architectural control of mechanotransduction. Nat Rev Mol Cell Biol 12, 308-319.

Dupont, S., Morsut, L., Aragona, M., Enzo, E., Giulitti, S., Cordenonsi, M., Zanconato, F., Le Digabel, J., Forcato, M., Bicciato, S., et al. (2011). Role of YAP/TAZ in mechanotransduction. Nature 474, 179-183.

Dupree, P., Parton, R.G., Raposo, G., Kurzchalia, T.V., and Simons, K. (1993). Caveolae and sorting in the trans-Golgi network of epithelial cells. Embo J 12, 1597-1605.

Echarri, A., and Del Pozo, M.A. (2015). Caveolae - mechanosensitive membrane invaginations linked to actin filaments. J Cell Sci 128, 2747-2758.

Echarri, A., Muriel, O., Pavon, D.M., Azegrouz, H., Escolar, F., Terron, M.C., Sanchez-Cabo, F., Martinez, F., Montoya, M.C., Llorca, O., et al. (2012). Caveolar domain organization and trafficking is regulated by Abl kinases and mDia1. J Cell Sci 125, 3097-3113.

Elosegui-Artola, A., Andreu, I., Beedle, A.E.M., Lezamiz, A., Uroz, M., Kosmalska, A.J., Oria, R., Kechagia, J.Z., Rico-Lastres, P., Le Roux, A.L., et al. (2017). Force Triggers YAP Nuclear Entry by Regulating Transport across Nuclear Pores. Cell 171, 1397-1410 e1314.

Elosegui-Artola, A., Oria, R., Chen, Y., Kosmalska, A., Perez-Gonzalez, C., Castro, N., Zhu, C., Trepat, X., and Roca-Cusachs, P. (2016). Mechanical regulation of a molecular clutch defines force transmission and transduction in response to matrix rigidity. Nat Cell Biol 18, 540-548.

Engler, A.J., Sen, S., Sweeney, H.L., and Discher, D.E. (2006). Matrix elasticity directs stem cell lineage specification. Cell 126, 677-689.

Enzo, E., Santinon, G., Pocaterra, A., Aragona, M., Bresolin, S., Forcato, M., Grifoni, D., Pession, A., Zanconato, F., Guzzo, G., et al. (2015). Aerobic glycolysis tunes YAP/TAZ transcriptional activity. EMBO J 34, 1349-1370.

Evans, N.D., Minelli, C., Gentleman, E., LaPointe, V., Patankar, S.N., Kallivretaki, M., Chen, X., Roberts, C.J., and Stevens, M.M. (2009). Substrate stiffness affects early differentiation events in embryonic stem cells. Eur Cell Mater 18, 1-13; discussion 13-14.

Fairn, G.D., Schieber, N.L., Ariotti, N., Murphy, S., Kuerschner, L., Webb, R.I., Grinstein, S., and Parton, R.G. (2011). High-resolution mapping reveals topologically distinct cellular pools of phosphatidylserine. J Cell Biol 194, 257-275.

Feng, X., Liu, P., Zhou, X., Li, M.T., Li, F.L., Wang, Z., Meng, Z., Sun, Y.P., Yu, Y., Xiong, Y., et al. (2016). Thromboxane A2 Activates YAP/TAZ Protein to Induce Vascular Smooth Muscle Cell Proliferation and Migration. J Biol Chem 291, 18947-18958.

Fernandez, L.A., Northcott, P.A., Dalton, J., Fraga, C., Ellison, D., Angers, S., Taylor, M.D., and Kenney, A.M. (2009). YAP1 is amplified and up-regulated in hedgehog-associated medulloblastomas and mediates Sonic hedgehog-driven neural precursor proliferation. Genes Dev 23, 2729-2741. 
Fernandez, M.A., Albor, C., Ingelmo-Torres, M., Nixon, S.J., Ferguson, C., Kurzchalia, T., Tebar, F., Enrich, C., Parton, R.G., and Pol, A. (2006). Caveolin-1 is essential for liver regeneration. Science $313,1628-1632$.

Fischer, R.S., Myers, K.A., Gardel, M.L., and Waterman, C.M. (2012). Stiffness-controlled threedimensional extracellular matrices for high-resolution imaging of cell behavior. Nat Protoc 7 , 2056-2066.

Frank, P.G., Pavlides, S., and Lisanti, M.P. (2009). Caveolae and transcytosis in endothelial cells: role in atherosclerosis. Cell and tissue research 335, 41-47.

Friedl, P., and Gilmour, D. (2009). Collective cell migration in morphogenesis, regeneration and cancer. Nat Rev Mol Cell Biol 10, 445-457.

Fujita, A., Cheng, J., Tauchi-Sato, K., Takenawa, T., and Fujimoto, T. (2009). A distinct pool of phosphatidylinositol 4,5-bisphosphate in caveolae revealed by a nanoscale labeling technique. Proc Natl Acad Sci U S A 106, 9256-9261.

Galbiati, F., Engelman, J.A., Volonte, D., Zhang, X.L., Minetti, C., Li, M., Hou, H., Jr., Kneitz, B., Edelmann, W., and Lisanti, M.P. (2001). Caveolin-3 null mice show a loss of caveolae, changes in the microdomain distribution of the dystrophin-glycoprotein complex, and t-tubule abnormalities. J Biol Chem 276, 21425-21433.

Gambin, Y., Ariotti, N., McMahon, K.A., Bastiani, M., Sierecki, E., Kovtun, O., Polinkovsky, M.E., Magenau, A., Jung, W., Okano, S., et al. (2013). Single-molecule analysis reveals self assembly and nanoscale segregation of two distinct cavin subcomplexes on caveolae. Elife 3, e01434.

Gaus, K., Le Lay, S., Balasubramanian, N., and Schwartz, M.A. (2006). Integrin-mediated adhesion regulates membrane order. J Cell Biol 174, 725-734.

Gavva, N.R., Gavva, R., Ermekova, K., Sudol, M., and Shen, C.J. (1997). Interaction of WW domains with hematopoietic transcription factor p45/NF-E2 and RNA polymerase II. J Biol Chem 272, 24105-24108.

Geiger, B., Bershadsky, A., Pankov, R., and Yamada, K.M. (2001). Transmembrane crosstalk between the extracellular matrix--cytoskeleton crosstalk. Nat Rev Mol Cell Biol 2, 793-805.

Glenney, J.R., Jr. (1989). Tyrosine phosphorylation of a 22-kDa protein is correlated with transformation by Rous sarcoma virus. J Biol Chem 264, 20163-20166.

Glenney, J.R., Jr., and Soppet, D. (1992). Sequence and expression of caveolin, a protein component of caveolae plasma membrane domains phosphorylated on tyrosine in Rous sarcoma virus-transformed fibroblasts. Proc Natl Acad Sci U S A 89, 10517-10521.

Goetz, J.G., Lajoie, P., Wiseman, S.M., and Nabi, I.R. (2008). Caveolin-1 in tumor progression: the good, the bad and the ugly. Cancer Metastasis Rev 27, 715-735.

Goetz, J.G., Minguet, S., Navarro-Lerida, I., Lazcano, J.J., Samaniego, R., Calvo, E., Tello, M., Osteso-Ibanez, T., Pellinen, T., Echarri, A., et al. (2011). Biomechanical remodeling of the microenvironment by stromal caveolin-1 favors tumor invasion and metastasis. Cell 146, 148163.

Golomb, L., Bublik, D.R., Wilder, S., Nevo, R., Kiss, V., Grabusic, K., Volarevic, S., and Oren, M. (2012). Importin 7 and exportin 1 link c-Myc and p53 to regulation of ribosomal biogenesis. Mol Cell 45, 222-232.

Gorodinsky, A., and Harris, D.A. (1995). Glycolipid-anchored proteins in neuroblastoma cells form detergent-resistant complexes without caveolin. J Cell Biol 129, 619-627. 
Goulev, Y., Fauny, J.D., Gonzalez-Marti, B., Flagiello, D., Silber, J., and Zider, A. (2008). SCALLOPED interacts with YORKIE, the nuclear effector of the hippo tumor-suppressor pathway in Drosophila. Curr Biol 18, 435-441.

Grande-Garcia, A., Echarri, A., de Rooij, J., Alderson, N.B., Waterman-Storer, C.M., Valdivielso, J.M., and del Pozo, M.A. (2007). Caveolin-1 regulates cell polarization and directional migration through Src kinase and Rho GTPases. J Cell Biol 177, 683-694.

Grannas, K., Arngarden, L., Lonn, P., Mazurkiewicz, M., Blokzijl, A., Zieba, A., and Soderberg, O. (2015). Crosstalk between Hippo and TGFbeta: Subcellular Localization of YAP/TAZ/Smad Complexes. J Mol Biol 427, 3407-3415.

Grijalva, J.L., Huizenga, M., Mueller, K., Rodriguez, S., Brazzo, J., Camargo, F., Sadri-Vakili, G., and Vakili, K. (2014). Dynamic alterations in Hippo signaling pathway and YAP activation during liver regeneration. Am J Physiol Gastrointest Liver Physiol 307, G196-204.

Gruber, R., Panayiotou, R., Nye, E., Spencer-Dene, B., Stamp, G., and Behrens, A. (2016). YAP1 and TAZ Control Pancreatic Cancer Initiation in Mice by Direct Up-regulation of JAK-STAT3 Signaling. Gastroenterology 151, 526-539.

Guerra, C., Schuhmacher, A.J., Canamero, M., Grippo, P.J., Verdaguer, L., Perez-Gallego, L., Dubus, P., Sandgren, E.P., and Barbacid, M. (2007). Chronic pancreatitis is essential for induction of pancreatic ductal adenocarcinoma by K-Ras oncogenes in adult mice. Cancer Cell 11, 291-302.

Guha, P., Kaptan, E., Gade, P., Kalvakolanu, D.V., and Ahmed, H. (2017). Tunicamycin induced endoplasmic reticulum stress promotes apoptosis of prostate cancer cells by activating mTORC1. Oncotarget 8, 68191-68207.

Gupta, M., Sarangi, B.R., Deschamps, J., Nematbakhsh, Y., Callan-Jones, A., Margadant, F., Mege, R.M., Lim, C.T., Voituriez, R., and Ladoux, B. (2015). Adaptive rheology and ordering of cell cytoskeleton govern matrix rigidity sensing. Nat Commun 6, 7525.

Gupta, M.P., Kogut, P., and Gupta, M. (2000). Protein kinase-A dependent phosphorylation of transcription enhancer factor-1 represses its DNA-binding activity but enhances its gene activation ability. Nucleic Acids Res 28, 3168-3177.

Hagiwara, Y., Sasaoka, T., Araishi, K., Imamura, M., Yorifuji, H., Nonaka, I., Ozawa, E., and Kikuchi, T. (2000). Caveolin-3 deficiency causes muscle degeneration in mice. Hum Mol Genet 9, 30473054.

Han, S.E., Park, K.H., Lee, G., Huh, Y.J., and Min, B.M. (2004). Mutation and aberrant expression of Caveolin-1 in human oral squamous cell carcinomas and oral cancer cell lines. Int J Oncol 24, 435-440.

Hansen, C.G., Howard, G., and Nichols, B.J. (2011). Pacsin 2 is recruited to caveolae and functions in caveolar biogenesis. J Cell Sci 124, 2777-2785.

Hansen, C.G., and Nichols, B.J. (2010). Exploring the caves: cavins, caveolins and caveolae. Trends Cell Biol 20, 177-186.

Harvey, K., and Tapon, N. (2007). The Salvador-Warts-Hippo pathway - an emerging tumoursuppressor network. Nat Rev Cancer 7, 182-191.

Harvey, K.F., Pfleger, C.M., and Hariharan, I.K. (2003). The Drosophila Mst ortholog, hippo, restricts growth and cell proliferation and promotes apoptosis. Cell 114, 457-467. 
Hauri, S., Wepf, A., van Drogen, A., Varjosalo, M., Tapon, N., Aebersold, R., and Gstaiger, M. (2013). Interaction proteome of human Hippo signaling: modular control of the co-activator YAP1. Molecular systems biology 9, 713.

Hayer, A., Stoeber, M., Bissig, C., and Helenius, A. (2010). Biogenesis of caveolae: stepwise assembly of large caveolin and cavin complexes. Traffic 11, 361-382.

He, M., Zhou, Z., Shah, A.A., Hong, Y., Chen, Q., and Wan, Y. (2016). New insights into posttranslational modifications of Hippo pathway in carcinogenesis and therapeutics. Cell Div $11,4$.

Hellemans, J., Mortier, G., De Paepe, A., Speleman, F., and Vandesompele, J. (2007). qBase relative quantification framework and software for management and automated analysis of real-time quantitative PCR data. Genome Biol 8, R19.

Henley, J.R., Krueger, E.W., Oswald, B.J., and McNiven, M.A. (1998). Dynamin-mediated internalization of caveolae. J Cell Biol 141, 85-99.

Hidalgo, M. (2012). New insights into pancreatic cancer biology. Ann Oncol 23 Suppl 10, x135138.

Hill, M.M., Bastiani, M., Luetterforst, R., Kirkham, M., Kirkham, A., Nixon, S.J., Walser, P., Abankwa, D., Oorschot, V.M., Martin, S., et al. (2008). PTRF-Cavin, a conserved cytoplasmic protein required for caveola formation and function. Cell 132, 113-124.

Holzinger, A. (2009). Jasplakinolide: an actin-specific reagent that promotes actin polymerization. Methods Mol Biol 586, 71-87.

Hossain, Z., Ali, S.M., Ko, H.L., Xu, J., Ng, C.P., Guo, K., Qi, Z., Ponniah, S., Hong, W., and Hunziker, W. (2007). Glomerulocystic kidney disease in mice with a targeted inactivation of Wwtr1. Proc Natl Acad Sci U S A 104, 1631-1636.

Huang, J., Wu, S., Barrera, J., Matthews, K., and Pan, D. (2005). The Hippo signaling pathway coordinately regulates cell proliferation and apoptosis by inactivating Yorkie, the Drosophila Homolog of YAP. Cell 122, 421-434.

Huang, W., Lv, X., Liu, C., Zha, Z., Zhang, H., Jiang, Y., Xiong, Y., Lei, Q.Y., and Guan, K.L. (2012). The N-terminal phosphodegron targets TAZ/WWTR1 protein for SCFbeta-TrCP-dependent degradation in response to phosphatidylinositol 3-kinase inhibition. J Biol Chem 287, 2624526253.

Huebsch, N., Lippens, E., Lee, K., Mehta, M., Koshy, S.T., Darnell, M.C., Desai, R.M., Madl, C.M., $\mathrm{Xu}, \mathrm{M}$., Zhao, X., et al. (2015). Matrix elasticity of void-forming hydrogels controls transplantedstem-cell-mediated bone formation. Nature materials 14, 1269-1277.

Ishizaki, T., Morishima, Y., Okamoto, M., Furuyashiki, T., Kato, T., and Narumiya, S. (2001). Coordination of microtubules and the actin cytoskeleton by the Rho effector mDia1. Nat Cell Biol 3, 8-14.

Jaalouk, D.E., and Lammerding, J. (2009). Mechanotransduction gone awry. Nat Rev Mol Cell Biol 10, 63-73.

Jacquemin, P., Hwang, J.J., Martial, J.A., Dolle, P., and Davidson, I. (1996). A novel family of developmentally regulated mammalian transcription factors containing the TEA/ATTS DNA binding domain. J Biol Chem 271, 21775-21785. 
Jakel, S., Mingot, J.M., Schwarzmaier, P., Hartmann, E., and Gorlich, D. (2002). Importins fulfil a dual function as nuclear import receptors and cytoplasmic chaperones for exposed basic domains. EMBO J 21, 377-386.

Jiang, S.W., Dong, M., Trujillo, M.A., Miller, L.J., and Eberhardt, N.L. (2001). DNA binding of TEA/ATTS domain factors is regulated by protein kinase $C$ phosphorylation in human choriocarcinoma cells. J Biol Chem 276, 23464-23470.

Joshi, B., Strugnell, S.S., Goetz, J.G., Kojic, L.D., Cox, M.E., Griffith, O.L., Chan, S.K., Jones, S.J., Leung, S.P., Masoudi, H., et al. (2008). Phosphorylated caveolin-1 regulates Rho/ROCKdependent focal adhesion dynamics and tumor cell migration and invasion. Cancer Res 68, 82108220.

Kalluri, R. (2016). The biology and function of fibroblasts in cancer. Nat Rev Cancer 16, 582-598.

Kalluri, R., and Zeisberg, M. (2006). Fibroblasts in cancer. Nat Rev Cancer 6, 392-401.

Kaneko, K., Ito, M., Naoe, Y., Lacy-Hulbert, A., and Ikeda, K. (2014). Integrin alphav in the mechanical response of osteoblast lineage cells. Biochem Biophys Res Commun 447, 352-357.

Kango-Singh, M., Nolo, R., Tao, C., Verstreken, P., Hiesinger, P.R., Bellen, H.J., and Halder, G. (2002). Shar-pei mediates cell proliferation arrest during imaginal disc growth in Drosophila. Development 129, 5719-5730.

Klein, E.A., Yin, L., Kothapalli, D., Castagnino, P., Byfield, F.J., Xu, T., Levental, I., Hawthorne, E., Janmey, P.A., and Assoian, R.K. (2009). Cell-cycle control by physiological matrix elasticity and in vivo tissue stiffening. Curr Biol 19, 1511-1518.

Kohli, P., Bartram, M.P., Habbig, S., Pahmeyer, C., Lamkemeyer, T., Benzing, T., Schermer, B., and Rinschen, M.M. (2014). Label-free quantitative proteomic analysis of the YAP/TAZ interactome. Am J Physiol Cell Physiol 306, C805-818.

Komuro, A., Nagai, M., Navin, N.E., and Sudol, M. (2003). WW domain-containing protein YAP associates with ErbB-4 and acts as a co-transcriptional activator for the carboxyl-terminal fragment of ErbB-4 that translocates to the nucleus. J Biol Chem 278, 33334-33341.

Kovtun, O., Tillu, V.A., Ariotti, N., Parton, R.G., and Collins, B.M. (2015). Cavin family proteins and the assembly of caveolae. J Cell Sci 128, 1269-1278.

Kovtun, O., Tillu, V.A., Jung, W., Leneva, N., Ariotti, N., Chaudhary, N., Mandyam, R.A., Ferguson, C., Morgan, G.P., Johnston, W.A., et al. (2014). Structural insights into the organization of the cavin membrane coat complex. Dev Cell 31, 405-419.

Krajewska, W.M., and Maslowska, I. (2004). Caveolins: structure and function in signal transduction. Cellular \& molecular biology letters 9, 195-220.

Kubisch, C., Schoser, B.G., von During, M., Betz, R.C., Goebel, H.H., Zahn, S., Ehrbrecht, A., Aasly, J., Schroers, A., Popovic, N., et al. (2003). Homozygous mutations in caveolin-3 cause a severe form of rippling muscle disease. Annals of neurology 53, 512-520.

Kuleshov, M.V., Jones, M.R., Rouillard, A.D., Fernandez, N.F., Duan, Q., Wang, Z., Koplev, S., Jenkins, S.L., Jagodnik, K.M., Lachmann, A., et al. (2016). Enrichr: a comprehensive gene set enrichment analysis web server 2016 update. Nucleic Acids Res 44, W90-97.

Kulkarni, M., Tan, T.Z., Syed Sulaiman, N.B., Lamar, J.M., Bansal, P., Cui, J., Qiao, Y., and Ito, Y. (2018). RUNX1 and RUNX3 protect against YAP-mediated EMT, stem-ness and shorter survival outcomes in breast cancer. Oncotarget 9, 14175-14192. 
Kwon, H., Lee, J., Jeong, K., Jang, D., and Pak, Y. (2013). A novel actin cytoskeleton-dependent noncaveolar microdomain composed of homo-oligomeric caveolin-2 for activation of insulin signaling. Biochim Biophys Acta 1833, 2176-2189.

Lajoie, P., Goetz, J.G., Dennis, J.W., and Nabi, I.R. (2009a). Lattices, rafts, and scaffolds: domain regulation of receptor signaling at the plasma membrane. J Cell Biol 185, 381-385.

Lajoie, P., Kojic, L.D., Nim, S., Li, L., Dennis, J.W., and Nabi, I.R. (2009b). Caveolin-1 regulation of dynamin-dependent, raft-mediated endocytosis of cholera toxin-B sub-unit occurs independently of caveolae. J Cell Mol Med 13, 3218-3225.

Lariccia, V., Nasti, A.A., Alessandrini, F., Pesaresi, M., Gratteri, S., Tagliabracci, A., and Amoroso, S. (2014). Identification and functional analysis of a new putative caveolin-3 variant found in a patient with sudden unexplained death. Journal of biomedical science 21, 58 .

Leclerc, C., Neant, I., and Moreau, M. (2012). The calcium: an early signal that initiates the formation of the nervous system during embryogenesis. Frontiers in molecular neuroscience 5 , 3.

Lei, Q.Y., Zhang, H., Zhao, B., Zha, Z.Y., Bai, F., Pei, X.H., Zhao, S., Xiong, Y., and Guan, K.L. (2008). TAZ promotes cell proliferation and epithelial-mesenchymal transition and is inhibited by the hippo pathway. Mol Cell Biol 28, 2426-2436.

Levental, K.R., Yu, H., Kass, L., Lakins, J.N., Egeblad, M., Erler, J.T., Fong, S.F., Csiszar, K., Giaccia, A., Weninger, W., et al. (2009). Matrix crosslinking forces tumor progression by enhancing integrin signaling. Cell 139, 891-906.

Levy, D., Adamovich, Y., Reuven, N., and Shaul, Y. (2008). Yap1 phosphorylation by c-Abl is a critical step in selective activation of proapoptotic genes in response to DNA damage. Mol Cell 29, 350-361.

Li, C., Rezania, S., Kammerer, S., Sokolowski, A., Devaney, T., Gorischek, A., Jahn, S., Hackl, H., Groschner, K., Windpassinger, C., et al. (2015). Piezo1 forms mechanosensitive ion channels in the human MCF-7 breast cancer cell line. Sci Rep 5, 8364.

Li, S., Couet, J., and Lisanti, M.P. (1996). Src tyrosine kinases, Galpha subunits, and H-Ras share a common membrane-anchored scaffolding protein, caveolin. Caveolin binding negatively regulates the auto-activation of Src tyrosine kinases. J Biol Chem 271, 29182-29190.

Li, S., Galbiati, F., Volonte, D., Sargiacomo, M., Engelman, J.A., Das, K., Scherer, P.E., and Lisanti, M.P. (1998). Mutational analysis of caveolin-induced vesicle formation. Expression of caveolin1 recruits caveolin-2 to caveolae membranes. FEBS Lett 434, 127-134.

Li, T., Sotgia, F., Vuolo, M.A., Li, M., Yang, W.C., Pestell, R.G., Sparano, J.A., and Lisanti, M.P. (2006). Caveolin-1 mutations in human breast cancer: functional association with estrogen receptor alpha-positive status. Am J Pathol 168, 1998-2013.

Li, V.S., and Clevers, H. (2013). Intestinal regeneration: YAP-tumor suppressor and oncoprotein? Curr Biol 23, R110-112.

Li, W.P., Liu, P., Pilcher, B.K., and Anderson, R.G. (2001). Cell-specific targeting of caveolin-1 to caveolae, secretory vesicles, cytoplasm or mitochondria. J Cell Sci 114, 1397-1408.

Lin, K.C., Park, H.W., and Guan, K.L. (2017). Regulation of the Hippo Pathway Transcription Factor TEAD. Trends in biochemical sciences 42, 862-872.

Liu, A.M., Xu, Z., and Luk, J.M. (2012). An update on targeting Hippo-YAP signaling in liver cancer. Expert opinion on therapeutic targets 16, 243-247. 
Liu, C.Y., Lv, X., Li, T., Xu, Y., Zhou, X., Zhao, S., Xiong, Y., Lei, Q.Y., and Guan, K.L. (2011). PP1 cooperates with ASPP2 to dephosphorylate and activate TAZ. J Biol Chem 286, 5558-5566.

Liu, C.Y., Zha, Z.Y., Zhou, X., Zhang, H., Huang, W., Zhao, D., Li, T., Chan, S.W., Lim, C.J., Hong, W., et al. (2010). The hippo tumor pathway promotes TAZ degradation by phosphorylating a phosphodegron and recruiting the SCF\{beta\}-TrCP E3 ligase. J Biol Chem 285, 37159-37169.

Liu, L., Brown, D., McKee, M., Lebrasseur, N.K., Yang, D., Albrecht, K.H., Ravid, K., and Pilch, P.F. (2008). Deletion of Cavin/PTRF causes global loss of caveolae, dyslipidemia, and glucose intolerance. Cell metabolism 8, 310-317.

Lo, C.M., Wang, H.B., Dembo, M., and Wang, Y.L. (2000). Cell movement is guided by the rigidity of the substrate. Biophys J 79, 144-152.

Loring, J.F., Porter, J.G., Seilhammer, J., Kaser, M.R., and Wesselschmidt, R. (2001). A gene expression profile of embryonic stem cells and embryonic stem cell-derived neurons. Restorative neurology and neuroscience $18,81-88$.

Ludwig, A., Howard, G., Mendoza-Topaz, C., Deerinck, T., Mackey, M., Sandin, S., Ellisman, M.H., and Nichols, B.J. (2013). Molecular composition and ultrastructure of the caveolar coat complex. PLoS Biol 11, e1001640.

Mackay, A.M., Ainsztein, A.M., Eckley, D.M., and Earnshaw, W.C. (1998). A dominant mutant of inner centromere protein (INCENP), a chromosomal protein, disrupts prometaphase congression and cytokinesis. J Cell Biol 140, 991-1002.

Magee, A.I., and Parmryd, I. (2003). Detergent-resistant membranes and the protein composition of lipid rafts. Genome Biol 4, 234.

Mahoney, W.M., Jr., Hong, J.H., Yaffe, M.B., and Farrance, I.K. (2005). The transcriptional coactivator TAZ interacts differentially with transcriptional enhancer factor-1 (TEF-1) family members. Biochem J 388, 217-225.

Makita, R., Uchijima, Y., Nishiyama, K., Amano, T., Chen, Q., Takeuchi, T., Mitani, A., Nagase, T., Yatomi, Y., Aburatani, H., et al. (2008). Multiple renal cysts, urinary concentration defects, and pulmonary emphysematous changes in mice lacking TAZ. American journal of physiology Renal physiology 294, F542-553.

Maller, O., DuFort, C.C., and Weaver, V.M. (2013). YAP forces fibroblasts to feel the tension. Nat Cell Biol 15, 570-572.

Mammoto, T., and Ingber, D.E. (2010). Mechanical control of tissue and organ development. Development 137, 1407-1420.

Mana-Capelli, S., Paramasivam, M., Dutta, S., and McCollum, D. (2014). Angiomotins link F-actin architecture to Hippo pathway signaling. Mol Biol Cell 25, 1676-1685.

Matsui, Y., and Lai, Z.C. (2013). Mutual regulation between Hippo signaling and actin cytoskeleton. Protein Cell 4, 904-910.

Maugeri-Sacca, M., and De Maria, R. (2018). The Hippo pathway in normal development and cancer. Pharmacology \& therapeutics 186, 60-72.

Mayoral, R., Valverde, A.M., Llorente Izquierdo, C., Gonzalez-Rodriguez, A., Bosca, L., and Martin-Sanz, P. (2010). Impairment of transforming growth factor beta signaling in caveolin-1deficient hepatocytes: role in liver regeneration. J Biol Chem 285, 3633-3642. 
McClatchey, A.I., and Giovannini, M. (2005). Membrane organization and tumorigenesis--the NF2 tumor suppressor, Merlin. Genes Dev 19, 2265-2277.

Meng, Z., Moroishi, T., Mottier-Pavie, V., Plouffe, S.W., Hansen, C.G., Hong, A.W., Park, H.W., Mo, J.S., Lu, W., Lu, S., et al. (2015). MAP4K family kinases act in parallel to MST1/2 to activate LATS1/2 in the Hippo pathway. Nat Commun 6, 8357.

Miller, E., Yang, J., DeRan, M., Wu, C., Su, A.I., Bonamy, G.M., Liu, J., Peters, E.C., and Wu, X. (2012). Identification of serum-derived sphingosine-1-phosphate as a small molecule regulator of YAP. Chem Biol 19, 955-962.

Minetti, C., Sotgia, F., Bruno, C., Scartezzini, P., Broda, P., Bado, M., Masetti, E., Mazzocco, M., Egeo, A., Donati, M.A., et al. (1998). Mutations in the caveolin-3 gene cause autosomal dominant limb-girdle muscular dystrophy. Nat Genet 18, 365-368.

Mishra, M., Huang, J., and Balasubramanian, M.K. (2014). The yeast actin cytoskeleton. FEMS Microbiol Rev 38, 213-227.

Mo, J.S., Yu, F.X., Gong, R., Brown, J.H., and Guan, K.L. (2012). Regulation of the Hippo-YAP pathway by protease-activated receptors (PARs). Genes Dev 26, 2138-2143.

Monier, S., Dietzen, D.J., Hastings, W.R., Lublin, D.M., and Kurzchalia, T.V. (1996). Oligomerization of VIP21-caveolin in vitro is stabilized by long chain fatty acylation or cholesterol. FEBS Lett 388, 143-149.

Monier, S., Parton, R.G., Vogel, F., Behlke, J., Henske, A., and Kurzchalia, T.V. (1995). VIP21caveolin, a membrane protein constituent of the caveolar coat, oligomerizes in vivo and in vitro. Mol Biol Cell 6, 911-927.

Moren, B., Shah, C., Howes, M.T., Schieber, N.L., McMahon, H.T., Parton, R.G., Daumke, O., and Lundmark, R. (2012). EHD2 regulates caveolar dynamics via ATP-driven targeting and oligomerization. Mol Biol Cell 23, 1316-1329.

Morin-Kensicki, E.M., Boone, B.N., Howell, M., Stonebraker, J.R., Teed, J., Alb, J.G., Magnuson, T.R., O'Neal, W., and Milgram, S.L. (2006). Defects in yolk sac vasculogenesis, chorioallantoic fusion, and embryonic axis elongation in mice with targeted disruption of Yap65. Mol Cell Biol $26,77-87$.

Moroishi, T., Park, H.W., Qin, B., Chen, Q., Meng, Z., Plouffe, S.W., Taniguchi, K., Yu, F.X., Karin, M., Pan, D., et al. (2015). A YAP/TAZ-induced feedback mechanism regulates Hippo pathway

Morvaridi, S., Dhall, D., Greene, M.I., Pandol, S.J., and Wang, Q. (2015). Role of YAP and TAZ in pancreatic ductal adenocarcinoma and in stellate cells associated with cancer and chronic pancreatitis. Sci Rep 5, 16759.

Mundy, D.I., Li, W.P., Luby-Phelps, K., and Anderson, R.G. (2012). Caveolin targeting to late endosome/lysosomal membranes is induced by perturbations of lysosomal $\mathrm{pH}$ and cholesterol content. Mol Biol Cell 23, 864-880.

Murakami, S., Shahbazian, D., Surana, R., Zhang, W., Chen, H., Graham, G.T., White, S.M., Weiner, L.M., and Yi, C. (2017). Yes-associated protein mediates immune reprogramming in pancreatic ductal adenocarcinoma. Oncogene 36, 1232-1244.

Muriel, O., Echarri, A., Hellriegel, C., Pavon, D.M., Beccari, L., and Del Pozo, M.A. (2011). Phosphorylated filamin A regulates actin-linked caveolae dynamics. Journal of cell science 124, 2763-2776. 
Muslin, A.J., Tanner, J.W., Allen, P.M., and Shaw, A.S. (1996). Interaction of 14-3-3 with signaling proteins is mediated by the recognition of phosphoserine. Cell $84,889-897$.

Nam, K.H., Lee, B.L., Park, J.H., Kim, J., Han, N., Lee, H.E., Kim, M.A., Lee, H.S., and Kim, W.H. (2013). Caveolin 1 expression correlates with poor prognosis and focal adhesion kinase expression in gastric cancer. Pathobiology : journal of immunopathology, molecular and cellular biology 80, 87-94.

Nardone, G., Oliver-De La Cruz, J., Vrbsky, J., Martini, C., Pribyl, J., Skladal, P., Pesl, M., Caluori, G., Pagliari, S., Martino, F., et al. (2017). YAP regulates cell mechanics by controlling focal adhesion assembly. Nat Commun 8, 15321.

Navarro-Lerida, I., Alvarez-Barrientos, A., Gavilanes, F., and Rodriguez-Crespo, I. (2002). Distance-dependent cellular palmitoylation of de-novo-designed sequences and their translocation to plasma membrane subdomains. J Cell Sci 115, 3119-3130.

Niesman, I.R., Zemke, N., Fridolfsson, H.N., Haushalter, K.J., Levy, K., Grove, A., Schnoor, R., Finley, J.C., Patel, P.M., Roth, D.M., et al. (2013). Caveolin isoform switching as a molecular, structural, and metabolic regulator of microglia. Molecular and cellular neurosciences 56, 283297.

Noland, C.L., Gierke, S., Schnier, P.D., Murray, J., Sandoval, W.N., Sagolla, M., Dey, A., Hannoush, R.N., Fairbrother, W.J., and Cunningham, C.N. (2016). Palmitoylation of TEAD Transcription Factors Is Required for Their Stability and Function in Hippo Pathway Signaling. Structure 24, 179-186.

Nwosu, Z.C., Ebert, M.P., Dooley, S., and Meyer, C. (2016). Caveolin-1 in the regulation of cell metabolism: a cancer perspective. Mol Cancer 15, 71.

Ohgushi, M., Minaguchi, M., and Sasai, Y. (2015). Rho-Signaling-Directed YAP/TAZ Activity Underlies the Long-Term Survival and Expansion of Human Embryonic Stem Cells. Cell stem cell $17,448-461$.

Oka, T., Mazack, V., and Sudol, M. (2008). Mst2 and Lats kinases regulate apoptotic function of Yes kinase-associated protein (YAP). J Biol Chem 283, 27534-27546.

Oka, T., Remue, E., Meerschaert, K., Vanloo, B., Boucherie, C., Gfeller, D., Bader, G.D., Sidhu, S.S., Vandekerckhove, J., Gettemans, J., et al. (2010). Functional complexes between YAP2 and ZO-2 are PDZ domain-dependent, and regulate YAP2 nuclear localization and signalling. Biochem J 432, 461-472.

Okamoto, T., Schlegel, A., Scherer, P.E., and Lisanti, M.P. (1998). Caveolins, a family of scaffolding proteins for organizing "preassembled signaling complexes" at the plasma membrane. J Biol Chem 273, 5419-5422.

Orimo, A., Gupta, P.B., Sgroi, D.C., Arenzana-Seisdedos, F., Delaunay, T., Naeem, R., Carey, V.J., Richardson, A.L., and Weinberg, R.A. (2005). Stromal fibroblasts present in invasive human breast carcinomas promote tumor growth and angiogenesis through elevated SDF-1/CXCL12 secretion. Cell 121, 335-348.

Orr, A.W., Helmke, B.P., Blackman, B.R., and Schwartz, M.A. (2006). Mechanisms of mechanotransduction. Dev Cell 10, 11-20.

Ostermeyer, A.G., Paci, J.M., Zeng, Y., Lublin, D.M., Munro, S., and Brown, D.A. (2001). Accumulation of caveolin in the endoplasmic reticulum redirects the protein to lipid storage droplets. J Cell Biol 152, 1071-1078. 
Overholtzer, M., Zhang, J., Smolen, G.A., Muir, B., Li, W., Sgroi, D.C., Deng, C.X., Brugge, J.S., and Haber, D.A. (2006). Transforming properties of YAP, a candidate oncogene on the chromosome 11q22 amplicon. Proc Natl Acad Sci U S A 103, 12405-12410.

Palade, G.E. (1953). An electron microscope study of the mitochondrial structure. J Histochem Cytochem 1, 188-211.

Pani, B., and Singh, B.B. (2009). Lipid rafts/caveolae as microdomains of calcium signaling. Cell calcium 45, 625-633.

Pantalacci, S., Tapon, N., and Leopold, P. (2003). The Salvador partner Hippo promotes apoptosis and cell-cycle exit in Drosophila. Nat Cell Biol 5, 921-927.

Paramasivam, M., Sarkeshik, A., Yates, J.R., 3rd, Fernandes, M.J., and McCollum, D. (2011). Angiomotin family proteins are novel activators of the LATS2 kinase tumor suppressor. Mol Biol Cell 22, 3725-3733.

Pardo-Pastor, C., Rubio-Moscardo, F., Vogel-Gonzalez, M., Serra, S.A., Afthinos, A., Mrkonjic, S., Destaing, O., Abenza, J.F., Fernandez-Fernandez, J.M., Trepat, X., et al. (2018). Piezo2 channel regulates RhoA and actin cytoskeleton to promote cell mechanobiological responses. Proc Natl Acad Sci U S A 115, 1925-1930.

Parsons, J.T., Horwitz, A.R., and Schwartz, M.A. (2010). Cell adhesion: integrating cytoskeletal dynamics and cellular tension. Nat Rev Mol Cell Biol 11, 633-643.

Parton, R.G. (1994). Ultrastructural localization of gangliosides; GM1 is concentrated in caveolae. J Histochem Cytochem 42, 155-166.

Parton, R.G., and del Pozo, M.A. (2013). Caveolae as plasma membrane sensors, protectors and organizers. Nat Rev Mol Cell Biol 14, 98-112.

Parton, R.G., and Simons, K. (2007). The multiple faces of caveolae. Nat Rev Mol Cell Biol 8, 185194.

Paszek, M.J., Zahir, N., Johnson, K.R., Lakins, J.N., Rozenberg, G.I., Gefen, A., Reinhart-King, C.A., Margulies, S.S., Dembo, M., Boettiger, D., et al. (2005). Tensional homeostasis and the malignant phenotype. Cancer Cell 8, 241-254.

Patel, H.H., Murray, F., and Insel, P.A. (2008). Caveolae as organizers of pharmacologically relevant signal transduction molecules. Annual review of pharmacology and toxicology 48, 359391.

Pathak, M.M., Nourse, J.L., Tran, T., Hwe, J., Arulmoli, J., Le, D.T., Bernardis, E., Flanagan, L.A., and Tombola, F. (2014). Stretch-activated ion channel Piezo1 directs lineage choice in human neural stem cells. Proceedings of the National Academy of Sciences of the United States of America 111, 16148-16153.

Pelham, R.J., Jr., and Wang, Y. (1997). Cell locomotion and focal adhesions are regulated by substrate flexibility. Proceedings of the National Academy of Sciences of the United States of America 94, 13661-13665.

Pelkmans, L., and Zerial, M. (2005). Kinase-regulated quantal assemblies and kiss-and-run recycling of caveolae. Nature 436, 128-133.

Pellinen, T., Blom, S., Sanchez, S., Valimaki, K., Mpindi, J.P., Azegrouz, H., Strippoli, R., Nieto, R., Viton, M., Palacios, I., et al. (2018). ITGB1-dependent upregulation of Caveolin-1 switches TGFbeta signalling from tumour-suppressive to oncogenic in prostate cancer. Sci Rep 8, 2338. 
Peng, C., Zhu, Y., Zhang, W., Liao, Q., Chen, Y., Zhao, X., Guo, Q., Shen, P., Zhen, B., Qian, X., et al. (2017). Regulation of the Hippo-YAP Pathway by Glucose Sensor O-GlcNAcylation. Mol Cell 68, 591-604 e595.

Peyton, S.R., and Putnam, A.J. (2005). Extracellular matrix rigidity governs smooth muscle cell motility in a biphasic fashion. J Cell Physiol 204, 198-209.

Piccolo, S., Dupont, S., and Cordenonsi, M. (2014). The biology of YAP/TAZ: hippo signaling and beyond. Physiol Rev 94, 1287-1312.

Pike, L.J. (2006). Rafts defined: a report on the Keystone Symposium on Lipid Rafts and Cell Function. Journal of lipid research 47, 1597-1598.

Pike, L.J., and Casey, L. (1996). Localization and turnover of phosphatidylinositol 4,5bisphosphate in caveolin-enriched membrane domains. J Biol Chem 271, 26453-26456.

Pobbati, A.V., and Hong, W. (2013). Emerging roles of TEAD transcription factors and its coactivators in cancers. Cancer Biol Ther 14, 390-398.

Pol, A., Martin, S., Fernandez, M.A., Ingelmo-Torres, M., Ferguson, C., Enrich, C., and Parton, R.G. (2005). Cholesterol and fatty acids regulate dynamic caveolin trafficking through the Golgi complex and between the cell surface and lipid bodies. Mol Biol Cell 16, 2091-2105.

Polte, T.R., Eichler, G.S., Wang, N., and Ingber, D.E. (2004). Extracellular matrix controls myosin light chain phosphorylation and cell contractility through modulation of cell shape and cytoskeletal prestress. Am J Physiol Cell Physiol 286, C518-528.

Pollard, T.D., and Goldman, R.D. (2018). Overview of the Cytoskeleton from an Evolutionary Perspective. Cold Spring Harbor perspectives in biology 10.

Qiao, Y., Chen, J., Lim, Y.B., Finch-Edmondson, M.L., Seshachalam, V.P., Qin, L., Jiang, T., Low, B.C., Singh, H., Lim, C.T., et al. (2017). YAP Regulates Actin Dynamics through ARHGAP29 and Promotes Metastasis. Cell Rep 19, 1495-1502.

Rajab, A., Straub, V., McCann, L.J., Seelow, D., Varon, R., Barresi, R., Schulze, A., Lucke, B., Lutzkendorf, S., Karbasiyan, M., et al. (2010). Fatal cardiac arrhythmia and long-QT syndrome in a new form of congenital generalized lipodystrophy with muscle rippling (CGL4) due to PTRFCAVIN mutations. PLoS Genet 6, e1000874.

Razani-Boroujerdi, S., Partridge, L.D., and Sopori, M.L. (1994). Intracellular calcium signaling induced by thapsigargin in excitable and inexcitable cells. Cell calcium 16, 467-474.

Razani, B., Engelman, J.A., Wang, X.B., Schubert, W., Zhang, X.L., Marks, C.B., Macaluso, F., Russell, R.G., Li, M., Pestell, R.G., et al. (2001). Caveolin-1 null mice are viable but show evidence of hyperproliferative and vascular abnormalities. J Biol Chem 276, 38121-38138.

Razani, B., Wang, X.B., Engelman, J.A., Battista, M., Lagaud, G., Zhang, X.L., Kneitz, B., Hou, H., Jr., Christ, G.J., Edelmann, W., et al. (2002a). Caveolin-2-deficient mice show evidence of severe pulmonary dysfunction without disruption of caveolae. Mol Cell Biol 22, 2329-2344.

Razani, B., Woodman, S.E., and Lisanti, M.P. (2002b). Caveolae: from cell biology to animal physiology. Pharmacological reviews 54, 431-467.

Reddy, B.V., and Irvine, K.D. (2013). Regulation of Hippo signaling by EGFR-MAPK signaling through Ajuba family proteins. Dev Cell 24, 459-471.

Reddy, P., Deguchi, M., Cheng, Y., and Hsueh, A.J. (2013). Actin cytoskeleton regulates Hippo signaling. PLoS One 8, e73763. 
Remue, E., Meerschaert, K., Oka, T., Boucherie, C., Vandekerckhove, J., Sudol, M., and Gettemans, J. (2010). TAZ interacts with zonula occludens-1 and -2 proteins in a PDZ-1 dependent manner. FEBS Lett 584, 4175-4180.

Richter, T., Floetenmeyer, M., Ferguson, C., Galea, J., Goh, J., Lindsay, M.R., Morgan, G.P., Marsh, B.J., and Parton, R.G. (2008). High-resolution 3D quantitative analysis of caveolar ultrastructure and caveola-cytoskeleton interactions. Traffic 9, 893-909.

Rodriguez, G., Ueyama, T., Ogata, T., Czernuszewicz, G., Tan, Y., Dorn, G.W., 2nd, Bogaev, R., Amano, K., Oh, H., Matsubara, H., et al. (2011). Molecular genetic and functional characterization implicate muscle-restricted coiled-coil gene (MURC) as a causal gene for familial dilated cardiomyopathy. Circulation Cardiovascular genetics 4, 349-358.

Ron, D., and Walter, P. (2007). Signal integration in the endoplasmic reticulum unfolded protein response. Nat Rev Mol Cell Biol 8, 519-529.

Rothberg, K.G., Heuser, J.E., Donzell, W.C., Ying, Y.S., Glenney, J.R., and Anderson, R.G. (1992). Caveolin, a protein component of caveolae membrane coats. Cell 68, 673-682.

Roy, S., Luetterforst, R., Harding, A., Apolloni, A., Etheridge, M., Stang, E., Rolls, B., Hancock, J.F., and Parton, R.G. (1999). Dominant-negative caveolin inhibits H-Ras function by disrupting cholesterol-rich plasma membrane domains. Nat Cell Biol 1, 98-105.

Sala-Vila, A., Navarro-Lerida, I., Sanchez-Alvarez, M., Bosch, M., Calvo, C., Lopez, J.A., Calvo, E., Ferguson, C., Giacomello, M., Serafini, A., et al. (2016). Interplay between hepatic mitochondriaassociated membranes, lipid metabolism and caveolin-1 in mice. Sci Rep 6, 27351.

Santinon, G., Pocaterra, A., and Dupont, S. (2016). Control of YAP/TAZ Activity by Metabolic and Nutrient-Sensing Pathways. Trends Cell Biol 26, 289-299.

Scherer, P.E., Lewis, R.Y., Volonte, D., Engelman, J.A., Galbiati, F., Couet, J., Kohtz, D.S., van Donselaar, E., Peters, P., and Lisanti, M.P. (1997). Cell-type and tissue-specific expression of caveolin-2. Caveolins 1 and 2 co-localize and form a stable hetero-oligomeric complex in vivo. $J$ Biol Chem 272, 29337-29346.

Scherer, P.E., Okamoto, T., Chun, M., Nishimoto, I., Lodish, H.F., and Lisanti, M.P. (1996). Identification, sequence, and expression of caveolin-2 defines a caveolin gene family. Proc Natl Acad Sci U S A 93, 131-135.

Scherer, P.E., Tang, Z., Chun, M., Sargiacomo, M., Lodish, H.F., and Lisanti, M.P. (1995). Caveolin isoforms differ in their $\mathrm{N}$-terminal protein sequence and subcellular distribution. Identification and epitope mapping of an isoform-specific monoclonal antibody probe. J Biol Chem 270, 1639516401.

Schlegel, A., Arvan, P., and Lisanti, M.P. (2001). Caveolin-1 binding to endoplasmic reticulum membranes and entry into the regulated secretory pathway are regulated by serine phosphorylation. Protein sorting at the level of the endoplasmic reticulum. J Biol Chem 276, 4398-4408.

Schlegelmilch, K., Mohseni, M., Kirak, O., Pruszak, J., Rodriguez, J.R., Zhou, D., Kreger, B.T., Vasioukhin, V., Avruch, J., Brummelkamp, T.R., et al. (2011). Yap1 acts downstream of alphacatenin to control epidermal proliferation. Cell 144, 782-795.

Schrader, J., Gordon-Walker, T.T., Aucott, R.L., van Deemter, M., Quaas, A., Walsh, S., Benten, D., Forbes, S.J., Wells, R.G., and Iredale, J.P. (2011). Matrix stiffness modulates proliferation, chemotherapeutic response, and dormancy in hepatocellular carcinoma cells. Hepatology 53, 1192-1205. 
Schwartz, M.A. (2010). Integrins and extracellular matrix in mechanotransduction. Cold Spring Harbor perspectives in biology 2, a005066.

Sero, J.E., and Bakal, C. (2017). Multiparametric Analysis of Cell Shape Demonstrates that betaPIX Directly Couples YAP Activation to Extracellular Matrix Adhesion. Cell Syst 4, 84-96 e86.

Shikanai, M., Nishimura, Y.V., Sakurai, M., Nabeshima, Y.I., Yuzaki, M., and Kawauchi, T. (2018). Caveolin-1 Promotes Early Neuronal Maturation via Caveolae-Independent Trafficking of NCadherin and L1. iScience 7, 53-67.

Shvets, E., Bitsikas, V., Howard, G., Hansen, C.G., and Nichols, B.J. (2015). Dynamic caveolae exclude bulk membrane proteins and are required for sorting of excess glycosphingolipids. Nat Commun 6, 6867.

Singer, S.J., and Nicolson, G.L. (1972). The fluid mosaic model of the structure of cell membranes. Science 175, 720-731.

Sinha, B., Koster, D., Ruez, R., Gonnord, P., Bastiani, M., Abankwa, D., Stan, R.V., Butler-Browne, G., Vedie, B., Johannes, L., et al. (2011). Cells respond to mechanical stress by rapid disassembly of caveolae. Cell 144, 402-413.

Smart, E.J., Ying, Y., Donzell, W.C., and Anderson, R.G. (1996). A role for caveolin in transport of cholesterol from endoplasmic reticulum to plasma membrane. J Biol Chem 271, 29427-29435.

Sonnichsen, B., De Renzis, S., Nielsen, E., Rietdorf, J., and Zerial, M. (2000). Distinct membrane domains on endosomes in the recycling pathway visualized by multicolor imaging of Rab4, Rab5, and Rab11. J Cell Biol 149, 901-914.

Sonntag, J., Bender, C., Soons, Z., der Heyde, S.v., König, R., Wiemann, S., Sinn, H.-P., Schneeweiss, A., Beißbarth, T., and Korf, U. (2014). Reverse phase protein array based tumor profiling identifies a biomarker signature for risk classification of hormone receptor-positive breast cancer. Translational Proteomics 2, 52-59.

Sorrentino, G., Ruggeri, N., Specchia, V., Cordenonsi, M., Mano, M., Dupont, S., Manfrin, A., Ingallina, E., Sommaggio, R., Piazza, S., et al. (2014). Metabolic control of YAP and TAZ by the mevalonate pathway. Nat Cell Biol 16, 357-366.

Spisni, E., Tomasi, V., Cestaro, A., and Tosatto, S.C. (2005). Structural insights into the function of human caveolin 1. Biochem Biophys Res Commun 338, 1383-1390.

Stahlhut, M., and van Deurs, B. (2000). Identification of filamin as a novel ligand for caveolin-1: evidence for the organization of caveolin-1-associated membrane domains by the actin cytoskeleton. Mol Biol Cell 11, 325-337.

Stein, C., Bardet, A.F., Roma, G., Bergling, S., Clay, I., Ruchti, A., Agarinis, C., Schmelzle, T., Bouwmeester, T., Schubeler, D., et al. (2015). YAP1 Exerts Its Transcriptional Control via TEADMediated Activation of Enhancers. PLoS Genet 11, e1005465.

Stickney, J.T., Bacon, W.C., Rojas, M., Ratner, N., and Ip, W. (2004). Activation of the tumor suppressor merlin modulates its interaction with lipid rafts. Cancer Res 64, 2717-2724.

Strano, S., Monti, O., Pediconi, N., Baccarini, A., Fontemaggi, G., Lapi, E., Mantovani, F., Damalas, A., Citro, G., Sacchi, A., et al. (2005). The transcriptional coactivator Yes-associated protein drives p73 gene-target specificity in response to DNA Damage. Mol Cell 18, 447-459.

Strassburger, K., Tiebe, M., Pinna, F., Breuhahn, K., and Teleman, A.A. (2012). Insulin/IGF signaling drives cell proliferation in part via Yorkie/YAP. Dev Biol 367, 187-196. 
Sverdlov, M., Shajahan, A.N., and Minshall, R.D. (2007). Tyrosine phosphorylation-dependence of caveolae-mediated endocytosis. J Cell Mol Med 11, 1239-1250.

Sverdlov, M., Shinin, V., Place, A.T., Castellon, M., and Minshall, R.D. (2009). Filamin A regulates caveolae internalization and trafficking in endothelial cells. Mol Biol Cell 20, 4531-4540.

Szklarczyk, D., Morris, J.H., Cook, H., Kuhn, M., Wyder, S., Simonovic, M., Santos, A., Doncheva, N.T., Roth, A., Bork, P., et al. (2017). The STRING database in 2017: quality-controlled proteinprotein association networks, made broadly accessible. Nucleic Acids Res 45, D362-D368.

Tagawa, A., Mezzacasa, A., Hayer, A., Longatti, A., Pelkmans, L., and Helenius, A. (2005). Assembly and trafficking of caveolar domains in the cell: caveolae as stable, cargo-triggered, vesicular transporters. J Cell Biol 170, 769-779.

Tang, Z., Okamoto, T., Boontrakulpoontawee, P., Katada, T., Otsuka, A.J., and Lisanti, M.P. (1997). Identification, sequence, and expression of an invertebrate caveolin gene family from the nematode Caenorhabditis elegans. Implications for the molecular evolution of mammalian caveolin genes. J Biol Chem 272, 2437-2445.

Tang, Z., Scherer, P.E., Okamoto, T., Song, K., Chu, C., Kohtz, D.S., Nishimoto, I., Lodish, H.F., and Lisanti, M.P. (1996). Molecular cloning of caveolin-3, a novel member of the caveolin gene family expressed predominantly in muscle. J Biol Chem 271, 2255-2261.

Tapon, N., Harvey, K.F., Bell, D.W., Wahrer, D.C., Schiripo, T.A., Haber, D., and Hariharan, I.K. (2002). salvador Promotes both cell cycle exit and apoptosis in Drosophila and is mutated in human cancer cell lines. Cell 110, 467-478.

Thastrup, O., Cullen, P.J., Drobak, B.K., Hanley, M.R., and Dawson, A.P. (1990). Thapsigargin, a tumor promoter, discharges intracellular $\mathrm{Ca} 2+$ stores by specific inhibition of the endoplasmic reticulum Ca2(+)-ATPase. Proc Natl Acad Sci U S A 87, 2466-2470.

Tomlinson, V., Gudmundsdottir, K., Luong, P., Leung, K.Y., Knebel, A., and Basu, S. (2010). JNK phosphorylates Yes-associated protein (YAP) to regulate apoptosis. Cell Death Dis 1, e29.

Tonelli, F.M., Santos, A.K., Gomes, D.A., da Silva, S.L., Gomes, K.N., Ladeira, L.O., and Resende, R.R. (2012). Stem cells and calcium signaling. Adv Exp Med Biol 740, 891-916.

Tse, J.R., and Engler, A.J. (2010). Preparation of hydrogel substrates with tunable mechanical properties. Curr Protoc Cell Biol Chapter 10, Unit 1016.

Udan, R.S., Kango-Singh, M., Nolo, R., Tao, C., and Halder, G. (2003). Hippo promotes proliferation arrest and apoptosis in the Salvador/Warts pathway. Nat Cell Biol 5, 914-920.

Uittenbogaard, A., and Smart, E.J. (2000). Palmitoylation of caveolin-1 is required for cholesterol binding, chaperone complex formation, and rapid transport of cholesterol to caveolae. J Biol Chem 275, 25595-25599.

Varelas, X. (2014). The Hippo pathway effectors TAZ and YAP in development, homeostasis and disease. Development 141, 1614-1626.

Varelas, X., Sakuma, R., Samavarchi-Tehrani, P., Peerani, R., Rao, B.M., Dembowy, J., Yaffe, M.B., Zandstra, P.W., and Wrana, J.L. (2008). TAZ controls Smad nucleocytoplasmic shuttling and regulates human embryonic stem-cell self-renewal. Nat Cell Biol 10, 837-848.

Wada, K., Itoga, K., Okano, T., Yonemura, S., and Sasaki, H. (2011). Hippo pathway regulation by cell morphology and stress fibers. Development 138, 3907-3914. 
Wanaski, S.P., Ng, B.K., and Glaser, M. (2003). Caveolin scaffolding region and the membrane binding region of SRC form lateral membrane domains. Biochemistry 42, 42-56.

Wang, D.X., Pan, Y.Q., Liu, B., and Dai, L. (2018). Cav-1 promotes atherosclerosis by activating JNK-associated signaling. Biochem Biophys Res Commun.

Wang, S., Lu, Y., Yin, M.X., Wang, C., Wu, W., Li, J., Wu, W., Ge, L., Hu, L., Zhao, Y., et al. (2016). Importin alpha1 Mediates Yorkie Nuclear Import via an N-terminal Non-canonical Nuclear Localization Signal. J Biol Chem 291, 7926-7937.

Wang, W., Li, X., Huang, J., Feng, L., Dolinta, K.G., and Chen, J. (2014). Defining the proteinprotein interaction network of the human hippo pathway. Molecular \& cellular proteomics: MCP $13,119-131$.

Wang, W., Xiao, Z.D., Li, X., Aziz, K.E., Gan, B., Johnson, R.L., and Chen, J. (2015). AMPK modulates Hippo pathway activity to regulate energy homeostasis. Nat Cell Biol 17, 490-499.

Wang, Z., Liu, P., Zhou, X., Wang, T., Feng, X., Sun, Y.P., Xiong, Y., Yuan, H.X., and Guan, K.L. (2017). Endothelin Promotes Colorectal Tumorigenesis by Activating YAP/TAZ. Cancer Res 77, 2413-2423.

Watanabe, N., Kato, T., Fujita, A., Ishizaki, T., and Narumiya, S. (1999). Cooperation between mDia1 and ROCK in Rho-induced actin reorganization. Nat Cell Biol 1, 136-143.

Way, M., and Parton, R.G. (1995). M-caveolin, a muscle-specific caveolin-related protein. FEBS Lett 376, 108-112.

Wente, S.R., and Rout, M.P. (2010). The nuclear pore complex and nuclear transport. Cold Spring Harbor perspectives in biology 2, a000562.

Wickstrom, S.A., Lange, A., Hess, M.W., Polleux, J., Spatz, J.P., Kruger, M., Pfaller, K., Lambacher, A., Bloch, W., Mann, M., et al. (2010). Integrin-linked kinase controls microtubule dynamics required for plasma membrane targeting of caveolae. Dev Cell 19, 574-588.

Wiechen, K., Sers, C., Agoulnik, A., Arlt, K., Dietel, M., Schlag, P.M., and Schneider, U. (2001). Down-regulation of caveolin-1, a candidate tumor suppressor gene, in sarcomas. Am J Pathol $158,833-839$.

Woudenberg, J., Rembacz, K.P., van den Heuvel, F.A., Woudenberg-Vrenken, T.E., Buist-Homan, M., Geuken, M., Hoekstra, M., Deelman, L.E., Enrich, C., Henning, R.H., et al. (2010). Caveolin-1 is enriched in the peroxisomal membrane of rat hepatocytes. Hepatology 51, 1744-1753.

Wu, S., Huang, J., Dong, J., and Pan, D. (2003). hippo encodes a Ste-20 family protein kinase that restricts cell proliferation and promotes apoptosis in conjunction with salvador and warts. Cell $114,445-456$.

Yadav, D., and Lowenfels, A.B. (2013). The epidemiology of pancreatitis and pancreatic cancer. Gastroenterology 144, 1252-1261.

Yaffe, M.B., Rittinger, K., Volinia, S., Caron, P.R., Aitken, A., Leffers, H., Gamblin, S.J., Smerdon, S.J., and Cantley, L.C. (1997). The structural basis for 14-3-3:phosphopeptide binding specificity. Cell 91, 961-971.

Yagi, R., Chen, L.F., Shigesada, K., Murakami, Y., and Ito, Y. (1999). A WW domain-containing yesassociated protein (YAP) is a novel transcriptional co-activator. The EMBO journal 18, 25512562. 
Yamada, E. (1955). The fine structure of the gall bladder epithelium of the mouse. J Biophys Biochem Cytol 1, 445-458.

Yeh, Y.C., Ling, J.Y., Chen, W.C., Lin, H.H., and Tang, M.J. (2017). Mechanotransduction of matrix stiffness in regulation of focal adhesion size and number: reciprocal regulation of caveolin-1 and beta1 integrin. Sci Rep 7, 15008.

Yeung, T., Georges, P.C., Flanagan, L.A., Marg, B., Ortiz, M., Funaki, M., Zahir, N., Ming, W., Weaver, V., and Janmey, P.A. (2005). Effects of substrate stiffness on cell morphology, cytoskeletal structure, and adhesion. Cell motility and the cytoskeleton 60, 24-34.

Yin, F., Yu, J., Zheng, Y., Chen, Q., Zhang, N., and Pan, D. (2013). Spatial organization of Hippo signaling at the plasma membrane mediated by the tumor suppressor Merlin/NF2. Cell 154, 1342-1355.

Young, R.A. (2011). Control of the embryonic stem cell state. Cell 144, 940-954.

Yu, F.X., and Guan, K.L. (2013). The Hippo pathway: regulators and regulations. Genes Dev 27, 355-371.

Yu, F.X., Zhao, B., and Guan, K.L. (2015). Hippo Pathway in Organ Size Control, Tissue Homeostasis, and Cancer. Cell 163, 811-828.

Yu, F.X., Zhao, B., Panupinthu, N., Jewell, J.L., Lian, I., Wang, L.H., Zhao, J., Yuan, H., Tumaneng, K., Li, H., et al. (2012). Regulation of the Hippo-YAP pathway by G-protein-coupled receptor signaling. Cell 150, 780-791.

Yuan, M., Tomlinson, V., Lara, R., Holliday, D., Chelala, C., Harada, T., Gangeswaran, R., MansonBishop, C., Smith, P., Danovi, S.A., et al. (2008). Yes-associated protein (YAP) functions as a tumor suppressor in breast. Cell death and differentiation 15, 1752-1759.

Zanconato, F., Cordenonsi, M., and Piccolo, S. (2016). YAP/TAZ at the Roots of Cancer. Cancer Cell 29, 783-803.

Zhang, L., Tang, F., Terracciano, L., Hynx, D., Kohler, R., Bichet, S., Hess, D., Cron, P., Hemmings, B.A., Hergovich, A., et al. (2015). NDR functions as a physiological YAP1 kinase in the intestinal epithelium. Curr Biol 25, 296-305.

Zhang, N., Bai, H., David, K.K., Dong, J., Zheng, Y., Cai, J., Giovannini, M., Liu, P., Anders, R.A., and Pan, D. (2010). The Merlin/NF2 tumor suppressor functions through the YAP oncoprotein to regulate tissue homeostasis in mammals. Dev Cell 19, 27-38.

Zhang, R., Ma, M., Dong, G., Yao, R.R., Li, J.H., Zheng, Q.D., Dong, Y.Y., Ma, H., Gao, D.M., Cui, J.F., et al. (2017). Increased matrix stiffness promotes tumor progression of residual hepatocellular carcinoma after insufficient heat treatment. Cancer Sci 108, 1778-1786.

Zhao, B., Li, L., Lu, Q., Wang, L.H., Liu, C.Y., Lei, Q., and Guan, K.L. (2011). Angiomotin is a novel Hippo pathway component that inhibits YAP oncoprotein. Genes Dev 25, 51-63.

Zhao, B., Li, L., Tumaneng, K., Wang, C.Y., and Guan, K.L. (2010). A coordinated phosphorylation by Lats and CK1 regulates YAP stability through SCF(beta-TRCP). Genes Dev 24, 72-85.

Zhao, B., Li, L., Wang, L., Wang, C.Y., Yu, J., and Guan, K.L. (2012). Cell detachment activates the Hippo pathway via cytoskeleton reorganization to induce anoikis. Genes Dev 26, 54-68.

Zhao, B., Wei, X., Li, W., Udan, R.S., Yang, Q., Kim, J., Xie, J., Ikenoue, T., Yu, J., Li, L., et al. (2007). Inactivation of YAP oncoprotein by the Hippo pathway is involved in cell contact inhibition and tissue growth control. Genes Dev 21, 2747-2761. 
Zhao, B., Ye, X., Yu, J., Li, L., Li, W., Li, S., Lin, J.D., Wang, C.Y., Chinnaiyan, A.M., Lai, Z.C., et al. (2008). TEAD mediates YAP-dependent gene induction and growth control. Genes Dev 22, 19621971.

Zheng, X., Han, H., Liu, G.P., Ma, Y.X., Pan, R.L., Sang, L.J., Li, R.H., Yang, L.J., Marks, J.R., Wang, W., et al. (2017). LncRNA wires up Hippo and Hedgehog signaling to reprogramme glucose metabolism. EMBO J 36, 3325-3335.

Zheng, Y.Z., Boscher, C., Inder, K.L., Fairbank, M., Loo, D., Hill, M.M., Nabi, I.R., and Foster, L.J. (2011). Differential impact of caveolae and caveolin-1 scaffolds on the membrane raft proteome. Mol Cell Proteomics 10, M110 007146.

Zhong, W., Tian, K., Zheng, X., Li, L., Zhang, W., Wang, S., and Qin, J. (2013). Mesenchymal stem cell and chondrocyte fates in a multishear microdevice are regulated by Yes-associated protein. Stem Cells Dev 22, 2083-2093.

Zhou, D., Conrad, C., Xia, F., Park, J.S., Payer, B., Yin, Y., Lauwers, G.Y., Thasler, W., Lee, J.T., Avruch, J., et al. (2009). Mst1 and Mst2 maintain hepatocyte quiescence and suppress hepatocellular carcinoma development through inactivation of the Yap1 oncogene. Cancer Cell $16,425-438$.

Zhou, X., Wang, S., Wang, Z., Feng, X., Liu, P., Lv, X.B., Li, F., Yu, F.X., Sun, Y., Yuan, H., et al. (2015). Estrogen regulates Hippo signaling via GPER in breast cancer. J Clin Invest 125, 21232135.

Zhu, Q., Wong, A.K., Krishnan, A., Aure, M.R., Tadych, A., Zhang, R., Corney, D.C., Greene, C.S., Bongo, L.A., Kristensen, V.N., et al. (2015). Targeted exploration and analysis of large crossplatform human transcriptomic compendia. Nat Methods 12, 211-214, 213 p following 214.

Zschocke, J., Manthey, D., Bayatti, N., van der Burg, B., Goodenough, S., and Behl, C. (2002). Estrogen receptor alpha-mediated silencing of caveolin gene expression in neuronal cells. J Biol Chem 277, 38772-38780. 
10. Anexo: Publicaciones 


\section{Publicaciones que forman parte de la Tesis Doctoral}

Moreno-Vicente R, Pavón DM, Martín-Padura I, Català-Montoro M, Díez-Sánchez A, QuílezÁlvarez A, López JA, Sánchez-Álvarez M, Vázquez J, Strippoli R and del Pozo MA. Caveolin-1 modulates mechanotransduction responses to substrate stiffness through actin-dependent control of YAP. Cell Reports, in press.

\section{Publicaciones que no forman parte de la Tesis Doctoral}

Strippoli, R, Moreno-Vicente R, Battistelli C, Cicchini C, Noce V, Amicone L, Marchetti A, Del Pozo MA, Tripodi M1. (2016). "Molecular Mechanisms Underlying Peritoneal EMT and Fibrosis." Stem cells international 2016: 3543678.

AJ Kosmalska; L Casares; A Elósegui-Artola; JJ Thottacherry; Moreno-Vicente R; V GonzálezTarragó; MA del Pozo; S Mayor; M Arroyo; D Navajas; X Trepat; NC Gauthier; P Roca-Cusachs. Physical principles of membrane remodelling during cell mechanoadaptation. Nature Communications. 15 - 6, pp. 7292. 2015.

Moreno-Cáceres; Caja L; Mainez J; Mayoral R; Martin-Sanz P; Moreno-Vicente R; Del Pozo MA; Dooley S;Egea G; Fabregat I. Caveolin-1 is required for TGF- $\beta$-induced transactivation of the EGF receptor pathway in hepatocytes through the activation of the metalloprotease TACE/ADAM17.Cell Death Dis.07/2014. 
